\title{
Analysis of Blowoff in a Low-Swirl Burner: Effects of Burner Geometry and Fuel Composition by
}

\author{
Graham E. Ballachey
}

A thesis submitted to the Faculty of Graduate and Postdoctoral Affairs in partial fulfillment of the requirements for the degree of

\section{Master of Applied Science in Mechanical Engineering}

Ottawa-Carleton Institute for Mechanical and Aerospace Engineering

\author{
Department of Mechanical and Aerospace Engineering \\ Carleton University \\ Ottawa, Ontario, Canada
}

November, 2011

Copyright (C) 2011

Graham E. Ballachey 
Library and Archives

Canada

Published Heritage

Branch

395 Wellington Street

Ottawa ON K1A ON4

Canada
Bibliothèque et

Archives Canada

Direction du

Patrimoine de l'édition

395 , rue Wellington

Ottawa ON K1A ON4

Canada
Your file Votre référence

ISBN: 978-0-494-87812-5

Our file Notre référence

ISBN: $978-0-494-87812-5$

\section{NOTICE:}

The author has granted a nonexclusive license allowing Library and Archives Canada to reproduce, publish, archive, preserve, conserve, communicate to the public by telecommunication or on the Internet, loan, distrbute and sell theses worldwide, for commercial or noncommercial purposes, in microform, paper, electronic and/or any other formats.

The author retains copyright ownership and moral rights in this thesis. Neither the thesis nor substantial extracts from it may be printed or otherwise reproduced without the author's permission.
AVIS:

L'auteur a accordé une licence non exclusive permettant à la Bibliothèque et Archives Canada de reproduire, publier, archiver, sauvegarder, conserver, transmettre au public par télécommunication ou par l'Internet, prêter, distribuer et vendre des thèses partout dans le monde, à des fins commerciales ou autres, sur support microforme, papier, électronique et/ou autres formats.

L'auteur conserve la propriété du droit d'auteur et des droits moraux qui protege cette thèse. $\mathrm{Ni}$ la thèse ni des extraits substantiels de celle-ci ne doivent être imprimés ou autrement reproduits sans son autorisation.
In compliance with the Canadian Privacy Act some supporting forms may have been removed from this thesis.

While these forms may be included in the document page count, their removal does not represent any loss of content from the thesis.
Conformément à la loi canadienne sur la protection de la vie privée, quelques formulaires secondaires ont été enlevés de cette thèse.

Bien que ces formulaires aient inclus dans la pagination, il n'y aura aucun contenu manquant. 
The undersigned recommend to the Faculty of Graduate Studies and Research acceptance of the thesis

\title{
Characterization of blowoff for a low-swirl burner: Effects of burner geometry and fuel composition
}

\author{
Submitted by Graham E. Ballachey \\ in partial fulfillment of the requirements for the degree of \\ Master of Applied Science in Mechanical Engineering
}

$X$

Dr. Matthew Johnson

Thesis Supervisor

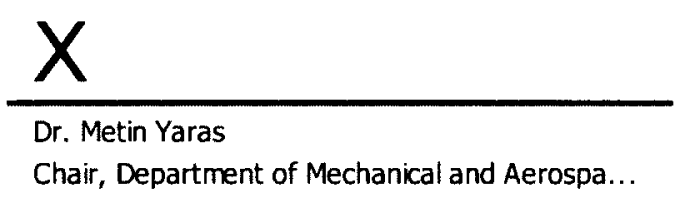

Carleton University

2011 


\section{Abstract}

Strict regulation on $\mathrm{NO}_{\mathrm{x}}$ emissions has created a need for technology capable of burning fuels at ultra-lean conditions as a means to lowering flame temperatures and impeding thermally-dependent $\mathrm{NO}_{\mathrm{x}}$ formation. The low-swirl burner (LSB) is one successful approach to stabilizing ultra-lean flames that has been effectively demonstrated in a variety of applications, although the mechanisms of flame stabilization are not fully understood. Using a unique fully controllable low swirl burner, stability 'volumes' in equivalence ratio-swirl number-heat release rate space were measured with three different LSB nozzle exit diameters of $38.1 \mathrm{~mm}, 50.8 \mathrm{~mm}$, and $76.2 \mathrm{~mm}$ for a reference fuel of methane and a range of syngas fuel mixtures. The results show that, in general, fuels become more blowoff resistant but more prone to flashback with increasing laminar flame speed, which is highly correlated with the hydrogen content in the fuel. For mixtures containing hydrogen, if the flowrate was lowered sufficiently at a fixed equivalence ratio, the flame was prone to attachment on the burner rim. Flame attachment was highly correlated with laminar flame speed $\left(S_{\mathrm{L}}\right)$, but was not observed in non-hydrogen containing mixtures at comparable $S_{L}$. For the reference methane case, two distinct blowoff mechanisms were documented. The dominant $\mathrm{W}$-type blowoff was observed to be stabilized in the shear layer between the central core flow and annular flow of the LSB. The less common R-type blowoff was characterized by a noticeable axial recirculation, even at low swirl numbers. A Damköhler number analysis showed these two types of blowoff were separated by a transition region of roughly $0.3<D a$ $<65$, with W-type blowoff generally occurring above, and R-type blowoff occurring below this range. For the $\mathrm{W}$-type regime, an empirical correlation was developed based on the strength of the 3D shear layer ( $\left.V_{\text {diff }}\right)$, which linearly related data for all available fuel mixtures and LSB sizes to the average exit velocity, $U_{a v e}$, such that $0.8<$ $V_{\text {diff }}{ }^{*} S_{L} 0.15 / U_{a v e}<1.2$ for all data at blowoff. This result provides a useful empirical tool for designing a low-swirl burner to operate at any exit velocity with a wide variety of fuels and equivalence ratios. 


\section{Acknowledgements}

None of this would have been possible without the support of my supervisor, Prof. Matthew Johnson. When I was a fresh physics graduate, 22 years old, unemployed and living in a strange new city, he gave me the opportunity to prove myself as a scientist and researcher in my new chosen field: engineering. With his encouragement, motivation, and guidance, I was able to present my research on the low-swirl burner at a national conference. After that success, he took me on as a graduate student (perhaps reluctantly at first), which allowed me to pursue a Master's degree immediately as opposed to starting over in undergraduate engineering. Where I am today is a result of Prof. Johnson giving me that opportunity. I will never forget that. Thank you.

I would also like to thank the other members of Prof. Johnson's research group that both helped me with my research, and provided companionship and support during the lonely trapped-in-the-lab stretches of time. Specifically, I'd like to thank, in no particular order, Brian Crosland, James McEwen, Stephen Schoonbaert, Adam Coderre, Patrizio Vena, Ian Joynes, Mike Shives, Jan Gorski, Clifton Pereira, Carol Brereton, Robin Devillers, and Darcy Corbin. I'd also like to thank all the other students from different groups I got to know over the years who became both colleagues and friends. Thank you to Alex Proctor and Kevin Sangster for all the hours put in helping me in the machine shop. I know I was demanding at times, so thanks for all the time, advice, and help you gave without ever asking anything in return (other than beer and health tips). Also, thank you to Christie Egbert and Nancy Powell for all their help in deciphering the red tape of being a graduate student.

Thank you to my friends outside of Carleton in Ottawa who for a time made me feel like I belonged here. The only times I was able to completely disconnect from my work was when I was with you. Special thanks to Chris Fleming, Ryan Maher, Amy Ede, and Laura Caughey. 
Thank you to my family for their unwavering support of my goals despite me living across the country for more than four years. I missed you all a lot. Especially, thank you Mom for all the emotional support when times were hard. You are the best mother a man could ask for. Finally, thank you Dad for always providing a role model for me, and for all the financial support over the years. Without you, I would have had a miserable, poor experience in graduate school and entered the working world with a mountain of debt and resentment. You taught me the rules of the game, which have brought me to where I am today. They are: 1 . Be neat and tidy; 2 . Work first, then play; and perhaps most importantly: 3 . Finish what you start. Finished! 


\section{Table of Contents}

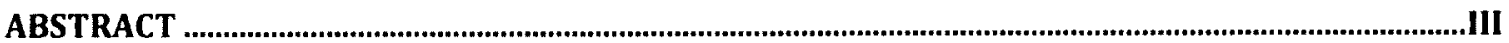

ACKNOWLEDGEMENTS ....................................................................................................................................

NOMENCLATURE

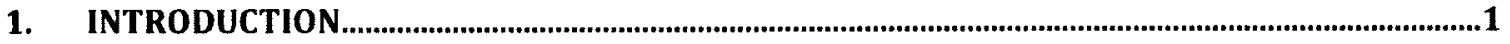

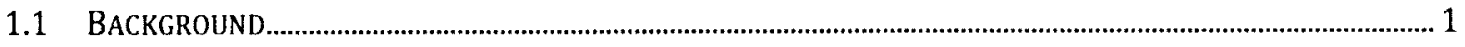

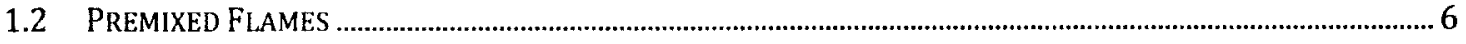

1.3 INFLUENCE OF FUEL COMPOSITION ON FLAME SPEED ….............................................................................. 9

1.4 REGIMES OF TURBULENT COMBUSTION..................................................................................................10

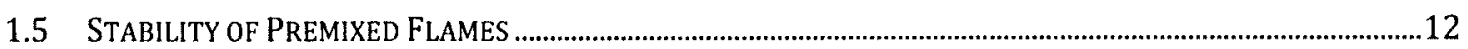

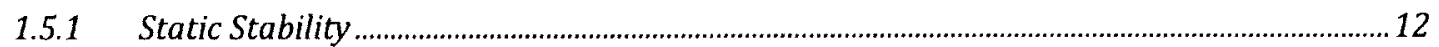

1.5.2 Dynamic Stability ................................................................................................................

1.5.3 Methods of stabilizing turbulent premixed flames ......................................................................17

1.6 OBJECTIVES..............................................................................................................................................

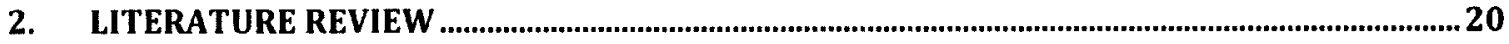

2.1 SWIRLING FLOWS AND THE SWIRL NUMBER ...................................................................................................20

2.2 Selected Previous Studies on Blowoff and Flashback for TuRbulent Flames .................................22

2.2.1 Selected Previous Studies of Blowoff for Premixed Turbulent Flames as Relevant to

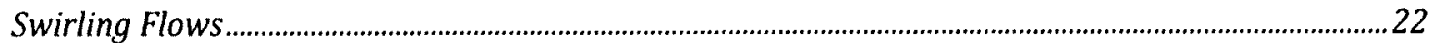

2.2.2 Selected Previous Studies of Flashback for Premixed Turbulent Flames as Relevant to

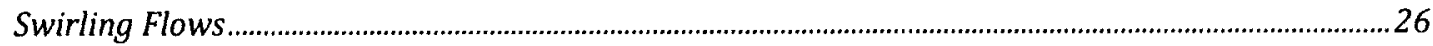

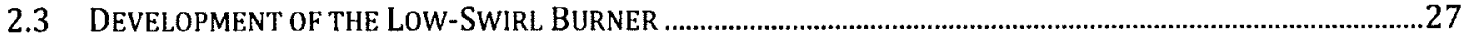

2.3.1 Low-Swirl Burner with Alternative Fuels .......................................................................................... 38

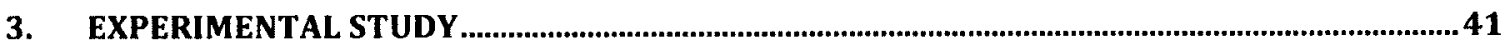

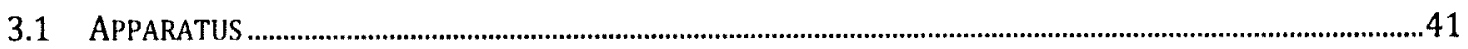

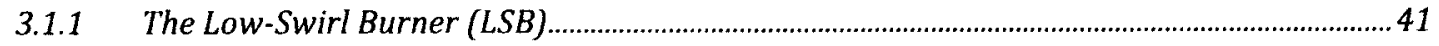

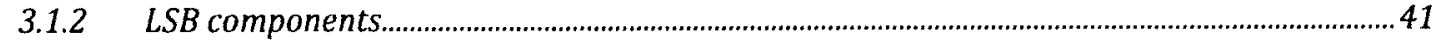

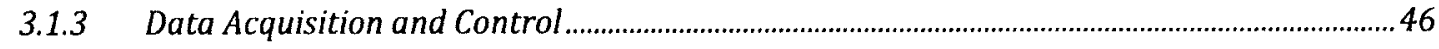

3.1.4 Particle Image Velocimetry (PIV) system ............................................................................... 48

3.1.5 PIV system components ............................................................................................................

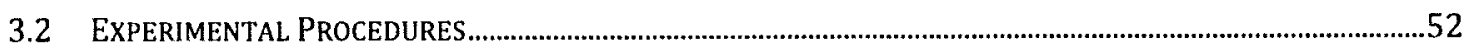

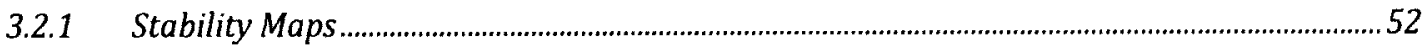

3.2.2 Uncertainty in Blowoff Measurements ..................................................................................... 
3.2.3 Flowfield measurements using PIV ....................................................................................... 55

3.2.4 PIV Setup and Calibration ……......................................................................................... 58

3.2.5 Uncertainty in PIV Measurements .................................................................................................69

4. STATIC STABILITY POINT MEASUREMENTS ….......................................................................

4.1 STABILITY MAPS...........................................................................................................................................

4.1.1 Geometric study with reference fuel of methane ..........................................................................

4.1.2 Blowoff Stability Limits for Biogas and Syngas Fuel Mixtures................................................... 77

4.1.3 Flame attachment investigation ................................................................................................... 82

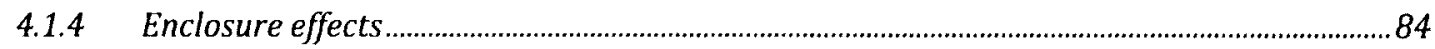

5. FLOWFIELD MEASUREMENTS USING PARTICLE IMAGE VELOCIMETRY (PIV)....................... 87

5.1 COMPARISON OF NON-REACTING AND REACTING FLOWFIELDS ..........................................................................

5.2 STABILIZATION OF FLAMES WITHOUT USING A SWIRLER .......................................................................................8

5.3 REFERENCE PIV VELOCITY FIELD MEASUREMENTS FOR METHANE ……..........................................................89

5.4 MATCHING BIOGAS/SYNGAS FUEL MIXTURES TO METHANE CONDITIONS..............................................................93

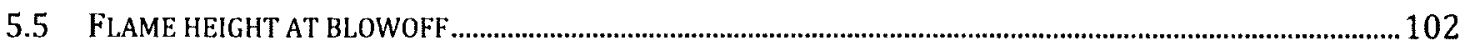

5.6 MEASUREMENTS OF VELOCITY INCREASE THROUGH THE FLAME FRONT ……….............................................105

5.7 ESTIMATES OF TURBULENT FLAME SPEEd FROM VELOCITY FIELD DATA ......................................................105

5.8 COMPARISON OF FLOWFIELdS For APPARENT DifFERENT STABILITY/BLOWOFF MODES .............................110

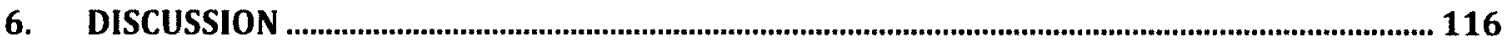

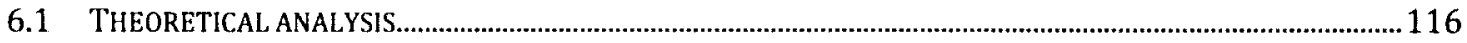

6.1.1 Turbulent Premixed Combustion Regimes of the LSB ……...................................................... 124

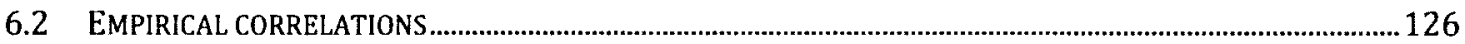

6.2.1 Horizontal Profiles of Measured Flow Turbulence ……………………..................................... 128

6.3 BLOWOFF STABILITY CORRELATION BASED ON SHEAR-LAYER STRENGTH....................................................134

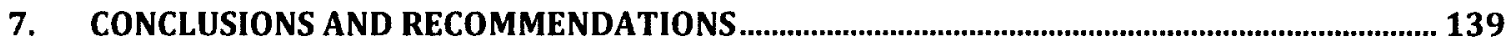

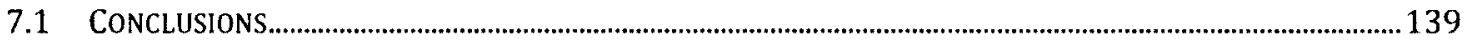

7.2 RECOMMENDATIONS FOR FUTURE WORK ………..........................................................................................141

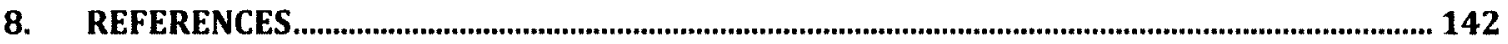

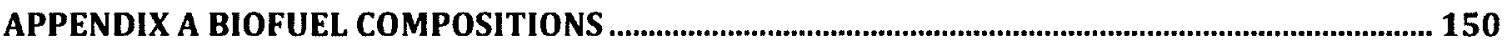

A.1 SYNGAS/BIOGAS COMPOSITIONS....................................................................................................................150

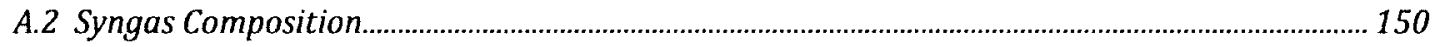

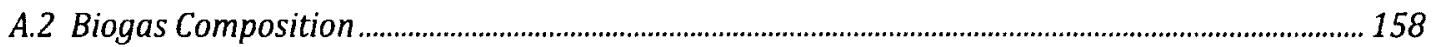

APPENDIX B NOZZLE CONTOUR CALCULATIONS ................................................................................... 161

vii 
CALIBRATion

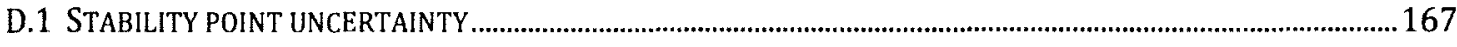

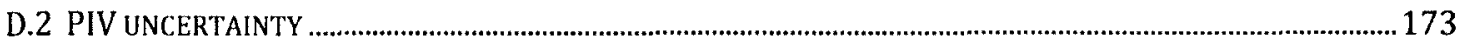

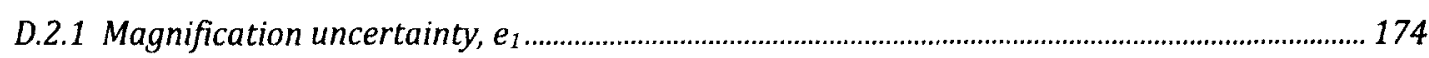

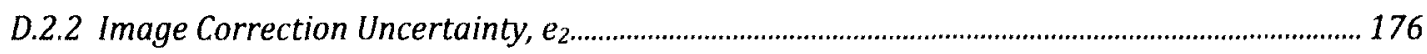

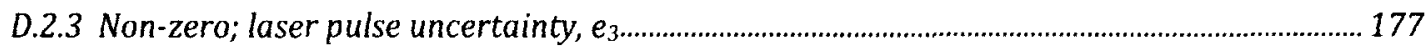

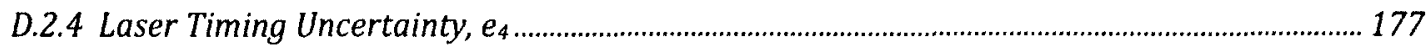

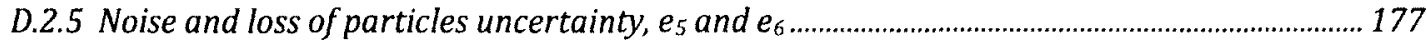

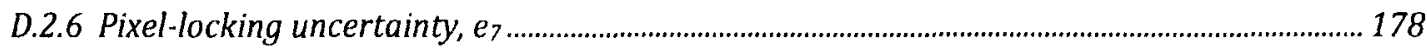

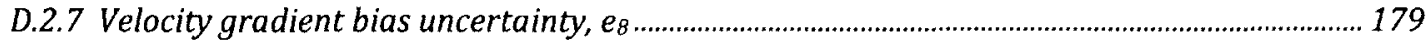

D.2.8 Traceability of seed particles........................................................................................................ 180

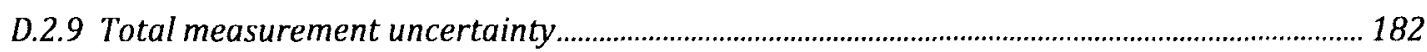

APPENDIX E: TURBULENCE STATISTICS CALCULATIONS .................................................................. 184

APPENDIX F: SWIRLER DEVIATION ANALYSIS.................................................................................... 188

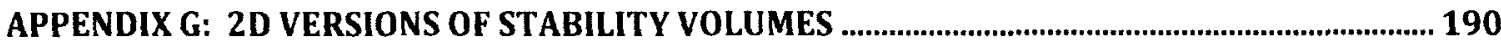

APPENDIX H: DERIVATION OF THE SWIRL NUMBER IN TERMS OF THE VELOCITY FIELD...... 194 


\section{List of Tables}

Table 1.1: Syngas/biogas compositions considered in this thesis ................................... 5

Table 2.2: Summary of low-swirl burner studies................................................................ 28

Table 3.1: LSB nozzle combinations....................................................................................... 45

Table 3.2: Swirler Details................................................................................................ 45

Table 3.3: Stability Map Test Matrix ......................................................................................... 54

Table 3.4: PIV Measurement Conditions …………………………................................... 57

Table 4.1: Summary of stability volume properties.......................................................... 82

Table 5.1: Comparison of biofuels to methane at matched $T_{a d}$ and $H R R_{H H V}$ near

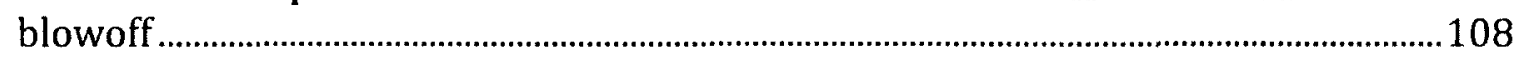

Table 5.2: Summary of observed stabilization modes .......................................................114

Table 6.2: Magnitude of $\boldsymbol{U R} \boldsymbol{M} \boldsymbol{S}^{\prime}$ and Umean radial gradients at anchor points of all flames at blowoff....................................................................................................................133

Table A.1: Chosen Experimental Syngas Compositions ..................................................158

Table C.1: Available mass flow controllers ......................................................................164

Table D.1: Relative uncertainties for measured and calculated values .........................167

Table D.2: Mass fractions of fuel and air in $\mathrm{CH}_{4}$ at $\Phi=0.8$ and $\mathrm{S} 6$ at $\Phi=0.6 \ldots \ldots \ldots \ldots . . .168$

Table D.3: Blowoff test uncertainty on $50.8 \mathrm{~mm}$ nozzle for $\mathrm{CH}_{4}$ fuel at $\Phi=0.8 \ldots \ldots . .173$

Table D.4: Analysis of velocity gradient bias uncertainty for three PIV measurements 180

Table D.5: Relative uncertainties at two interframe times and various displacements: 


\section{List of Figures}

Figure 1.1: Equilibrium adiabatic flame temperature as a function of equivalence ratio for the various fuel mixtures considered in this work calculated using Cantera (Cantera, 2011). Refer to Table 1.1 for details of the fuel mixtures.

Figure 1.2: Laminar flame speed, $S_{L}$, of standardized mixtures used in this study.....7

Figure 1.3: Dependence of $S_{T}$ upon $u^{\prime}$ for several fuel mixtures at a constant $S_{L}$ (Kido et al. 2002). 10

Figure 1.4: Peters' Regime Diagram for 'Turbulent Premixed Combustion (Peters, 2000)

Figure 1.5: Dependence of chemical time scale [ms] upon fuel composition at fixed adiabatic flame temperature of $1500 \mathrm{~K}$ at $1.7 \mathrm{~atm}$ with $300 \mathrm{~K}$ reactant temperature. From Zhang (2008). 14

Figure 1.6: Illustration of a feedback loop resulting in a dynamic combustion instability (Lieuwen, 2006) 16

Figure 2.1: a) tangential jet-type LSB b) vane-type LSB. Similar configurations are present in non-LSB swirling flows.

Figure 2.2: Original hypothesis for the LSB stability mechanism based on flow divergence 31

Figure 3.1: a) Burner components b) Burner exploded view 42

Figure: 3.2 LSB with mass flow controllers setup 42

Figure 3.3: a) Outer nozzles b) Inner nozzles with attached turbulence generating plates 43

Figure 3.4: Nozzles assembly (76.2 mm nozzle example) ………………………………. 44

Figure 3.5 a) $38.1 \mathrm{~mm}$ swirler b) three $50.8 \mathrm{~mm}$ swirlers c) $76.2 \mathrm{~mm}$ swirler ........... 44

Figure 3.6: Mass flow controllers and seeders....................................................................... 46

Figure 3.7: LabVIEW interface for operating the fully controlled low swirl burner 47

Figure 3.8: PIV setup (from Strahman (2007)) 48

Figure 3.9 Seeder used for PIV a) Side view b) Inside view with top lid removed .... 51

Figure 3.10: a) Stable flame b) Near Blowoff c) Flashback d) In burner e) Attached Flame 
Figure 3.11: Stability map as output on the computer screen by the LabVIEW data acquisition program during measurements. Results are shown for methane fuel at $\Phi=0.8$ using the $50.8 \mathrm{~mm}$ nozzle

Figure 3.12: Uncertainty in swirl number and heat release at blowoff.......................... 56

Figure 3.13: Example of adequate PIV seeding for this study …………………………... 61

Figure 3.14: Example of particle image normalization preprocessing algorithm a) Raw image b) Result. 62

Figure 3.15: Example of instantaneous velocity field from stereo-PIV measurement 65

Figure 3.16: PIV vector convergence for a) $U_{\text {mean }}$ b) $u_{R M S}^{\prime}$ c) $\delta_{u u}$ 66

Figure 3.17: a) Corrected Image b) Image after 7x7 pixel smoothing and sliding maximum

Figure 3.18: a) Image after user-defined function subtracts mean of image b) Image after counts changed depending on a threshold of 127 counts where counts above 127 were set to 255 and counts below 127 were set to 0 .

Figure 3.19: a) Ensemble averaged binarized image b) Mean flame front with false flame fronts 68

Figure: 3.20 Mean flow field with edited flame front contour 69

Figure 4.1: Stability volume plotted with $\Phi$ for methane fuel on $50.8 \mathrm{~mm}$ nozzle $\ldots 72$ Figure 4.2: Stability volumes plotted with $T_{a d}$ for methane fuel with $50.8 \mathrm{~mm}$ nozzle 73

Figure 4.3: Blowoff and flashback curves for methane fuel with $50.8 \mathrm{~mm}$ nozzle.... 74

Figure 4.4: Stability volume for methane fuel on $38.1 \mathrm{~mm}$ nozzle 76

Figure 4.5: Blowoff curves at $\Phi=0.65$ and 0.70 for methane fuel on $38.1 \mathrm{~mm}$ nozzle 76

Figure 4.6: Stability volume for methane fuel on $76.2 \mathrm{~mm}$ nozzle 77

Figure 4.7: Stability volumes low-swirl flames with $50.8 \mathrm{~mm}$ nozzle $\left(37.5^{\circ}\right.$ vane angle) for a) B1 b) S1 c) S2 d) S3 e) S4 f) S5 g) S6 h) S14 i) S5M50 j) S5M25 78

Figure 4.8: Fuel mixtures S1, S2, S3, S4, S5, S6, and S14 at $S=0.46$ and $\Phi=0.5,0.6$, and 0.7 . Plots show the average exit velocity where the flame attached for a given condition. 
Figure 4.9: Laminar flame speed matched at $37.2 \mathrm{~cm} / \mathrm{s}$ on $50.8 \mathrm{~mm}$ nozzle with $S=0.43$ and $Q_{\text {tot }}=400 \mathrm{SLPM} / U_{\text {ave }}=3.7 \mathrm{~m} / \mathrm{s}$ for $\mathrm{CH}_{4}, \mathrm{~S} 1, \mathrm{~S} 2$, and S3

Figure 4.10: Enclosure effect on blowoff, $50.8 \mathrm{~mm}$ nozzle, $\mathrm{CH}_{4}, \Phi=0.8$, $H H R_{H H V}=37 \mathrm{~kW}$. 86

Figure 4.11: Vertical heights of enclosed LSB flames 86

Figure 5.1: Velocity fields measured via PIV using olive oil seeding. Plots show data on the $50.8 \mathrm{~mm}$ nozzle at $Q_{\text {tot }}=800 \mathrm{SLPM}$ and $S=0.62$. a) $\Phi=0$ (Non-reacting) b) Methane at $\Phi=0.8$

Figure 5.2: $\mathrm{CH}_{4}-\Phi=0.8-800$ SLPM near blowoff without swirl on $50.8 \mathrm{~mm}$ nozzle a) Measured PIV flowfield b) Radial divergence contour plot 88

Figure 5.3: Velocity fields measured via PIV at near blowoff conditions. Plots show data for the $50.8 \mathrm{~mm} \mathrm{LSB}$ burning methane at $\Phi=0.8$ and a total reactant flow rate $\left(Q_{t o t}\right)$ of a) 400 SLPM b) 800 SLPM c) 1200 SLPM 90

Figure 5.4: Radial divergence angle contour plot from PIV measurement for LSB burning methane near blowoff at $\Phi=0.8$ and $Q_{t o t}=800$ SLPM on $50.8 \mathrm{~mm}$ nozzle .91

Figure 5.5: Velocity fields measured via PIV at near blowoff conditions. Plots show data for the LSB burning methane at $\Phi=0.7$ at an average exit velocity ( $\left.U_{\text {ave }}\right)$ of $6.7 \mathrm{~m} / \mathrm{s}$ on the a) $38.1 \mathrm{~mm}$ nozzle b) $50.8 \mathrm{~mm}$ nozzle c) $76.2 \mathrm{~mm}$ nozzle 92

Figure 5.6: Velocity fields measured via PIV at near blowoff conditions. Plots show data for the LSB burning methane at $\Phi=0.8$ at an average exit velocity ( $U_{\text {ave }}$ ) of $6.7 \mathrm{~m} / \mathrm{s}$ on the a) $38.1 \mathrm{~mm}$ nozzle b) $50.8 \mathrm{~mm}$ nozzle c) $76.2 \mathrm{~mm}$ nozzle .94

Figure 5.7: Velocity fields measured via PIV at near blowoff conditions. Plots show data for the LSB burning methane on the $50.8 \mathrm{~mm}$ nozzle to obtain conditions for matching biofuel mixture $T_{a d}$ and $H R_{H H V}$ to the methane case for direct comparison. a) $\Phi=0.7, Q_{\text {tot }}=800 \mathrm{SLPM}$ and b) $\Phi=0.8, Q_{\text {tot }}=800 \mathrm{SLPM}$ (repeated from Figure $5.3 b)$ 95

Figure 5.8: Velocity fields measured via PIV at near blowoff conditions. Plots show data for the LSB on the $50.8 \mathrm{~mm}$ nozzle with matched $T_{a d}$ and $H R R_{H H V}$ to the methane case of Figure 5.7a for direct comparison. a) B1 b) S1 c) S2 d) S3 e) S4 f) S5 g) S6 h) S14 i) S5M50 j) S5M25. 97

Figure 5.9: Velocity fields measured via PIV at near blowoff conditions. Plots show data for the LSB on the $50.8 \mathrm{~mm}$ nozzle with matched $T_{a d}$ and $H R R_{H H V}$ to the methane case of Figure 5.7b for direct comparison. a) B1 b) S1 c) S2 d) S3 e) S4 f) S5 g) S6 h) S14 i) S5M50 j) S5M25 100 
Figure 5.10: Flame height as measured along the centreline for all blowoff PIV measurements.

Figure 5.11: Centreline axial velocity profiles for $\mathrm{CH}_{4}$ at a) $\Phi=0.8$ for the $50.8 \mathrm{~mm}$ nozzle at $\left.U_{\text {ave }}=3.72,7.41,11.1 \mathrm{~m} / \mathrm{s} \mathrm{b}\right) \Phi=0.7$ for all nozzles at $U_{\text {ave }}=6.70 \mathrm{~m} / \mathrm{s} \ldots .104$

Figure 5.12: Centreline $(r=0 \mathrm{~mm})$ and anchor point $(r=-20 \mathrm{~mm})$ axial velocity profiles for the reference methane case at $\phi=0.8$. Example for how the turbulent flame speeds, $S_{T, L D}$ and $S_{T, A P}$, and velocity increase past the flame front, $\Delta U$, are measured.

Figure 5.13: Measured velocity increase past flame front plotted against estimated velocity increase past flame front, both as compared to reference methane case ..107

Figure 5.14: The sensitivity of the turbulent flame speeds of to turbulent fluctuations normalized by laminar flame speed. a) Turbulent flame speeds measured as defined by the local displacement speed (Cheng, 2010)b) Turbulent flame speeds measured at the anchor point

Figure 5.15: Turbulent flame speeds for all ' $W$ '-methane flames and all biofuel cases a) The local displacement turbulent flame speed b) Anchor point turbulent flame speed.

Figure 5.16: 2D stability map showing PIV measurement locations.

Figure 5.17: Near blowoff for $38.1 \mathrm{~mm}$ nozzle at $\Phi=0.7$ and $H R R_{H H V}=40.8 \mathrm{~kW}$ for a) $S=0.66$ b) $S=0.55$

Figure 5.18: Near blowoff for $38.1 \mathrm{~mm}$ nozzle at $\Phi=0.7$ and $H R R_{H H V}=45.2 \mathrm{~kW}$ for a) $S=0.72$ b) $S=0.58$

Figure 5.19: Near blowoff for $38.1 \mathrm{~mm}$ nozzle at $\Phi=0.65$ and a) $H R R_{H H V}=17.0 \mathrm{~kW}$ b) $H R R_{H H V}=42.3 \mathrm{~kW}$

Figure 5.20: PIV flowfield and flame front contour for the $50.8 \mathrm{~mm}$ LSB nozzle with $\mathrm{CH}_{4}$ at a) $\Phi=0.6, Q_{t o t}=800 \mathrm{SLPM}$, near blowoff at $S=0.60$, and b) $\Phi=0.9$, $Q_{t o t}=800 \mathrm{SLPM}$, at a stable condition at $S=0.62$.

Figure 6.1: $D a$ contour of LSB burning methane at $\Phi=0.8$ on $50.8 \mathrm{~mm}$ nozzle near W-type blowoff, $U_{\text {ave }}=7.42 \mathrm{~m} / \mathrm{s}\left(Q_{\text {tot }}=800 \mathrm{SLPM}\right.$ ) (See Figure $5.3 \mathrm{~b}$ for corresponding velocity field)

Figure 6.2: Da contours of LSB burning S1 fuel mixture methane at $\Phi=0.75$ on $50.8 \mathrm{~mm}$ nozzle near W-type blowoff, $U_{a v e}=8.16 \mathrm{~m} / \mathrm{s}\left(Q_{t o t}=881 \mathrm{SLPM}\right)$ (adiabatic flame temperature and heat release rate are matched to Figure 6.1; See Figure 5.9b for corresponding velocity field) 
Figure 6.3: $D a$ contour of LSB burning methane at $\Phi=0.6$ on $50.8 \mathrm{~mm}$ nozzle near R-type blowoff, $U_{a v e}=7.42 \mathrm{~m} / \mathrm{s}\left(Q_{\text {tot }}=800\right.$ SLPM) (See Figure 5.20a for corresponding velocity field).

Figure 6.4: $D a$ contours for $\mathrm{CH}_{4}$ on $38.1 \mathrm{~mm}$ nozzle at $\Phi=0.65$ near a) R-type blowoff- $U_{\text {ave }}=16.7 \mathrm{~m} / \mathrm{s}\left(Q_{t o t}=1000\right.$ SLPM) b) W-type blowoff $-U_{\text {ave }}=6.70 \mathrm{~m} / \mathrm{s}$ $\left(Q_{\text {tot }}=400\right.$ SLPM $)$ (See Figure 5.19 for corresponding velocity fields)

Figure 6.5: $\mathrm{Da}$ contours for LSB burning $\mathrm{CH}_{4}$ on $38.1 \mathrm{~mm}$ nozzle at $\Phi=0.7$ at $U_{\text {ave }}=16.7 \mathrm{~m} / \mathrm{s}\left(Q_{\text {tot }}=1000\right.$ SLPM) near a) R-type blowoff $-S=0.72$ and b) W-type blowoff $-S=0.58$ (See Figure 5.18 for corresponding velocity fields)

Figure 6.6: Peter's premixed turbulent combustion regime diagram with $\mathrm{CH}_{4} \mathrm{LSB}$ blowoff points

Figure 6.7: Comparison of methane blowoff curves to Mansour and Chen (2008) correlation

Figure 6.8: Mean flame contour superimposed on velocity field, for $\Phi=0.8, S=0.55$, and $Q_{t o t}=400$ SLPM (from Strahman (2007))

Figure 6.9: Turbulence contours for the $50.8 \mathrm{~mm} \mathrm{LSB} \mathrm{nozzle} \mathrm{burning} \mathrm{CH}_{4}$ at $\Phi=0.8$, $Q_{\text {tot }}=800$ SLPM, near blowoff (W-type blowoff $-S=0.44$ ) for a) 3D turbulence intensity b) 3D RMS turbulence fluctuations, $V^{\prime}$

Figure 6.10: Turbulence contours for the $50.8 \mathrm{~mm} \mathrm{LSB}$ nozzle burning $\mathrm{CH}_{4}$ at $\Phi=0.8, Q_{t o t}=800$ SLPM, at a stable condition $(S=0.60)$. a) 3D turbulence normalized intensity b) 3D RMS turbulence fluctuations, $V^{\prime}$

Figure 6.11: Radial 3D RMS turbulence fluctuation gradients for the $50.8 \mathrm{~mm} \mathrm{LSB}$ nozzle burning $\mathrm{CH}_{4}$ at $\Phi=0.8$ and $Q_{\text {tot }}=800$ SLPM. a) Conditions near blowoff $(S=0.44)$ b) Stable conditions $(S=0.60)$

Figure 6.12: Turbulence contours for the $38.1 \mathrm{~mm}$ LSB nozzle burning $\mathrm{CH}_{4}$ at $\Phi=0.7, Q_{t o t}=1000$ SLPM, near blowoff (R-type blowoff $-S=0.72$ ) for a) 3D turbulence intensity b) 3D RMS turbulence fluctuations, $V^{\prime}$.....

Figure 6.13: Turbulence contours for the $38.1 \mathrm{~mm} \mathrm{LSB}$ nozzle burning $\mathrm{CH}_{4}$ at $\Phi=0.7, Q_{t o t}=1000$ SLPM, near blowoff (transitional W-type blowoff $-S=0.58$ ) for a) 3D turbulence intensity b) 3D RMS turbulence fluctuations, $V^{\prime}$.. 132

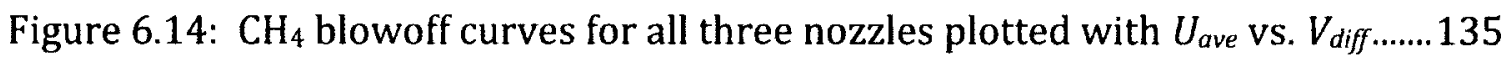

Figure 6.15: $50.8 \mathrm{~mm}$ nozzle with $\mathrm{CH}_{4}$ at $\Phi=0.8$, at blowoff (W-type blowoff) with and without swirl plotted with a) Inner flow fraction (\%) and b) $V_{\text {diff }}$ 136 
Figure 6.16: All blowoff points (W-type blowoff only) for all fuel mixtures, all $\Phi$, all nozzles $\left(35^{\circ}, 37.5^{\circ}, 47^{\circ}\right.$ and no swirl for $50.8 \mathrm{~mm}$ nozzle)

Figure 6.17: Empirical correlation for blowoff points (W-type blowoff only) for all fuel mixtures, all $\Phi$, all nozzles, all swirl angles $\left(35^{\circ}, 37.5^{\circ}, 47^{\circ}\right.$ and no swirl for 50.8 $\mathrm{mm}$ nozzle) a) Average exit velocity vs. 3D shear layer strength ( $\left.V_{\text {diff }}\right)$ times $S_{L^{0}}^{0.15} \mathrm{~b}$ ) Histogram $\left(V_{\text {diff }}^{*} S_{L} 0.15 / U_{\text {ave }}\right)$.

Figure A.1: Gasification steps, from (Ciferno and Marano, 2002) 151

Figure A.2: Mean composition and ranges for all syngas mixtures. 154

Figure A.3: Directly heated and (a) airblown syngas (b) oxygen blown syngas......155

Figure A.4: Mean composition and ranges for indirectly-heated steam-blown syngas

Figure A.5: Directly-heated and (a) airblown coalfed syngas (b) $\mathrm{O}_{2}$ blown coalfed syngas.

Figure A.6: Directly-heated and (a) airblown biomass-fed syngas (b) $\mathrm{O}_{2}$-blown biomass-fed syngas

Figure A.7: Composition of all types of biogas considered 159

Figure A.8: Composition range of (a) landfill biogas and (b) digester biogas. 160

Figure B.1: Example MATLAB code for determining nozzle contours 161

Figure B.2: Contour for $38.1 \mathrm{~mm}$ outer nozzle inner contour 162

Figure B.3: Contour for $76.2 \mathrm{~mm}$ outer nozzle inner contour. 162

Figure B.4: Contour for $76.2 \mathrm{~mm}$ inner nozzle outer contour. 163

Figure B.5: Contour for $76.2 \mathrm{~mm}$ inner nozzle inner contour. 163

Figure C.1: Example calibration curves and equations for MFCs 166

Figure D.1: A histogram of displacement, in pixels 179

Figure: F.1: Deflection vs. incident angle for a compressor cascade. From Dixon (2005), page 69 . 188

Figure G.1: Blowoff and flashback curves for methane fuel on a) $38.1 \mathrm{~mm} \mathrm{LSB} \mathrm{b}$ ) $50.8 \mathrm{~mm} \mathrm{LSB} \mathrm{c)} 76.2 \mathrm{~mm} \mathrm{LSB}$. 190 
Figure G.2: Blowoff and flashback curves on $50.8 \mathrm{~mm} \mathrm{LSB}$ with a) B1 b) S1 c) S2 d) S3 e) S4 f) S5 g) S6 h) S14 i) S5M50 j) S5M25. 


\section{Nomenclature}

\begin{tabular}{|c|c|c|}
\hline & Variables & First Use \\
\hline$d$ & Diameter $[\mathrm{mm}]$ & Table 2.1 \\
\hline$D a$ & Damköhler number [-] & $\mathrm{Eq} .(1.3)$ \\
\hline$e$ & Error & Appendix D \\
\hline$f$ & Frequency $[\mathrm{Hz}]$ & Appendix D, Eq.(D.44) \\
\hline$f \#$ & Camera f-stop number.[-] & Section 3.1.5. \\
\hline$G_{\text {ang }}$ & Axial flux of angular momentum & Eq.(2.1) \\
\hline$G_{x}$ & Axial thrust & $\mathrm{Eq} \cdot(2.1)$ \\
\hline$H R R$ & Heat release rate $[\mathrm{kW}]$ & Table 3.4 \\
\hline$\% I F F$ & Inner flow fraction (\%). & Section 3.1 .3 \\
\hline$K_{T}$ & From Cheng (1995) in chap 2 & Section 2.3 \\
\hline$K a$ & Karlovitz number & Section 1.4 \\
\hline$l$ & Length scale of turbulence (see Subscripts) & Section 1.4 \\
\hline$\dot{m}$ & Mass flow rate $[\mathrm{g} / \mathrm{s}]$ & $\mathrm{Eq} \cdot(2.3)$ \\
\hline$M$ & PIV camera magnification & Appendix D, Section D.2 \\
\hline $\mathrm{px}$ & Camera pixel & Appendix D \\
\hline$Q$ & Volume flow rate [LPM;SLPM] & Table 3.4 \\
\hline$r$ & Burner radial location [mm] & Figure 3.15 \\
\hline $\mathrm{R}$ & Radius [mm] & Eq. (2.1) \\
\hline $\operatorname{Re}$ & Reynolds number & Section 1.4 \\
\hline$S$ & Swirl number & Eq.(2.1) \\
\hline$S_{L}$ & Laminar flame speed $[\mathrm{m} / \mathrm{s}]$ & Section 1.2 \\
\hline$S_{T}$ & Turbulent flame speed $[\mathrm{m} / \mathrm{s}]$ & Section 1.2 \\
\hline$T$ & Temperature $[\mathrm{K}]$ & Section 1.1 \\
\hline$T_{\text {int }}$ & 3D Turbulence intensity & Appendix E \\
\hline \multirow[t]{2}{*}{$u$} & Mansour and Chen tangential jet velocity & Section 2.3 \\
\hline & Uncertainty & Appendix D \\
\hline$u^{\prime}$ & Axial velocity fluctuation $[\mathrm{m} / \mathrm{s}]$ & Section 1.3 \\
\hline$\Delta U$ & Velocity increase past flame front $[\mathrm{m} / \mathrm{s}]$ & Section 5.6 \\
\hline$U$ & Axial velocity $[\mathrm{m} / \mathrm{s}]$ & $\mathrm{Eq} \cdot(1.1)$ \\
\hline$V$ & Vector magnitude & Eq.(6.6) \\
\hline$W$ & Tangential velocity $[\mathrm{m} / \mathrm{s}]$ & Appendix E \\
\hline$x$ & Burner axis [mm] & Figure 3.15 \\
\hline$\alpha$ & Thermal diffusivity $\left[\mathrm{m}^{2} / \mathrm{s}\right]$ & Section 1.3 \\
\hline$\beta$ & Phase response of PIV seeding particles & Eq.(D.46) \\
\hline
\end{tabular}




$\begin{array}{lll}\rho & \text { Density }\left[\mathrm{kg} / \mathrm{m}^{3}\right] & \text { Eq. }(2.2) \\ \theta & \text { PIV camera off-axis angle }\left[^{\circ}\right] & \text { Figure } 3.8 \\ \lambda & \text { Wavelength [m] } & \text { Eq.(3.2) } \\ \eta & \text { Relative amplitude of PIV seeding particles } & \text { Eq.(D.45) } \\ v & \text { Kinematic viscosity }\left[\mathrm{m}^{2} / \mathrm{s}\right] & \text { Eq.(2.5) } \\ \infty & \text { Infinity } & \text { Appendix E } \\ \omega & \text { Angular frequency }[\mathrm{rad} / \mathrm{s}] & \text { Appendix D }\end{array}$

\section{Subscripts}

ad Adiabatic

ave

d

diff

$F$, or fuel Fuel

g Geometric

$\mathrm{h}$ Hub of a swirler

HHV Higher heating value

inner/i Inner nozzle

$\mathrm{k} \quad$ Kolmogorov (See length scale in variables)

L Laminar

LHV Lower heating value

outer/o Outer nozzle

P Particle

$\mathrm{R} \quad$ Reaction zone

T Turbulent

tot Total

$\tau \quad$ Image of particle

0 Integral (See length scale in variables)

\section{First Use}

Section 1.1

Section 1.1

Eq. (3.2)

Eq.(6.6)

Eq.(2.5)

Eq. (2.3)

Eq.(2.4)

Table 3.4

Eq.(2.4)

Section 1.4

Section 1.2

Section 1.1

Eq.(2.4)

Eq.(3.1)

Section 1.2

Section 1.2

Table 3.4

Eq.(3.1)

Section 1.4

\section{Abbreviations}

CCD Charge-coupled device

Section 3.1.4

CCME Canadian Council of the Ministers of the Environment

Section 1.1

CRIAQ Consortium for Research and Innovation in Aerospace in Quebec

Section 1.1

DAQ Data acquisition

Section 3.1.3

FGR Flue gas recirculation

Section 2.3 
FOV Field of view

GCF Gas conversion factor

HSB High-swirl burner

LSB Low-swirl burner

MFC Mass flow controller

NG Natural gas

PIV Particle image velocimetry

PRNG Partially reformed natural gas

PTU Programmable timing unit

VI Virtual instrument
Section 3.1 .5

Section 3.1.3

Section 2.3

Section 1.1

Section 3.1.3

Table 2.2

Section 1.4

Section 2.3

Section 3.1.5

Section 3.1.3 


\section{Introduction}

\subsection{Background}

In $2008,91.3 \%$ of global primary energy was combustion derived, with $81.3 \%$ sourced from fossil fuels, and $10 \%$ coming from renewable combustibles and waste (International Energy Agency, 2010). Though the relative fraction of combustion derived energy fell slightly from $97.2 \%$ in 1973 (86.6\% fossil fuels, $10.6 \%$ renewable combustibles and waste), this change is dwarfed by the near doubling of total primary energy production from 6615 to 12267 Mtoe during that same 25year period. This trend will continue due to ever increasing global energy demands and the comparatively slow growth of non-combustion based energy (International Energy Agency, 2010). Environmental mitigation of combustion-based pollution must be a priority for energy supply research now and in the future.

Concerns over various pollutants produced by combustion have prompted strict regulations. The major pollutants emitted by combustion are unburned hydrocarbons, nitrogen oxides $\left(\mathrm{NO}_{\mathrm{x}}\right)$, carbon monoxide ( $\left.\mathrm{CO}\right)$, sulphur oxides $\left(\mathrm{SO}_{2}\right.$ and $\mathrm{SO}_{3}$ ), and particulate matter (Turns, 2000; Bender, 2006; Strahman, 2007). To achieve lower pollutant emission rates, a variety of pre-formation and postformation control strategies have been utilized either individually or in combination, including (Bender, 2006):

- Wet controls (water or steam injection);

- Dry combustion controls (lean combustion, reduced residence time, lean premixed combustion, and two-stage rich/lean combustion);

- Selective catalytic reduction (SCR);

- SCONOX (selective carbon monoxide and nitrogen oxide) catalytic absorption ;

- Catalytic combustion;

- Rich Quench Lean Combustors; and

- CO oxidation catalysts. 
The research presented in this thesis focuses primarily upon the reduction of $\mathrm{NO}_{\mathrm{x}}$ emissions through the use of a low-swirl burner employing ultra-lean, turbulent premixed combustion. $\mathrm{NO}_{\mathrm{x}}$ production within a combustion reaction is governed by four main mechanisms (Turns, 2000; Miller and Bowman, 1989):

1) The thermal, or Zeldovich, mechanism dominates $\mathrm{NO}_{x}$ formation in combustion at high temperatures over a wide range of equivalence ratios. Its significance becomes relevant at temperatures above $1800 \mathrm{~K}$, and it is the chief $\mathrm{NO}_{\mathrm{x}}$ formation pathway at temperatures above $2500 \mathrm{~K}$ (Kuo, 2005).

2) The prompt, or Fenimore mechanism is especially relevant in rich combustion (equivalence ratios, $\Phi$, higher than 1). The Fenimore mechanism is the major mechanism controlling the rate of $\mathrm{NO}_{\mathrm{x}}$ formation below temperatures of $2000 \mathrm{~K}$ (Kuo, 2005).

3) The $\mathrm{N}_{2} \mathrm{O}$-intermediate mechanism is relevant only for low temperature conditions which occur at low equivalence ratios $(\Phi<0.8)$.

4) Fuels with chemically bound nitrogen recombine to form hydrogen cyanide that reacts to form $\mathrm{NO}_{\mathrm{x}}$ via the Fenimore mechanism. This mechanism is irrelevant to fuels without chemically bound nitrogen.

All four of these mechanisms are extremely slow relative to the formation rates of the primary combustion products. Longer residence times of the products in the combustion region lead to more $\mathrm{NO}_{\mathrm{x}}$ production from all sources. The reaction rate of the Zeldovich mechanism is exponentially dependent on temperature and increases substantially above $1800 \mathrm{~K}$. Thus, lowering the temperatures of combustion processes has the effect of minimizing emissions from this mechanism (Kuo, 2005). The Fenimore (prompt) mechanism is much more rapid than the Zeldovich mechanism, and, as mentioned above, becomes very significant for rich combustion. While close to $95 \%$ of the NO emissions are formed via the Fenimore mechanism in premixed laminar combustion at $\Phi=1.32$, (Bowman, 1992), this mechanism can be minimized by providing a lean mixture for combustion, resulting in even further reductions in $\mathrm{NO}_{\mathrm{x}}$ emissions. The $\mathrm{N}_{2} \mathrm{O}$-intermediate mechanism is 
unaffected by lower temperatures, showing that complete elimination of $\mathrm{NO}_{\mathrm{x}}$ emissions from combustion is unachievable. However, overall $\mathrm{NO}_{\mathrm{x}}$ emissions can still be reduced substantially by controlling the key variables of these mechanisms including residence time of products in the combustion region (for all mechanisms), temperature (for the thermal/Zeldovich mechanism), mixture strength (i.e. lean/rich as important for Fenimore/ $\mathrm{N}_{2} \mathrm{O}$ mechanisms), and fuel composition (for the fuel bound $\mathrm{N}_{2}$ mechanism).

Lean premixed combustion minimizes the Fenimore mechanism while simultaneously lowering flame temperatures to suppress the Zeldovich mechanism. Premixed combustion allows for better control of temperature compared to diffusion flames. At lean conditions, excess air in the fuel/air stream acts as a heat sink that significantly reduces flame temperature. Intense turbulent premixing of the fuel and oxidizer also promotes uniform composition of the fuel/air mixture resulting in a much more homogeneous temperature distribution throughout the combustion zone. After these steps have been taken, assuming the use of fuels without chemically bound nitrogen such as natural gas and typical bio- and syn-gas mixtures, the only remaining path of any significance for $\mathrm{NO}_{x}$ production with lean premixed combustion is the $\mathrm{N}_{2} \mathrm{O}$-intermediate mechanism.

The effect of $\Phi$ on flame temperatures is shown in Figure 1.1 for the various fuel mixtures used in this study as summarized in Table 1.1. Adiabatic flame temperatures were calculated using the open-source software Cantera (Cantera, 2011). As is seen on the curve, the adiabatic flame temperature falls below $1800 \mathrm{~K}$ for a methane-air mixture at the ultra-lean equivalence ratio of just under $\Phi=0.7$. Temperatures peak at just above $\Phi=1$, at conditions slightly richer than stoichiometric. This occurs since excess fuel tends to act as less of a heat sink than excess air. 


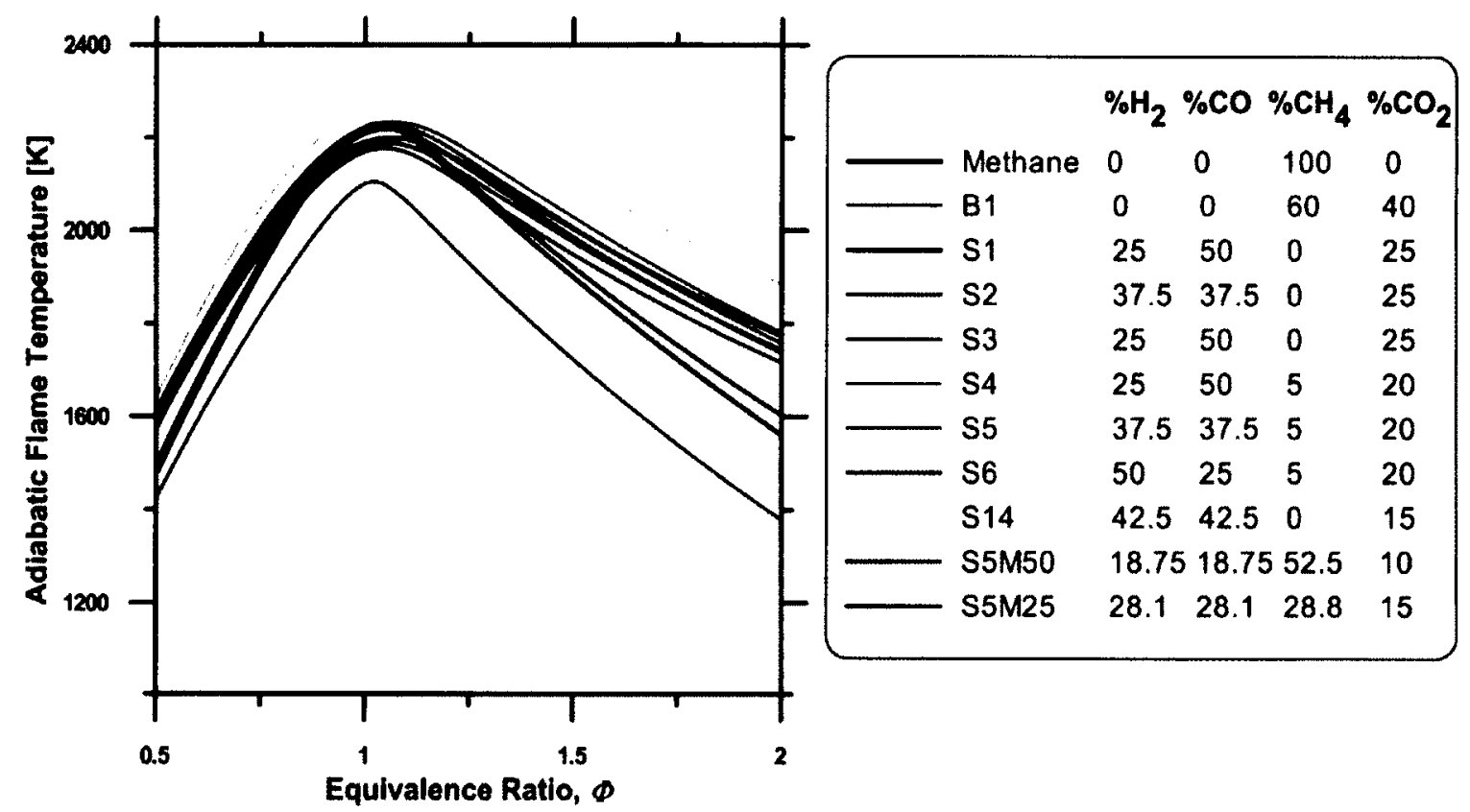

Figure 1.1: Equilibrium adiabatic flame temperature as a function of equivalence ratio for the various fuel mixtures considered in this work calculated using Cantera (Cantera, 2011). Refer to Table 1.1 for details of the fuel mixtures.

The stabilization of an ultra-lean premixed flame has traditionally been quite challenging. One piece of equipment to overcome this issue is the low-swirl burner developed by Cheng and coworkers (Cheng et al. 1995; Cheng, 2006). The lowswirl burner (LSB) has been successfully demonstrated in a number of combustion applications and has been shown to simultaneously emit $<15$ ppmv $\mathrm{NO}_{\mathrm{x}}$ and $<10$ ppmv CO over equivalence ratios of $\Phi=0.8-0.9$ and thermal inputs of 210 to $280 \mathrm{~kW}$ at atmospheric pressure (Cheng et al. 2000). Johnson et al. (2005) tested the concept of the LSB applied to gas turbine operating conditions $\left(20<U_{\text {ave }}<50 \mathrm{~m} / \mathrm{s}\right.$; $230<T_{\text {inlet }}<430^{\circ} \mathrm{C} ; 6<P_{\text {inlet }}<15 \mathrm{~atm}$ ) and reported values of $\mathrm{NO}_{\mathrm{x}}$ below 5 ppm (@ $15 \% \mathrm{O}_{2}$ ) (Strahman, 2007). By comparison, standards for gas turbines set out by the Canadian Council of the Ministers of the Environment (CCME) require gas turbines using natural gas operating at heat release rates above $20 \mathrm{MW}$ are regulated to emit < $25 \mathrm{ppmv} \mathrm{NO}_{\mathrm{x}}(140 \mathrm{~g} / \mathrm{G}$ ) energy) and < 50 ppmv CO (CCME, 1992; Kiameh, 2003). Despite the success of the LSB in meeting emissions targets, a clear understanding of the stability mechanism is still lacking.

Most research to date has focused on using the LSB, and other dry lowemissions technologies, with natural gas as a fuel. However, the confluence of 
concerns about climate change, environmental degradation, and energy supply has raised interest in using coal or biomass-derived syngas and biogas fuels. Since the compositions of these gaseous fuels vary widely due to several variables in their production, the influence of fuel composition upon burner operability is a critical issue and will be a major part of this thesis. Specifically, the research presented in this thesis will focus upon the effects of fuel composition variability reflected in these syngas and biogas mixtures on the static stability limits of LSB flames. Through a collaborative effort with several other university researchers, RollsRoyce Canada, and CRIAQ (Consortium for Research and Innovation in Aerospace in Quebec) a range of relevant fuel compositions were selected for experimentation. These compositions are presented in Table 1.1, and further justification for their selection is outlined in Appendix A. The laminar flame speeds and thermal diffusivities used in the study were all calculated using the Curran mechanism (Curran, 2002).

Table 1.1: Syngas/biogas compositions considered in this thesis

\begin{tabular}{|c|c|c|c|c|c|c|c|c|c|c|}
\hline Label & $\begin{array}{c}\mathrm{H}_{2} / \mathrm{CO} \\
\text { ratio }\end{array}$ & $\begin{array}{c}\mathrm{CO} \\
(\% \mathrm{vol})\end{array}$ & $\begin{array}{c}\% \mathrm{H}_{2} \\
(\% \mathrm{vol})\end{array}$ & $\begin{array}{l}\% \mathrm{CH}_{4} \\
(\% \text { vol) }\end{array}$ & $\begin{array}{c}\% \mathrm{CO}_{2} \\
(\% \text { vol) }\end{array}$ & $\begin{array}{c}A / F \text { at } \\
\Phi=1\end{array}$ & $\begin{array}{l}\text { HRR }_{\text {HWV }} \\
\text { LHV } \\
\left.\text { [M] } / \mathbf{m}^{3}\right]\end{array}$ & $\begin{array}{c}\text { Density } \\
\text { at } 293 \mathrm{~K} \\
\text { and } \\
1 \mathrm{~atm} \\
{\left[\mathrm{~kg} / \mathrm{m}^{3}\right]}\end{array}$ & $\begin{array}{c}\text { Laminar } \\
\text { flame } \\
\text { speed at } \\
\Phi=1 \\
{[\mathrm{~m} / \mathrm{s}]}\end{array}$ & $\begin{array}{c}\text { Adiabatic } \\
\text { flame } \\
\text { temp. at } \\
\Phi=1 \text { [K] }\end{array}$ \\
\hline $\mathrm{CH}_{4}$ & - & 0 & 0 & 100 & 0 & 9.52 & $\begin{array}{c}37.2 / \\
33.5\end{array}$ & 0.67 & 0.36 & 2222 \\
\hline B1 & - & 0 & 0 & 60 & 40 & 5.71 & $\begin{array}{c}29.6 / \\
26.7 \\
\end{array}$ & 1.51 & 0.24 & 2101 \\
\hline S1 & 0.5 & 50 & 25 & 0 & 25 & 1.79 & $\begin{array}{c}10.8 / \\
10.2\end{array}$ & 1.29 & 0.53 & 2191 \\
\hline S2 & 1.0 & 37.5 & 37.5 & 0 & 25 & 1.79 & $\begin{array}{c}11.1 / \\
10.2\end{array}$ & 1.16 & 0.70 & 2181 \\
\hline S3 & 2.0 & 25 & 50 & 0 & 25 & 1.79 & $\begin{array}{c}11.5 / \\
10.3\end{array}$ & 1.02 & 0.90 & 2171 \\
\hline S4 & 0.5 & 50 & 25 & 5 & 20 & 2.26 & $\begin{array}{c}12.7 / \\
11.9 \\
\end{array}$ & 1.19 & 0.56 & 2223 \\
\hline S5 & 1.0 & 37.5 & 37.5 & 5 & 20 & 2.26 & $\begin{array}{c}13.0 / \\
12.0\end{array}$ & 1.05 & 0.69 & 2216 \\
\hline$\overline{56}$ & 2.0 & 25 & 50 & 5 & 20 & 2.26 & $\begin{array}{c}13.5 / \\
12.1\end{array}$ & 0.92 & 0.84 & 2209 \\
\hline S14 & 1.0 & 42.5 & 42.5 & 0 & 15 & 2.02 & $\begin{array}{c}12.1 / \\
11.2\end{array}$ & 1.08 & 0.86 & 2264 \\
\hline S5M50 & 1.0 & 18.8 & 18.8 & 52.5 & 10 & 5.89 & $\begin{array}{l}26.8 / \\
24.3 \\
\end{array}$ & 0.96 & 0.42 & 2220 \\
\hline S5M25 & 1.0 & 28.1 & 28.1 & 28.8 & 15 & 4.07 & $\begin{array}{c}20.3 / \\
18.4\end{array}$ & 0.86 & 0.50 & 2218 \\
\hline
\end{tabular}


Overall, the same strategies for reducing $\mathrm{NO}_{\mathrm{x}}$ emissions from syngas/biogas flames are employed as those for hydrocarbon flames. More details on the fuel effects on $\mathrm{NO}_{x}$ production can be found in Whitty et al. (2010).

\subsection{Premixed Flames}

In general, for a premixed flame to be stable, the local propagation velocity of the flame must match the component of the flow velocity normal to the flame. The laminar flame speed, $S_{L}$, is recognized as a fundamental quantity with regard to flame characterization, and is unique to fuel type and fuel-oxidant mixture strength (equivalence ratio). The value of the laminar flame speed has important impacts upon the propensity of a flame to flashback and blowoff, and also controls other key combustion characteristics, such as the flame's spatial distribution (Natarajan et al. 2008).

The laminar flame speeds of all the standardized gas mixtures used in this study (see Table 1.1 for mixture compositions) are plotted in Figure 1.2. It is obvious from this graph that $\Phi$ has a significant effect on $S_{L}$, and thus its effect on stability is very pronounced. The basic flame speed dependencies of $\mathrm{CH}_{4}, \mathrm{CO}$, and $\mathrm{H}_{2}$ are discussed at length in a variety of sources (Glassman and Yetter, 2008), so it will only be summarized here that $S_{L, H 2} \gg S_{L, C O}>S_{L, C H 4}$. Unfortunately, the flame speed of a fuel mixture is not a linear combination of the flame speed values of the constituents (i.e. $S_{L, m i x} \neq X_{1} S_{L, 1}+X_{2} S_{L, 2}+\ldots$, where $X$ denotes either mole or mass fraction of each species in the fuel mixture (Lieuwen et al. 2008)). The coupling in the oxidation chemistry between the fuels and diluents present in syngas mixtures makes $S_{L}$ difficult to predict (Natarajan and Seitzman, 2010; Ribert et al., 2010).

Turbulence is generally seen as an advantage in combustion since for the combustion process to take place there must be a mixing of fuel and oxidizer at the molecular level (Peters, 2000). Damköhler (1940) was the first to recognize the ability of turbulence to augment the rate of combustion and hence the flame speed. He visualized a turbulent flame as having essentially the same structure as a laminar flame, but where the increase in burning was attributed to turbulence induced wrinkling of the flame front that augments the specific surface area of the flame, and 
hence its ability to consume fresh reactants. Analogous to $S_{L}$, the turbulent flame speed, $S_{T}$, is commonly defined as the velocity at which unburned mixture enters the flame zone in a direction normal to the flame (Turns, 2000). However, while $S_{L}$ is a unique thermochemical property of a fuel-oxidizer mixture ratio, $S_{T}$ is a function not only of the fuel-oxidizer mixture ratio, but also of the flow characteristics and experimental configuration (Glassman and Yetter, 2008).

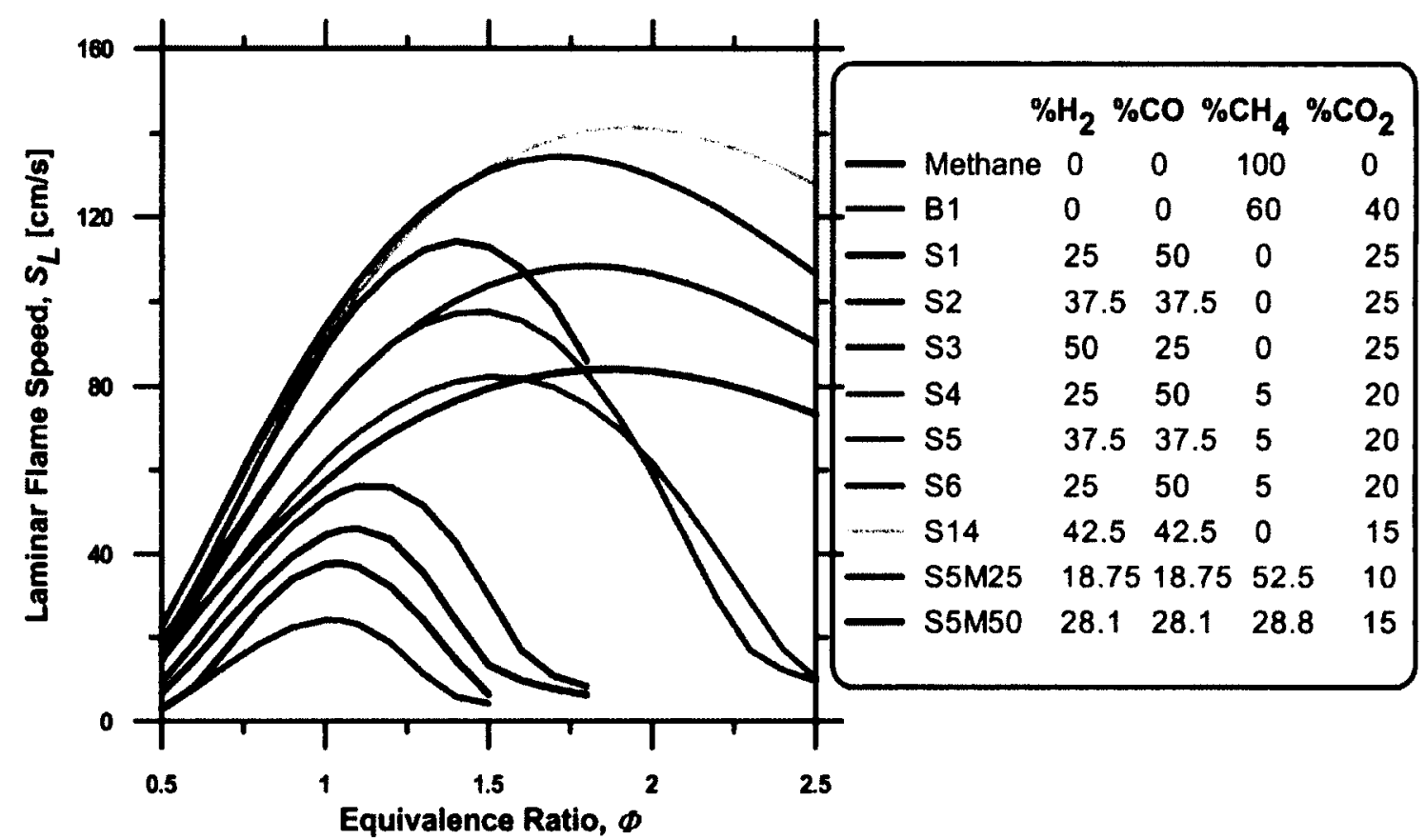

Figure 1.2: Laminar flame speed, $S_{L}$, of standardized mixtures used in this study

As discussed by Cheng (2010), several different techniques have been used to measure $S_{T}$, and comparable results reported in the literature vary significantly. Cheng (2010) argues that much of this inconsistency is attributable to the use of overly simplistic models for the complex flame configurations, and by a lack of strict discipline in the experimental methods. This realization by combustion researchers prompted the formation of guidelines for the measurement of $S_{T}$ from different laboratory experiments. The foundation of the guideline is the recognition that there are four different ways to define $S_{T}$. The characteristics of the laboratory flame configuration and its flow field dictate which definition applies. The four definitions are the local displacement speed, the global displacement speed, the local consumption speed, and the global consumption speed, whose definitions are 
all found in Cheng (2010). For the low-swirl burner, Cheng recommends defining the turbulent flame speed with the local displacement speed, which is defined as follows:

$$
S_{T, L D}=U_{f}-U_{r}=|U| \sin \theta
$$

where $U_{f}$ is the propagating velocity of the flame, $U_{r}$ is the flow velocity of the reactants, and $\theta$ is the relative angle between the flow velocity vector and the contour chosen to represent the mean turbulent flame brush orientation. This definition is convenient for the LSB since the flame brush is locally normal to the approach flow at the centerline, and thus by definition the mean axial velocity entering the flame brush is $S_{T, L D}$.

Despite the above mentioned discrepancies, several trends in $S_{T}$ data are apparent (Glassman and Yetter, 2008; Strahman, 2007):

1) $S_{T}$ is always greater than $S_{L}$. This trend would be expected since the increased area of the turbulent flame allows greater total mass consumption.

2) $S_{T}$ increases with increasing intensity of turbulence upstream of the flame. This relationship has often been found to be approximately linear.

3) Some experiments show $S_{T}$ to be insensitive to the scale of the approach flow turbulence beyond a certain point.

4) In open flames, the variation of $S_{T}$ with composition is generally much the same as for $S_{L}$, and $S_{T}$ has a well-defined maximum close to stoichiometric. Thus, many report turbulent flame speed data as the ratio of $S_{T} / S_{L}$.

5) Very large values of $S_{T}$ may be observed in ducted burners at high approach flow velocities. Under these conditions, $S_{T}$ increases in proportion to the approach flow velocities, but is insensitive to approach flow turbulence and composition. It is believed that these effects result from the dominant influence of turbulence generated within the stabilized flame by the large velocity gradients. 


\subsection{Influence of Fuel Composition on Flame Speed}

Most common correlations for $S_{T}$ have the form $S_{T}=S_{L}^{*} f\left(u^{\prime}\right)$, where $u^{\prime}$ denotes turbulent fluctuations (Lieuwen et al. 2008; Cheng, 2010). This means that for a given turbulence intensity and a given burner, fuels with higher laminar flame speeds should have higher turbulent flame speeds, such that the main influence of fuel composition on flame speed is through changes in $S_{L}$. There are, however, secondary fuel sensitivities to turbulent fluctuations as expressed in the turbulent flame speed related to "preferential diffusion". Differences in the relative rates of mass and/or thermal diffusion (of the deficient species) can affect the local laminar flame speed and the tendency of the flame to become spontaneously wrinkled even in the absence of turbulence fluctuations (Lieuwen et al. 2008). Preferential diffusion is generally expressed by the Lewis number, which is defined as follows (Turns, 2000):

$$
L e=\frac{\propto}{D}
$$

where $\alpha\left[\mathrm{m}^{2} / \mathrm{s}\right]$ is the thermal diffusivity of the mixture, and $D\left[\mathrm{~m}^{2} / \mathrm{s}\right]$ is the mass diffusivity of the deficient species in the reactant mixture. The Lewis number is of specific importance for syngas fuels due to the large differences in diffusivity of the various fuel components. Hydrogen, with its high mass diffusivity and lower thermal diffusivity has a lower Lewis number than methane, which has a larger thermal diffusivity than mass diffusivity. It is because of these diffusivity differences that two different fuel mixtures with the same laminar flame speed running on the same burner with the same turbulence intensity, can have considerably different turbulent flame speeds (Lieuwen, 2008). This is illustrated in Figure 1.3 (reproduced from Kido et al. 2002) which shows the dependence of $S_{T}$ upon turbulence intensity for different fuel mixtures of $\mathrm{CH}_{4}, \mathrm{H}_{2}$, or $\mathrm{C}_{3} \mathrm{H}_{8}$ with $\mathrm{N}_{2}$. Note that these mixtures were carefully chosen to have laminar flame speeds all very close to $15 \mathrm{~cm} / \mathrm{s}$. This is indicated by the $S_{T}$ curves converging at $u^{\prime}=0$. The naming convention for the fuels is as follows; the first letter represents the fuel $\mathrm{H}$ for hydrogen, $M$ for methane, and $\mathrm{P}$ for propane) while the numerical digits after the letter stand for the equivalence ratio, and the final two digits represent $S_{L}$ for the 
mixture in $\mathrm{cm} / \mathrm{s}$. In order to keep $S_{L}$ constant, after the fuel:oxygen ratio was altered within one fuel type, the relative amount of nitrogen in the mixture was altered accordingly (Kido et al. 2002).

As $u$ ' increases, the curves diverge from one another. The hydrogen fuel blend H07-15N in particular has a much higher turbulent flame speed than the methane blends. This graph clearly indicates that fuels with the same laminar flame speed and at the same turbulence intensity can easily have variations in turbulent flame speed that approach an order of magnitude (Lieuwen et al. 2008).

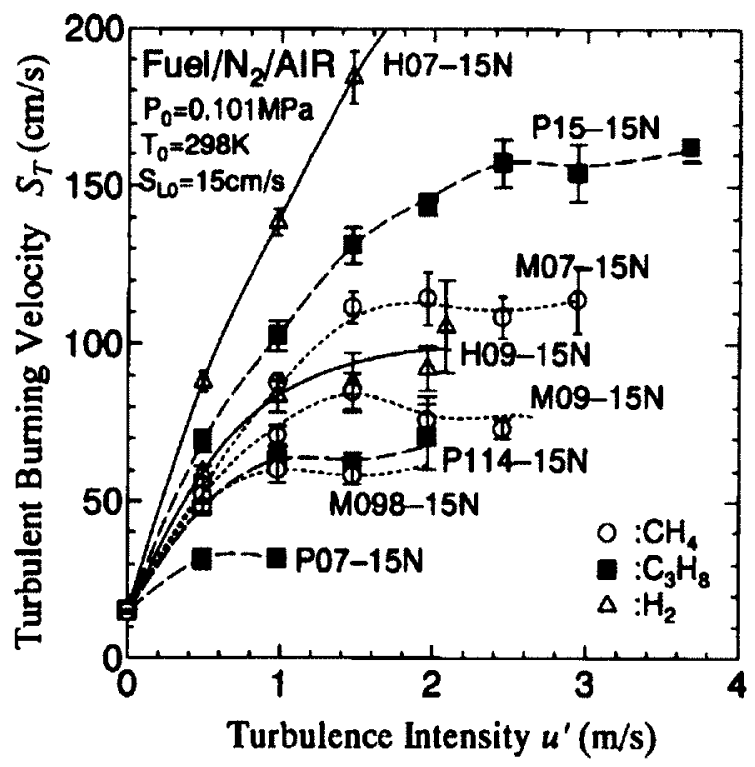

Figure 1.3: Dependence of $S_{T}$ upon $u^{\prime}$ for several fuel mixtures at a constant $S_{\mathrm{L}}$ (Kido et al. 2002)

\subsection{Regimes of Turbulent Combustion}

Damköhler described the distinctions between flames at low-level and high-level turbulence (Lefebvre, 1999), and Borghi (1985), Peters (1986), Abdel-Gayed and Bradley (1989), Poinsot et al. (1990), and many others have proposed diagrams of premixed turbulent combustion in terms of velocity and length scale ratios (Peters, 2000 ). Figure 1.4 shows the regime diagram from Peters (2000) with a circle illustrating the estimated operating range of the LSB used in this study. In this diagram $l_{k}$ refers to the Kolmogorov scale of turbulence, $l_{0}$ is the integral length scale, $\delta_{L}$ is the laminar flame thickness, $\delta_{R}$ is the reaction zone thickness, $u^{\prime}$ is the turbulence fluctuation in the axial direction, $K a$ is the Karlovitz number, and $R e$ is 
the Reynolds number. The Karlovitz number, in this case, is the ratio of either the laminar flame thickness $\left(\delta_{L}\right)$ or the reaction zone thickness $\left(\delta_{L}\right)$ to the Kolmogorov scale of turbulence. To calculate the turbulence parameters needed to locate the LSB within this diagram, velocity statistics from particle image velocimetry (PIV) measurements (See Appendix E) were used to determine turbulence information. All turbulence statistics used in this diagram $\left(u^{\prime}\right.$ and $\left.l_{0}\right)$ were calculated in the burner axial direction.

In the current study, the LSB was operated such that the flames straddled the intersection between the thin reaction zones and corrugated flamelets regimes. The thin reaction zones regime is characterized by $R e>1, K a_{R}<1$, and $K a>1$, with the last inequality indicating that eddies of scale $l_{k}$ can enter into the reactive-diffusive flame structure since $l_{k}<\delta_{L}$. These small eddies are still larger than the reaction zone thickness $\left(\delta_{R}\right)$ and therefore cannot penetrate into that layer.

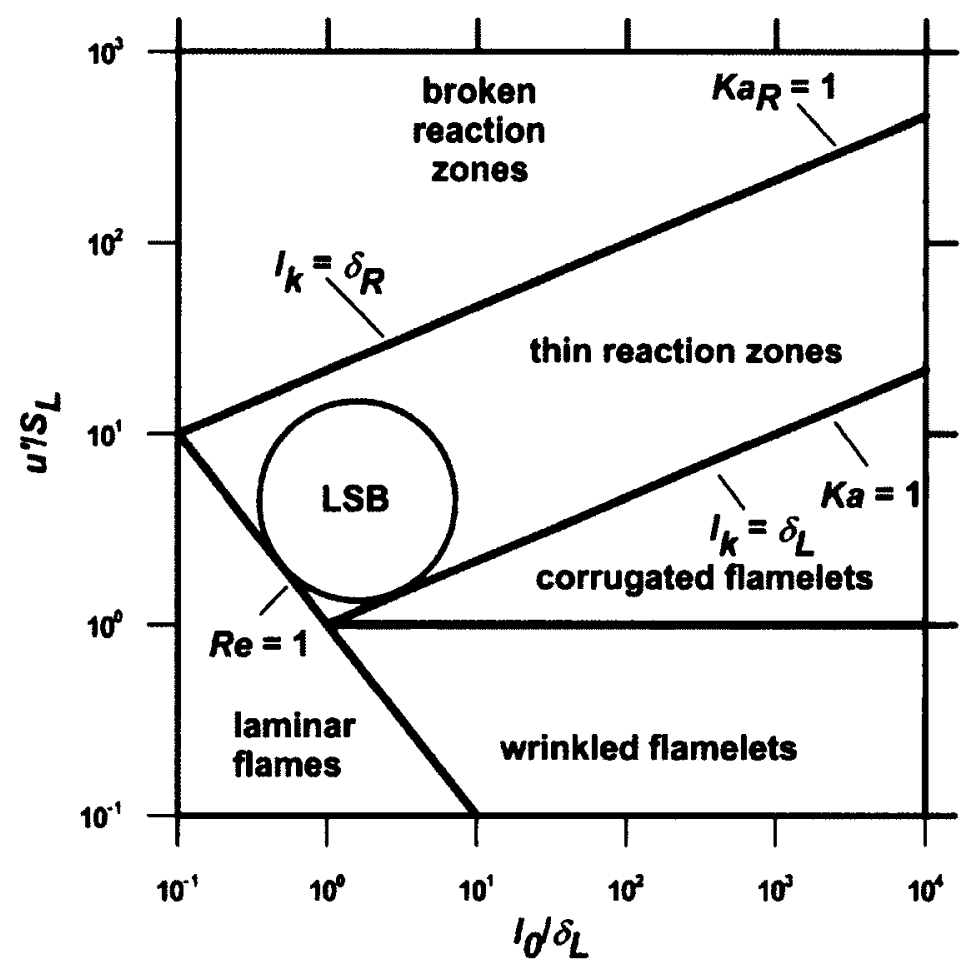

Figure 1.4: Peters' Regime Diagram for Turbulent Premixed Combustion (Peters, 2000) 


\subsection{Stability of Premixed Flames}

The term "stability" is used quite loosely in combustion science (Lefebvre, 1999; Strahman, 2007). Stability can be used to describe the range of fuel/air ratios over which stable combustion can be achieved, or as a measure of the maximum air velocity the system can tolerate before flame extinction occurs (Lefebvre, 1999). For most combustors, it is desirable to have a flowfield that produces a particular type of flame, which resides at a certain position under prescribed operational conditions. In general, flame stability is composed of the following main categories:

- Flammability limits,

- Extinction,

- Static stability, and

- Dynamic stability.

Flammability limits refer to the range of fuel/air ratios over which stable combustion for the premixed flame can be achieved. By contrast, flame extinction can occur in nominally flammable mixtures depending on the flowfield properties. Extinction can occur via many different mechanisms controlled by thermal, chemical, or aerodynamic effects. Thermally induced extinction occurs when there is excessive heat loss from the flame. This can occur through the addition of diluents, or when a flame passes through a sufficiently narrow opening and loses enough heat and chain-carrying radicals to the walls of the opening so as to hinder flame propagation. This latter example is known as quenching (Strahman, 2007).

Chemically induced extinction occurs through the addition of chemicals that consume radicals in the combustion reactions. Aerodynamic effects, such as large velocity gradients that result in flame stretching; can also lead to extinction, as first studied by Karlovitz et al. (1953).

\subsubsection{Static Stability}

The research presented in this thesis is focused on the static stability limits of the LSB. The major static stability limits for the mixture flow are blowoff and flashback. Blowoff, also known as the "static stability point" (Lieuwen, 2006) often begins with liftoff where the flame detaches from the burner exit plane and stabilizes at some 
position downstream (Turns, 2000). Conceptually this means that the burning velocity of the mixture matches the local flow velocity at the stabilizing height. Any amount of change in the flow near a lifted flame can move the flame and cause blowoff. Blowoff happens when the flame is displaced far enough downstream that it extinguishes.

Development of physics-based correlations of blowoff behaviour is complicated by a lack of understanding of the detailed phenomenology of the blowoff process, such as the dynamics of near blowoff flames or the flame characteristics at the stabilization point (Lieuwen et al. 2008). Studies on developing blowoff correlations for premixed gases have been offered by numerous authors as presented in Glassman and Yetter (2008), where it is noted that they all lead to similar correlations that relate the blowoff limits to a Damköhler number. The Damköhler number is defined as the ratio of a characteristic flow timescale to a characteristic chemical kinetic timescale, $\tau_{\text {fow }} / \tau_{\text {chem }}$ :

$$
D a=\frac{\tau_{\text {flow }}}{\tau_{\text {chem }}}
$$

These characteristic timescales have been defined differently depending on the author or the experimental arrangement. Typically, $\tau_{\text {flow }}$ is calculated from bulk flow velocity and a characteristic length from the burner apparatus, or from turbulence statistics. The chemical timescale $\tau_{\text {chem }}$ is typically defined as $\tau_{\text {chem }}=\alpha / S_{L}{ }^{2}$, where $\alpha$ is the thermal diffusivity. Figure 1.5 (Zhang, 2008) shows the variation of $\tau_{\text {chem }}$ with the $\mathrm{H}_{2} / \mathrm{CO} / \mathrm{CH}_{4}$ ratio for matched adiabatic flame temperatures of $1500 \mathrm{~K}$ (i.e. equivalence ratios were adjusted to fix the temperature). The chemical timescale for $\mathrm{H}_{2}$ is an order of magnitude shorter than those of the slower $\mathrm{CO}$ or $\mathrm{CH}_{4}$ mixtures. This is consistent with experimental findings that show that percentage of hydrogen in the fuel mixture is a key parameter influencing blowoff characteristics of syngas flames (Schefer, 2003; Vagelopoulos and Egolfopoulos, 1994). Hydrogen tends to make fuel mixtures much more blowoff resistant.

Damköhler number scalings effectively describe blowoff trends for fuels with up to $50 \% \mathrm{H}_{2}$ (Zhang, 2008). However, as noted by Noble et al. (2006), the blowoff Damköhler number (in this case based upon a perfectly stirred reactor's simulated 
time scales), changes by four orders of magnitude with 50 to $100 \% \mathrm{H}_{2}$. Both Noble et al. (2006) and Zhang (2008) independently observed that there appears to be a fundamental difference in the stabilization mechanism for fuel mixtures with $>50 \% \mathrm{H}_{2}$ by volume.

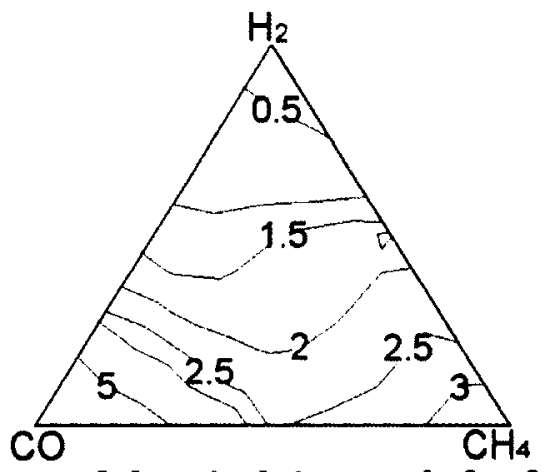

Figure 1.5: Dependence of chemical time scale [ms] upon fuel composition at fixed adiabatic flame temperature of $1500 \mathrm{~K}$ at $1.7 \mathrm{~atm}$ with $300 \mathrm{~K}$ reactant temperature. From Zhang (2008).

Flashback is essentially the opposite problem to blowoff, and occurs when the flame speed surpasses the flow speed causing the flame to propagate upstream into the burner tube. This can lead to ignition of fuel within the mixer, and can even produce an explosion. Often during burner shutdown, the reduction of the flow velocity allows flashback to occur (Strahman, 2007).

According to a recent review by Lieuwen et al. (2010), there are four distinct flashback mechanisms: turbulent flame propagation in the core flow, combustion pulsation-induced flashback, flashback in the boundary layer, and vortex breakdowndriven flame propagation in the core of swirling flows. The first three types can occur in swirling as well as non-swirling premixed burners, whereas the fourth mechanism requires a swirling flow in the mixing zone.

Turbulent flame propagation in the core flow occurs when the turbulent burning velocity exceeds the local flow velocity along some streamline allowing propagation to the mixing zone. Combustion pulsation-induced flashback occurs through velocity fluctuations in the burner associated with combustion instabilities. At high pulsation levels, the velocity field above the burner exit is quite modulated which can lead to a periodic drop of the flow velocity below the time average. This can 
give the flame the chance to flashback. This is not a concern for regular, stable combustor operation. Flashback in the boundary layer near the wall of the exit sleeve of the burner can occur since the low velocities and boundary layer turbulence promote flame propagation upstream. Finally, vortex breakdown-driven flame propagation in the core of swirling flows is, unsurprisingly, only a concern for swirling flows. When vortex breakdown occurs, a region of low or negative flow velocity is created ahead of the vortex. The flame can then advance forward. This causes the location of the vortex breakdown to advance farther upstream into the mixing zone. This situation allows for flashback to occur even if the burning velocity of the mixture is below the flow velocity everywhere.

Increased $\mathrm{H}_{2}$ fraction in the fuel tends to exacerbate flashback, related to an increase in laminar flame speed that strengthens each of the potential flashback mechanisms described above. By contrast, diluents in the fuel mixture would lower the laminar flame speed, making the mixture more resistant to flashback but more prone to blowoff. A more detailed review of static stability limits in swirling flows is presented in Chapter 2.

\subsubsection{Dynamic Stability}

The dynamic stability of a combustor is defined by the behaviour of large amplitude oscillations of pressure, heat release, and velocity inside the combustor chamber (Lieuwen, 2006). Most often, these oscillations occur at discrete frequencies associated with natural acoustic modes of the combustor. Their occurrence is usually problematic because they produce large amplitude pressure and velocity oscillations that result in enhanced heat transfer and thermal stresses to combustor walls, oscillatory mechanical loads that result in low or high cycle fatigue of system components, and can even lead to a statically unstable condition such as blowoff or flashback (Lieuwen, 2006). Though dynamic stability limits are not considered in the present work, they are very briefly introduced here for completeness.

A generic feedback loop is shown in Figure 1.6 showing the sequence of events leading to self-excited high amplitude oscillations in the combustion chamber (Lieuwen, 2006). First, fluctuations in the velocity, pressure, fuel/air ratio, etc. 
excite a fluctuation in the heat release rate. This fluctuation in the heat release rate can excite an acoustic oscillation due to the natural modes of the combustor. Finally, these acoustic oscillations lead to further flow and mixture perturbations which close the feedback loop. Depending upon the phase between the pressure and heat release, the flame may add or remove energy from the acoustic field during any single cycle, represented by one loop in this diagram. If the energy supplied to the acoustic field by the heat release process exceeds any energy losses of the mode, the amplitude of this instability will grow in time until it saturates at some limit cycle amplitude. When this occurs, it is known as a limit cycle.

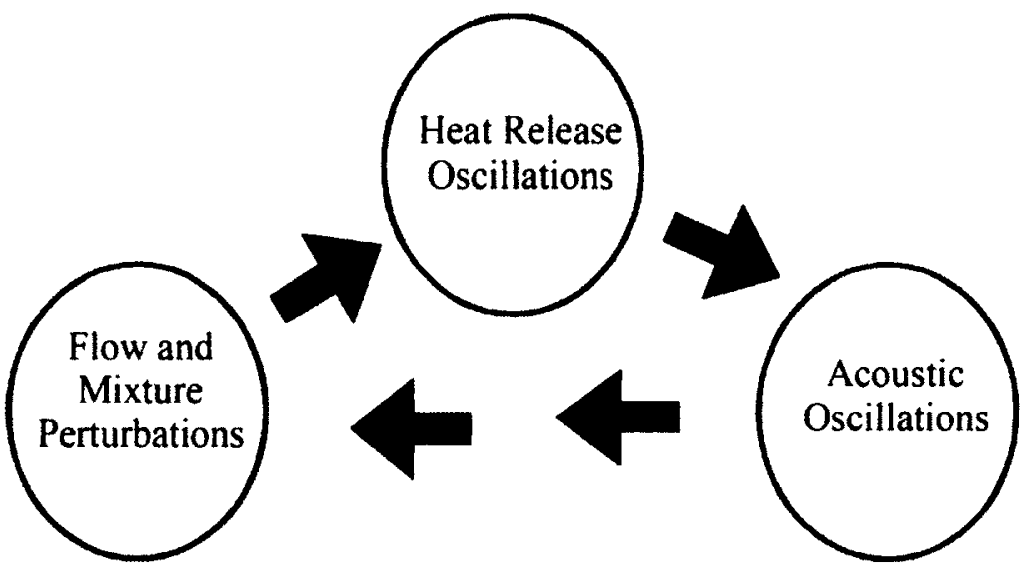

Figure 1.6: Illustration of a feedback loop resulting in a dynamic combustion instability (Lieuwen, 2006)

On occasion, the oscillations are not associated with a purely acoustic mode and are excited by a coupled "convective-acoustic mode", which occurs at frequencies lower than those of purely acoustic modes (Lieuwen, 2006). An example of this could be a hot gas packet or vortex convecting through a nozzle, where it excites an acoustic wave that propagates back to the flame, exciting another convected wave, and so forth repeating the process. This specific type of mode is often encountered in systems that are operating at conditions close to flame blowoff, showing how dynamic stability can affect static stability. Further information on dynamic stability can be found in Lieuwen (2006). 


\subsubsection{Methods of stabilizing turbulent premixed flames}

A stable flame is defined as a flame that is anchored at a desired location and is resistant to blowoff and flashback over the device's operating range (Turns, 2000). In most practical devices such as industrial gas burners and gas-turbine engines, the stabilization of premixed, turbulent flames is essential. Several methods are commonly employed to stabilize flames, including (Turns, 2000):

- Low-velocity bypass ports (North American Manufacturing Co., 1952);

- Refractory burner tiles (Presser et al., 1982);

- Bluff-body flameholders (Hermanson et al. 1997; Johnson et al, 1998; Chaudhuri et al. 2010);

- Swirl or jet-induced recirculating flows (Jeffs, 1962; Johnson et al. 2005); and

- Rapid increase in flow area creating recirculating separated flow (Ponizy and Leyer, 1999; Bicen et al., 1990).

Some applications use a combination of these methods simultaneously. In essence, the main principle involved is what has already been discussed above; the local turbulent flame speed must match the local mean flow velocity for the flame to be stable.

Low-velocity bypass ports are typically used to stabilize industrial burner flames. The bypass ports serve to relight the main flame in the event of blowoff. Refractory burner tiles (or just burner tiles) are also used in industrial burners. These tiles are placed just after the burner's nozzle exit, and represent a nearadiabatic boundary, reradiating back to the flame and thereby maintaining nearadiabatic flame temperatures (Turns, 2000). Since flame speeds (both laminar and turbulent) have such a strong dependency on temperature, this process keeps the turbulent flame speed high and allows for stabilization with the mean flow. Bluffbody flameholders, swirl or jet-induced recirculating flows, and rapid increase in flow area are all methods of producing recirculating flows as a means to stabilizing turbulent premixed flames. Recirculating flows are somewhat preferable with regards to turbulent-premixed flame stabilization since the hot products are 
recirculated back to re-ignite the fast moving turbulent mixture (Glassman and Yetter, 2008). Recirculation zones do increase the residence times of the products in the combustion zone, which increases the $\mathrm{NO}_{\mathrm{x}}$ production (See Section 1.1).

Unlike the typical cold-flow turbulent wake behind a cylinder or other object in crossflow, the recirculation zone downstream of a bluff-body flameholder generally contains a well-defined steady vortex (Glassman and Yetter, 2008). The difference is attributable to a decrease of the turbulent Reynolds number associated with the large increase in kinematic viscosity generated by the temperature rise. Moreover, it is well understood that the residence time of particles in the recirculation zone increases up to eight times due to combustion, and is independent of the mixture ratio (Beér and Chigier, 1972; Strahman, 2007). As per the above discussion on $\mathrm{NO}_{\mathrm{x}}$ formation, the potentially large residence times in bluff-body stabilized flames are undesirable for $\mathrm{NO}_{\mathrm{x}}$ reduction. Hermanson et al. (2010) present a study exploring the different bluff-body stabilized flame configurations and their effect on $\mathrm{NO}_{\mathrm{x}}$ production.

Research conducted by Johnson et al. (2005) has demonstrated through PIV that unlike flames stabilized with bluff bodies or large amounts of swirl, LSB flames do not rely on significant flow recirculation in the flowfield as a means for providing flame stabilization. This provides an explanation for the LSB as a low- $\mathrm{NO}_{\mathrm{x}}$ burner despite using a swirling flow for stabilization.

\subsection{Objectives}

Although the LSB has been successfully implemented in a variety of industrial applications, the design guidelines used for the adaptation to different roles remain largely empirical. It has also become apparent that the swirl number developed by Beér and Chigier (1972) does not alone define a range of flame stability for the LSB (Strahman, 2007). This problem is severely exacerbated by the array of possible fuel compositions resulting from the use of syngas and biogas.

The objectives of this study are to identify and understand the mechanisms involved in different types of LSB stabilization modes observed with methane/air mixtures and the above-mentioned syngas/biogas/air mixtures, and to attempt to 
develop models to predict blowoff limits of the LSB. Predictive models for the stability envelope of an LSB would aid significantly in the future design of LSBs in an assortment of applications.

Chapter 2 reviews previous studies relevant to the work presented in this thesis. Details of the apparatus, experimental methodology, and data processing are outlined in Chapter 3. Results from stability measurements are presented in Chapter 4, with results from measured flowfields presented in Chapter 5. Detailed discussion of blowoff stability results and attempts to predict observed behaviour are discussed in Chapter 6. Finally, Chapter 7 presents brief conclusions and recommendations for future work. 


\section{Literature Review}

\subsection{Swirling flows and the Swirl Number}

The addition of swirl to gaseous flows has been implemented successfully in many different applications such as industrial burners, furnaces, and gas turbine combustors in order to improve blowoff characteristics, ignition stability, mixing enhancement, flame stabilization, and pollutant reduction (Ji and Gore, 2002; Strahman, 2007). As shown in Figure 2.1, there are two main configurations for adding swirl to a flow. Tangential jets can be used (Figure 2.1a), where either fuel, air, or a mixture of the two are injected tangentially to the main axial flow to impart a tangential component to the velocity vector of the fluid leaving the burner. Alternatively, swirl-vanes can be used (Figure 2.1b) where some or all of the main flow is diverted through vanes that redirect the diverted flow tangentially. The two configurations produce very similar flow fields that create a low-pressure region in the core and adverse (increasing) pressure gradients in the radial and axial directions. If enough swirl is added to the fluid leaving the burner, part of the downstream flow can reverse direction, creating a recirculation zone. Some swirl configurations use a solid centerbody, and thus only have an annular swirling flow.

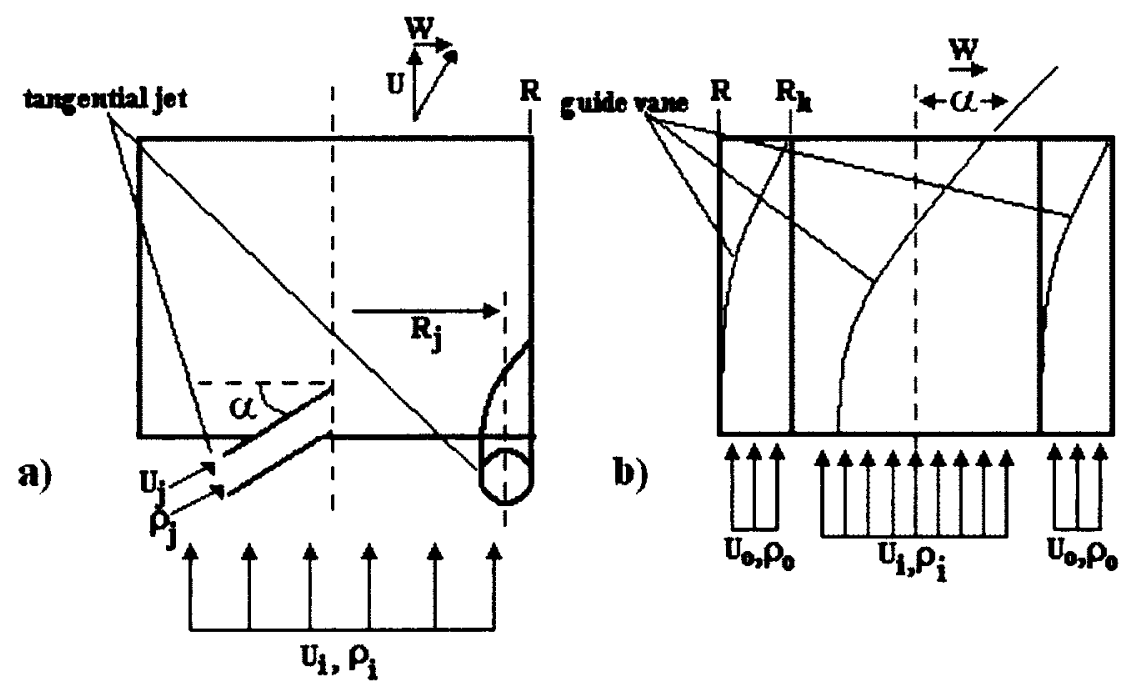

Figure 2.1: a) tangential jet-type LSB b) vane-type LSB. Similar configurations are present in non-LSB swirling flows. 
To characterize the degree of swirl in a flow, the most common parameter quoted is the non-dimensional swirl number $S$, as proposed by Beér and Chigier (1972):

$$
S=\frac{\text { axial flux of angular momentum }}{\text { axial thrust } \cdot R}=\frac{G_{\text {ang }}}{G_{x} \cdot R}
$$

where $G_{\text {ang }}$ is the axial flux of angular momentum about the centre axis of the burner, $R$ is the radius of the burner, and both $G_{\text {ang }}$ and $G_{x}$ are integrated radially over a plane perpendicular to the burner axis. For each of the terms in Eq.(2.1), the fluctuating components of the velocity are ignored. For the axial thrust, to avoid measuring the pressure field, the radial component of the momentum equation is used to express the pressure in terms of the angular velocity, $W$. In terms of the velocity field, the swirl number is calculated as:

$$
S=\frac{\int_{0}^{\infty} \rho U W r^{2} d r}{R \int_{0}^{\infty} \rho\left(U^{2}-\frac{1}{2} W^{2}\right) r d r}
$$

where $U$ and $W$ are the axial and tangential (angular) velocity components and $\rho$ is the density of the fluid mixture leaving the burner. A full derivation of Eq.(2.2) is in Appendix $\mathrm{H}$.

Given the challenges in measuring of the velocity field in a reacting flow, it is usually more practical to define a geometric swirl number, $S_{g}$, for a particular burner based on measured inlet conditions and taking into account the geometry of the burner (Strahman, 2007). For the jet-type type LSB, Johnson et al. (2005) proposed

$$
S_{g}=\frac{\pi r_{j} R \dot{m}_{j}^{2} \cos (\alpha)}{\left(\dot{m}_{i}+\dot{m}_{j}\right)\left(\dot{m}_{i} \frac{\rho_{j}}{\rho_{i}}+\dot{m}_{j}\right) A_{j}}
$$

where $\dot{m}_{i}$ and $\dot{m}_{j}$ are the mass flow rates for the inner axial flow and tangential jets respectively and $A_{j}$ is the total area of the tangential jets. For the vane-type LSB, Strahman (2007) found the geometric swirl number as proposed by Johnson et al. (2005) to be a useful surrogate for the actual swirl number. It is defined as follows:

$$
S_{g}=\frac{\frac{2}{3} \tan (\alpha)\left(1-\frac{R_{h}^{3}}{R^{3}}\right)}{\left(1-\frac{R_{h}^{2}}{R^{2}}+\frac{\rho_{i} U_{i}^{2}}{\rho_{o} U_{o}^{2}} \frac{R_{h}^{3}}{R^{2}}\right)}
$$


The swirl number can be used to classify swirling flows into groups. Classically, swirling flows have been separately labeled as either weak swirl, with a swirl number from 0 to 0.6 , and high swirl for swirl number higher than 0.6. This distinction, made by Beér and Chigier (1972), is based upon the onset of the recirculation zone mentioned above. Above $S=0.6$, the kinetic energy of the fluid can no longer overcome the strength of the adverse pressure gradient created from the swirling flow and recirculation occurs (Beér and Chigier, 1972). This recirculation zone can be used to advantage in high-swirl combusting flows as a means of convecting hot products upstream to ignite incoming fresh reactant mixture in a sustainable fashion.

\subsection{Selected Previous Studies on Blowoff and Flashback for Turbulent Flames}

Table 2.1 summarizes several previous studies on blowoff and flashback for turbulent premixed flames. Many of these studies use swirling flows for stabilization, while the three oldest studies (Edmonson and Heap, 1970; Kalghatgi, 1981; Broadwell et al. 1985) are included due to their relevance in directing future research in swirling flow blowoff studies (i.e. Feikema et al. 1990)

\subsubsection{Selected Previous Studies of Blowoff for Premixed Turbulent Flames as Relevant to Swirling Flows}

Edmonson and Heap (1970) performed early comprehensive experiments on standardized burning velocity and blowoff measurements for several different hydrocarbon/air flames stabilized on inverted flat flame and Bunsen type burners. They employed the Karlovitz number ( $K a$, nondimensional stretch factor) to interpret the data in terms of the flame stretch concept. In their experiments, blowoff occurred at an approximately constant value of $K a=0.95 \pm 0.15$, irrespective of mixture composition. The authors concluded that blowoff of their inverted flames occurred as a result of excessive flame stretch in the stabilization zone.

Kalghatgi (1981) formulated a simple yet widely used blowoff theory from his work on gaseous jet diffusion flames. Kalghatgi assumed that the base of the lifted 
diffusion flame was effectively premixed and modelled flame blowoff as occurring only when the local gas velocity of the reactants close to the centreline, $U_{C L}$, was higher than the local turbulent burning velocity, $S_{T}$, of the flame base. He postulated a dimensionless parameter for blowoff that is directly related to the heat release of the burner. Kalghatgi's non-dimensional relation for the blowoff velocity (rewritten as in Feikema et al., 1990), is as follows:

$$
\frac{U_{F} / d_{F}}{S_{L}^{2} / \alpha_{F}}=0.017\left(\frac{\propto_{F}}{v_{F}}\right)\left(\frac{\rho_{A}}{\rho_{F}}\right)\left[\frac{4}{\theta_{S}}\left(\frac{\rho_{F}}{\rho_{A}}\right)^{1 / 2}-5.8\right]
$$

where $U_{F}$ is the fuel velocity, $\theta_{S}$ is the mass fraction of the fuel for a stoichiometric mixture, $d_{F}$ is the fuel tube diameter, $\rho$ is the density, $\alpha$ is the thermal diffusivity, $v$ is the kinematic viscosity, and the subscripts $\mathrm{F}$ and $\mathrm{A}$ refer to the fuel and air, respectively.

Broadwell et al. (1985) proposed a blowoff model for vertical turbulent diffusion flames (known as BDM due to the other authors' names: Dahm, and Mungal) that leads to a single parameter for determines the blowoff velocity of pure fuels and of fuels diluted with air and with $\mathrm{CO}_{2}$. The parameter is the ratio of a characteristic chemical reaction time and a time associated with the mixing of reentrained hot products into fresh reactants. They show good agreement with a set of experimental observations for both pure and diluted gases. The parameter, as presented in Feikema et al. (1990) who considered it as an inverse Damköhler number, is as follows:

$$
D a_{B D M}^{-1}=\frac{(1+\Psi)^{2}}{4.8}\left(\frac{\rho_{F}}{\rho_{A}}\right)^{1 / 2} \frac{\alpha_{F}}{\alpha_{S}}
$$

where $\psi$ is the stoichiometric air-to-fuel mass ratio, $\alpha_{S}$ is the thermal diffusivity of the stoichiometric fuel-air mixture at the adiabatic flame temperature, and $\alpha_{F}$ is the thermal diffusivity of the fuel at the inlet temperature.

Building on the work on Kalghatgi and BDM, Feikema et al. (1990) investigated blowoff limits of non-premixed (diffusion) flames stabilized by swirl. They extended the theoretical concepts used to predict blowoff in vertical non-premixed flames to non-premixed swirling flows. Feikema et al. considered the parameters derived by both Kalghatgi and BDM to be inverse Damköhler numbers. They 
developed another inverse Damköhler number $\left(\mathrm{Da}_{F E I K}^{-1}\right)$ based on a characteristic angular velocity that characterizes swirling flow, which is defined as follows:

$$
D a_{F E I K}^{-1}=f\left\{\frac{\left(U_{A} S-U_{\theta, C}\right) / d_{A}}{S_{L}^{2} / \alpha_{F}}\right\}
$$

where $U_{A}$ is the axial air velocity, $S$ is the swirl number, $U_{\theta, c}$ is the critical value of angular velocity to create a recirculation zone, and $d_{A}$ is the diameter of the air inlet.

This inverse Damköhler number is used to correlate blowoff data for two burner sizes, two fuel types, and several swirl numbers. They observed that with the addition of swirl, the flame became five times more stable based on maximum fuel velocity before blowoff. They suggested that swirl caused a jet-vortex interaction and that the recirculation vortex reduces the fuel jet velocity on the centerline, which strongly stabilizes the lifted flame. As they increased the fuel tube diameter or the reaction rate (through hydrogen addition), the swirl flame became more stable. Feikema et al. also showed that fuel-lean operation is possible with swirl, and that their flame was unstable without swirl for fuel-lean conditions.

Zhang (2008) performed lean-blowoff experiments using $\mathrm{CH}_{4} / \mathrm{H}_{2} / \mathrm{CO}$ blends on a high-pressure high-swirl combustor designed to simulate gas turbine conditions. His results show that hydrogen controls the lean blowoff limits, and many other physically meaningful variables (laminar flame speed, turbulent flame speed, thermal diffusivity) are simply functions of percentage of hydrogen. A Damköhler number based on the well-stirred reactor residence time was found to correlate the lean blowoff limit data for mixtures with up to $50 \% \mathrm{H}_{2}$. The unique thermodiffusive properties of hydrogen were found to be responsible for the correlation failing above $50 \% \mathrm{H}_{2}$. The Damköhler number was modified with a diffusion correction and was found to correlate lean blowoff limits over all mixture ranges of $\mathrm{CH}_{4} / \mathrm{H}_{2} / \mathrm{CO}$ blends. 
Table 2.1: Summary of blowoff and flashback studies for turbulent flames with a focus on swirling flow

\begin{tabular}{|c|c|c|c|c|c|c|c|c|}
\hline Authors & Burner & $\begin{array}{c}d \\
{[\mathrm{~mm}]}\end{array}$ & Fuel & $\begin{array}{l}\text { HRR } \\
{[\mathrm{kW}]}\end{array}$ & $\begin{array}{c}P \\
{[\text { atm] }}\end{array}$ & $T[K]$ & Experiment & $\begin{array}{l}\text { Main Conclusions / } \\
\text { Observations }\end{array}$ \\
\hline $\begin{array}{l}\text { Edmonson } \\
\text { and Heap } \\
(1970)\end{array}$ & $\begin{array}{l}\text { Premixed } \\
\text { inverted } \\
\text { flat-flame } \\
\text { burner \& } \\
\text { bunsen } \\
\text { burner }\end{array}$ & 25.4 & $\begin{array}{c}\mathrm{CH}_{4}, \mathrm{C}_{2} \mathrm{H}_{6} \\
\mathrm{C}_{3} \mathrm{H}_{8} \\
\mathrm{C}_{4} \mathrm{H}_{10} \\
\mathrm{C}_{2} \mathrm{H}_{4}\end{array}$ & - & 1 & 295 & $\begin{array}{c}\text { Burning } \\
\text { velocity meas. } \\
\text { (flat-flames) \& } \\
\text { blowoff meas. } \\
\text { (flat-flames \& } \\
\text { bunsen burner) }\end{array}$ & $\begin{array}{l}\text { Inverted flame blowoff } \\
\text { occurs at } K a=0.95 \pm \\
0.15 . \text { Blowoff occurs due } \\
\text { to excessive flame } \\
\text { stretch. Bunsen burner } \\
\text { results inconclusive. }\end{array}$ \\
\hline $\begin{array}{c}\text { Kalghatgi } \\
\text { (1981) }\end{array}$ & $\begin{array}{l}\text { Turbulent } \\
\text { diffusion } \\
\text { burner }\end{array}$ & 152 & $\begin{array}{c}\mathrm{CH}_{4}, \mathrm{C}_{3} \mathrm{H}_{8} \\
\mathrm{C}_{4} \mathrm{H}_{10} \\
\mathrm{C}_{2} \mathrm{H}_{4}, \mathrm{C}_{2} \mathrm{H}_{2} \\
\mathrm{H}_{2} \\
\end{array}$ & - & 1 & 290 & $\begin{array}{c}\text { Blowoff } \\
\text { measurements }\end{array}$ & $\begin{array}{l}\text { Non-dimensional } \\
\text { relation for blowoff } \\
\text { found. See Eq.(2.5) }\end{array}$ \\
\hline $\begin{array}{c}\text { Broadwell } \\
\text { et al. (1985) }\end{array}$ & $\begin{array}{l}\text { Turbulent } \\
\text { diffusion } \\
\text { burner }\end{array}$ & 1.8 & $\begin{array}{c}\mathrm{CH}_{4}, \mathrm{C}_{3} \mathrm{H}_{8} \\
\mathrm{C}_{4} \mathrm{H}_{10} \\
\mathrm{C}_{2} \mathrm{H}_{4}, \mathrm{C}_{2} \mathrm{H}_{2} \\
\mathrm{H}_{2}\end{array}$ & - & 1 & - & $\begin{array}{c}\text { Blowoff } \\
\text { measurements }\end{array}$ & $\begin{array}{l}\text { Non-dimensional } \\
\text { relation for blowoff } \\
\text { found. See Eq.(2.6) }\end{array}$ \\
\hline $\begin{array}{l}\text { Feikema et } \\
\text { al. }(1990)\end{array}$ & $\begin{array}{c}\text { Swirling } \\
\text { turbulent } \\
\text { diffusion } \\
\text { burner, } \mathrm{S}= \\
0-1.56 \\
\end{array}$ & $\begin{array}{l}14.4 \\
22.2 \\
31.4\end{array}$ & $\begin{array}{l}\mathrm{CH}_{4}, \mathrm{CH}_{4} \\
/ \mathrm{H}_{2} \mathrm{mix}\end{array}$ & $\begin{array}{l}15.5 \\
33.4 \\
62.0 \\
70.0 \\
75.5 \\
\end{array}$ & 1 & - & $\begin{array}{c}\text { Blowoff } \\
\text { measurements }\end{array}$ & $\begin{array}{l}\text { Non-dimensional } \\
\text { relation for swirling } \\
\text { blowoff found. See } \\
\text { Eq. (2.7) }\end{array}$ \\
\hline $\begin{array}{l}\text { Zhang } \\
(2008)\end{array}$ & $\begin{array}{c}\text { Premixed } \\
\text { high-swirl } \\
\text { buter. S = } \\
0.85\end{array}$ & 190 & $\begin{array}{c}\mathrm{H}_{2}, \mathrm{CO} \\
\mathrm{CH}_{4}\end{array}$ & & $1-4.4$ & 300 & $\begin{array}{l}\text { Lean blowoff } \\
\text { meas. PIV. }\end{array}$ & $\begin{array}{l}\text { Modified Damköhler } \\
\text { number at lean blowoff } \\
\text { constant for all fuel } \\
\text { mixtures. Hydrogen } \\
\text { lowers lean blowoff } \\
\text { limit. }\end{array}$ \\
\hline $\begin{array}{l}\text { Nauert et al. } \\
(2007)\end{array}$ & $\begin{array}{c}\text { Premixed, } \\
\text { high-swirl } \\
\text { burner, } S=0 \\
-1.98 \\
\end{array}$ & 60 & $\mathrm{CH}_{4}$ & $\begin{array}{l}\text { Up to } \\
35\end{array}$ & 1 & - & $\begin{array}{c}\text { Flashback } \\
\text { measurements }\end{array}$ & $\begin{array}{c}\text { Scrit }_{\text {for flashback }} \\
\text { decreases from } \Phi=0.7- \\
0.9 . \text { Above } \Phi=0.9 . \\
\text { begins to increase again. }\end{array}$ \\
\hline $\begin{array}{l}\text { Konle and } \\
\text { Sattel- } \\
\text { mayer } \\
(2009 a)\end{array}$ & $\begin{array}{c}\text { Premixed, } \\
\text { high-swirl } \\
\text { burner, } S \sim \\
0.55\end{array}$ & 40 & - & $30-90$ & 1 & - & $\begin{array}{l}\text { High-speed } \\
\text { PIV/OH-PLIF, } \\
\text { Comparison of } \\
\text { isothermal \& } \\
\text { reacting flows, } \\
\text { study CIVB }\end{array}$ & $\begin{array}{l}\text { At CIVB, azimuthal vort- } \\
\text { icity creates a closed re- } \\
\text { circulation bubble at tip } \\
\text { of the internal recircula- } \\
\text { tion zone. Bubble prop- } \\
\text { agates upstream, flame } \\
\text { follows, and propagates } \\
\text { relative to the bulk flow } \\
\text { velocity at a velocity }>S r \text {. }\end{array}$ \\
\hline $\begin{array}{l}\text { Konle and } \\
\text { Sattel- } \\
\text { mayer } \\
(2009 \mathrm{~b})\end{array}$ & $\begin{array}{c}\text { Premixed, } \\
\text { high-swirl } \\
\text { burner, } S \sim \\
0.55\end{array}$ & 40 & - & $\begin{array}{l}\text { up to } \\
100\end{array}$ & 1 & - & $\begin{array}{l}\text { High-speed } \\
\text { PIV/OH-PLIF, } \\
\text { Compare iso- } \\
\text { thermal \& } \\
\text { reacting flows, } \\
\text { study CIVB }\end{array}$ & $\begin{array}{l}\text { Chemical time scale } \\
\text { shown to be } \propto 1 / S_{L} \text {, and } \\
\text { the flow-based time scale } \\
\text { is simply the diameter of } \\
\text { the burner exit divided } \\
\text { by the bulk flow speed. }\end{array}$ \\
\hline
\end{tabular}

${ }^{\dagger} d \equiv$ diameter; $Q \equiv$ heat release rate; $P \equiv$ pressure; $T \equiv$ reactant temperature. 


\subsubsection{Selected Previous Studies of Flashback for Premixed Turbulent Flames as Relevant to Swirling Flows}

Nauert et al. (2007) used geometrical adaptations to their generic high-swirl centerbody-based burner to vary the swirl number in order to study flashback. They observed that the critical swirl number, $S_{c r i t}$, required for the occurrence of flashback depended on equivalence ratio, geometric features, and Reynolds number. Varying the equivalence ratio from 0.7 to 0.9 showed that $S_{c r i t}$ decreased monotonically. This effect was attributed to the influence of the density jump between unburned and burned gases across the flame front which increases with equivalence ratio. The authors cited a study by Hasegawa et al (2002) where a main conclusion was that flame propagation along a fine vortex was found to depend on this density jump. For equivalence ratios above $0.9, S_{\text {crit }}$ increased again and reached a value of $S_{c r i t}=1.0$ at an equivalence ratio of 1.0. This contradicted their previous explanation since the largest density jump is expected to occur closer to an equivalence ratio of 1.0. The authors were unable to derive any definitive explanation for the observed behaviour.

As mentioned in Section 1.5.1, there are four known flashback mechanisms. The one most relevant to swirling flows is vortex breakdown-driven flame propagation in the core of swirling flows. In other literature, this phenomenon is also known as combustion induced vortex breakdown (CIVB). In their work, Konle and Sattelmayer (2009a) studied the contribution of combustion to vortex breakdown by comparing isothermal and reacting flows on their premixed high-swirl burner. Their data revealed that at the onset of CIVB, the azimuthal vorticity leads to the formation of a closed recirculation bubble at the tip of the internal recirculation zone. This bubble then propagates upstream, and the flame is able to follow and thus propagate relative to the bulk flow velocity at a velocity much greater than the normal turbulent flame speed. In a separate study, the same authors Konle and Sattelmayer (2009b) presented a model for the prediction of CIVB occurrence based on the comparison of a chemical time scale to that of a flow-based time scale. The chemical time scale is shown to be proportional to $1 / S_{L}$, and the flow-based time scale is simply the diameter of the burner exit divided by the bulk flow speed. They 
supported this idea with both numerical and experimental data. The authors extended this model to a prediction tool that could be applied to the full mass flow range of swirl burners, but not necessarily low-swirl burners.

\subsection{Development of the Low-Swirl Burner}

Table 2.2 summarizes the low-swirl burner literature. Chan et al. (1992) introduced the use of weak swirl to stabilize freely propagating open premixed turbulent flames (swirl numbers between 0.05 and 0.3 in this case). A jet type burner, as in Figure 2.1a was used in their experiments. A definite lack of recirculation zone was observed for these weak-swirl stablized flames in accordance with the prediction of Beér and Chigier (1972) that swirl numbers less than 0.6 would not produce a recirculation zone. Chan et al. (1992) also noted that the measured tangential velocity within the flame zone (downstream of the nozzle exit) was close to zero for the entire radius of the burner from which they concluded that the flame itself was unaffected by the swirl. They hypothesized that the centrifugal forces induced by the weak swirl creates radial pressure gradients that generate flow divergence allowing the flame to settle where the local mass flux balances the burning rate as shown in Figure 2.2. This model proved useful for the determination of the burning velocity based on estimates of the centerline velocity at the flame front, as in the method described in Cheng (2010). This is a measure of the local displacement speed, since the velocity vector at that point is locally normal to the turbulent flame brush. Chan et al. also noted that the weak swirl-stabilized flames have the properties of wrinkled laminar flames, typical of the wrinkled and corrugated flamelet regimes of Figure 1.4. Weak swirl stabilized flames are considered freely propagating, but stationary (Strahman, 2007). 
Table 2.2: Summary of low-swirl burner studies

\begin{tabular}{|c|c|c|c|c|c|c|c|c|c|}
\hline Study & Burner & $\mathrm{d}[\mathrm{mm}]$ & Fuel & $\Phi$ & $\begin{array}{l}\text { HRR } \\
{[\mathrm{kW}]}\end{array}$ & $\begin{array}{c}\mathbf{P} \\
{[\mathrm{atm}]}\end{array}$ & $\begin{array}{c}\mathrm{T} \\
{[\mathrm{K}]}\end{array}$ & Experiment & Conclusions \\
\hline $\begin{array}{c}\text { Chan et al. } \\
\text { (1992) }\end{array}$ & $\begin{array}{l}\text { Premixed, jet-type, } \\
\text { low-swirl burner, } \\
S=0.05-0.3\end{array}$ & 114 & $\begin{array}{l}\mathrm{CH}_{4} \\
\mathrm{C}_{2} \mathrm{H}_{4}\end{array}$ & $\begin{array}{l}0,0.65 \\
0.8,1.0\end{array}$ & - & 1 & - & $\begin{array}{c}\text { Laser Doppler } \\
\text { anemometry, laser mie } \\
\text { scattering measurements }\end{array}$ & $\begin{array}{l}\text { Flame stabilization does not rely on flow } \\
\text { recirculation. Radial divergence drives } \\
\text { stability. }\end{array}$ \\
\hline $\begin{array}{l}\text { Cheng } \\
(1995)\end{array}$ & $\begin{array}{l}\text { Premixed, jet-type, } \\
\text { low-swirl burner, } \\
\quad S=0.05-0.3\end{array}$ & 114 & $\begin{array}{l}\mathrm{CH}_{4} \\
\mathrm{C}_{2} \mathrm{H}_{4}\end{array}$ & $0.6-1.0$ & $\sim 30$ & 1 & - & $\begin{array}{c}\text { Laser Doppler } \\
\text { anemometry, laser mie } \\
\text { scattering measurements }\end{array}$ & $\begin{array}{l}\text { Flame speeds show linear dependence } \\
\text { on averaged rms velocity. } \Phi=0.6 \text { more } \\
\text { similar to non-reacting than higher } \Phi \text {. }\end{array}$ \\
\hline $\begin{array}{l}\text { Bedat and } \\
\text { Cheng } \\
(1995)\end{array}$ & $\begin{array}{l}\text { Premixed, jet-type, } \\
\text { low-swirl burner, } \\
\quad S=0-0.09\end{array}$ & 50.8 & $\mathrm{CH}_{4}$ & $\begin{array}{c}0.6 \\
0.65 \\
0.8\end{array}$ & $15-35$ & 1 & - & $\begin{array}{c}\text { Laser Doppler } \\
\text { anemometry, hot-wire } \\
\text { anemometry, Rayleigh } \\
\text { scattering }\end{array}$ & $\begin{array}{l}\text { Linear decay in axial velocity along the } \\
\text { centerline. Scale invariance } \\
\text { unnapplicable for } S_{T} \text {. Swirling motion } \\
\text { has no effect on small-scale interaction. }\end{array}$ \\
\hline $\begin{array}{l}\text { Yegian and } \\
\text { Cheng } \\
(1998)\end{array}$ & $\begin{array}{l}\text { Premixed, jet-type, } \\
\text { low-swirl burner, } \\
\mathrm{S}=0.02-0.35\end{array}$ & 26.4 & NG & $0.7-0.9$ & $10-22.5$ & 1 & - & $\begin{array}{c}\text { Stability mapping, 2D } \\
\text { laser Doppler velocimetry, } \\
\text { Mie-scattering, Emissions } \\
\text { testing }\end{array}$ & $\begin{array}{l}\text { Extending tube length increases swirl } \\
\text { requirement. Enclosure does not affect } \\
\text { flashback or blowoff. NO } \mathrm{x}_{\mathrm{x}} \text { levels } \\
\text { independent of thermal input. CO } \\
\text { decreases with } \Phi \text {. }\end{array}$ \\
\hline $\begin{array}{l}\text { Cheng et } \\
\text { al. }(2000)\end{array}$ & $\begin{array}{l}\text { Premixed, jet-type } \\
\text { and vane-type, } \\
\text { low-swirl burner, } \\
S=0.02-0.12\end{array}$ & $\begin{array}{l}\text { Jet: } \\
102.6 \\
\text { Vane: } \\
52.8 \\
\& 76.8\end{array}$ & $\mathrm{NG}$ & $\begin{array}{l}0.58- \\
0.95\end{array}$ & $\begin{array}{l}\text { Jet: } 528 \\
\text { Vane: } \\
73 \& \\
280\end{array}$ & 1 & $\overline{-}$ & Scaling study for the LSB & $\begin{array}{l}\text { Constant velocity criterion is valid for } \\
\text { scaling the burner diameter to accept a } \\
\text { higher thermal input. NO } O_{x} \text { emissions are } \\
\text { independent of thermal input and are } \\
\text { only a function of } \Phi \text {. }\end{array}$ \\
\hline $\begin{array}{l}\text { Plessing et } \\
\text { al. }(2000)\end{array}$ & $\begin{array}{l}\text { Premixed, jet-type, } \\
\text { low-swirl burner, } \\
S=0-0.09\end{array}$ & 50.8 & $\mathrm{CH}_{4}$ & 0.7 & - & 1 & - & $\begin{array}{c}S_{T} \text { measurements. } \\
\text { Simultaneous OH-PLIF } \\
\text { with Rayleigh } \\
\text { thermometry or PIV }\end{array}$ & $\begin{array}{c}S_{T} \text { agrees with predictions from a model } \\
\text { equation from Peters (1999). }\end{array}$ \\
\hline $\begin{array}{l}\text { Shepherd } \\
\text { et al. } \\
(2002)\end{array}$ & $\begin{array}{l}\text { Premixed low- } \\
\text { swirl burner }\end{array}$ & - & $\overline{\mathrm{CH}_{4}}$ & 0.7 & $12 \cdot 70$ & 1 & - & $\begin{array}{l}\text { Rayleigh laser sheet } \\
\text { measurements of gas } \\
\text { density }\end{array}$ & $\begin{array}{l}\text { The main effects from increasing } \\
\text { turbulence are an increase in flame } \\
\text { surface density and burning rate }\end{array}$ \\
\hline $\begin{array}{l}\text { Littlejohn } \\
\text { et al. } \\
(2002)\end{array}$ & $\begin{array}{l}\text { Premixed, vane- } \\
\text { type, low-swirl } \\
\text { burner, } S=0.4\end{array}$ & $\begin{array}{c}128 \& \\
184\end{array}$ & $\begin{array}{l}\text { NG, } \\
\text { FGR, } \\
\text { PRNG }\end{array}$ & $\begin{array}{c}0.7,0.8 \\
0.9\end{array}$ & 18 & 1 & - & $\begin{array}{l}\text { Stability and emissions } \\
\text { testing. }\end{array}$ & $\begin{array}{l}\text { Suggested that the emissions and system } \\
\text { efficiency of an LSB boiler with PRNG } \\
\text { can be optimized by operating at a high } \\
\text { FGR ratio and } \Phi \text { closer to stoichiometry. }\end{array}$ \\
\hline $\begin{array}{l}\text { Johnson et } \\
\text { al. (2005) }\end{array}$ & $\begin{array}{l}\text { Premixed, vane- } \\
\text { type, high-swirl } \\
\text { burner }(S=0.73) \\
\text { and low-swirl } \\
\text { burner }(S=0.5)\end{array}$ & 34.7 & $\mathrm{CH}_{4}$ & $\begin{array}{c}0.48- \\
0.8\end{array}$ & $\begin{array}{c}9-87, \& \\
80- \\
2200\end{array}$ & $\begin{array}{l}1, \text { and } \\
6-15\end{array}$ & $\begin{array}{c}293 \\
\& \\
500- \\
700\end{array}$ & PIV & $\begin{array}{l}\text { LSB devoid of large recirculation zone as } \\
\text { compared to high-swirl. LSB } \mathrm{NO}_{\mathrm{x}} \\
\text { emissions } 60 \% \text { lower than that of high } \\
\text { swirl over same operating range. }\end{array}$ \\
\hline
\end{tabular}




\begin{tabular}{|c|c|c|c|c|c|c|c|c|c|}
\hline $\begin{array}{l}\text { Littlejohn } \\
\text { and Cheng } \\
(2007)\end{array}$ & $\begin{array}{l}\text { Premixed, vane- } \\
\text { type, low-swirl } \\
\text { burner, } S=0.57\end{array}$ & 63.4 & $\begin{array}{c}\mathrm{CH}_{4} \\
\mathrm{C}_{2} \mathrm{H}_{4} \\
\mathrm{C}_{3} \mathrm{H}_{8} \\
\mathrm{H}_{2}\end{array}$ & $0-0.83$ & - & $1-14$ & $\begin{array}{l}620- \\
770\end{array}$ & $\begin{array}{l}\text { Blowoff measurements, } \\
\text { PIV at } 1-14 \text { atm and } 620- \\
770 \mathrm{~K} \text { preheat } \\
\text { temperature. }\end{array}$ & $\begin{array}{l}\text { Velocity statistics show that the coldflow } \\
\text { and reacting flowfields of the LSB exhibit } \\
\text { similarity features. Overall effect of the } \\
\text { flame is equivalent to an aerodynamic } \\
\text { blockage to the flow supplied by the LSB. }\end{array}$ \\
\hline $\begin{array}{l}\text { Kang et al. } \\
(2007)\end{array}$ & $\begin{array}{l}\text { Premixed, vane- } \\
\text { type, low-swirl } \\
\text { burner }\end{array}$ & 25.4 & $\mathrm{CH}_{4}$ & $\begin{array}{l}0.5,0.6 \\
0.75\end{array}$ & $3-5$ & 1 & - & $\begin{array}{l}\text { Acoustic forcing from } 22- \\
400 \mathrm{~Hz} \text {. OH-PLIF }\end{array}$ & $\begin{array}{l}\text { Thermoacoustic coupling is significant in } \\
\text { the shear-layer mixing zone near the } \\
\text { flame boundary. The driving force for } \\
\text { the formation of toroidal structures is } \\
\text { the axial component of the flow field } \\
\text { exerting shear stress on the outer } \\
\text { airflow. }\end{array}$ \\
\hline $\begin{array}{l}\text { Strahman } \\
(2007)\end{array}$ & $\begin{array}{l}\text { Premixed, vane- } \\
\text { type, low-swirl } \\
\text { burner }\end{array}$ & 50.8 & $\mathrm{CH}_{4}$ & $\begin{array}{c}0.57- \\
1.2\end{array}$ & $14-107$ & 1 & - & $\begin{array}{l}\text { Stability mapping and PIV } \\
\text { measurements }\end{array}$ & $\begin{array}{l}\text { The main effect of swirl is not on the } \\
\text { creation or modification of flow } \\
\text { divergence, but on the flowfield velocity } \\
\text { and turbulence intensity, which } \\
\text { determines stability limits. }\end{array}$ \\
\hline $\begin{array}{l}\text { Cheng and } \\
\text { Littlejohn } \\
(2008)\end{array}$ & $\begin{array}{l}\text { Premixed, low- } \\
\text { swirl burner, } \mathrm{S}= \\
0.51\end{array}$ & 63.5 & $\begin{array}{l}\mathrm{CH}_{4} \\
\mathrm{H}_{2}\end{array}$ & $\begin{array}{l}0.35- \\
0.7\end{array}$ & - & 1 & - & Enclosure study, PIV & $\begin{array}{l}\text { Enclosures have no significant effect on } \\
\text { LSB flowfield }\end{array}$ \\
\hline $\begin{array}{l}\text { Mansour } \\
\text { and Chen } \\
(2008)\end{array}$ & $\begin{array}{l}\text { Jet-type, low-swirl } \\
\text { burner }\end{array}$ & $\begin{array}{l}40 \& \\
53.5\end{array}$ & $\mathrm{CH}_{4}$ & $0.6-1.0$ & - & 1 & - & $\begin{array}{l}\text { Blowoff measurements, } \\
\text { Rayleigh thermometry, } \\
\text { OH-PLIF }\end{array}$ & $\begin{array}{l}\text { Blowoff shows an almost constant ratio } \\
\qquad \text { of } U D / u=5.08 \mathrm{~mm}\end{array}$ \\
\hline $\begin{array}{l}\text { Cheng et } \\
\text { al. (2009) }\end{array}$ & $\begin{array}{l}\text { Premixed, vane- } \\
\text { type, low-swirl } \\
\text { burner, } S=0,5\end{array}$ & 57.2 & $\begin{array}{l}\mathrm{CH}_{4} \\
\mathrm{H}_{2}\end{array}$ & $0.4-0.7$ & - & $1-8$ & $\begin{array}{l}298- \\
580\end{array}$ & $\begin{array}{c}\text { Video, } \mathrm{OH} \\
\text { chemiluminescence }\end{array}$ & $\begin{array}{l}\mathrm{H}_{2} \text { causes upstream propagation and } \\
\text { burner rim attachment. Flame remains } \\
\text { similar until } 60 \% \mathrm{H}_{2} \text {. }\end{array}$ \\
\hline $\begin{array}{l}\text { Yilmaz et } \\
\text { al. }(2010)\end{array}$ & $\begin{array}{l}\text { Premixed, vane- } \\
\text { type, low-swirl } \\
\text { burner, } S=0.5\end{array}$ & $\sim 100$ & $\begin{array}{c}\mathrm{CH}_{4} / \\
\mathrm{H}_{2} \\
\operatorname{mix}\end{array}$ & 0.5 & $\overline{-}$ & 1 & - & $\begin{array}{l}\text { Acoustic forcing from } 85- \\
400 \mathrm{~Hz} \text { with varying } \\
\text { amounts of } \mathrm{H}_{2} \text {. }\end{array}$ & $\begin{array}{l}\text { Combustion characteristics are very } \\
\text { sensitive to the fraction of } \mathrm{H}_{2} \text { in the fuel } \\
\text { mixture. The flame exhibits significant } \\
\text { increases in flame base coupling and } \\
\text { flame compaction with increasing } \mathrm{H}_{2} \\
\text { concentration under all conditions }\end{array}$ \\
\hline $\begin{array}{l}\text { Nogenmyr } \\
\text { et al. } \\
(2010)\end{array}$ & $\begin{array}{l}\text { Premixed, vane- } \\
\text { type, low-swirl } \\
\text { burner, } S=0.55\end{array}$ & 50 & $\mathrm{CH}_{4}$ & 0.62 & - & 1 & - & Rayleigh scattering, PIV & $\begin{array}{l}\text { Flame stabilization for a low-swirl flame } \\
\text { is dictated by the large-scale vortex rings } \\
\text { created in the shear layer. }\end{array}$ \\
\hline
\end{tabular}




\begin{tabular}{|c|c|c|c|c|c|c|c|c|c|}
\hline $\begin{array}{l}\text { Legrand et } \\
\text { al. }(2010)\end{array}$ & $\begin{array}{l}\text { Premixed, jet-type, } \\
\text { low-swirl burner, } \\
S \sim 0.45-0.7\end{array}$ & 26 & $\mathrm{C}_{3} \mathrm{H}_{8}$ & $1.5,2.0$ & $\sim 50$ & 1 & - & $\begin{array}{c}\text { Non-reacting and reacting } \\
\text { PIV, stability mapping, } \\
\text { POD }\end{array}$ & $\begin{array}{l}\text { Asymmetries are present in the mean } \\
\text { flowfields of low-swirl flames due to the } \\
\text { rotation of low-velocity structures about } \\
\text { the inner core axial flow since a low } \\
\text { velocity zone appears to produce a lower } \\
\text { flame front. Domain between high and } \\
\text { low-swirl defined with Reynold's } \\
\text { number and } S \text {. }\end{array}$ \\
\hline $\begin{array}{l}\text { Littlejohn } \\
\text { et al. } \\
(2010)\end{array}$ & $\begin{array}{l}\text { Premixed, vane- } \\
\text { type, low-swirl } \\
\text { burner, } S=0.51 \\
\text { and } 0.425\end{array}$ & $\begin{array}{c}63.5 \& \\
25.4\end{array}$ & $\begin{array}{l}\mathrm{CH}_{4} \\
\mathrm{CO}, \\
\mathrm{H}_{2}, \\
\mathrm{CO}_{2} \\
\text { mix }\end{array}$ & $\begin{array}{l}0.5 \\
0.64\end{array}$ & - & $\begin{array}{c}1, \& \\
1.5-14\end{array}$ & $\begin{array}{c}293 \\
\& \\
450- \\
505\end{array}$ & $\begin{array}{c}\text { PIV, emission } \\
\text { measurements, video, }\end{array}$ & $\begin{array}{l}\text { Flowfields from syngas-fueled LSB } \\
\text { flames are essentially the same as those } \\
\text { observed in hydrocarbon and pure or } \\
\text { diluted hydrogen flames. LSB } \\
\text { successfully fired with syngas mixtures } \\
\text { at GT conditions. }\end{array}$ \\
\hline
\end{tabular}




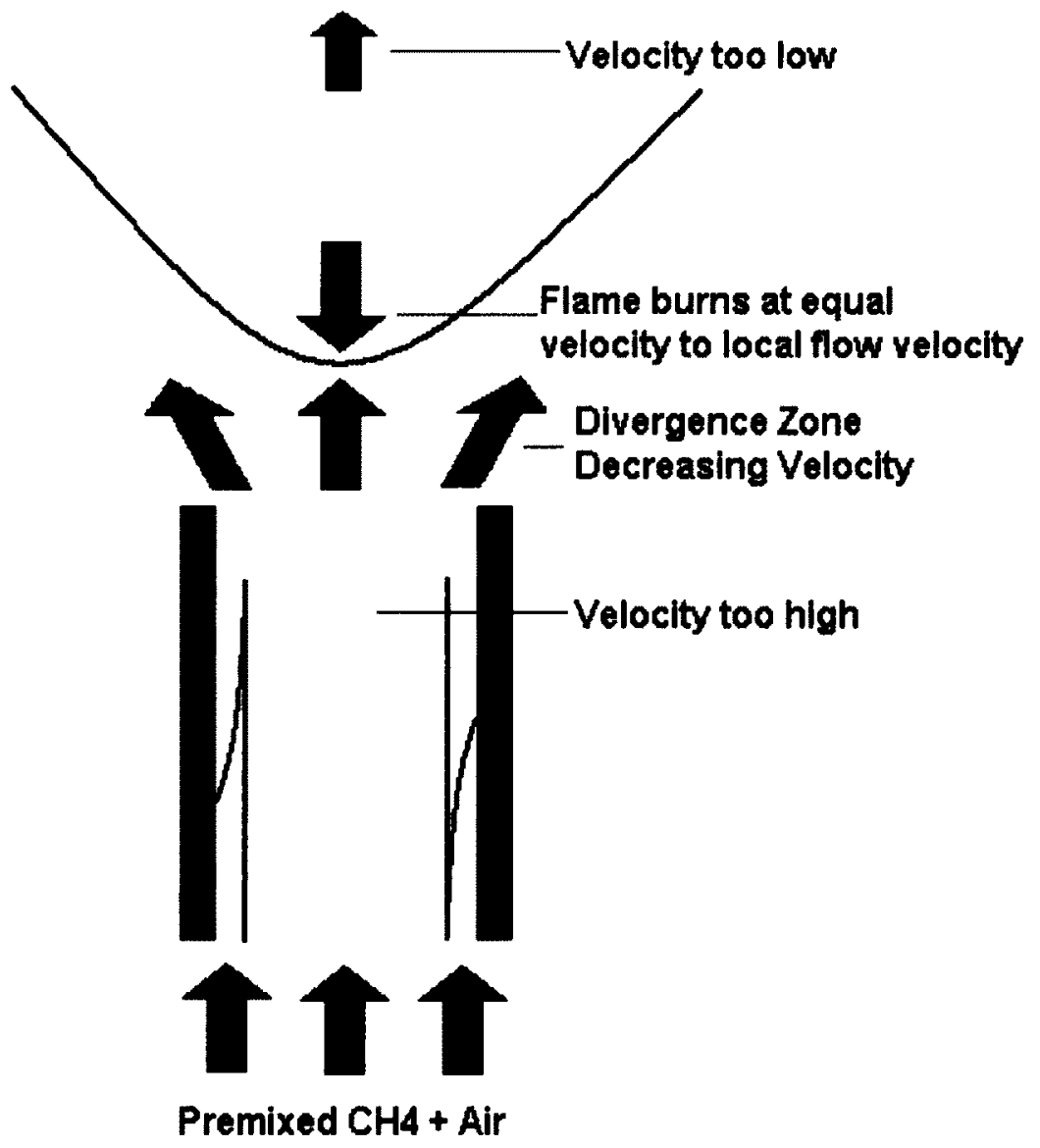

Figure 2.2: Original hypothesis for the LSB stability mechanism based on flow divergence

Cheng (1995) and Bedat and Cheng (1995) used a jet-type low-swirl burner in research on premixed turbulent flame propagation. Although the focus of these works was not on the development of the LSB itself, they are indirectly relevant to the present discussion. Cheng (1995) conducted experiments on the LSB with cold flow and reacting flows, and used results to propose a linear correlation between the turbulent flame speed, $S_{T}$, and the rms of the fluctuating velocity component $u^{\prime}$. He further identified the major influences of combustion on the flowfield statistics as combustion induced flow acceleration, flow divergence, and turbulence intensity and noted that depending on the relative significance of these effects, the flame could cause significant changes in the velocity statistics as compared to cold flow, or very little difference. Cheng (1995) then compared all of these effects using an 
indicator parameter, $K_{t}$, which included the stretch from flame turbulence and the pure aerodynamic stretch from the incoming flow field. He used this parameter to separate flows under the leanest condition $(\Phi=0.6)$ from higher equivalence ratios, based on the limited ability of the lean flames to generate significant flow acceleration or increase turbulence in the flowfield. Although he did not specifically consider how this affected the static stability of the flame at low equivalence ratios, his analysis supports the notion that the stretch produced by the turbulence in the flame and the mean aerodynamic stretch are additive.

Bedat and Cheng (1995) used LDA (laser doppler anemometry) and Rayleigh scattering to observe the changes in flame structure that occur when the KlimovWilliams criterion is crossed $(K a>1)$. For all of the flames studied, there was a linear decay in axial velocity along the centerline that was observed to plateau at a certain point downstream. A similar linear decay was observed for the isothermal (non-reacting) case but without a downstream axial velocity plateau. The turbulence characteristics (rms of the fluctuating components) showed no decay for either the isothermal or reacting cases. From this result, they argued that the scaling laws for isotropic turbulence apply to the LSB. Turbulent flame speed measurements were performed as in Chan et al. (1992). $S_{T}$ was found to scale linearly with the rms of the fluctuating component of axial velocity, $u^{\prime}$, as in Cheng (1995). This is typical for the turbulent burning velocity, but showed no sign of leveling to an asymptotic value as it would if scale invariance was applicable. It is also observed that the turbulence spectrums for the isothermal with swirl, isothermal without swirl, and reacting with swirl cases were all virtually identical above $50 \mathrm{~Hz}$. Below $50 \mathrm{~Hz}$, the non-swirling turbulence spectrum was different, but it was similar to that produced by grid-generated turbulence. Bedat and Cheng (1995) concluded that swirling motion has no significant effect on small-scale turbulence in the flowfield.

Yegian and Cheng (1998) performed tests on a jet-type LSB designed to investigate the potential for the LSB to be used for practical applications. The radius of the experimental burner was $26.4 \mathrm{~mm}$, and a perforated screen was included with 
holes of $3.2 \mathrm{~mm}$ in diameter for turbulence generation. The exit tube length was varied from 20 to $120 \mathrm{~mm}$ for additional experimentation. Their results indicated that the LSB permits a turn-down ratio higher than 10 to 1 , limited only by the experimental facility. Blowoff and flashback limits were recorded at different equivalence ratios at varying geometric swirl numbers (see Eq.(2.3)). Extending the tube length had the effect of increasing the swirl number range between blowoff and flashback while also increasing the swirl requirement (higher swirl number at blowoff as opposed to lower swirl number at blowoff implying more stability). This result was attributed to the longer residence time that the flows had for mixing in the longer tube lengths. They observed that the blowoff limits were insensitive to $\Phi$, while flashback limits occurred at lower swirl numbers with an increase in $\Phi$. Yegian and Cheng (1998) also showed that there was no significant alteration in the flashback or blowoff limits for a LSB due to flow enclosure. The absence of spectral peaks within the turbulence spectrum measured with laser Doppler velocimetry showed that the enclosed LSB had no discrete fluctuation frequencies, from which the authors suggested that the LSB may be less susceptible to instability, vibration and noise problems common to other enclosed premixed combustion systems. Tests performed in a water heater simulator show that the LSB has low $\mathrm{NO}_{x}$ emissions (5-40 ppm at $3 \% \mathrm{O}_{2}$ ) while maintaining comparable thermal efficiencies as current commercial units. At $15 \mathrm{~kW}$, the optimum operating conditions was found to be at $\Phi=0.85$ with $\mathrm{NO}_{\mathrm{x}}=25 \mathrm{ppm}, \mathrm{CO}=25 \mathrm{ppm}$ and an operating efficiency of $79 \%$. The authors concluded that the lean premixed LSB could be a simple, economical and versatile burner for low emission atmospheric boilers and furnaces (Yegian and Cheng, 1998).

Hsieh et al. (1998) described the difficulties in the scaling of low- $\mathrm{NO}_{x}$ burners. In their study, an analytical approach concerning $\mathrm{NO}_{\mathrm{x}}$ emissions and the results for a reduced model are discussed. The work of Cheng et al. (2000) presents results for a scaling study on the LSB specifically. Both jet- and vane-type LSBs were investigated (see Figure 2.1). The authors determined that a constant velocity criterion was valid for scaling the burner diameter to accept a higher thermal input, 
which means that increasing burner diameter increases the minimum flow velocity for stable operation. The swirl number needed for stable operation scaled separately using a constant residence time criterion. The $\mathrm{NO}_{\mathrm{x}}$ emissions were found to be independent of thermal input and were only a function of the equivalence ratio. Emission of $\mathrm{CO}$ and unburned hydrocarbons were strongly coupled to chamber size and were extremely high at low thermal input.

Plessing et al. (2000) measured the turbulent burning velocity for an LSB using the local displacement speed method (Cheng, 2010) and showed that there is good agreement with predictions from a model equation (Peters, 1999). Particle image velocimetry (PIV) measurements showed a recirculation zone downstream of the flame stabilization area. However, due to the flame stabilizing close to the exit, mean strain rates were much lower, and the recirculation zone did not affect the flame. Shepherd et al. (2002) proved that the main effects from increasing turbulence were an increase in flame surface density and burning rate (Strahman, 2007).

Littlejohn et al. (2002) conducted experiments on an $18 \mathrm{~kW}$ LSB for industrial boilers combined with flue gas recirculation (FGR) and partially reformed natural gas (PRNG) for ultra-low $\mathrm{NO}_{\mathrm{x}}$ emissions. Their results showed that PRNG improves flame stability at $\Phi=0.7$ and an FGR ratio $>0.2$ (defined as the fraction of flue gas that gets recirculated). PRNG is found to have no effect on $\mathrm{NO}_{\mathrm{x}}$, but $\mathrm{CO}$ was reduced significantly at $\Phi=0.8$. It was suggested that the emissions and system efficiency of an LSB boiler with PRNG could be optimized by operating at a high FGR ratio and $\Phi$ closer to stoichiometry.

Johnson et al. (2005) carried out a comprehensive comparison of the flowfields and emissions of a high-swirl burner (HSB, $S=0.73$ ) and the same burner modified for operation as a vane-type low-swirl burner(LSB with $S=0.5$ ). Measurements were performed at both atmospheric and gas turbine relevant conditions at elevated temperature and pressure. Using PIV, the authors demonstrated that the flowfields of the LSB were devoid of a large dominant recirculation zone, which was fundamentally different than the strong, and large recirculation zones characteristic 
of HSB flowfields. The LSB had the same operating range as the HSB, yet the $\mathrm{NO}_{\mathrm{x}}$ emissions from the LSB were about $60 \%$ lower than the HSB, and its CO emissions were comparable. The $\mathrm{NO}_{\mathrm{x}}$ reduction for the LSB was attributed to the lack of recirculating flow, which led to a shorter flame residence time. For the LSB, only the non-reacting flow showed a weak recirculation zone in the far field that disappeared in the presence of combustion.

Littlejohn and Cheng (2007) presented tests on an LSB for gas turbines. They proved its capability for supporting various hydrocarbons (and hydrogen, see Section 2.3.1) other than methane. They again verified a linear correlation between $S_{T}$ and turbulence intensity. Analysis of the velocity statistics showed that the nonreacting and reacting flowfields of the LSB exhibited similarity centerline axial velocity profiles when normalized by the bulk flow velocity. The authors presented two parameters to characterize the nearfield region of the LSB. The first was the virtual origin, $x_{0}$, of the flow, which was obtained by extrapolating the linear velocity decay region downstream of the exit to the point where it would match the bulk flow velocity. The second parameter was the slope of this linear velocity decay region, known as the normalized axial divergence rate. It is defined as follows:

$$
a_{x}=\frac{d U / d x}{U_{o}}
$$

The comparison between the reacting and non-reacting flow indicated that the overall effect of the flame is equivalent to an aerodynamic blockage to the flow supplied by the LSB. It is suggested that the similarity features and linear $S_{T}$ correlation provide an analytical model that explains why the LSB flame position does not change with flow velocity.

Kang et al. (2007) investigated dynamic instabilities of a premixed, methane/air-fueled, low-swirl burner. The combustion chamber was acoustically excited at frequencies of $22-400 \mathrm{~Hz}$ using two radially oriented loudspeakers controlled with a function generator. OH-PLIF imaging of the flame region was used to produce phase-resolved measurements of flame behaviour at each frequency. Results indicated that thermoacoustic coupling was significant in the shear-layer mixing zone near the flame boundary. Observed toroidal structures did not appear 
to be caused by the swirl manifested from the swirler in the burner, since they showed no asymmetries. Asymmetries would be expected if the toroidal structure were created by swirl, since they would be distorted by the spiraling flowfield. . Toroidal structures near the flame boundary were observed to be perfectly symmetric over all excitation frequencies and equivalence ratios. The authors concluded that the driving force for the formation of these toroidal structures was not the swirling tangential and radial flows, but was the axial component of the flow field exerting shear stress on the outer air flow.

Strahman (2007) showed that although the swirl number is a critical parameter in describing the flow, it alone cannot be used as a single scaling parameter. With stereoscopic PIV images, it was shown that the volume expansion through the flame, rather than swirling action of the flow, is responsible for creating the observed divergent flowfield. It was suggested that the major effect of swirl was a change of mean axial velocities and turbulence intensities, which directly influence the position of the flame and its stability limits. In the central core flow of a vanetype LSB, the flame position moved away from the burner as the reactant velocity increased, and moved toward the burner as the turbulence intensity increased. The induced shear layer between the central core flow and the outer annular flow created high levels of turbulence, which directly influenced the position of the flame. This idea is in stark contrast to the explanation from Cheng et al. (1992) (Figure 2.2).

Cheng and Littlejohn (2008) explored different combustor geometries and their effect on LSB operation. They conducted PIV measurements in open and enclosed flames produced by a $6.35 \mathrm{~cm}$ diameter LSB using two quartz cylinders of 15.5 and $20 \mathrm{~cm}$ diameter to simulate a combustor casing. Results from 18 methane/air flames showed that the use of enclosures did not alter the flame properties or the nearfield flow structures. The only differences the authors observed occurred in the farfield where the tighter enclosure discouraged the formation of a weak recirculation zone. The effect of the enclosure on the static stability limits still needs to be explored in future studies. 
Mansour and Chen (2008) used a premixed tangential jet-type LSB (Figure 2.1) to investigate the stability characteristics of methane/air LSB flames. They tested two different nozzle diameters of $40 \mathrm{~mm}$ and $53.5 \mathrm{~mm}$. They noted from the data that the relation between the main jet velocity, $U$, and the velocity of the four tangential jets, $u$, was linear at blowoff. Using the two nozzles, they showed that, within the bounds of their data, the linear trend led to an almost constant ratio of $U D / u=5.08 \mathrm{~mm}$, where $D$ is the nozzle diameter of the burner. Using a combined two-dimensional Rayleigh/LIPF-OH (laser induced predissociation fluorescence) technique for simultaneous measurement of temperature and $\mathrm{OH}$-radical concentrations at the flame front, the authors observed that the flame structure varied from corrugated to highly wrinkled according to the turbulence level.

Nogenmyr et al. (2010) developed the shear-layer induced low-swirl burner stability hypothesis even further with their joint numerical and experimental investigation of the structure and stabilization of a low-swirl turbulent stratified lean premixed methane/air flame. They demonstrated that the leading edge of the flame exhibits large-scale flame front wrinkling, and the flame front alternated from a $\mathrm{W}$-shape to an asymmetric $\mathrm{V}$-shape that was tilted to one side of the burner. They concluded that the flame behaviour was related to the interaction of the flame front with the large-scale flow motion in the inner low speed zone (central core flow) and the outer high-speed shear layer of the burner. In this manner, the W-structures form, disappear to be replaced with V-shapes, and subsequently reform at low frequencies. They concluded that the flame stabilization for a low-swirl flame is dictated by the large-scale vortex rings created in the shear layer, and that the coherent structures generated in the swirler and the burner enhance the shear layer instability, which produces more energetic vortices in the shear layer. This aligns with the observations of Strahman (2007), and again differs from the original explanation for LSB stability from Chan et al. (1992).

Legrand et al. (2010) used stereoscopic PIV measurements and proper orthogonal decomposition (POD) analysis on a burner designed to produce the topology of both a conventional high-swirl burner (HSB), and that of a low-swirl burner. They defined stability domains of the low- and high-swirl topologies based 
on a Reynolds number, and the PIV-integrated swirl number (Eq.(2.2)). In-house algorithms were used to track large periodic traveling coherent structures from the statistically independent stereo-PIV realizations. They observed that the LSB has a reduced recirculation zone in comparison with the HSB configuration. The authors inferred that the flame in the LSB configuration is actually stabilized by means of a low-velocity zone more than by the presence of a strong recirculation zone. They also noted that asymmetries were present in the mean flowfields of low-swirl flames due to the rotation of low-velocity structures about the inner core axial flow.

\subsubsection{Low-Swirl Burner with Alternative Fuels}

Littlejohn and Cheng (2007) performed tests on a LSB examining the effects of fuel type. Their conclusions state that the LSB does not need to undergo significant alterations to operate with hydrocarbon fuels other than methane, but further studies are required for adaptation of the burner to burn diluted $\mathrm{H}_{2}$ fuels.

Cheng and Littlejohn (2008) studied the effects of combustor geometry on the flowfields and flame properties of a LSB by changing the diameter of the enclosure attached at the exit plane of the nozzle. For the hydrogen mixtures, their results show that the outer recirculation zone generated at the corner of the nozzle exit plane due to the presence of an enclosure promotes the formation of attached flames (where the flame physically attaches to the burner rim (see Section 3.2.1). The properties and nearfield flow features of the attached flames were comparable to those of the usual lifted flames. At high enough stoichiometries, the attached flame collapsed to form a compact disc shaped flame with flowfield features dissimilar from lifted or attached flames. These results led to the conclusion that the enclosure effects on the LSB are strongly coupled to the fuel type and nozzle exit plane geometry but are much less dependent on the enclosure size.

Cheng et al. (2009) conducted experiments at gas turbine and atmospheric conditions (pressures from 0.101 to $0.810 \mathrm{MPa}$, temperatures from 298 to $580 \mathrm{~K}$ ) to characterize the behaviours and emissions of LSB flames for potential use in gas turbine combustors. The effect of hydrogen on the combustion process was investigated for potential adaptation of the LSB to gas turbines in a power plant 
using some amount of syngas fuels. Experimental results at high pressure and temperatures show that the LSB can indeed operate with up to $100 \% \mathrm{H}_{2}$ up to an equivalence ratio of 0.5 while also producing a slightly higher flashback tolerance than an analogous high-swirl design. Increasing the $\mathrm{H}_{2}$ concentration in the fuel resulted in the LSB flame shifting closer to the nozzle exit and eventually attaching to the nozzle rim assuming a different shape entirely. The attachment phenomenon was observed at both atmospheric and gas turbine conditions. Analysis of PIV data showed that the stabilization mechanism of the LSB remained unchanged up to $60 \% \mathrm{H}_{2} . \mathrm{NO}_{\mathrm{x}}$ emissions showed a log linear dependency on adiabatic flame temperatures, with concentrations of $\mathrm{NO}_{\mathrm{x}}$ being similar to those obtained in previous work for an LSB developed for natural gas (Leonard and Stegmaier, 1994).

Similar to Kang et al. (2007), Yilmaz et al. (2010) investigated thermoacoustic coupling of the LSB, but with the addition of hydrogen to the fuel mixture. Their results showed that the combustion characteristics are very sensitive to the fraction of hydrogen in the fuel mixture. The flame exhibited significant increases in flame base coupling and flame compaction (shorter and flatter flame) with increasing hydrogen concentration under all conditions. This effect was shown to enhance the flame-response at non-resonant frequencies while the coupling intensity at the resonant frequency was shown to decrease.

Littlejohn et al. (2010) attempted to gain a fundamental understanding of the effect of syngas on LSB flame behaviour, emissions, flowfield characteristics, and potential for adapting to gas turbine conditions (elevated pressure and temperatures). A full size laboratory LSB $(6.35 \mathrm{~cm})$ was used for the study on LSB flame behaviour, emissions, and flowfield characteristics. Verification of syngas operation at elevated pressures and temperatures was performed with a smaller LSB $(2.54 \mathrm{~cm})$ in a small, pressurized combustion channel. Results were in agreement with Cheng et al. (2009) in that they showed that the LSB was amenable to burning syngases with up to $60 \% \mathrm{H}_{2}$. The syngases with higher $\mathrm{H}_{2}$ concentration had lower lean blowoff limits. PIV results showed that the flowfields from syngasfueled LSB flames were essentially the same as those observed in hydrocarbon and pure or diluted hydrogen flames. The reduced scale LSB at $450 \mathrm{~K}<T<505 \mathrm{~K}$ and 
8 atm was successfully fired, verifying the operability of syngas-fueled LSBs at gas turbine conditions.

From the preceding review, it is apparent that the LSB has been studied by a number of researchers and has been successfully used to stabilize lean premixed flames in a wide variety of conditions with a wide variety of fuels. However, there is still no clear understanding of the blowoff mechanism. Nogenmyr (2010) and Strahman (2007) suggest that the shear layer between the inner core flow and swirling outer annular flow is of critical importance for flame stability, while the LSB's original developers suggest that the primary function of the swirling flow is to provide radial divergence that slows the reactant flow and allows the freely propagating flame to settle where the flame speed matches the reactant flow speed. The experiments presented in the following chapters were designed to specifically investigate the stabilization mechanism of the LSB with the hope of providing deeper insight into the design and operation of the LSB in applications using gaseous bio- and syn-gas fuels. 


\section{Experimental Study}

\subsection{Apparatus}

\subsubsection{The Low-Swirl Burner (LSB)}

The LSB used in this study consisted of an axial inner core flow surrounded by a swirling annular flow. For the work presented in this thesis, a fully controlled laboratory-scale LSB was used to independently control the inner core flow and outer swirling annular flow. Figure 3.1 and Figure: 3.2 show schematic diagrams and photographs of the apparatus.

Premixed methane and air enter separate, concentric settling chambers at the base of the burner. The concentric settling chambers contain lead shot of $3 \mathrm{~mm}$ diameter to a depth of $12.5 \mathrm{~cm}$, which break up the incoming jets, and act as a flame arrestor in the event of flashback. Downstream of the lead shot, the flow passes through two sets of concentric settling screens to eliminate turbulence and promote a uniform velocity profile. After the settling screens, the flows enter concentric, cubic-contoured nozzles. The inner nozzle includes a perforated plate at its exit to create a desired amount of grid turbulence within the flowfield (Strahman, 2007). The outer flow encounters optional curved swirl vanes, which generate annular tangential (swirl) velocity at the outlet.

Three combinations of sizes for the inner and outer nozzles were used in this study. The diameters of the outer exit nozzles were $38.1 \mathrm{~mm}, 50.8 \mathrm{~mm}$, and $76.2 \mathrm{~mm}$. The corresponding diameters of the inner exit nozzles were specified to maintain a constant inner to outer diameter ratio of 0.8 .

\subsubsection{LSB components}

\section{Settling screens and Turbulence Plates}

The settling screens used for this LSB were selected by Strahman (2007) as described on page 32 of his thesis. The design of the turbulence generator plates is outlined in Strahman (2007), page 35. Strahman (2007) shows that turbulence generator plate solidity (inverse of porosity) has no effect on the static stability 
points of the LSB. The solidity of the turbulence generator plates is thus held at $48 \%$ for these experiments.

a)

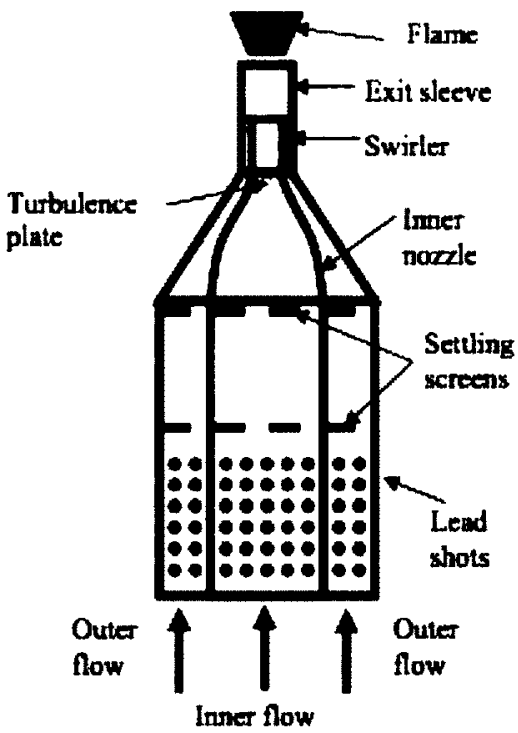

b)

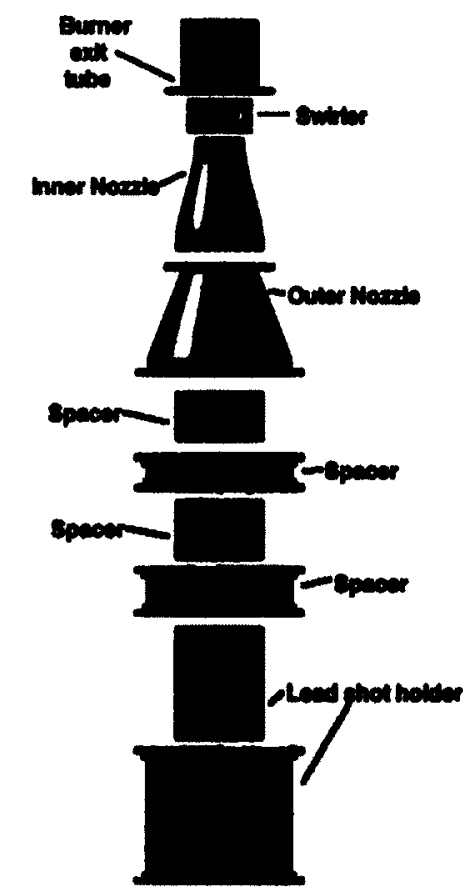

Figure 3.1: a) Burner components b) Burner exploded view

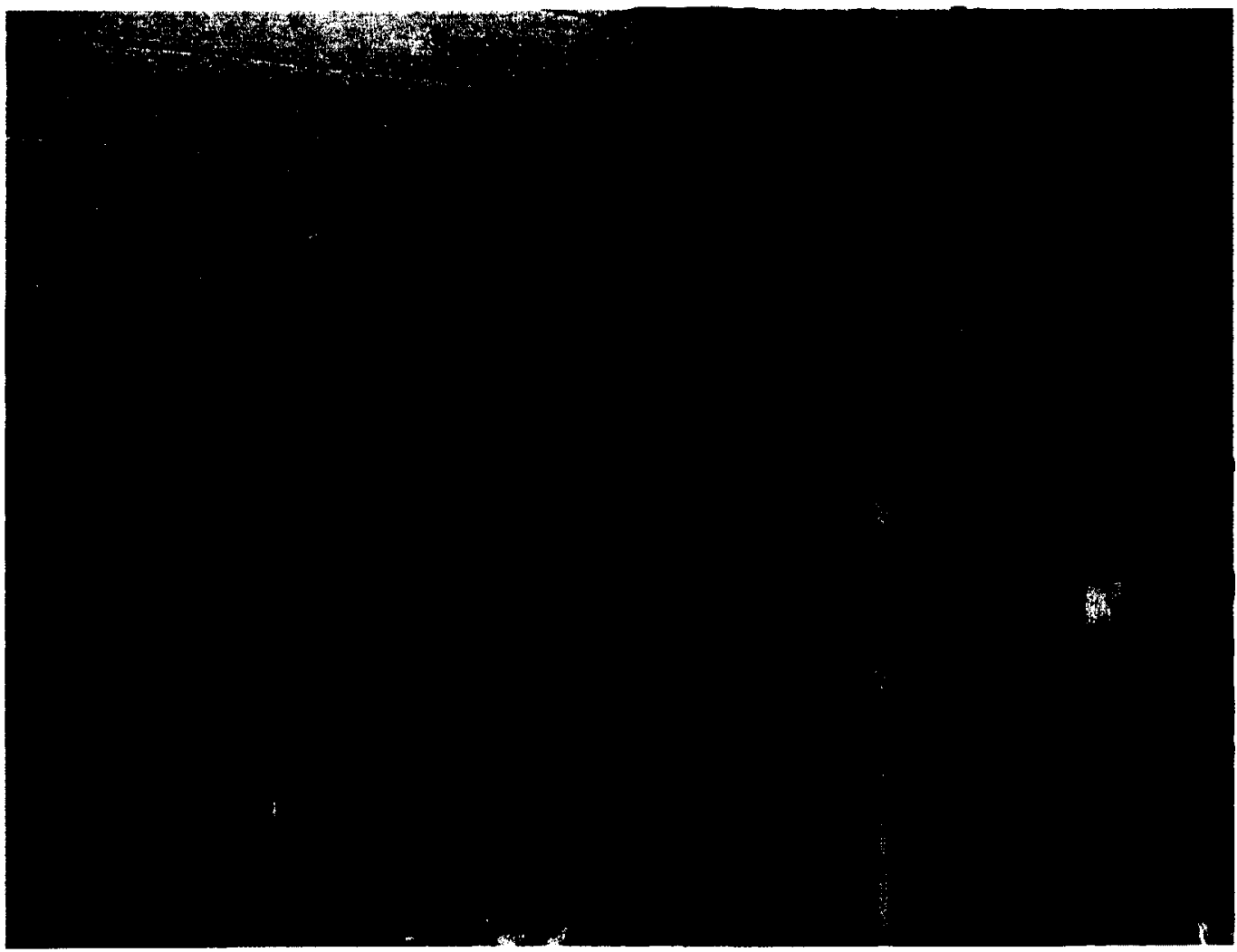

Figure: 3.2 LSB with mass flow controllers setup 


\section{Concentric converging nozzles}

As shown in Figure 3.3, the two concentric nozzles located at the top of the burner were each cubic contoured and acted to increase in the flow uniformity in the axial direction, while reducing the streamwise turbulence intensity level (defined in this case as the standard deviation of the streamwise fluctuations divided by the local mean velocity) (Tavoularis, 2005). The inner nozzle directed the inner flow toward the turbulence generator plate, which was mounted at the bottom of the swirler. Between the outer contour of the inner nozzle, and the inner contour of the outer nozzle, the outer (annular) flow was directed toward the vanes of the swirler. The assembly of the nozzles with the swirler in place is shown in Figure 3.4 using the $76.2 \mathrm{~mm}$ nozzle as an example. Table 3.1 shows physical details of the nozzles and Appendix B describes the procedure used to determine the nozzle contours.

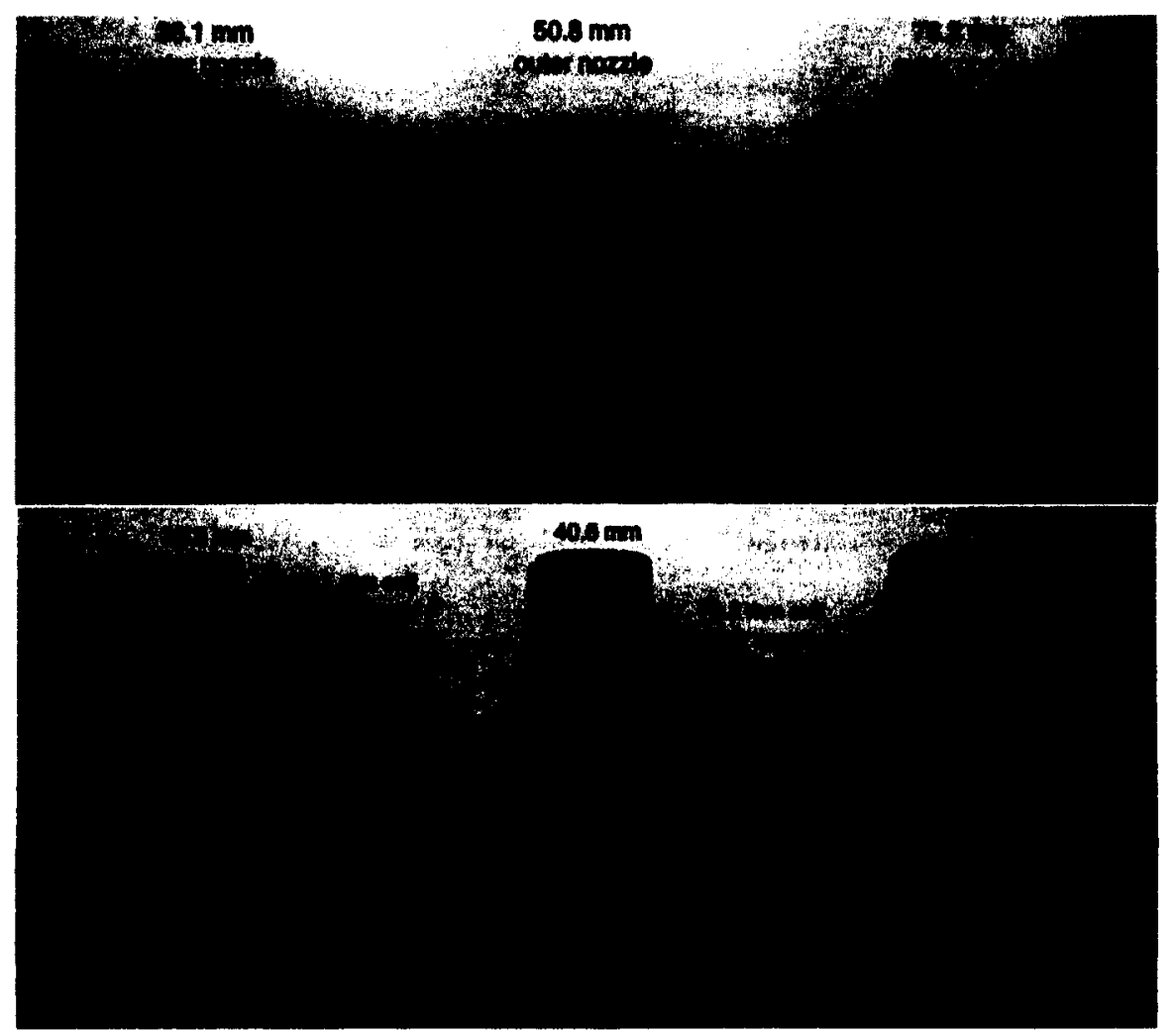

Figure 3.3: a) Outer nozzles b) Inner nozzles with attached turbulence generating plates 


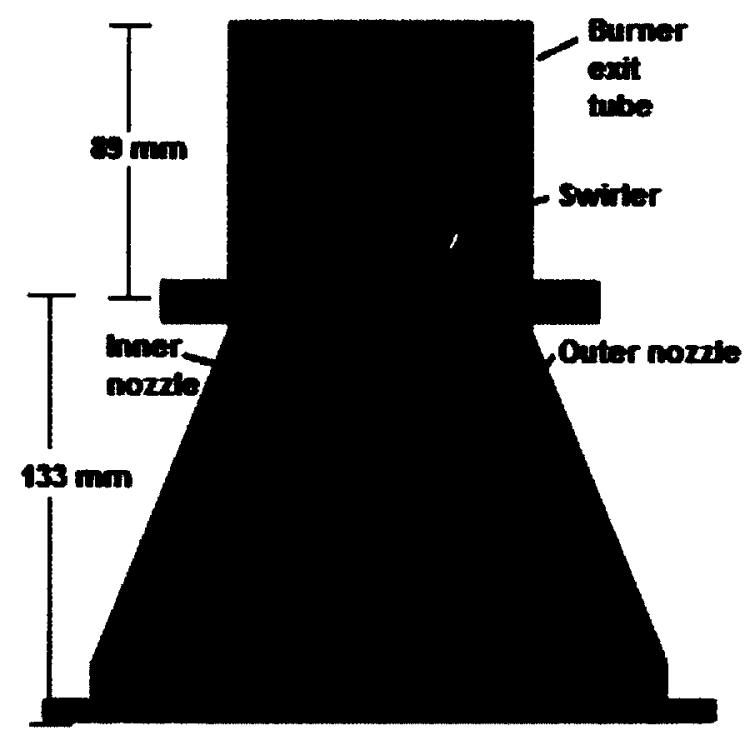

Figure 3.4: Nozzles assembly (76.2 $\mathrm{mm}$ nozzle example)

\section{Vane-Swirlers}

Figure 3.5 shows photographs of the swirlers which mount at the top of (downstream of) the inner nozzles. The swirlers consisted of thin-walled $(12.5 \mathrm{~mm}$ ) cylinders with annular vanes wrapped around the outside. Geometric details of the vanes are summarized in Table 3.2 .

a)

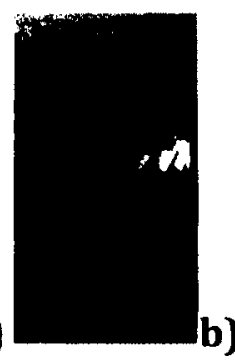

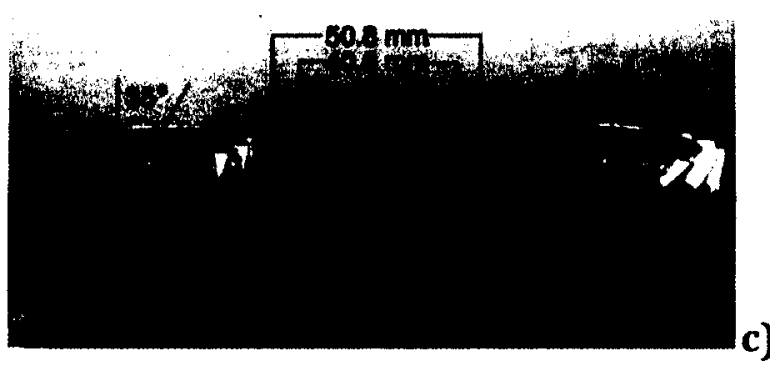

c)

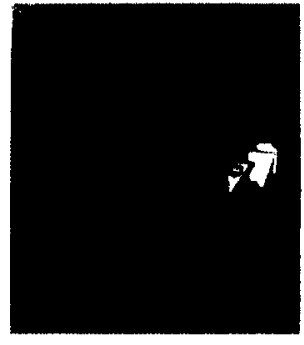

vit

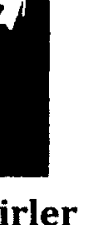

Figure 3.5 a) $38.1 \mathrm{~mm}$ swirler b) three $50.8 \mathrm{~mm}$ swirlers c) $76.2 \mathrm{~mm}$ swirler

The turbulence plate rested against the inlet of the swirler, which was press fitted into the burner exit tube. The swirl vanes were aligned with the burner axis at the inlet, followed by a curve to their desired exit angle. It was initially desired for each size nozzle to have at least one swirler with the same exit angle of $37.5^{\circ}$, but due to machining constraints, a compromise had to be made. For the $38.1 \mathrm{~mm}$ diameter burner, the exit angle for the swirler was $44.4^{\circ}$. For the $50.8 \mathrm{~mm}$ burner, 
there were three swirlers available with different exit angles of $35^{\circ}, 37.5^{\circ}$, and $44^{\circ}$.

The $76.2 \mathrm{~mm}$ burner had a swirler with an exit angle of $40.4^{\circ}$.

Table 3.1: LSB nozzle combinations

\begin{tabular}{|c|c|c|c|c|c|}
\hline \multirow[b]{2}{*}{$\begin{array}{c}\text { Outer nozzle } \\
\text { inner } \\
\text { diameter at } \\
\text { exit plane } \\
\text { [mm] }\end{array}$} & \multicolumn{2}{|c|}{ Inner nozzle } & \multirow{2}{*}{$\begin{array}{c}\text { Annular Flow } \\
\text { Contraction } \\
\text { Ratio }\end{array}$} & \multirow{2}{*}{$\begin{array}{c}\text { Inner Flow } \\
\text { Contraction } \\
\text { Ratio }\end{array}$} & \multirow{2}{*}{$\begin{array}{l}\text { Length in the axial } \\
\text { direction [mm] }\end{array}$} \\
\hline & $\begin{array}{c}\text { Inner } \\
\text { diameter at } \\
\text { exit plane } \\
\text { [mm] }\end{array}$ & $\begin{array}{c}\text { Outer } \\
\text { diameter at } \\
\text { exit plane } \\
{[\mathrm{mm}]}\end{array}$ & & & \\
\hline 38.1 & 29.1 & 30.5 & $36.2: 1$ & $8.73: 1$ & 132.0 \\
\hline 50.8 & 39.8 & 40.6 & $22.2: 1$ & $4.64: 1$ & 131.6 \\
\hline 76.2 & 59.2 & 61.0 & $9.04: 1$ & $2.10: 1$ & 134.0 \\
\hline
\end{tabular}

Table 3.2: Swirler Details

\begin{tabular}{|c|c|c|c|c|c|c|}
\hline $\begin{array}{c}\text { Diameter } \\
\text { (measured } \\
\text { to outer } \\
\text { edge of swirl } \\
\text { vanes) [mm] }\end{array}$ & $\begin{array}{c}\text { Exit vane } \\
\text { angle } \\
\text { [degrees] }\end{array}$ & $\begin{array}{c}\text { Length in } \\
\text { axial } \\
\text { direction } \\
\text { [mm] }\end{array}$ & $\begin{array}{c}\text { Number of } \\
\text { Vanes }\end{array}$ & $\begin{array}{c}\text { Vane } \\
\text { thickness } \\
\text { at exit } \\
\text { [mm] }\end{array}$ & $\begin{array}{c}\text { Axial rotation } \\
\text { between } \\
\text { upstream and } \\
\text { downstream } \\
\text { ends of the } \\
\text { vanes [degrees] }\end{array}$ & $\begin{array}{c}\text { *Estimated } \\
\text { Deviation } \\
\text { of Flow } \\
\text { Relative to } \\
\text { Vane } \\
\text { Angle } \\
\text { [degrees] }\end{array}$ \\
\hline $\mathbf{3 8 . 1}$ & 44.4 & 38.1 & 16 & 0.60 & 50 & 1.5 \\
\hline $\mathbf{5 0 . 8}$ & 35 & 38.1 & 16 & 0.80 & 30 & 1.6 \\
\cline { 2 - 7 } & 37.5 & 38.1 & 8 & 1.45 & 46 & 3.4 \\
\cline { 2 - 7 } & 47 & 38.1 & 16 & 0.70 & 49 & 2.1 \\
\hline $\mathbf{7 6 . 2}$ & 40.4 & 38.1 & 16 & 1.50 & 29 & 2.7 \\
\hline
\end{tabular}

*See Appendix F

\section{The Burner Exit Tube}

Each outer nozzle size, $(38.1 \mathrm{~mm}, 50.8 \mathrm{~mm}$, and $76.2 \mathrm{~mm}$ ) had a burner exit tube of equal diameter with a $45^{\circ}$ exit angle chamfer. Previous research from Strahman (2007) shows that the length of the exit tube has a minimal influence on the static stability points of the LSB. The lengths of the exit tubes were thus held constant at $89 \mathrm{~mm}$.

\section{The enclosure}

An optional quartz tube enclosure with an inner diameter of $195 \mathrm{~mm}$, an outer diameter of $201 \mathrm{~mm}$, and a length of $457 \mathrm{~mm}$ could be optionally mounted on the flange between the outer nozzle and the nozzle cap to simulate enclosure effects 
such as those that would occur within a "can-configuration" of a typical gas turbine burner. The majority of experiments were conducted without the enclosure.

\subsubsection{Data Acquisition and Control}

As visible in the photograph in Figure: 3.2 and shown schematically in Figure 3.6, the gaseous flows provided to the LSB were regulated by a system of up to 12 thermal mass flow controllers (MFC). Up to four MFCs were used simultaneously to meter air flowing to the inner and outer sections of the burner and to their corresponding particle seeders used during PIV experiments (see Section 3.1.5). The other twelve MFCs controlled the inner and outer flows of $\mathrm{H}_{2}, \mathrm{CO}, \mathrm{CO}_{2}$, and $\mathrm{CH}_{4}$ to create the fuel mixtures outlined in Table 1.1. With these MFCs, it was possible to fully control the total flowrate, equivalence ratio, inner flow fraction (\%IFF, defined as the percentage of the total flow that goes through the inner nozzle), geometric swirl number, and the percentage of total air flow entering each section of the burner that passes through the particle seeders (see Section 3.1.5). The calibration and operation procedures for the MFCs are outlined in Appendix C.

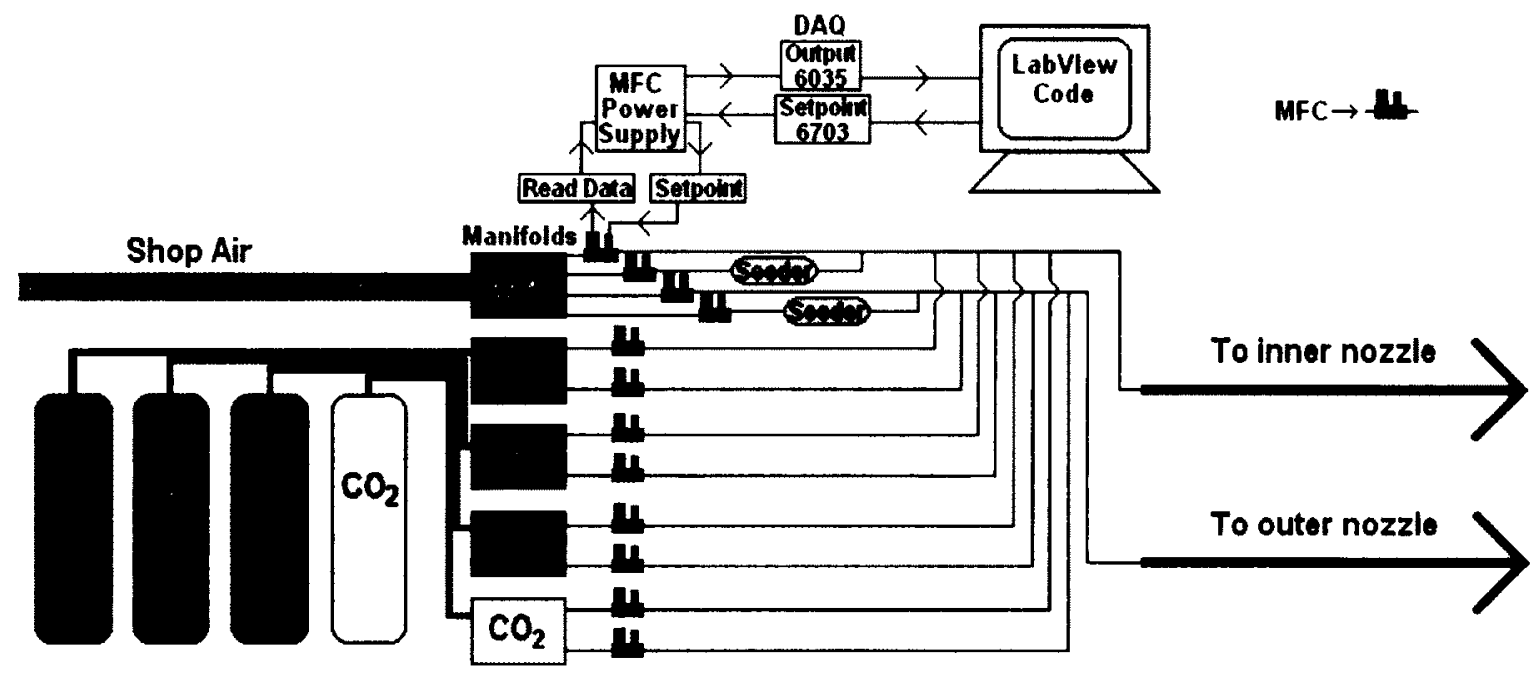

Figure 3.6: Mass flow controllers and seeders

A Pentium processor computer controlled the data acquisition (DAQ) using a pair of National Instrument data acquisition cards (PCI-6703 and PCI-6035E). Coaxial cables were used for the data transmission between the computer and DAQ 
cards. To set flow rates based on various input parameters (fuel mixture, $\Phi$, total flow rate, \%IFF, etc.), and calculate velocities based on flowrates and the chosen geometry, an expanded LabVIEW code originally written by M.R. Johnson was used. Each MFC was represented by a unique virtual instrument (VI) in the LabVIEW code, which contains the calibration equations relating voltage signal to mass flow, and hence volume flow. The MFCs were calibrated for several relevant gases to avoid reduced accuracies associated with using the gas conversion factor (GCF) tables (see Appendix C). A screenshot of the LabVIEW interface is shown in Figure 3.7 .

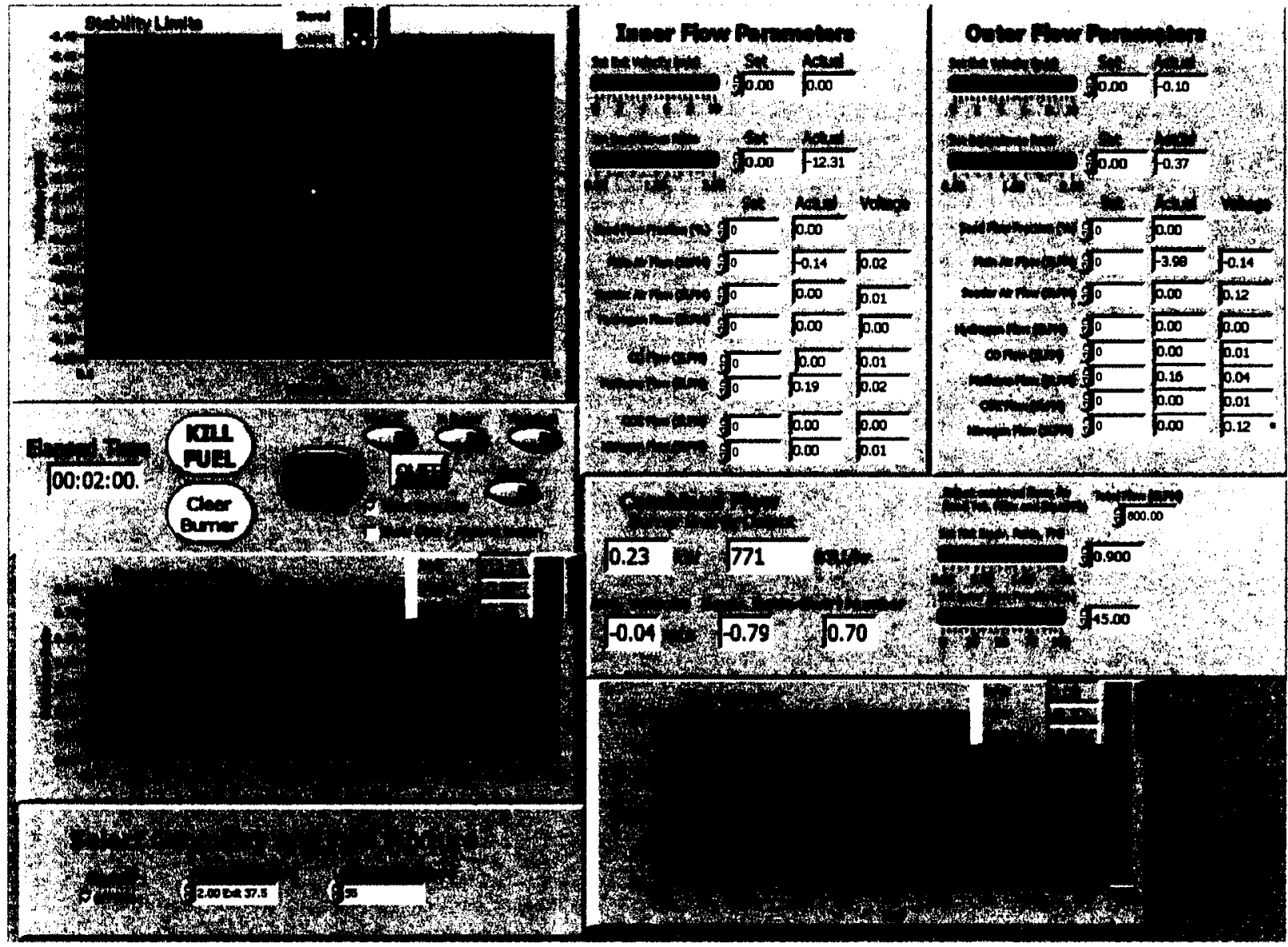

Figure 3.7: LabVIEW interface for operating the fully controlled low swirl burner 


\subsubsection{Particle Image Velocimetry (PIV) system}

A forward-backward scattering stereoscopic PIV system was employed for the determination of the reactant and product velocity fields. The setup of the system is shown schematically in Figure 3.8 (Strahman, 2007). A LaVision computer with Davis and Flowmaster software (LaVision Inc., 2010) was used to control the data acquisition. The system hardware, explored in more depth in Section 3.1.5, included an ND:YAG laser, two frame-straddling 12 bit CCD cameras with $532 \mathrm{~nm}$ band-pass filters, light-sheet optics, two solid-particle seeders, $\mathrm{SiO}_{2}$ particles, and Davis PIV software.

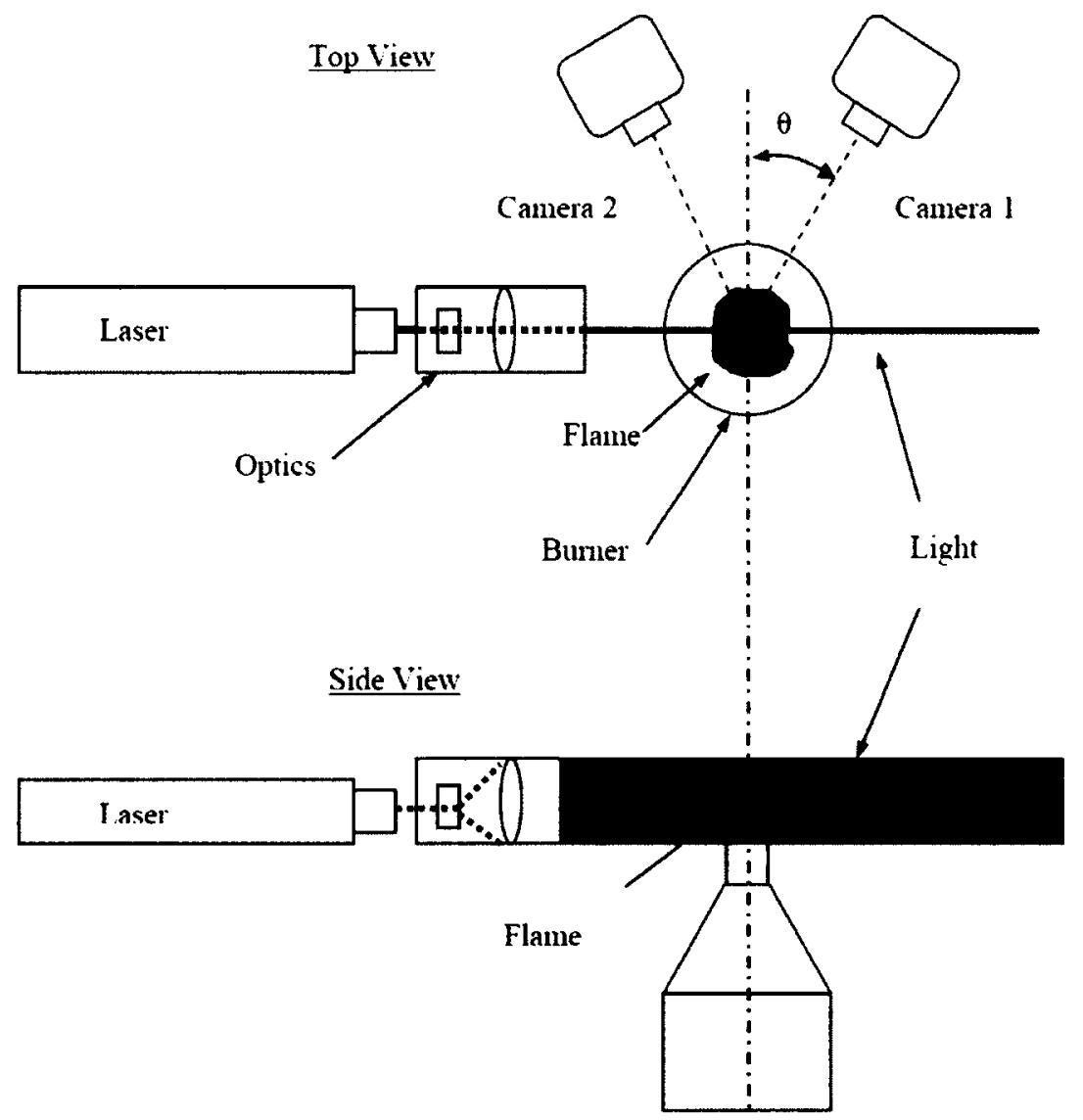

Figure 3.8: PIV setup (from Strahman (2007)) 


\subsubsection{PIV system components}

\section{The Laser}

A frequency-doubled, dual-head Q-switched Nd:YAG laser (New Wave, Solo PIV) was used to create the light-sheet for the PIV measurements. A maximum energy per pulse of $120 \mathrm{~mJ}$ at a wavelength of $532 \mathrm{~nm}$ was possible with a pulse duration of $\sim 5 \mathrm{~ns}$. Assuming a maximum value of particle motion at $30 \mathrm{~m} / \mathrm{s}$ (highest flow rates on the smallest burner), the image of the particle will travel $0.155 \mu \mathrm{m}$ during this time, so this was considered negligible, and the velocity obtained was considered instantaneous (See Appendix D). The laser generated a fundamental wavelength of $1064 \mathrm{~nm}$, which was frequency doubled to provide green visible light at a wavelength of $532 \mathrm{~nm}$. The programmable timing unit (PTU) in the data acquisition computer controlled the firing of the lasers to be in sync with the two cameras (see below).

\section{Light-sheet optics}

A plano-concave lens $(f=38 \mathrm{~mm}$, height $=26 \mathrm{~mm})$ followed by a plano-convex lens $(f=1000 \mathrm{~mm}, d=100 \mathrm{~mm}$ ) was used to transform the circular cross-section laser beam into a planar sheet for PIV measurements. The distance between the convex lens and the field of view (FOV) of the cameras (i.e. the exit plane of the burner) controlled the light-sheet thickness since the produced light sheet converged to a waist at the focal length of the convex lens and then diverged again. Due to the high tangential (swirl) velocities of the LSB, generally the thicker regions of the lightsheet ( $>2 \mathrm{~mm}$ ) were used to maximize the amount of particles captured in both image frames.

\section{PIV Cameras}

Two frame-straddling 12 bit CCD cameras were used for the stereo-PIV measurements. The camera collecting forward-scattered light was a LaVision Imager Pro $2 \mathrm{M}$ with $1600 \times 1200$ pixels and a pixel size of $7.4 \mu \mathrm{m}$. The camera collecting backward scattered light was a LaVision Imager Intense with 1376 x 1040 pixels and a pixel size of $6.45 \mu \mathrm{m}$. Both cameras were equipped with band-pass 
filters with a center wavelength of $532.5 \mathrm{~nm}$ to ensure that the vast majority of the light collected came from the laser scattering off the seeding particles. The cameras were also equipped with Scheimpflug mounts to provide more uniform magnification in the off-axis arrangement shown in Figure 3.8. These cameras worked in a double-shuttered mode known as "frame straddling" which is necessary for PIV as it allows for two pictures to be taken in quick succession.

\section{Particle Seeders}

Figure 3.9 shows a view of the seeders built for this study. The seeders used were stainless steel cylinders of height $165 \mathrm{~mm}$ and inner diameter $145 \mathrm{~mm}$. A controlled portion of the main air flows (air flows for the inner and outer flow sections of the LSB) could be optionally diverted through separate particle seeders, prior to being mixed back into the air stream, premixed with the fuel and injected into the burner. This configuration permitted full control of the equivalence ratio, total flow rate, and seeding density in the mixture directed to the LSB. The "seeder air" fed into the seeder tangentially through two $1 / 2$ " ports at the bottom of the seeder, entrained the solid seeding particles, and exited through a centered $3 / 4$ " port at the top of the seeder. The interior of the seeders contained wooden cones of height $140 \mathrm{~mm}$ and diameter $120 \mathrm{~mm}$. These cones were centered on the bottom, which helped to keep the seeding particles from settling in the middle so they were more likely to be picked up by the incoming tangential air. Both the amount of seed in the seeders and the amount of air going through the seeders were found to affect the seeding density at the exit of the LSB. At times, the portion of air going through the seeders had to be increased throughout measurements in order to keep a somewhat constant seeding density.

\section{Seed Particles}

The seeding particles used were AEROSIL R 972 hydrophobic fumed silica $\left(\mathrm{SiO}_{2}\right)$ particles supplied by Evonik-Univar. The hydrophobic feature, defined as a weight loss after 2 hours at $105^{\circ} \mathrm{C}$ of $\leq 0.5 \%$, was selected based on the need to keep these particles in the lab for over a year without any moisture absorption changing the 
particle size. The average primary particle size is listed as $16 \mathrm{~nm}$, though this is before settling and conglomeration. The specific surface area is listed as $110 \pm 20 \mathrm{~m}^{2} / \mathrm{g}$.

a)
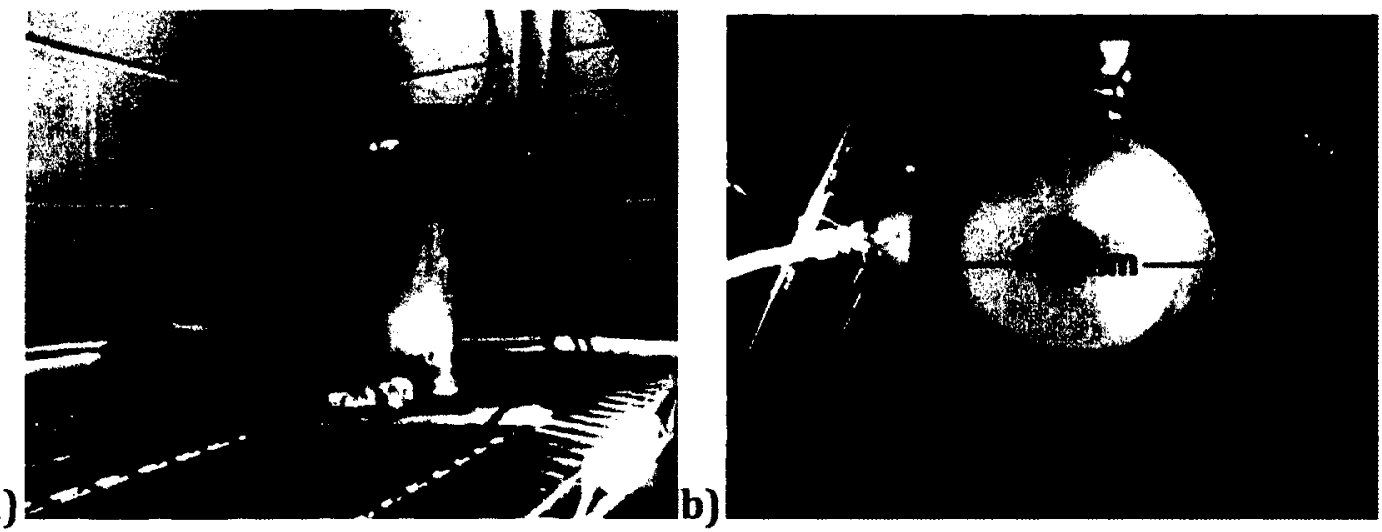

Figure 3.9 Seeder used for PIV a) Side view b) Inside view with top lid removed

The light received from the particles by the camera is scattered, not reflected, so the actual imaged particle diameter $\left(d_{\tau}\right)$ is a function of the true particle diameter $\left(d_{p}\right)$, the magnification $(M)$, and the diffraction limited minimum image diameter $\left(d_{d}\right):$

$$
d_{\tau}=\sqrt{\left(M d_{p}\right)^{2}+d_{d}^{2}}
$$

The diffraction-limited minimum image diameter is a function of the lens aperture and can be estimated as:

$$
d_{d}=2.44 * f \#(M+1) \lambda
$$

where $f \#$ is the dimensionless ratio of the lens focal length to the diameter of the lens aperture as noted on the camera lens and $\lambda$ is the wavelength of the scattered light. Using Camera 1 (Imager Pro) as an example, with a magnification of $\mathrm{M}=0.104$ as calculated by the Davis software, an $f \#$ of 16 used during PIV measurements, and the laser wavelength of $532 \mathrm{~nm}$, the diffraction limited minimum imaged diameter of a particle is:

$$
d_{d}=2.44 * 16 * 1.104 * 0.000000532=2.29 * 10^{-5} \mathrm{~m}=22.9 \mu \mathrm{m}
$$


Since a pixel on Camera 1 is $7.4 \mu \mathrm{m}$, this works out to 3.1 pixels. The PIV images show that the vast majority of the actual particle image diameters are approximately 3 pixels wide, which confirms that the imaged particles are diffraction limited, such that true diameters cannot be determined accurately from the PIV images. Using Eq.(3.1), particles with true diameters ranging from $1 \mu \mathrm{m}<d_{p}$ $<20 \mu \mathrm{m}$ would all have the same diffracted imaged size of approximately $23 \mu \mathrm{m}$ in the PIV images, demonstrating that the actual imaged particle size is extremely insensitive to true particle size under these conditions. For the purpose of estimating uncertainty in Appendix D, the mean particle diameter was assumed to be $10 \mu \mathrm{m}$ to provide a worst-case estimate, although it is anticipated that the actual entrained seed particles should have been smaller.

\subsection{Experimental Procedures}

This section describes the procedures used to obtain stability maps of the low-swirl burner and to measure flowfield velocities using particle image velocimetry (PIV).

\subsubsection{Stability Maps}

Measurements of flashback and blowoff were recorded by varying the swirl number (i.e. by varying the inner flow fraction, \%[FF) at constant equivalence ratio and fixed total flow rates ranging from 400 SLPM to 1200 SLPM. A stable swirl number was first found for a given $\Phi$ and total flow rate, and then the \%IFF was increased (lowering the swirl number) until blowoff eventually occurred, at which point the operating conditions monitored by LabVIEW were recorded. To measure flashback limits, starting from a stable flame the \%IFF was lowered (increasing the swirl number) to eventually induce flashback. In some cases, where the flame did not flashback, the flow conditions were marked when the leading edge of the flame propagated upstream into the nozzle itself as 'in burner'. When hydrogen was present in the fuel mixture, there was also the possibility of another stability mode in which the flame was attached to the rim of the burner exit tube (denoted as an 'attached flame'). In this stability mode, there was still a possibility of flashback 
occurring, but the attached flame did not blowoff regardless of the swirl number at the flow rates considered.

Figure 3.10 illustrates the possible conditions for the LSB flame. Figure 3.11 shows a typical stability map, in this case for a methane flame with the $50.8 \mathrm{~mm}$ nozzle, the $37.5^{\circ}$ swirler, and an equivalence ratio of $\Phi=0.8$. Blowoff within an enclosure was also investigated for several test conditions, and the results are presented in Section 4.1.4.

a)

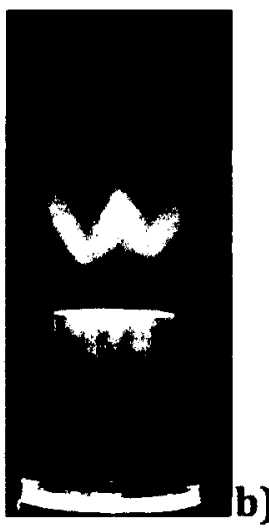

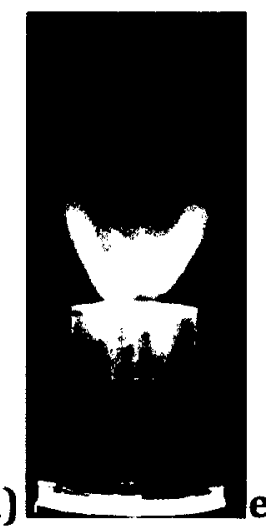

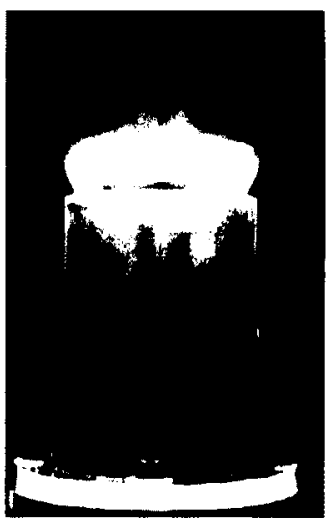

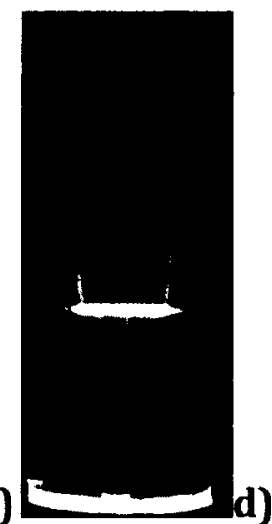

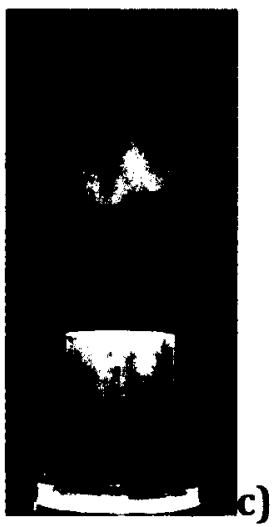

woff Attached Flame

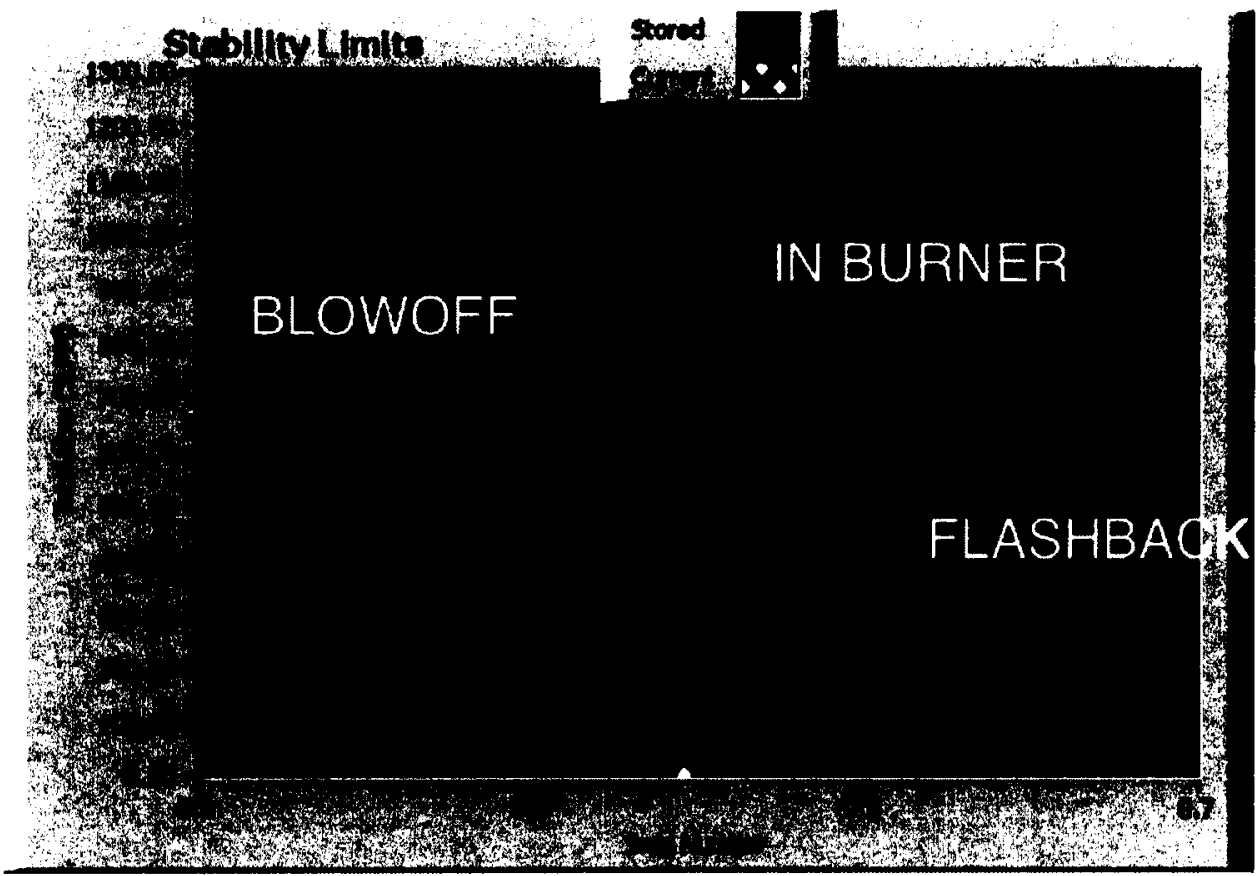

Figure 3.11: Stability map as output on the computer screen by the LabVIEW data acquisition program during measurements. Results are shown for methane fuel at $\Phi=0.8$ using the $50.8 \mathrm{~mm}$ nozzle 
Stability maps of blowoff and flashback limits over a range of operating conditions were recorded and Table 3.3 shows the matrix of possible tests using all the different fuel mixtures, at relevant equivalence ratios in all possible geometric configurations (nozzle diameters and swirler exit angles). All combinations marked with an ' $\mathrm{X}$ ' were measured in the present work (each corresponding to approximately 9 blowoff measurements).

Table 3.3: Stability Map Test Matrix

\begin{tabular}{|c|c|c|c|c|c|c|c|c|c|c|c|c|c|}
\hline LSB & Swirl? & $\Phi$ & $\mathrm{CH}_{4}$ & B1 & S1 & S2 & S3 & 54 & S5 & 56 & S14 & S5M50 & S5M25 \\
\hline \multirow{14}{*}{$\begin{array}{l}38.1 \\
\mathrm{~mm}\end{array}$} & With Swirl & 0.5 & & & & & & & & & & & \\
\hline & & 0.6 & & & $\mathrm{X}$ & $\bar{X}$ & $\mathrm{X}$ & $\mathrm{X}$ & $\bar{X}$ & $\mathrm{X}$ & $\bar{X}$ & & \\
\hline & & 0.65 & & & & & & & & & & & \\
\hline & & 0.7 & $X$ & & & & & & & & & & \\
\hline & & 0.75 & $X$ & & & & & & & & & & \\
\hline & & 0.8 & $X$ & $\mathrm{X}$ & & & & & & & & $\bar{X}$ & $\bar{x}$ \\
\hline & & 0.9 & $\mathrm{X}$ & & & & & & & & & & \\
\hline & & 1.0 & $X$ & & & & & & & & & & \\
\hline & No Swirl & 0.5 & & & & & & & & & & & \\
\hline & & 0.6 & $x$ & & & & & & & & & & \\
\hline & & 0.7 & $\mathrm{X}$ & & & & & & & & & & \\
\hline & & 0.8 & $X$ & & & & & & & & & & \\
\hline & & 0.9 & $\mathrm{X}$ & & & & & & & & & & \\
\hline & & 1.0 & $\mathrm{X}$ & & & & & & & & & & \\
\hline \multirow{24}{*}{$\begin{array}{l}50.8 \\
\mathrm{~mm}\end{array}$} & $35^{\circ}$ Swirl & 0.5 & & & & & & & & & & & \\
\hline & & 0.6 & & & & & & & & & & & \\
\hline & & 0.7 & $X$ & & & & & & & & & & \\
\hline & & 0.8 & $\mathrm{X}$ & & & & & & & & & & \\
\hline & & 0.9 & $x$ & & & & & & & & & & \\
\hline & & 1.0 & & & & & & & & & & & \\
\hline & $37.5^{\circ}$ Swirl & 0.5 & & & $\mathrm{X}$ & $\mathrm{X}$ & $\mathrm{X}$ & $\mathrm{X}$ & $X$ & $\mathrm{X}$ & $\bar{X}$ & $\bar{X}$ & $\mathrm{X}$ \\
\hline & & 0.6 & $X$ & & $X$ & $\mathrm{X}$ & $\mathrm{X}$ & $\mathrm{X}$ & $X$ & $X$ & $\mathrm{X}$ & $\mathrm{X}$ & $x$ \\
\hline & & 0.7 & $x$ & $\mathrm{X}$ & $\mathrm{X}$ & $\mathrm{X}$ & $X$ & $\mathrm{X}$ & $X$ & $X$ & $\mathrm{X}$ & $x$ & $X$ \\
\hline & & 0.8 & $x$ & $\mathrm{X}$ & & & & & & & & & \\
\hline & & 0.9 & $x$ & $\mathrm{X}$ & & & & & & & & & \\
\hline & & 1.0 & $\mathrm{X}$ & & & & & & & & & & \\
\hline & $47^{\circ}$ Swirl & 0.5 & & & & & & & & & & & \\
\hline & & 0.6 & & & & & & & & & & & \\
\hline & & 0.7 & $\bar{X}$ & & & & & & & & & & \\
\hline & & 0.8 & $\mathrm{X}$ & & & & & & & & & & \\
\hline & & 0.9 & $\mathrm{X}$ & & & & & & & & & & \\
\hline & & 1.0 & & & & & & & & & & & \\
\hline & No Swirl & 0.5 & & & & & & & & & & & \\
\hline & & 0.6 & $\mathrm{X}$ & & & & & & $\mathrm{X}$ & & & & \\
\hline & & 0.7 & $\mathrm{X}$ & & & & & & & & & & \\
\hline & & 0.8 & $X$ & $\mathrm{X}$ & & & & & & & & & \\
\hline & & 0.9 & $X$ & & & & & & & & & & \\
\hline & & 1.0 & $X$ & & & & & & & & & & \\
\hline
\end{tabular}


Table 3.3: (continued): Stability Map Test Matrix

\begin{tabular}{|c|c|c|c|c|c|c|c|c|c|c|c|c|c|}
\hline LSB & Swirl? & $\Phi$ & $\mathbf{C H}_{4}$ & B1 & S1 & S2 & S3 & S4 & S5 & S6 & S14 & S5M50 & S5M25 \\
\hline \multirow{13}{*}{$\begin{array}{l}76.2 \\
\mathrm{~mm}\end{array}$} & Swirl? & $\Phi$ & $\mathrm{CH} 4$ & B1 & S1 & S2 & S3 & S4 & S5 & 56 & S14 & S5M50 & S5M25 \\
\hline & With Swirl & 0.5 & & & & & & & & & & & \\
\hline & & 0.6 & & & $\mathrm{X}$ & $\mathrm{X}$ & $\mathrm{X}$ & $\mathrm{X}$ & $\mathrm{X}$ & $\mathrm{X}$ & $\mathrm{X}$ & & \\
\hline & & 0.7 & $\mathrm{X}$ & & & & & & & & & & \\
\hline & & 0.8 & $\bar{X}$ & $\bar{x}$ & & & & & & & & $\bar{x}$ & $\mathrm{X}$ \\
\hline & & 0.9 & $\mathrm{X}$ & & & & & & & & & & \\
\hline & & 1.0 & & & & & & & & & & & \\
\hline & No Swirl & 0.5 & & & & & & & & & & & \\
\hline & & 0.6 & $\mathrm{X}$ & & & & & & & & & & \\
\hline & & 0.7 & $\bar{x}$ & & & & & & & & & & \\
\hline & & 0.8 & $\mathrm{x}$ & & & & & & & & & & \\
\hline & & 0.9 & $\bar{x}$ & & & & & & & & & & \\
\hline & & 1.0 & $\mathrm{X}$ & & & & & & & & & & \\
\hline
\end{tabular}

\subsubsection{Uncertainty in Blowoff Measurements}

For the blowoff curves specifically, repeatability tests were conducted to determine the precision error at the blowoff point. This was combined with the bias error from the experimental hardware to determine the total uncertainty in the swirl number at blowoff for the specific case of methane fuel at $\Phi=0.8$ on the $50.8 \mathrm{~mm}$ nozzle. The specific calculations and methodology determining component uncertainties can be found in Appendix D. The error bars determined on a typical blowoff curve are shown in Figure 3.12, where the swirl number is calculated using Eq.(2.4). The $95 \%$ confidence limits of the total uncertainty in measured swirl number at blowoff are within $\pm 6 \%$. The uncertainty in the heat release calculation derived from the fuel flow measurement is comparatively negligible as apparent in the figure.

\subsubsection{Flowfield measurements using PIV}

For this study, PIV measurements were taken of LSB flames, mostly at the lowest possible stable swirl number near the blowoff condition. Table 3.4 documents the complete set of PIV measurement conditions recorded in this thesis work. The field of view (FOV) was always at the mid-plane of the burner. All conditions listed used the $37.5^{\circ}$ swirler on the $50.8 \mathrm{~mm}$ with the exception of the one no swirl case for the $50.8 \mathrm{~mm}$ nozzle. 


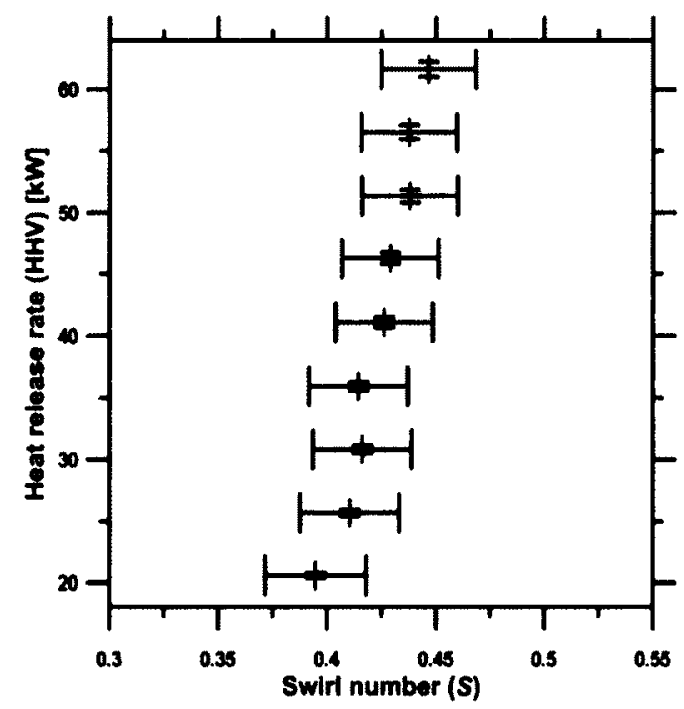

Figure 3.12: Uncertainty in swirl number and heat release at blowoff

Using pure methane fuel, total flowrates were increased from 400 to 1200 SLPM with the $50.8 \mathrm{~mm}$ nozzle at fixed $\Phi=0.8$ to explore changes in the flowfield with increasing bulk velocity. Subsequent tests matched the average velocities at $6.68 \mathrm{~m} / \mathrm{s}$ (total volume flow divided by total area) for all three nozzle sizes, at $\Phi=0.7$ and 0.8 . To investigate fuel effects, flowfield measurements were conducted for different fuel mixtures in which both the adiabatic flame temperature and heat release rates were matched to those of $\mathrm{CH}_{4}$ at $\Phi=0.7$ and 0.8 . This was accomplished by first altering $\Phi$ to match the adiabatic flame temperature, and then by changing the total flow rate until the higher heating value was matched. This combination was intended to model the potential for substituting various fuels into an existing low-swirl burner such that energy output and temperature could be maintained approximately constant. In addition to these experiments, a no-swirl condition with the $50.8 \mathrm{~mm}$ nozzle was measured, along with a flame condition for both the 38.1 and $50.8 \mathrm{~mm}$ nozzles where the swirl number was high enough to be sufficiently removed from blowoff, but not close to flashback. These flames are labeled 'stable flames'.

Several other near-blowoff cases were also measured that were part of no particular experiment or were chosen to document some curious results from the 
stability mapping. The complete set of PIV measurements taken are presented in

Table 3.4

Table 3.4: PIV Measurement Conditions

\begin{tabular}{|c|c|c|c|c|c|c|c|c|}
\hline Experiment & $\begin{array}{c}\text { Nozzle } \\
\text { [mm] }\end{array}$ & Fuel & $\Phi$ & $\begin{array}{c}Q_{t o t} \\
{[S L P M]}\end{array}$ & $\begin{array}{c}U_{a v e} \\
{[\mathrm{~m} / \mathbf{s}]}\end{array}$ & $\begin{array}{c}\text { HRRHHV } \\
\text { [kW] }\end{array}$ & $\% I F F$ & $\boldsymbol{s}$ \\
\hline \multirow{3}{*}{$\begin{array}{l}\text { Flowrate } \\
\text { range for one } \\
\text { nozzle. Near } \\
\text { Blowoff. }\end{array}$} & 50.8 & $\mathrm{CH}_{4}$ & 0.8 & 400 & 3.7 & 20.6 & 52.5 & 0.41 \\
\hline & 50.8 & $\mathrm{CH}_{4}$ & 0.8 & 800 & 7.41 & 41.2 & 50.2 & 0.44 \\
\hline & 50.8 & $\mathrm{CH}_{4}$ & 0.8 & 1200 & 11.3 & 61.5 & 48.5 & 0.46 \\
\hline \multirow{6}{*}{$\begin{array}{l}\text { Matching } U_{\text {ave }} \\
\text { for } 3 \text { nozzle } \\
\text { sizes. Near } \\
\text { blowoff. }\end{array}$} & 38.1 & $\mathrm{CH}_{4}$ & 0.7 & 400 & 6.68 & 18.2 & 51.5 & 0.52 \\
\hline & 50.8 & $\mathrm{CH}_{4}$ & 0.7 & 720.6 & 6.68 & 32.8 & 48.0 & 0.47 \\
\hline & 76.2 & $\mathrm{CH}_{4}$ & 0.7 & 1639.9 & 6.68 & 74.5 & 50.8 & 0.47 \\
\hline & 38.1 & $\mathrm{CH}_{4}$ & 0.8 & 400 & 6.68 & 20.5 & 53.0 & 0.49 \\
\hline & 50.8 & $\mathrm{CH}_{4}$ & 0.8 & 720.6 & 6.68 & 37.0 & 50.3 & 0.44 \\
\hline & 76.2 & $\mathrm{CH}_{4}$ & 0.8 & 1639.9 & 6.68 & 84.3 & 50.8 & 0.47 \\
\hline \multirow{11}{*}{$\begin{array}{l}\text { Matching Tad } \\
\text { and HRR to } \\
\mathrm{CH}_{4} . \Phi=0.7- \\
800 \text { SLPM. } \\
\text { Near blowoff. }\end{array}$} & 50.8 & $\mathrm{CH}_{4}$ & 0.7 & 800 & 7.43 & 36.2 & 48.5 & 0.46 \\
\hline & 50.8 & B1 & 0.76 & 778 & 7.22 & 36.2 & 48.6 & 0.46 \\
\hline & 50.8 & S1 & 0.63 & 878 & 8.14 & 36.2 & 51.0 & 0.43 \\
\hline & 50.8 & $\mathrm{S2}$ & 0.65 & 856 & 7.93 & 36.2 & 52.6 & 0.41 \\
\hline & 50.8 & S3 & 0.66 & 845 & 7.81 & 36.2 & 57.0 & 0.35 \\
\hline & 50.8 & S4 & 0.63 & 869 & 8.05 & 36.2 & 51.2 & 0.43 \\
\hline & 50.8 & 55 & 0.64 & 858 & 7.96 & 36.2 & 52.0 & 0.42 \\
\hline & 50.8 & $\overline{56}$ & 0.66 & 837 & 7.75 & 36.2 & 54.6 & 0.38 \\
\hline & 50.8 & S14 & 0.61 & 871 & 8.07 & 36.2 & 53.7 & 0.40 \\
\hline & 50.8 & S5M50 & 0.69 & 810 & 7.50 & 36.2 & 50.3 & 0.44 \\
\hline & 50.8 & S5M25 & 0.68 & 820 & 7.59 & 36.2 & 50.5 & 0.44 \\
\hline \multirow{11}{*}{$\begin{array}{l}\text { Matching } \mathrm{T}_{\mathrm{ad}} \\
\text { and HRR to } \\
\mathrm{CH}_{4} \cdot \Phi=08 \text { - } \\
800 \text { SLPM. } \\
\text { Near blowoff. }\end{array}$} & 50.8 & $\mathrm{CH}_{4}$ & 0.8 & 800 & 7.41 & 41.2 & 50.2 & 0.44 \\
\hline & 50.8 & $\mathrm{B1}$ & 0.88 & 778 & 7.23 & 41.2 & 50.2 & 0.44 \\
\hline & 50.8 & S1 & 0.75 & 881 & 8.16 & 41.2 & 52.2 & 0.42 \\
\hline & 50.8 & $\mathrm{~S} 2$ & 0.77 & 879 & 8.15 & 41.2 & 54.0 & 0.38 \\
\hline & 50.8 & 53 & 0.78 & 854 & 7.91 & 41.2 & 57.0 & 0.35 \\
\hline & 50.8 & $S 4$ & 0.74 & 874 & 8.10 & 41.2 & 52.5 & 0.41 \\
\hline & 50.8 & S5 & 0.75 & 865 & 8.01 & 41.2 & 54.0 & 0.39 \\
\hline & 50.8 & 56 & 0.77 & 847 & 7.88 & 41.2 & 57.0 & 0.35 \\
\hline & 50.8 & S14 & 0.71 & 884 & 8.18 & 41.2 & 55.5 & 0.37 \\
\hline & 50.8 & S5M50 & 0.79 & 817 & 7.59 & 41.2 & 52.0 & 0.42 \\
\hline & 50.8 & S5M25 & 0.78 & 830 & 7.69 & 41.2 & 53.2 & 0.40 \\
\hline \multirow{9}{*}{$\begin{array}{l}\text { Documentation } \\
\text { of abnormal } \\
\text { LSB operation } \\
\text { near blowoff. } \\
\text { Includes no- } \\
\text { swirl } \\
\text { condition. }\end{array}$} & 50.8 & $\mathrm{CH}_{4}$ & 0.8 & 800 & 7.42 & 41.2 & 35.0 & 0.00 \\
\hline & 50.8 & $\mathrm{CH}_{4}$ & 0.6 & 800 & 7.44 & 31.4 & 35.0 & 0.60 \\
\hline & 38.1 & $\mathrm{CH}_{4}$ & 0.7 & 900 & 15.1 & 40.8 & 42.0 & 0.66 \\
\hline & 38.1 & $\mathrm{CH}_{4}$ & 0.7 & 900 & 15.1 & 40.8 & 49.6 & 0.55 \\
\hline & 38.1 & $\mathrm{CH}_{4}$ & 0.7 & 1000 & 16.7 & 45.2 & 37.5 & 0.72 \\
\hline & 38.1 & $\mathrm{CH}_{4}$ & 0.7 & 1000 & 16.7 & 45.2 & 48.0 & 0.58 \\
\hline & 38.1 & $\mathrm{CH}_{4}$ & 0.65 & 400 & 6.71 & 17.0 & 48.6 & 0.56 \\
\hline & 38.1 & $\mathrm{CH}_{4}$ & 0.65 & 900 & 15.1 & 38.1 & 35.0 & 0.75 \\
\hline & 38.1 & $\mathrm{CH}_{4}$ & 0.65 & 1000 & 16.7 & 42.3 & 33.0 & 0.77 \\
\hline Near blowoff. & 50.8 & B1 & 0.8 & 800 & 7.43 & 39.0 & 47.0 & 0.48 \\
\hline Near blowoff. & 50.8 & $\mathrm{CH}_{4}$ & 0.7 & 1200 & 11.1 & 58.4 & 47.5 & 0.48 \\
\hline Near blowoff. & 38.1 & $\mathrm{CH}_{4}$ & 0.9 & 1000 & 16.7 & 57.1 & 51.0 & 0.53 \\
\hline Near blowoff. & 38.1 & $\mathrm{CH}_{4}$ & 0.9 & 1200 & 20.1 & 68.7 & 50.8 & 0.53 \\
\hline Stable flame. & 38.1 & $\mathrm{CH}_{4}$ & 0.8 & 800 & 13.4 & 37.2 & 39.6 & 0.70 \\
\hline Stable flame. & 50.8 & $\mathrm{CH}_{4}$ & 0.8 & 800 & 7.42 & 41.0 & 35.00 & 0.60 \\
\hline Attached. & 50.8 & S3 & 0.6 & 400 & 3.72 & 16.0 & 53.0 & 0.41 \\
\hline Non-attached. & 50.8 & S1 & 0.6 & 400 & 3.72 & 15.9 & 53.0 & 0.41 \\
\hline
\end{tabular}




\subsubsection{PIV Setup and Calibration}

The PIV measurement equipment was set up as shown in Figure 3.8. The camera off-axis angle $\theta$ was set to $28^{\circ}$ to balance out-of-plane vector errors with uniformity in magnification (Prasad, 2000). Since the two cameras had different resolutions (i.e. the Imager PRO camera had 1600x1200 pixels whereas the Imager Intense camera has $1376 \times 1040$ pixels), the field of view of the larger Imager PRO camera was restricted within the software to only use the corresponding number of pixels (pixels between 112-1488 horizontally and 80-1120 vertically). The Imager PRO camera was used in the forward scattering position (Camera 1 in Figure 3.8) since its quantum efficiency was lower, and the intensity of forward scattered light is stronger. The more sensitive (higher quantum efficiency) Imager Intense camera was used in the lower intensity backward scattering position (Camera 2 in Figure 3.8). Positioning the cameras in this way helped to balance the recorded intensities between the two cameras.

\section{PIV Spatial Calibration}

The cameras were then calibrated using a staggered grid target (a \#20 calibration plate provided by LaVision) using the procedures specified within the La Vision software (DaVis, version 7.2). The calibration plate was mounted to the midplane of the burner exit nozzle. Prior to each calibration, all of the following conditions had to be met:

- the images from both cameras were in focus over the full range of the calibration plate (i.e. the Scheimpflug mount, camera angles, and lens focus were all optimally adjusted);

- the light sheet was aligned to be parallel to the calibration plate; and

- the calibration plate covered the full FOV.

Each camera then acquired images of the calibration plate, and the cameras were re-positioned as necessary and the process repeated so that the middle of the calibration plate was aligned in both camera images. The software could then 
spatially correct (calibrate) the images by mapping the images of the dots on the calibration plate from one camera to the other to obtain an accurate pixel by pixel mapping. The software automatically identified the calibration dots in the image. The software manual suggests that if 20-30 dots are found the calibration should be adequate (LaVision, 2010). For these experiments approximately 70 dots were found in each image.

The software then fitted a dewarping mapping function to the identified dots. A pinhole or polynomial calibration function could be used, and for these experiments a pinhole was selected to be able to use the self-calibration function necessary for stereoscopic PIV as described below. The average deviation of the dewarped mark positions was obtained after the function fitting. A value lower than one pixel is considered reasonably accurate (LaVision, 2010), while all experiments in this study had a value of lower than 0.5 pixels, and most had a value lower than 0.3 pixels. For validation, the final step showed the dewarped images overlayed on each other, and if all the marks from both images coincided, the calibration was accepted. If not, the above procedure was repeated until the spatial calibration was improved to an acceptable level. After this spatial calibration, actual data sets were obtained as described below.

As described previously, for each condition a portion of the main air flow was diverted to the seeders, and the amount of air required for a given seeding density changed based on the amount of particles in the seeders. Seeding density was adjusted along with the laser power and camera lens aperture $(f \#)$ to provide both adequate seeding for cross-correlation (up to a certain point, more seeding is considered better), and an optimal signal to noise ratio without saturating the pixels in the cameras. The $f \#$ 's were also constrained in that they had to be high enough to ensure that the depth of field was sufficient that the entire laser sheet thickness remain in focus.

As part of the standard calibration procedure, once a data set was taken a final calibration step, known as the PIV self-calibration, was performed. The purpose of this self-calibration was to align the plane $\mathrm{z}=0 \mathrm{~mm}$ exactly to the middle of the laser light sheet since during the spatial calibration the laser light sheet would never be 
exactly aligned with the calibration plate. This calibration worked under the assumption that the images taken at the same time by Camera 1 and Camera 2 should contain identical information after the spatial image correction had been applied. Any discrepancies were determined and corrected using the built-in Stereo PIV self-calibration wizard. Further details of the procedure are described in the DaVis software manual (LaVision, 2010).

\section{PIV Experimental Parameters}

Adjustment of the interframe time, $d t$, between images was critical. Shorter interframe times increased the correlation strength when calculating velocity vectors at the expense of reduced accuracy (a result of quantifying smaller displacements relative to a pixel displacement measurement resolution of $\sim 0.2$ pixels). To keep displacement uncertainties to below $5 \%$, the minimum particle displacement in the high-velocity regions of the flame had to be 4 pixels. This put a lower limit on the displacement time.

After several iterations, the $f \#$ was set to 16 for Camera 1 and to 11 for Camera 2 for the chosen seeding density with a laser power of $400 / 1000$ on the high setting. Though the seeding density could not be measured quantitatively, the seeding density was qualitatively altered until correlation strength was high in both the reactant and product zone of the LSB flames, which due to the extreme density gradients present, required a compromise between vectors obtained in both regions. An example of adequate seeding is shown in Figure 3.13, from a measurement with methane fuel on the $50.8 \mathrm{~mm}$ nozzle at $\Phi=0.8$ at a total flow rate of 800 SLPM. This sample case will be used as an example for the rest of this discussion. The PIV settings were generally held constant for all data sets, and the interframe time was chosen for each individual flow condition to be low enough so that a good amount of vectors were obtained from the correlation, but also high enough that the displacement of the particles in the high velocity regions was at least 4 pixels as explained above. For the highest velocity flows (high flow rates with the $38.1 \mathrm{~mm}$ nozzle), interframe times were as low as $25 \mu \mathrm{s}$, and for the lowest 
velocity flows (lower flow rates with the $50.8 \mathrm{~mm}$ nozzle, and most conditions with the $76.2 \mathrm{~mm}$ nozzle), the interframe times were as high as $100 \mu \mathrm{s}$.

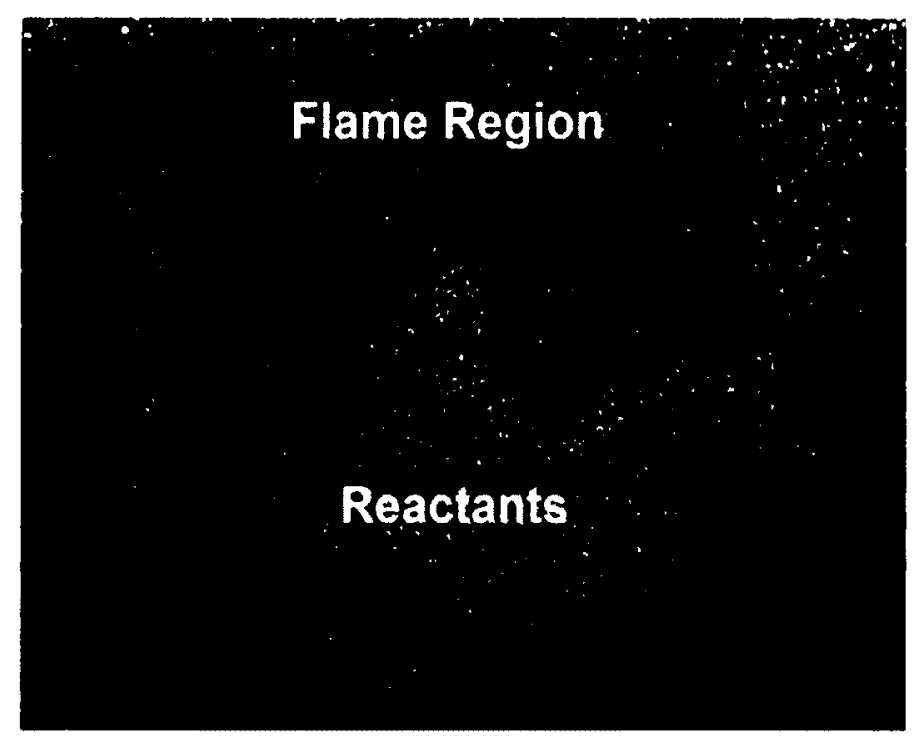

Figure 3.13: Example of adequate PIV seeding for this study

\section{PIV Image Processing}

Prior to calculating PIV velocity vectors, a built-in LaVision particle intensity normalization preprocessing algorithm was applied. This algorithm was necessary to improve correlation statistics since the seeding particles had a broader range of particle sizes than expected, which created an inhomogeneous intensity distribution in the raw images. The procedure involved determining the maximum and minimum intensity on a local window of specified pixel dimension. Preliminary results were obtained on 20 image sets for several flow conditions, and it was determined that use of a three-pixel window for the intensity normalization calculation led to the most vectors.

The procedure for normalizing the particle intensities began by extracting a sliding minimum over a three-pixel wide window from the entire image. This sliding minimum result was then subtracted from the original image to remove the local background intensity level. This result was denoted as result0. Afterwards, a sliding maximum over the same 3-pixel scale length was computed and denoted as 
result1. Another sliding maximum was computed over a window of 30 pixels $(10 \mathrm{x}<$ scale length $>)$ and was stored as result 2 . The ratio of local to global maximum was then calculated as result $3=$ result $2 /$ result 1 . The final result, the normalized image, was then computed by multiplying result0 (the raw image minus the background) by result3 (the ratio of local to global maximum). This created an image very similar to the original, but with much more homogeneous particle intensities so that smaller particles contributed to the correlation on an equal level with the larger particles. This algorithm did not change the results as it only manipulated the particle intensity, and not the particle position. Figure 3.14 compares a corresponding raw and normalized image for the same example conditions as above.

a)

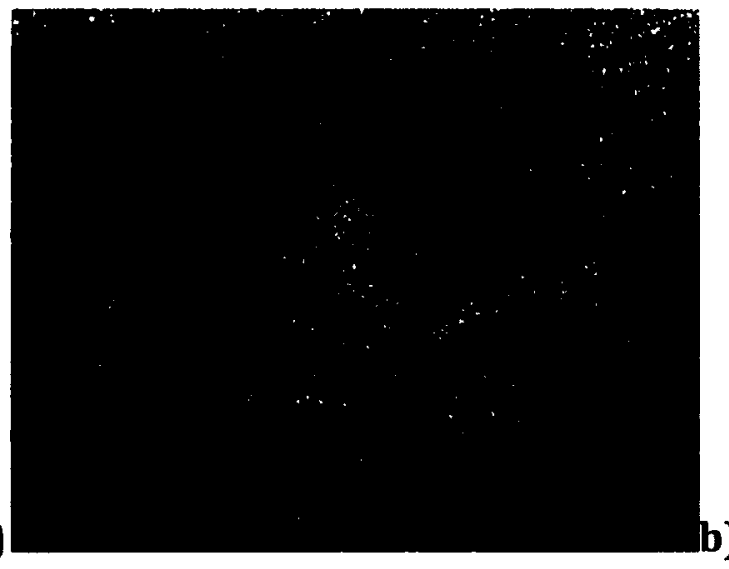

Figure 3.14: Example of particle image normalization preprocessing algorithm a) Raw image b) Result

After the preprocessing step, the vector calculation would begin. The vector calculation consisted of a stereo-cross correlation algorithm, which detected particle motion from each camera to produce the vector components in the plane of the FOV. The correlations from each camera were then used to get the out of plane velocity component based on the calibration. Specific vector calculation parameters consisted of a multipass correlation of decreasing window size. The first two passes used interrogation windows of $64 \times 64$ pixels with $50 \%$ overlap, while the second two passes used interrogation windows of $32 \times 32$ pixels with $50 \%$ overlap. This resulted in a vector field with 16 pixel resolution (equivalent to approximately 
$0.16 \mathrm{~mm}$ in the flame region). To ensure that the fewest particles were lost out of the interrogation windows, for each of these two-pass correlations the initial pass searched $1 / 2$ of the interrogation window size in all directions from the centre between the first and second frame from each respective camera. An approximate velocity vector was then returned. On the second pass for the first frame the interrogation window would shift to where more particles would presumably be found from the initial velocity gradient estimation, and for the second frame would shift and deform to where the particles were predicted to go based on the same initial guess at the velocity vector. This pixel-wise translation and deformation was performed on the entire image, and then applied to each interrogation window as necessary. This tended to result in a stronger, more symmetric correlation peak in flows with high shear. For this reason, the velocity gradient bias error $\left(\mathrm{e}_{8}\right)$ discussed in Appendix D was neglected.

The first two passes used a square interrogation 'window weight'. This means that all pixels within the interrogation window contributed equally to the correlation. The $32 \times 32$ pixel passes used a Gaussian 2:1 elliptical weighting function in the axial direction to improve results. With the Gaussian weighting function, a square interrogation window twice the size of the specified window size (in this case it was $64 \times 64$ pixels) was used for the calculation, but the pixels were weighted such that the integral of all weighted pixels was equivalent to the specified interrogation window (Lavision, 2010). The 2:1 Gaussian weighting function was deemed necessary in the present work even at the cost of a much higher calculation time because of the high velocity gradients in the radial directly.

For each of the intermediate vector calculation passes, there was a mandatory multipass postprocessing algorithm applied to the intermediate vector fields (LaVision, 2010). This involved a 4-step median filter where in the first step vectors were removed if their difference to the median of the surround 8 vectors was greater than $2.5 \mathrm{x}$ the RMS of the eight surrounding vectors. The second step eliminated all vectors with an insufficient number of remaining neighbor vectors (generally the minimum number is three). After these two steps, most questionable vectors were removed. Leftover at this point were only those vectors that satisfied 
the median criteria and were surrounded by a good number of neighbouring vectors. For the third step, the program then recomputed the deviation of the surrounding vectors and re-inserted vectors that fell within $2.5 \mathrm{x}$ the RMS of the surrounding vectors (at that point generally less than eight, but not always). The program would not only look at the vector with the highest correlation peak, but also at the second, third, or fourth highest correlation peaks and selected the first one that fell within the median criteria. The fourth and final pass rejected any interrogation window's group of vectors if there was less than five. This algorithm was known to be very successful in removing spurious vectors from the final vector fields of each of the vector calculation passes.

After the multipass postprocessing, the final vector field also underwent the same median filter algorithm as described above. The final result was accepted as the instantaneous vector field. To obtain the mean fields, the average at each interrogation window was calculated with a minimum of 800 vectors used in the calculation at each location. If fewer than 800 vectors were present at a given location from the 2000 image data set, that location was left blank in the final mean fields. To obtain turbulence statistics, an in-house code created in MATLAB was used to read the instantaneous vector fields and determine the average velocities, velocity fluctuations, the RMS of the fluctuations, turbulence intensity, and the integral length scales in the axial, radial, and tangential directions (See Appendix E). An example of an instantaneous vector field (using same example data set as above) is shown in Figure 3.15, where the arrows represent the vectors in the laser sheet plane, the colour contour represents the tangential velocity component, and the black lines are streamlines.

\section{Convergence Testing of PIV Results}

For each PIV condition as outlined in Table 3.4, 2000 image pairs were acquired providing 2000 instantaneous vector fields. This amount was chosen following a convergence study based on the axial velocity statistics, as shown in Figure 3.16. In this figure, the axial velocity component $\left(U_{\text {mean }}\right)$, the RMS value of the fluctuating axial velocity $\left(u_{R M S}^{\prime}\right)$, and the axial integral length scale $\left(\delta_{u u}\right.$, see description on 
turbulence statistics below) were extracted at three points for two different flow conditions. These points were the left and right lowest position in the " $\mathrm{W}$ " shaped flame (known as the anchor points), and the position of minimum axial velocity along the centerline (see Section 2.2). Figure 3.16a and $b$ show that a data set of more than 1000 images was sufficient to obtain convergence within 5\% (note that the artificially large apparent uncertainty in the centerline mean velocity measurement (circles) in Figure 3.16a is an artefact of dividing by near-zero mean velocities). Figure 3.16c suggests that 2000 images should be just adequate to ensure convergence on the more challenging length scale calculation to within $5 \%$ or better.

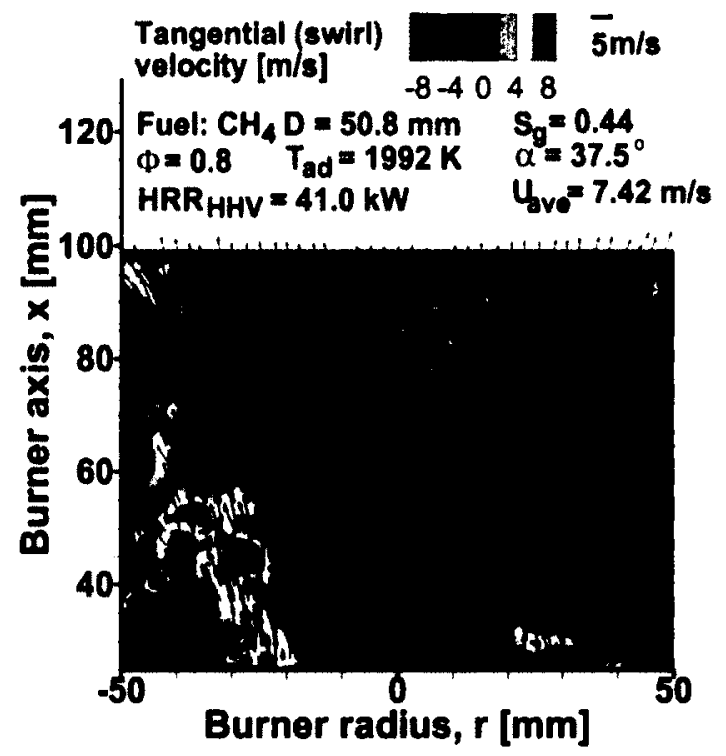

Figure 3.15: Example of instantaneous velocity field from stereo-PIV measurement 

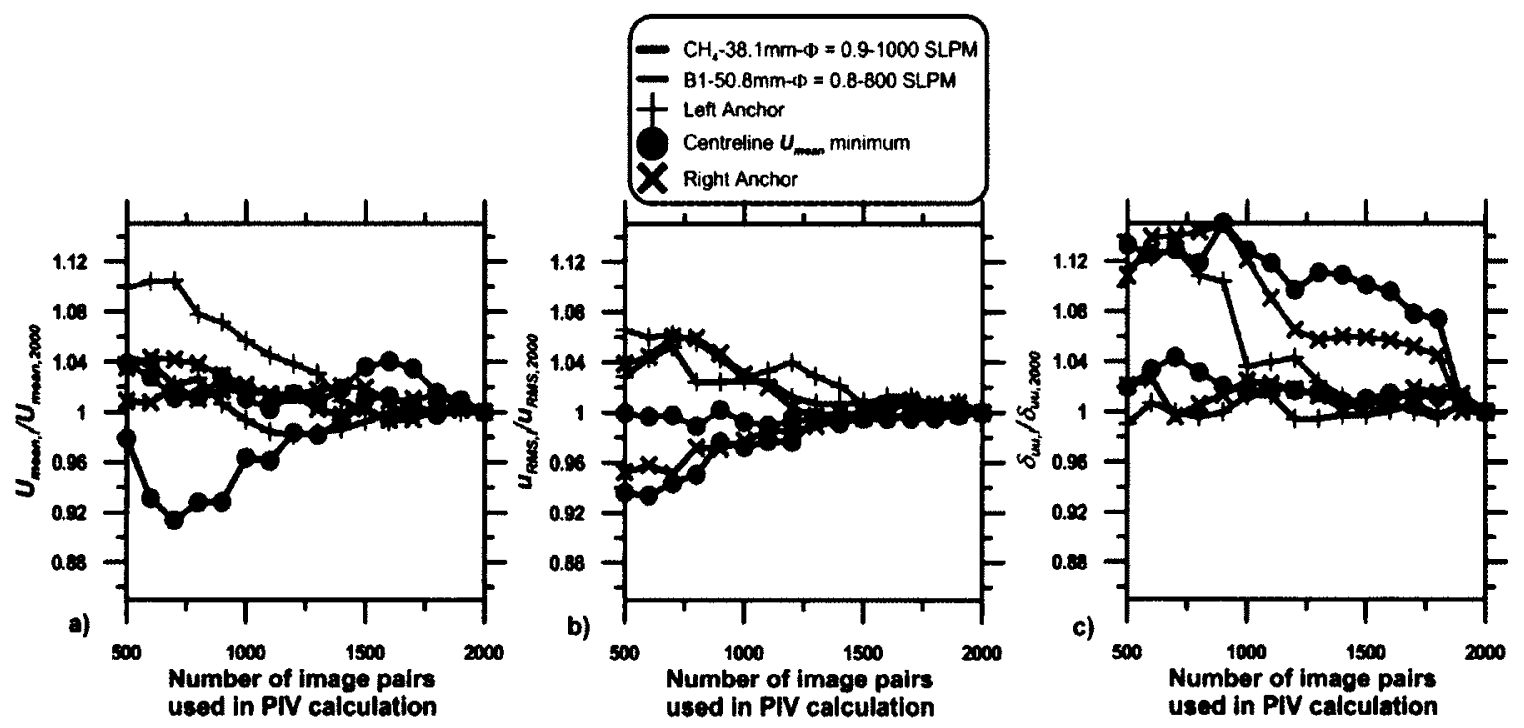

Figure 3.16: PIV vector convergence for a) $U_{\text {mean }}$ b) $u_{R M S}^{\prime}$ c) $\delta_{u u}$

\section{Determination of Flame-front Position}

The instantaneous and mean flame front position was determined based on gradients in seeding density as calculated using image processing tools within the Davis 7.2 software (LaVision, 2010). The first raw image from Camera 1 was extracted from each image set, and was spatially corrected using the active calibration (a sample image is shown in Figure 3.17a). To smooth out the brightness from the seeding particles and produce a more obvious distinction between the flame and reactant regions, a $7 \times 7$ pixel smoothing linear filter followed by a sliding maximum non-linear filter with a 10 pixel scale length were applied to the images. A sample of the result at this point is shown in Figure 3.17b. 

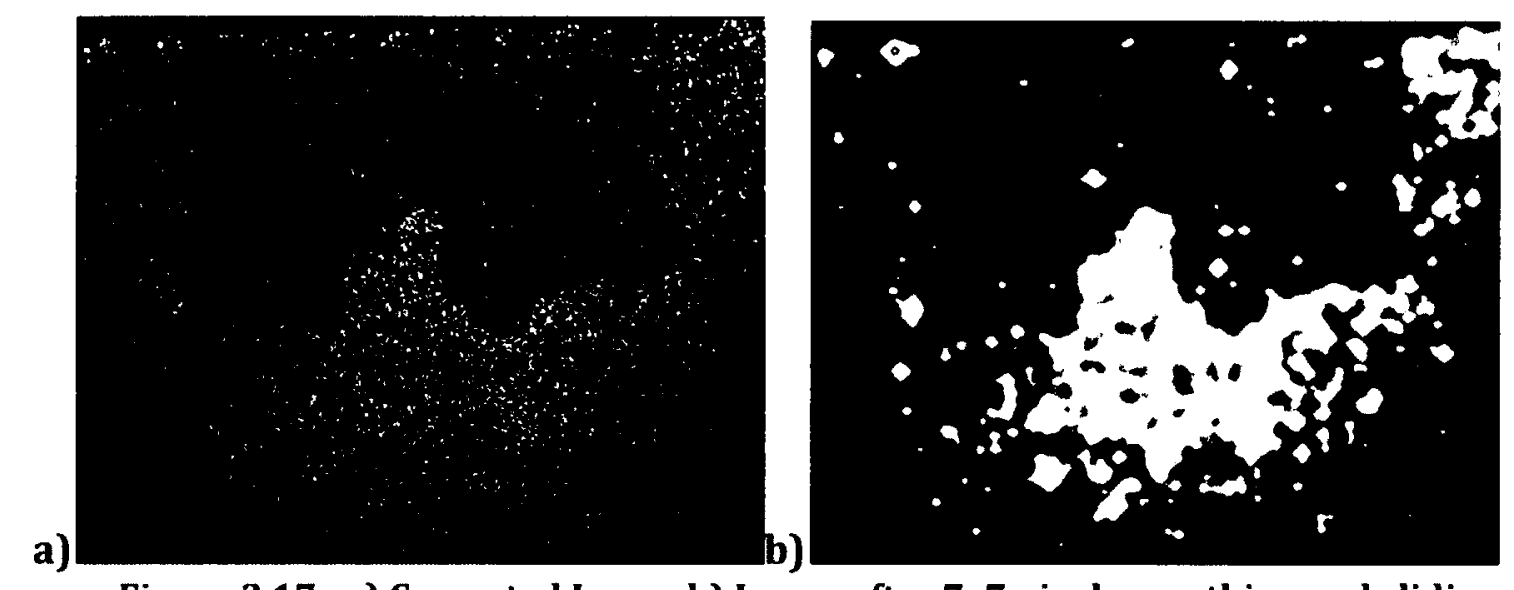

Figure 3.17: a) Corrected Image b) Image after 7x7 pixel smoothing and sliding maximum

The mean brightness of the filtered images was then calculated and subtracted using a user-defined function developed in Davis. This user-defined function first determines the mean pixel intensity of the image. This mean intensity is then subtracted from each pixel so that only the brightest pixels with higher than average intensities remain. Figure 3.18a shows a sample result after this step. A binary threshold was then applied to the image so that pixels with intensity values less than 10 counts were levelled to zero, and pixels with intensities above 10 counts were raised to 255. As shown in Figure 3.18b, this produces an image for each of the 2000 data sets where high-density seeding areas (reactants) have a value of 255 , and low-density seeding areas (flame region, and unseeded regions) have a value of 0 . These 2000 binarized images were then ensemble averaged to produce a single 8-bit greyscale image. This greyscale image was then binarized with pixels receiving values of 0 or 1 depending on the median threshold value of 127 counts. As shown in Figure 3.19a, this procedure clearly separates the flame and reactant regions with a distinct edge. A Laplace edge detection algorithm was then applied to extract this edge to produce a result as shown in Figure 3.19b. False flame fronts along the sides of the image are produced at the boundary between the seeded reactants and unseeded environment. Similarly, along the bottom of the image the boundary of the laser sheet near the burner exit appears as a false flame front. Edges detected by the algorithm in these regions were not due to the presence of the flame. The top edge of Figure $3.18 \mathrm{~b}$ is the actual flame front. The unedited flame 
fronts were then manually edited to remove residual false flame fronts at the edges (i.e. just above the nozzle exit and at the outer edges of the flow).
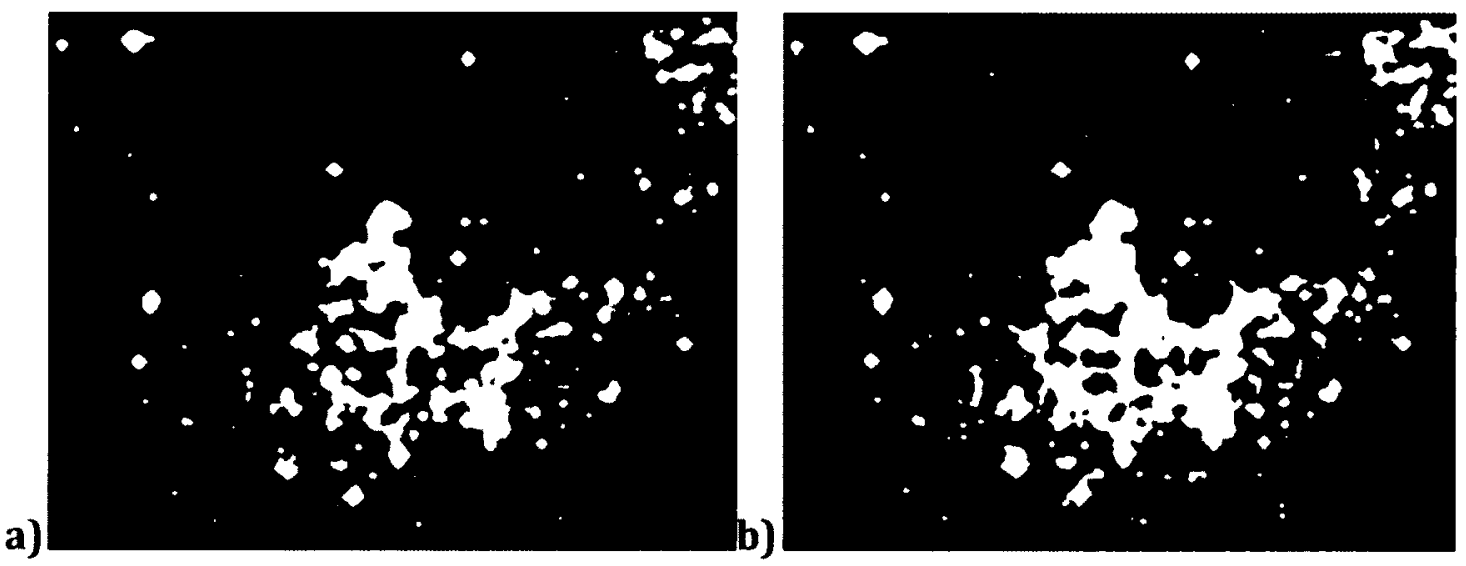

Figure 3.18: a) Image after user-defined function subtracts mean of image b) Image after counts changed depending on a threshold of 127 counts where counts above 127 were set to 255 and counts below 127 were set to 0 .
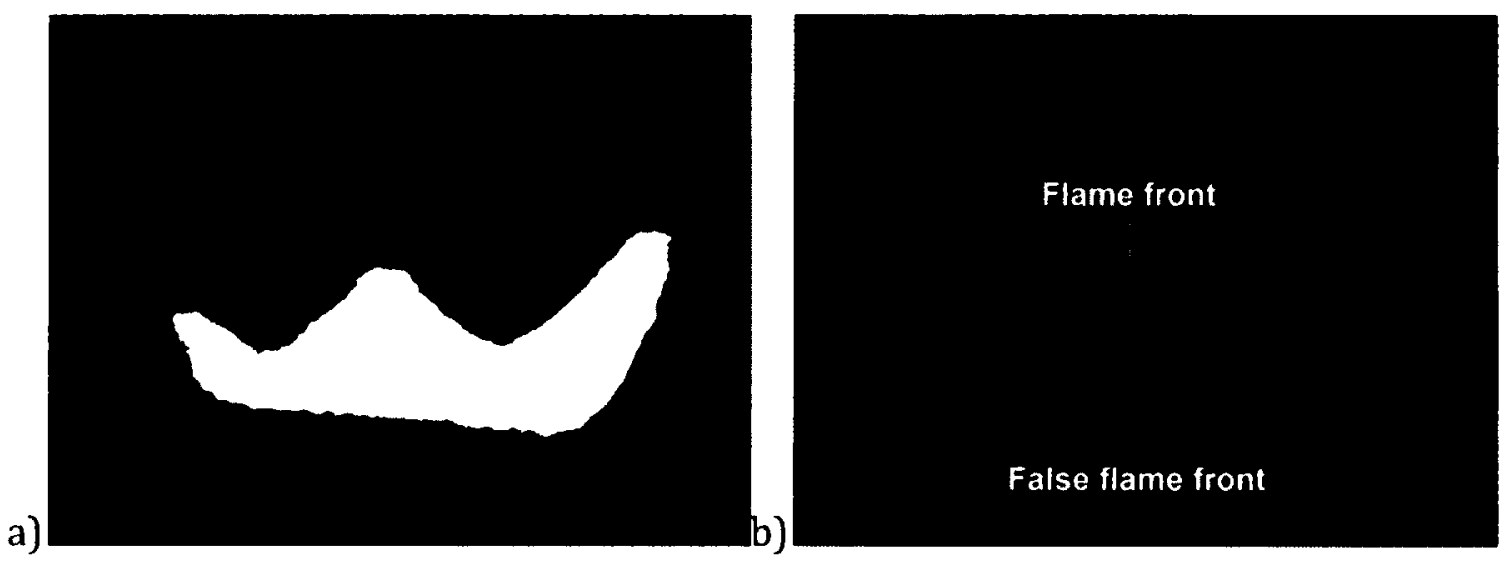

Figure 3.19: a) Ensemble averaged binarized image b) Mean flame front with false flame fronts

Figure: 3.20 shows a sample final post-processed mean velocity field with the superimposed mean flame front contour. The $\mathrm{W}$-shaped flame front is shown in magenta, and the black lines are streamlines. Only every second velocity vector is shown in the plot for visual clarity. The thick black lines in the plot are streamlines. 


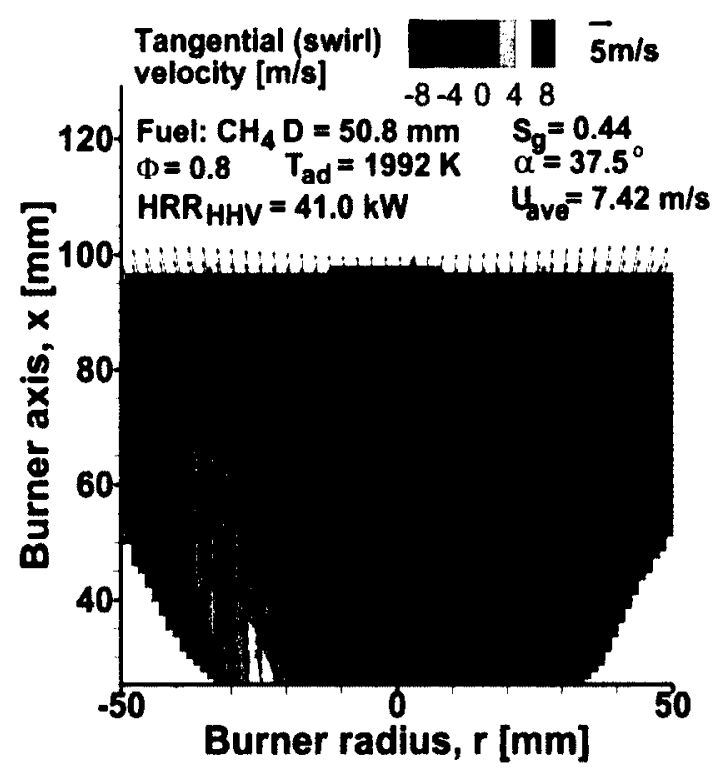

Figure: 3.20 Mean flow field with edited flame front contour

\subsubsection{Uncertainty in PIV Measurements}

Great care was taken to minimize the intrusiveness of the PIV measurements by blasting clean air through the burner in an effort to reduce the amount of seed sticking to the sides and to the lead shot. However, due to the time-consuming nature of taking 2000 image sets at a time, the seeding had an inevitable tendency to build-up along the interior walls of the burner and in between the lead shot in the base of the burner. This could induce an asymmetric flame front at times which is apparent in some of the data. The asymmetries were more obvious with the larger diameter nozzles, especially the $76.2 \mathrm{~mm}$ nozzle (consistent with the low exit velocities of the experiments). Also, potentially due to the propensity for attachment to the burner nozzle, the fuel mixtures with higher amounts of hydrogen appeared more asymmetric since these flames may have been close to attachment (if not attached already), and therefore were more sensitive to flowfield asymmetries. These asymmetries were considered an inevitable limit of the PIV measurement technique in this application such that the measurements could not truly be regarded as non-intrusive. However, the effects on the data included in this thesis were deemed to be negligible within the context of overall PIV measurement 
uncertainties. For the vectors obtained, as outlined in Appendix D, the highest velocity vectors can be assumed to have an uncertainty of approximately $7.5 \%$ of their magnitude (e.g. typical values in the range of $8.0 \pm 0.6 \mathrm{~m} / \mathrm{s}$ ). The absolute uncertainty on a velocity measurement of $0 \mathrm{~m} / \mathrm{s}$ would be approximately $\pm 0.37 \mathrm{~m} / \mathrm{s}$. 


\section{Static stability point measurements}

\subsection{Stability Maps}

Maps of blowoff and flashback limits as a function of swirl number(calculated using Eq. (2.4)), equivalence ratio, and heat-release rate were obtained as described in Table 3.3. Experiments were performed first using methane as a reference fuel, prior to considering more complex fuel mixtures. The total flow rate was held constant in the range of 400 to 1200 SLPM during most experiments (i.e. for a given fuel type, geometry, and equivalence ratio combination), although some higher flow rate experiments were run using the $76.2 \mathrm{~mm}$ nozzle. To determine blowoff limits, the swirl number (via the $\% I F F$ ) was varied at a fixed $\Phi$ (and thus fixed $T_{a d}$ ) to isolate variables. The flammability-limited lean blow off was thus not specifically encountered; if it was not possible to stabilize or ignite a flame due to inflammability, the measurement was not taken. In this manner, blowoff or flashback limit curves were created by manipulating aerodynamic flowfield properties while reactant chemistry was held constant. All measurements were at lean conditions $(\Phi<1)$ such that increasing $\Phi$ had the effect of increasing $T_{a d}$.

\subsubsection{Geometric study with reference fuel of methane}

As illustrated in Figure 4.1, when results are plotted in heat release rate equivalence ratio - swirl number space, a unique stability 'volume' exists for every fuel and LSB geometry combination. Figure 4.1 shows the stability volume for methane fuel on the $50.8 \mathrm{~mm}$ burner. Similar volumes can be plotted by substituting the adiabatic temperature for the equivalence ratio (as shown in subsequent plots). The colour of the surfaces of the stability volumes scales from black to yellow with the heat release rate calculated using the higher heating value of the fuel mixture $\left(H H R_{H H V}\right)$. Blowoff is represented by the surfaces on the left (at lower swirl numbers) while flashback is represented by the surfaces on the right (higher swirl numbers). 
A first general observation is that the LSB is capable of stable operation at leanpremixed conditions over a significant turndown ratio (defined as the ratio of the maximum to minimum stable heat release rate at constant $\Phi$ ). The total flowrates range from $Q_{\text {tot }}=400-1200$ SLPM from $\Phi=0.6-1.0$ showing significant flexibility in operating conditions. These experiments produced stable flames at a heat release rate based on the higher heating value $\left(H R R_{H H V}\right)$ as high as $75.2 \mathrm{~kW}$ and as low as $15.7 \mathrm{~kW}$. All blowoff and flashback surfaces show a basic trend of decreasing swirl number with decreasing flow rate (and thus heat release rate), and increasing $\Phi$. In general, increasing $\Phi$ (and thus $T_{a d}$ ) makes the flame harder to blowoff, but easier to flashback, which means that both blowoff and flashback occur at lower swirl numbers. Increasing the flow rate (at a fixed $\Phi$ / fixed $T_{a d}$ ) has the opposite effect making it easier for the flame to blowoff, but harder to flashback, which means that both blowoff and flashback occur at higher swirl numbers. However, there are obvious deviations from this trend which are discussed further below. For the $50.8 \mathrm{~mm}$ LSB burner fueled by methane as shown in Figure 4.1, flashback did not occur at $\Phi=0.6$. For all the stability volume plots, the colours on the surfaces scale from red to yellow with the heat release rate, and the vertices on the surfaces are the actual measured points.

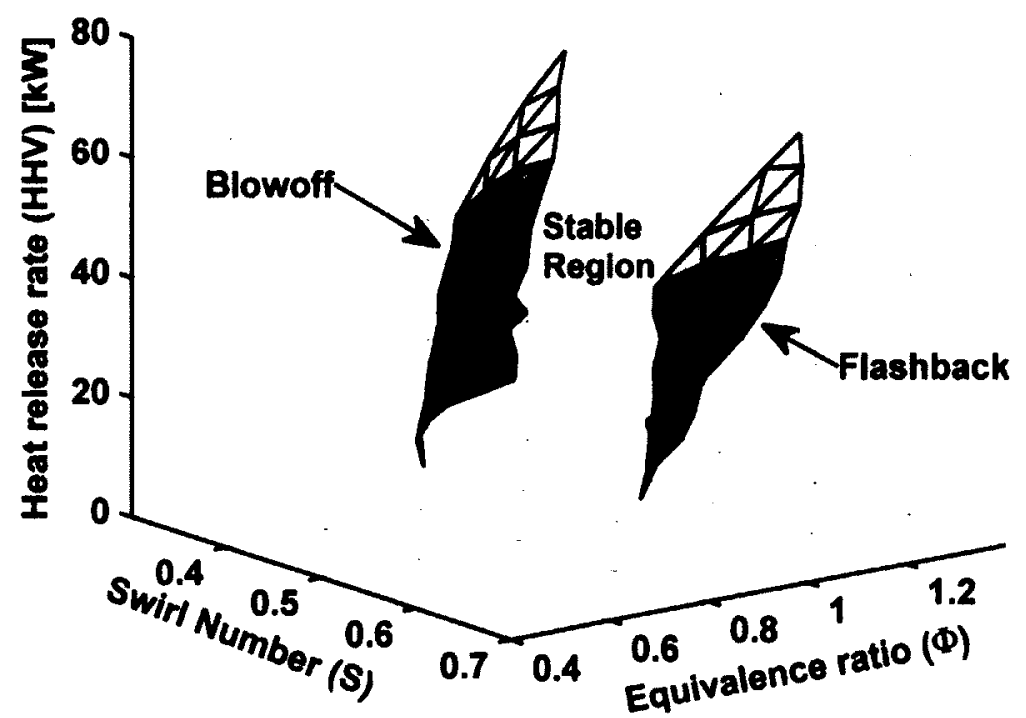

Figure 4.1: Stability volume plotted with $\Phi$ for methane fuel on $50.8 \mathrm{~mm}$ nozzle 
Figure 4.2 shows the same stability volume as Figure 4.1, plotted versus $T_{a d}$ instead of equivalence ratio. For any one fuel, the two versions of the plot are equivalent. In the context of thermally dependent NOx formation, to facilitate comparisons among different fuels, $T_{a d}$ was determined to be a more illustrative variable than $\Phi$, since most industrial applications have designs based on flame temperature, and equivalence ratios near the lean flammability limits for different fuels vary widely (e.g. approximately 0.50 for $\mathrm{CH}_{4} ; 0.10$ for $\mathrm{H}_{2} ; 0.34$ for $\mathrm{CO}$ at standard conditions (Kuo, 2005)). The blowoff surface shows a sharp discontinuity toward the 'front' of the plot, where $T_{a d}=1660 \mathrm{~K}(\Phi=0.6)$. At this flame temperature, blowoff occurs at a much higher swirl number, deviating from the trend from the higher flame temperatures. This trend is more clearly illustrated in Figure 4.3 which shows 2D slices of Figure 4.2 at various fixed $\Phi$. It is obvious in this plot that the higher flowrates show different behavior at $\Phi=0.6$ than at higher equivalence ratios. Blowoff points at the lower flowrates at $\Phi=0.6$ start off in the same linear way as the higher $\Phi$ curves, but at the higher flowrates, blowoff occurs at much higher swirl numbers than the trends from the other curves would suggest. 2D plots similar to Figure 4.3 for all stability volumes presented are in Appendix G.

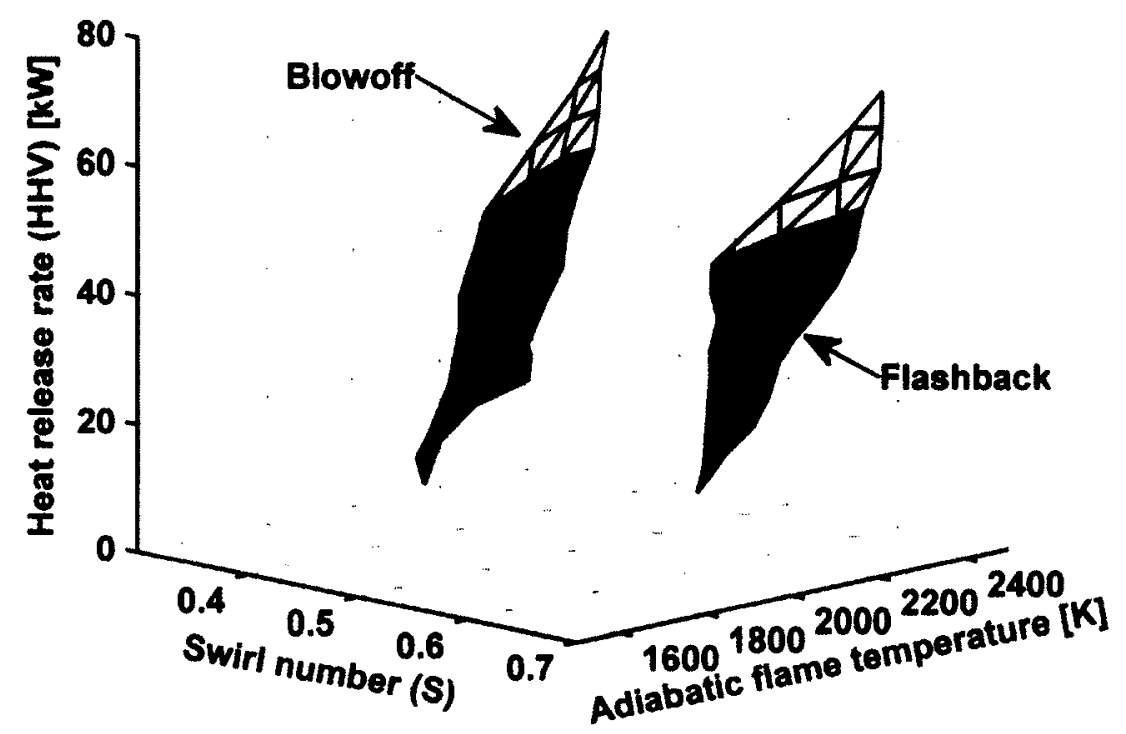

Figure 4.2: Stability volumes plotted with $T_{a d}$ for methane fuel with $50.8 \mathrm{~mm}$ nozzle 


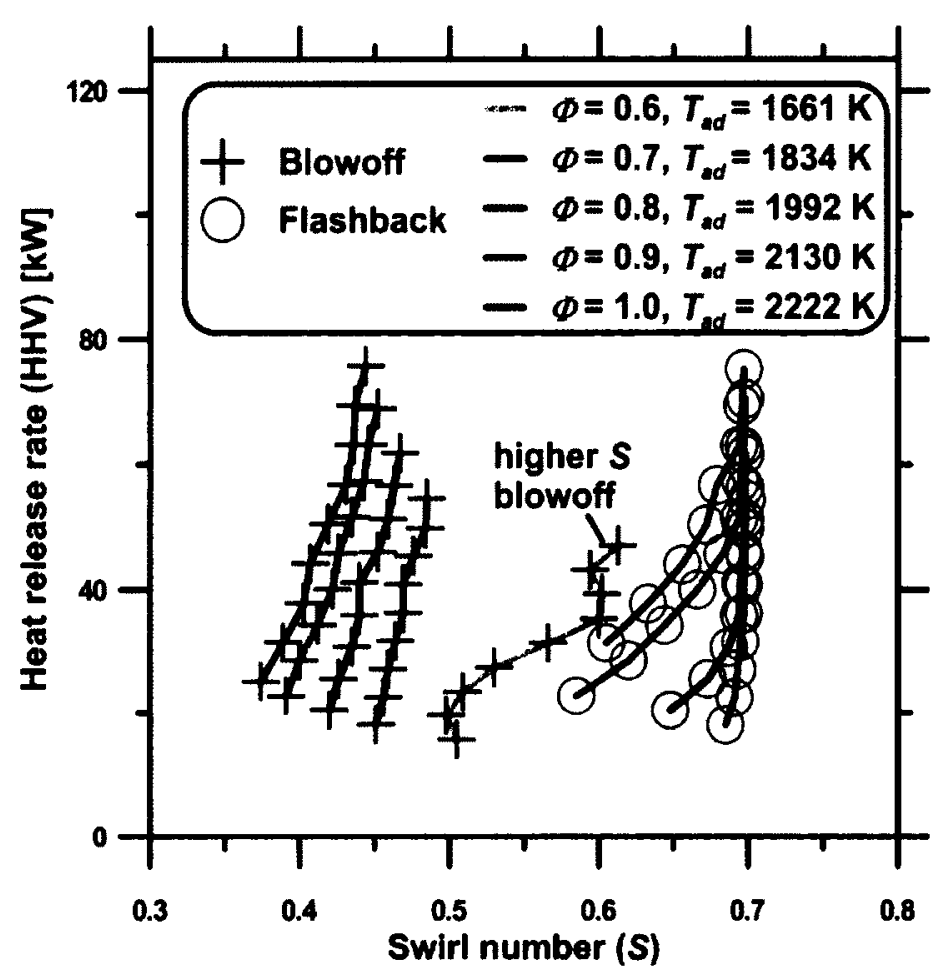

Figure 4.3: Blowoff and flashback curves for methane fuel with $50.8 \mathrm{~mm}$ nozzle

Figure 4.4 shows the stability volumes for methane fuel on the $38.1 \mathrm{~mm}$ nozzle. Due to the high velocities with the $38.1 \mathrm{~mm}$ nozzle geometry, flames could not be stabilized at $\Phi=0.6$, and flashback did not occur at any $\Phi=<0.9$. However, recognizing that for some practical applications the transition from a fully lifted flame to a flame where the leading edge sat stably below the exit plane of the burner (i.e. 'in burner') may be of interest, these points were documented and plotted as a separate surface.

There is a sharp discontinuity on the blowoff surface at the lowest $T_{a d}$ $\left(T_{a d}<1830 \mathrm{~K}, \Phi<0.7\right)$. At higher heat release rates (and correspondingly higher total flow rates and velocities), for $\Phi=0.65$ and 0.7 as the swirl number was lowered, blowoff occurred at higher swirl numbers than what would be predicted from the trend at the lower flow rates. This higher swirl number blowoff (labeled as 'R-type' blowoff due to the role of recirculation in stabilization to be discussed later) was not observed at any flow rate at the higher flame temperatures $(\Phi \geq 0.8)$. At $(\Phi=0.7)$, the flame could be relit at a lower swirl number than that of this first blowoff point, and the swirl number could be lowered further until a second blowoff point was reached at a lower swirl number. This second blowoff point followed the 
linear trends of the blowoff curves from the higher $\phi^{\prime}$ 's. The lower swirl number blowoff points were labeled as 'W-type' blowoff based in part on the shape of the flame front as discussed later in this Chapter.

At the lowest flame temperature $(\Phi=0.65)$ for higher flow rates, the higher swirl number blowoff (R-type blowoff) occurred but the flame could not be relit at the lower swirl numbers to go on to the second blowoff point. This means that at the higher flowrates for $\Phi=0.65$, there was only R-type blowoff, and no secondary W-type blowoff. This phenomenon is more easily seen in Figure 4.5, which shows blowoff curves at various constant $\Phi$. For both the 38.1 and $50.8 \mathrm{~mm}$ nozzles, much higher swirl numbers are required to stabilize the leanest mixtures at the higher flow rates (compared to the trends for richer mixtures / higher flame temperatures). Relative to the $38.1 \mathrm{~mm}$ nozzle, the R-type blowoff phenomenon on the $50.8 \mathrm{~mm}$ nozzle occurred at leaner mixtures with lower adiabatic temperatures ( $1830 \mathrm{~K}, \Phi=0.7$ for the $38.1 \mathrm{~mm}$ nozzle; $1660 \mathrm{~K}, \Phi=0.6$ for the $50.8 \mathrm{~mm}$ nozzle). The highest flow rate (1200 SLPM) on the $50.8 \mathrm{~mm}$ nozzle produced an average flow velocity ( $U_{\text {ave }}$, volume flow rate over total area) of $11.3 \mathrm{~m} / \mathrm{s}$ while the $38.1 \mathrm{~mm}$ burner produced $20.1 \mathrm{~m} / \mathrm{s}$. Thus, the occurrence of R-type blowoff at higher $\Phi$ on the $38.1 \mathrm{~mm}$ burner could be related to the higher flow velocities.

Figure 4.6 shows the stability volume for methane fuel with the $76.2 \mathrm{~mm}$ LSB nozzle. The blowoff trends are constant, but there is a sharp discontinuity in the flashback curve at flame temperatures above $T_{a d}=1990 \mathrm{~K}(\Phi=0.8)$. Note that for clarity the $T_{a d}$ axis is plotted in reverse for this figure. The discontinuity is most apparent at the lower flowrates where at heat release rates below approximately $45 \mathrm{~kW}$ with $\Phi>0.8\left(T_{a d}>1990 \mathrm{~K}\right)$, the flashback points and blowoff points occur in the same range of swirl numbers. The combination of richer mixture and low exit velocity produces a flame which, when lit, flashes back very easily due to the high flammability and low resistance to the flame's propagation. This same flame, however, is also close to the blowoff point and is only stable over a small range of swirl numbers. As an example, at $\Phi=0.9, H R R_{H H V}=28.7 \mathrm{~kW}$, blowoff occurred at 
$S=0.26$ and flashback at $S=0.28$. At a lower $\Phi=0.8$ and at a higher

$H R R_{H H V}=51.5 \mathrm{~kW}$, blowoff occurred at $S=0.43$ and flashback at $S=0.70$.

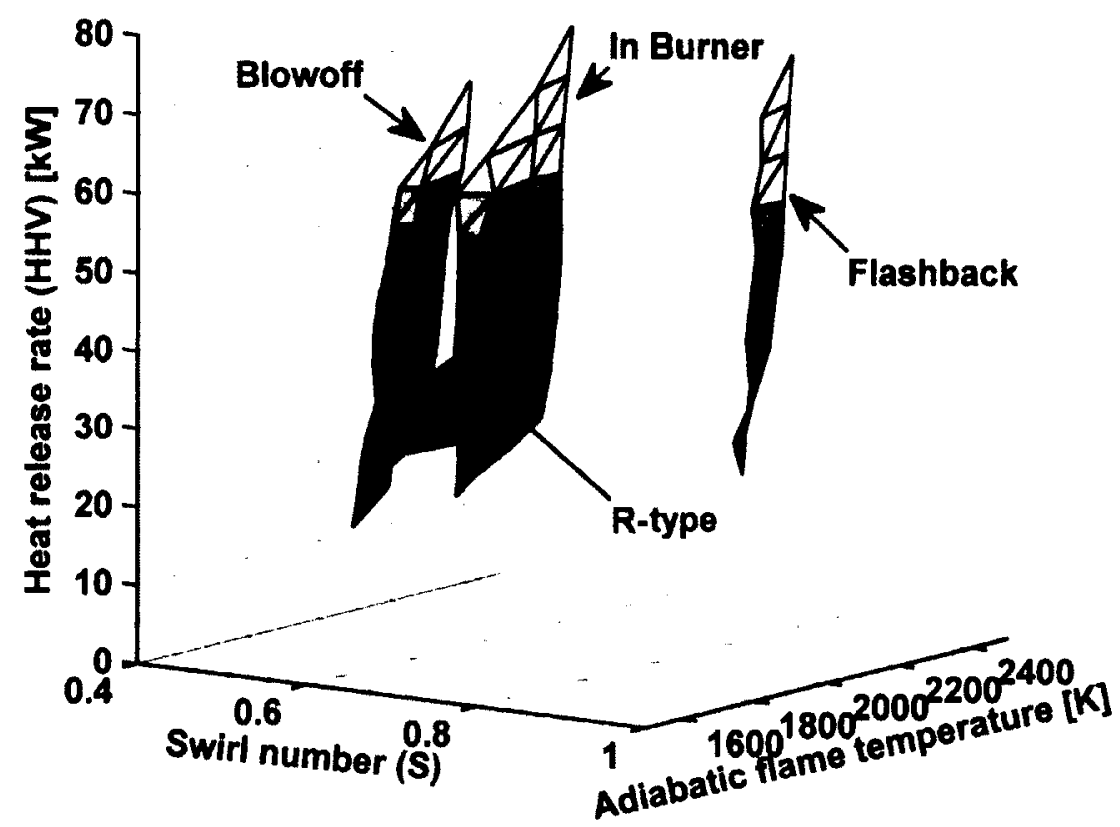

Figure 4.4: Stability volume for methane fuel on $38.1 \mathrm{~mm}$ nozzle

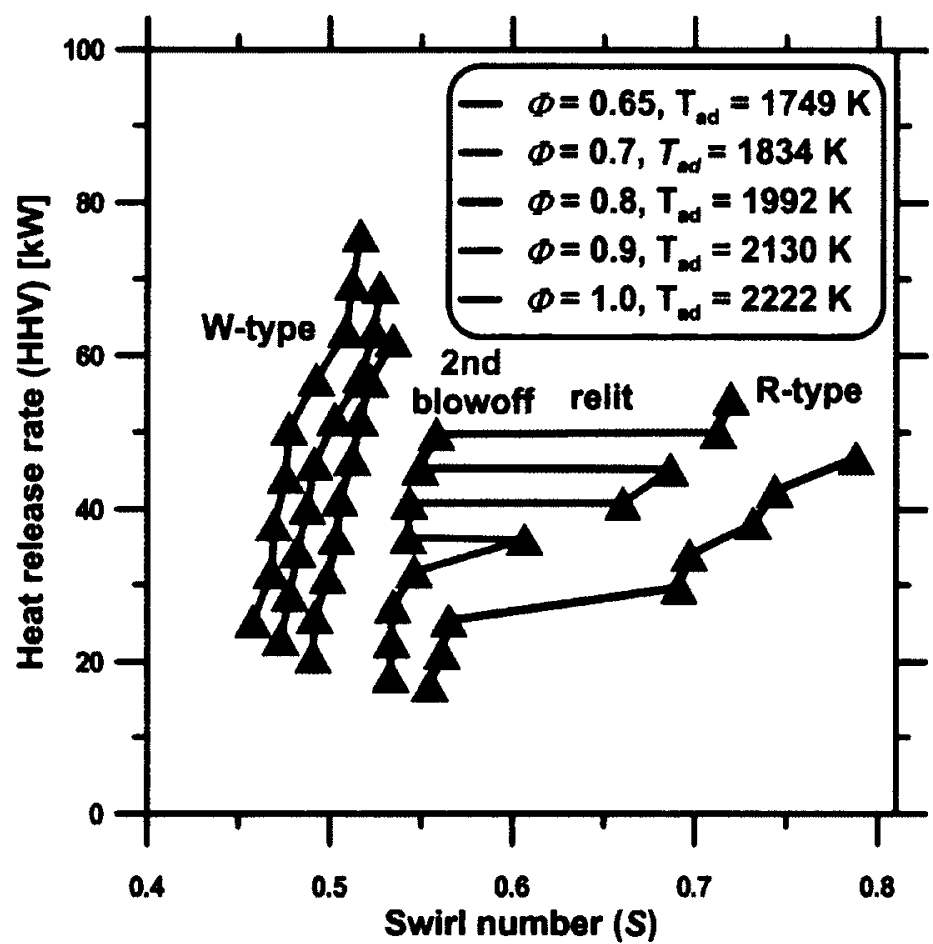

Figure 4.5: Blowoff curves at $\Phi=0.65$ and 0.70 for methane fuel on $38.1 \mathrm{~mm}$ nozzle 


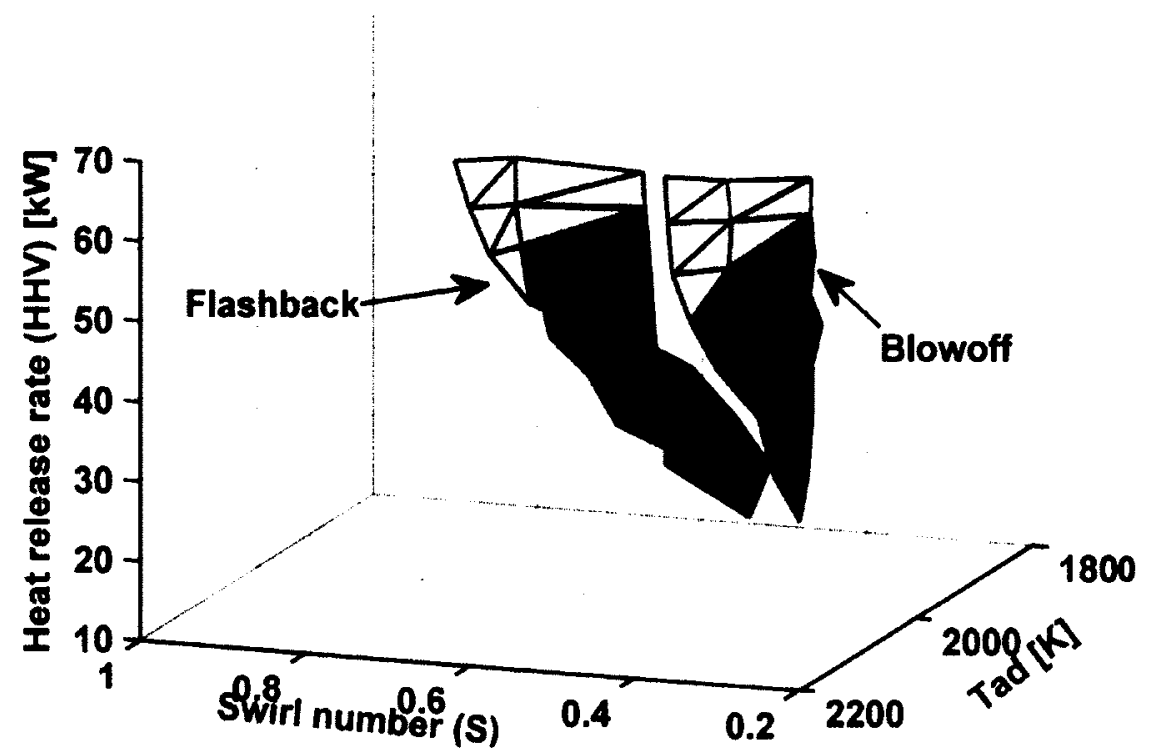

Figure 4.6: Stability volume for methane fuel on $76.2 \mathrm{~mm}$ nozzle

\subsubsection{Blowoff Stability Limits for Biogas and Syngas Fuel Mixtures}

For the biogas/syngas mixture stability maps (B1, S1-S6, S14, S5M50 and S5M25), stability volumes were created only for the $50.8 \mathrm{~mm}$ nozzle. There are stability maps for each combination of fuel mixture and nozzle geometry, but for the $38.1 \mathrm{~mm}$ and $76.2 \mathrm{~mm}$ nozzles, only one equivalence ratio was tested, sufficient to provide data for potential correlations as discussed in Section 6.2. The stability volumes for the $50.8 \mathrm{~mm}$ LSB burning the various biofuel mixtures are shown in Figure $4.7 \mathrm{a}-\mathrm{j}$. Table 4.1 summarizes the observations that can be made from these figures.

The results in Figure 4.7 show that the LSB is amenable to multiple different fuel mixtures. All of the stability volumes have similar shapes with a stable flame turndown ratio of at least 3:1 (400-1200 SLPM). Aside from the attached flame condition (discussed below), the blowoff and flashback curves follow the basic trends observed from the methane stability volumes. Thus, increasing $T_{a d}$ (via $\Phi$ ) makes the flame harder to blowoff and easier to flashback (lower $S$ at each limit) and increasing the flowrate has the opposite effect (higher $S$ at each limit).

Figure 4.7a (the B1 volume) shows a deviation toward higher $S$ from the general blowoff trend at the highest flow rates for the lowest $T_{a d}=1750 \mathrm{~K}(\Phi=0.7)$. 
This is similar to what was observed for methane at lower $T_{a d}=1660 \mathrm{~K}(\Phi=0.6)$ in Figure 4.2. Data were not collected at $1750 \mathrm{~K}$ for methane (would be $\Phi=0.65$ ) with the $50.8 \mathrm{~mm}$ nozzle, but it would be interesting to see if the abnormal blowoff behaviour was observed there as well. Overall, for a given $H R R_{H H V}$ and $T_{a d}, \mathrm{~B} 1$ appears more prone to blowoff, and more flashback resistant than methane, as evident by the higher swirl numbers at both stability limits.
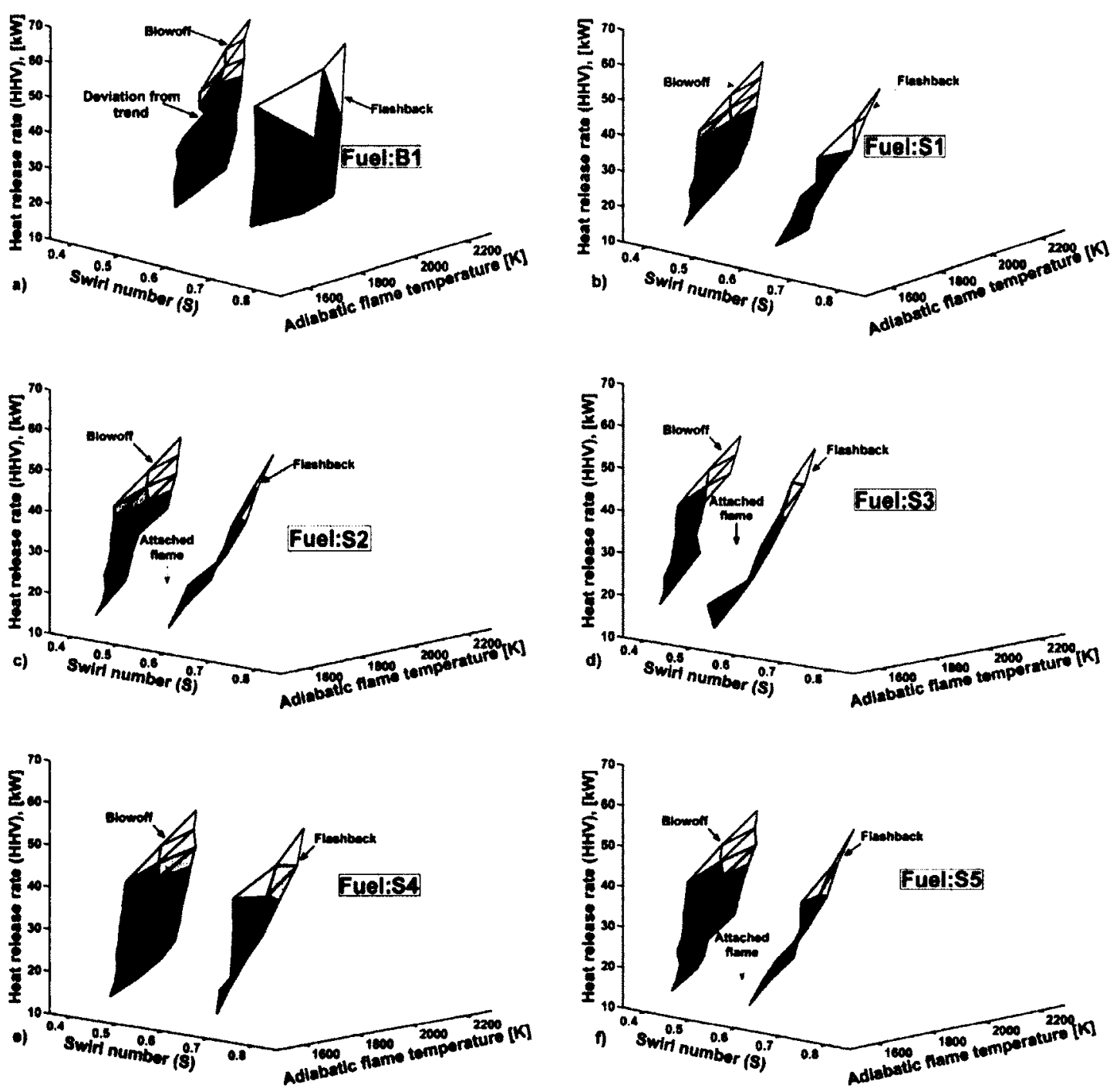

Figure 4.7: Stability volumes low-swirl flames with $50.8 \mathrm{~mm}$ nozzle $\left(37.5^{\circ}\right.$ vane angle) for a) B1 b) S1 c) S2 d) S3 e) S4 f) S5 g) S6 h) S14 i) S5M50 j) S5M25 

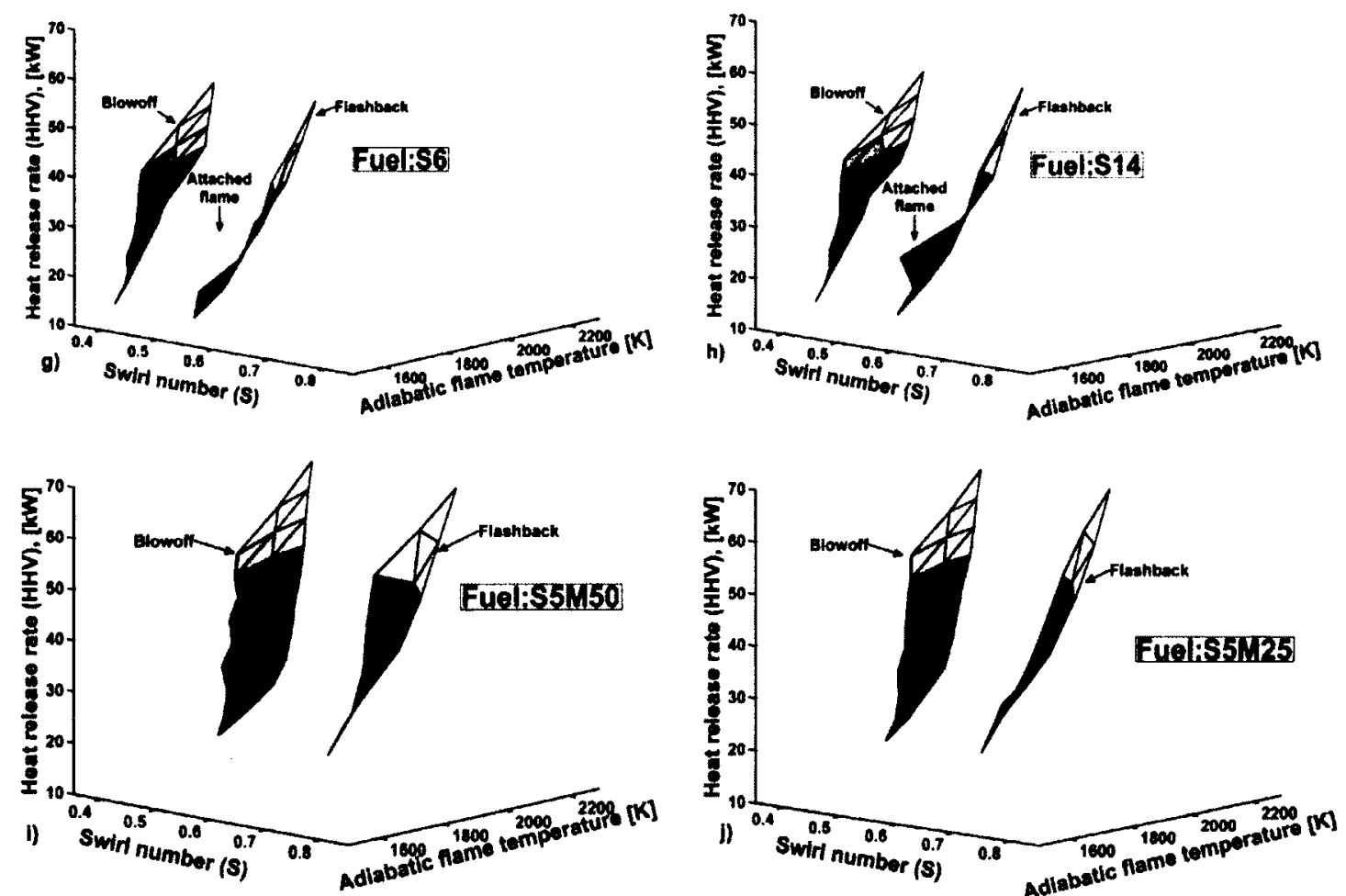

Figure 4.7: (continued): Stability volumes low-swirl flames with $50.8 \mathrm{~mm}$ nozzle $\left(37.5^{\circ}\right.$ vane angle) for a) B1 b) S1 c) S2 d) S3 e) S4 f) S5 g) S6 h) S14 i) S5M50 j) S5M25

As shown in Figure $4.7 \mathrm{~b}$, blowoff behaviour for the $\mathrm{S} 1$ mixture is similar to methane, but with the highest $T_{a d}=1925 \mathrm{~K}(\Phi=0.7)$ flame remaining stable as low as $S=0.35$ for the lowest flowrate. Compared to methane at $T_{\mathrm{ad}}=1990 \mathrm{~K}(\Phi=0.8)$ which blows off at $S=0.42, \mathrm{~S} 1$ is more blowoff resistant. However, the $\mathrm{S} 1$ flame is more prone to flashback, which occurs at lower swirl numbers compared to methane for similar $T_{\mathrm{ad}}$. This is generally true for all the syngas mixtures, as summarized in Table 4.1.

The stability volume for the S2 fuel is shown Figure 4.7c. The general blowoff and flashback trends are the same as for S1 and methane, but both blowoff and flashback occur at lower S for S2 than for S1. This is likely as a result of the S2 mixture's higher $S_{L}$ at similar $T_{a d}$ due to its higher $\mathrm{H}_{2}$ content, as shown in Table 1.1. For all fuel mixtures, a higher $\mathrm{H}_{2}$ content made the flames more blowoff resistant but more prone to flashback such that the swirl number was lower at both limits. This is consistent with the results of Schefer (2003), and Vagelopoulos and Egolfopoulos (1994). 
The stability volume for fuel S2 shows the emergence of the attached flame mode (introduced in Section 3.2.1), which is also seen in the stability volume for S3 (Figure 4.7d). The label 'attached flame' is accompanied by an arrow pointed downward which signifies that all locations below where the surface ends produce an attached flame. $\mathrm{S} 1, \mathrm{~S} 2$, and $\mathrm{S} 3$ have the same stoichiometric air to fuel ratio $(A / F)$ of 1.79. Fuels S4, S5, and $S 6$ have a different common A/F of 2.26. For these subsets of the possible fuel mixtures, $\Phi$ can be used as a parameter for comparison. Within these subsets, the $\% \mathrm{H}_{2}$ increases from $25 \%$ to $37.5 \%$ to $50 \%$ from S1-S3 and S4-S6. Generally speaking, with more $\mathrm{H}_{2}$ content in the fuel, there is a greater likelihood for flame attachment. This means that, at constant flowrate, a fuel mixture with a higher $\mathrm{H}_{2}$ content will attach at a lower $\Phi$. Similarly, at constant $\Phi$ a fuel mixture with a higher $\mathrm{H}_{2}$ content will attach up to a higher flowrate. The substantial increase in $S_{L}$ with increased $\mathrm{H}_{2}$ content is potentially the reason for this behaviour as further discussed below.

The trend of the attached flame occurring at lower $\Phi$ and higher flow rates with higher $\mathrm{H}_{2}$ can be seen in the stability volumes of $\mathrm{S} 2$ and $\mathrm{S} 3$. For $\mathrm{S} 2$, the flame first attaches at $\Phi=0.6$ at the lowest total flow rate $\left(Q_{t o t}\right)$ of 400 SLPM $\left(H R R_{H H V}=15.9 \mathrm{~kW}\right)$. When the equivalence ratio for $\mathrm{S} 2$ is raised to $\Phi=0.7$, the flowrate where attachment occurs rises to $Q_{\text {tot }}=700$ SLPM, meaning it can attach at a higher flowrate due to its higher $\Phi$. For S3 (Figure 4.7d), the attachment occurs at $\Phi=0.5$ at the lowest flowrate where $Q_{t o t}=400 \operatorname{SLPM}\left(H R R_{H H V}=13.3 \mathrm{~kW}\right)$. When $\Phi$ is raised to 0.6 , the flame attaches at $Q_{t o t}=600 \operatorname{SLPM}\left(H R R_{H H V}=24.0 \mathrm{~kW}\right)$. At $\Phi=0.7$, the flame attaches at $Q_{t o t}=900 \operatorname{SLPM}\left(H R R_{H H V}=40.4 \mathrm{~kW}\right)$.

Figure 4.7e-g show the stability volumes for fuels $\mathrm{S} 4, \mathrm{~S} 5$, and $\mathrm{S} 6$ respectively. The same trends are seen in these volumes, and are analogous to the stability volumes of S1, S2, and S3. S4, like S1, shows no attached flame. Flame attachment behavior for S5-S6 is consistent with the results for S2-S3 where increasing $\Phi$ leads to attachment occurring at higher flow rates, and S6 more readily attaches than S5 due to a higher $\mathrm{H}_{2}$ content. S14 (Figure $4.7 \mathrm{~h}$ ) behaves as expected within this trend, showing attached flame behaviour very close to that of S6 despite having less 
hydrogen ( $42.5 \%$ vs. $50 \%$ ). This discrepancy is likely explained by $\mathrm{S} 14$ having a $\mathrm{CO}_{2}$ fraction of $15 \%$ as opposed to $20 \%$ for $S 6$.

Stability volumes for S5M50 and S5M25 (Figure 4.7i-j) appear to follow the basic trends without any flame attachment. Swirl numbers at blowoff and flashback for S5M25 were lower than for S5M50, which is likely explained by the increased hydrogen content as it was for S1-S3 and S4-S6. A summary of observations from the stability volumes is presented in Table 4.1 . 
Table 4.1: Summary of stability volume properties

\begin{tabular}{|c|c|c|c|c|c|c|}
\hline \multirow{2}{*}{ Fuel } & \multirow{2}{*}{$\begin{array}{l}\text { Nozzle } \\
\text { diameter } \\
\text { [mm] }\end{array}$} & \multicolumn{2}{|c|}{$\begin{array}{c}\text { Laminar flame } \\
\text { speed }[\mathrm{cm} / \mathrm{s}]\end{array}$} & \multirow{2}{*}{ Blowoff } & \multirow{2}{*}{ Flashback } & \multirow{2}{*}{$\begin{array}{c}\text { Attachment } \\
\text { [lowest } \Phi \text { and } \\
\left.\text { highest } Q_{t o t}\right]\end{array}$} \\
\hline & & $\phi=1$ & $T_{a d}=1800 \mathrm{~K}$ & & & \\
\hline \multirow{4}{*}{$\mathrm{CH}_{4}$} & 38.1 & \multirow{3}{*}{36.3} & \multirow{3}{*}{15.1} & $\begin{array}{l}\text { Stable trends until } \\
\Phi \leq 0.7 \text { where } R- \\
\text { type blowoff and } \\
\text { W-type blowoff } \\
\text { occur }\end{array}$ & $\begin{array}{c}\text { No flashback until } \\
\Phi \geq 0.8 \text {. In burner } \\
\text { plotted as well. }\end{array}$ & No attachment \\
\hline & 50.8 & & & $\begin{array}{l}\text { Stable trends until } \\
\qquad \Phi=0.6\end{array}$ & $\begin{array}{c}\text { No flashback until } \\
\Phi>0.6 \text {. In burner } \\
\text { plotted for } \\
\Phi=0.6 \text {. }\end{array}$ & No attachment \\
\hline & 76.2 & & & Stable trends. & $\begin{array}{c}\text { Flashback only at } \\
\Phi \geq 0.8 \text { below } \\
H R R_{H H V}=45 \mathrm{~kW} .\end{array}$ & No attachment \\
\hline & \multicolumn{6}{|c|}{ Comparison to $\mathrm{CH}_{4}$ with $50.8 \mathrm{~mm}$ nozzle: } \\
\hline B1 & 50.8 & 23.7 & 13.9 & $\begin{array}{c}\text { More prone to } \\
\text { blowoff. }\end{array}$ & $\begin{array}{l}\text { Less prone to } \\
\text { flashback. }\end{array}$ & No attachment \\
\hline S1 & 50.8 & 53.0 & 22.2 & $\begin{array}{c}\text { Less prone to } \\
\text { blowoff. }\end{array}$ & $\begin{array}{c}\text { More prone to } \\
\text { flashback. }\end{array}$ & No attachment \\
\hline $\mathrm{S} 2$ & 50.8 & 69.6 & 29.8 & $\begin{array}{l}\text { Less prone to } \\
\text { blowoff. }\end{array}$ & $\begin{array}{c}\text { More prone to } \\
\text { flashback. }\end{array}$ & $\begin{array}{c}\text { Attached at } \\
\Phi=0.6, \\
Q_{\text {tot }}=400 \text { SLPM. }\end{array}$ \\
\hline$\$ 3$ & 50.8 & 89.9 & 38.4 & $\begin{array}{l}\text { Less prone to } \\
\text { blowoff. }\end{array}$ & $\begin{array}{l}\text { More prone to } \\
\text { flashback. }\end{array}$ & $\begin{array}{c}\text { Attached at } \\
\Phi=0.5 \\
Q_{\text {tot }}=400 \text { SLPM. }\end{array}$ \\
\hline \$4 & 50.8 & 56.2 & 22.8 & $\begin{array}{c}\text { Less prone to } \\
\text { blowoff. }\end{array}$ & $\begin{array}{c}\text { More prone to } \\
\text { flashback. }\end{array}$ & No attachment \\
\hline S5 & 50.8 & 68.8 & 28.0 & $\begin{array}{l}\text { Less prone to } \\
\text { blowoff. }\end{array}$ & $\begin{array}{c}\text { More prone to } \\
\text { flashback. }\end{array}$ & $\begin{array}{c}\text { Attached at } \\
\Phi=0.7 \\
Q_{\text {tot }}=600 \text { SLPM. }\end{array}$ \\
\hline S6 & 50.8 & 83.6 & 34.4 & $\begin{array}{l}\text { Less prone to } \\
\text { blowoff. }\end{array}$ & $\begin{array}{c}\text { More prone to } \\
\text { flashback. }\end{array}$ & $\begin{array}{c}\text { Attached at } \\
\Phi=0.6, \\
Q_{\text {tot }}=600 \text { SLPM. }\end{array}$ \\
\hline S14 & 50.8 & 85.7 & 30.5 & $\begin{array}{l}\text { Less prone to } \\
\text { blowoff. }\end{array}$ & $\begin{array}{l}\text { More prone to } \\
\text { flashback. }\end{array}$ & $\begin{array}{c}\text { Attached at } \\
\Phi=0.6, \\
Q_{\text {tot }}=600 \text { SLPM. }\end{array}$ \\
\hline S5M50 & 50.8 & 42.2 & 18.2 & $\begin{array}{c}\text { Less prone to } \\
\text { blowoff. }\end{array}$ & $\begin{array}{l}\text { More prone to } \\
\text { flashback. }\end{array}$ & No attachment \\
\hline S5M25 & 50.8 & 49.6 & 22.1 & $\begin{array}{l}\text { Less prone to } \\
\text { blowoff. }\end{array}$ & $\begin{array}{l}\text { More prone to } \\
\text { flashback. }\end{array}$ & No attachment \\
\hline
\end{tabular}

\subsubsection{Flame attachment investigation}

Targeted experiments were performed to investigate flame attachment with certain

$\mathrm{H}_{2}$ mixtures. Using the $50.8 \mathrm{~mm}$ LSB nozzle with fuel mixtures $\mathrm{S} 1, \mathrm{~S} 2, \mathrm{~S} 3, \mathrm{~S} 4, \mathrm{~S} 5, \mathrm{~S} 6$, 
and S14, the onset of flame attachment was recorded in experiments where $\Phi$ was held constant at $0.5,0.6$, or 0.7 , and the swirl number was held constant at 0.46 . Starting from a total flow rate sufficiently high to achieve an unattached floating flame, the flowrate was slowly decreased until the flame attached to the nozzle rim. Figure 4.8a shows results of these experiments with the velocity at the onset of flame attachment plotted versus $\mathrm{H}_{2}$ fraction in the fuel. Figure $4.8 \mathrm{~b}$ shows the same data plotted versus the laminar flame speed of the fuel. Both plots show a clear increasing trend with similar amounts of scatter. This suggests that the laminar flame speed is a critical determining factor for LSB flame attachment.

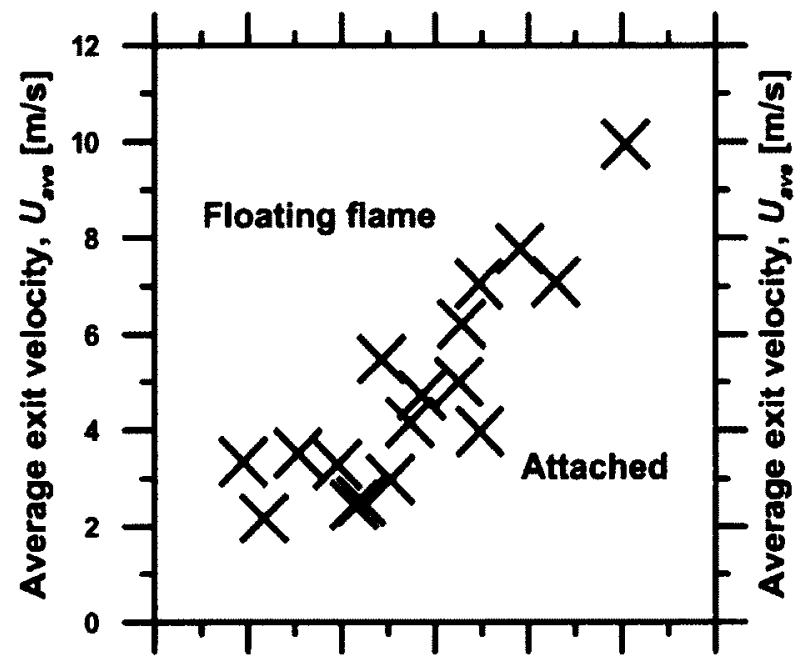

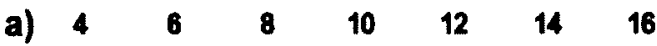
$\mathrm{H}_{2}$ content in fuel/air mixture (\%vol)

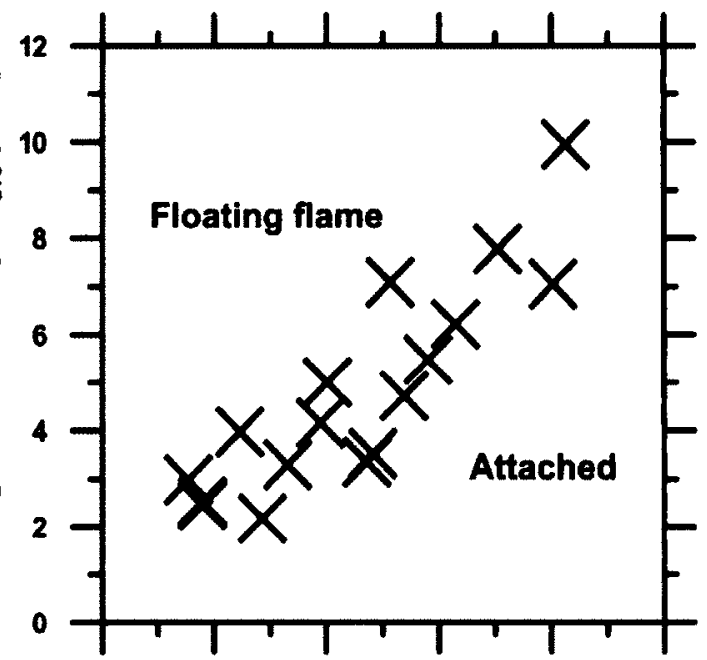

b) $\begin{array}{llllll}0.1 & 0.2 & 0.3 & 0.4 & 0.5 & 0.6\end{array}$ Laminar flame speed, $S_{L}[\mathrm{~m} / \mathrm{s}]$

Figure 4.8: Fuel mixtures S1, S2, S3, S4, S5, S6, and S14 at $S=0.46$ and $\Phi=0.5$, 0.6 , and 0.7 . Plots show the average exit velocity where the flame attached for a given condition.

However, results shown in Figure 4.9 suggest that $S_{L}$ is not the only determining factor. Figure 4.9 shows photos of LSB flames burning different fuel mixtures $\left(\mathrm{CH}_{4}, \mathrm{~S} 1, \mathrm{~S} 2\right.$, and $\left.\mathrm{S} 3\right)$ at the same total flow rate $\left(Q_{\text {tot }}=400 \mathrm{SLPM}\right.$, $\left.U_{\text {ave }}=3.7 \mathrm{~m} / \mathrm{s}\right)$ and swirl number $(S=0.43)$ where $\Phi$ has been adjusted in each case to match $S_{L}$ at $37.2 \mathrm{~cm} / \mathrm{s}$. Fuels S3 and $\mathrm{S} 2$ produce attached flames in this case, but fuels $\mathrm{S} 1$ and $\mathrm{CH}_{4}$ do not. Although this result confirms that $\% \mathrm{H}_{2}$ in the fuel is critical in determining flame attachment, they also show that the phenomenon is not fully correlated with $S_{L}$. From these experiments, it is clear that a high enough $\% \mathrm{H}_{2}$ in the fuel/air mixture (potentially 10\%) is necessary for flame attachment for a given $\Phi$ 
and $Q_{t o t} / U_{\text {ave. }}$. It remains unclear; however, what specific physical or chemical property of hydrogen causes it to occur. As mentioned in the introduction, the turbulent flame speed, $S_{T}$, of hydrogen rich fuel mixtures is much more sensitive to turbulence fluctuations than other flammable gases (Kido et al., 2002). Namely, $d\left(S_{T} / S_{L}\right) / d\left(u^{\prime} / S_{L}\right)$ is much higher for hydrogen-rich mixtures as compared to other flammable gases. This means that it could be the significantly higher turbulent flame speed of hydrogen rich fuel mixtures, and not the laminar flame speed, responsible for flame attachment. An analysis of the turbulent flame speed as measured from PIV results is presented in Section 5.7.
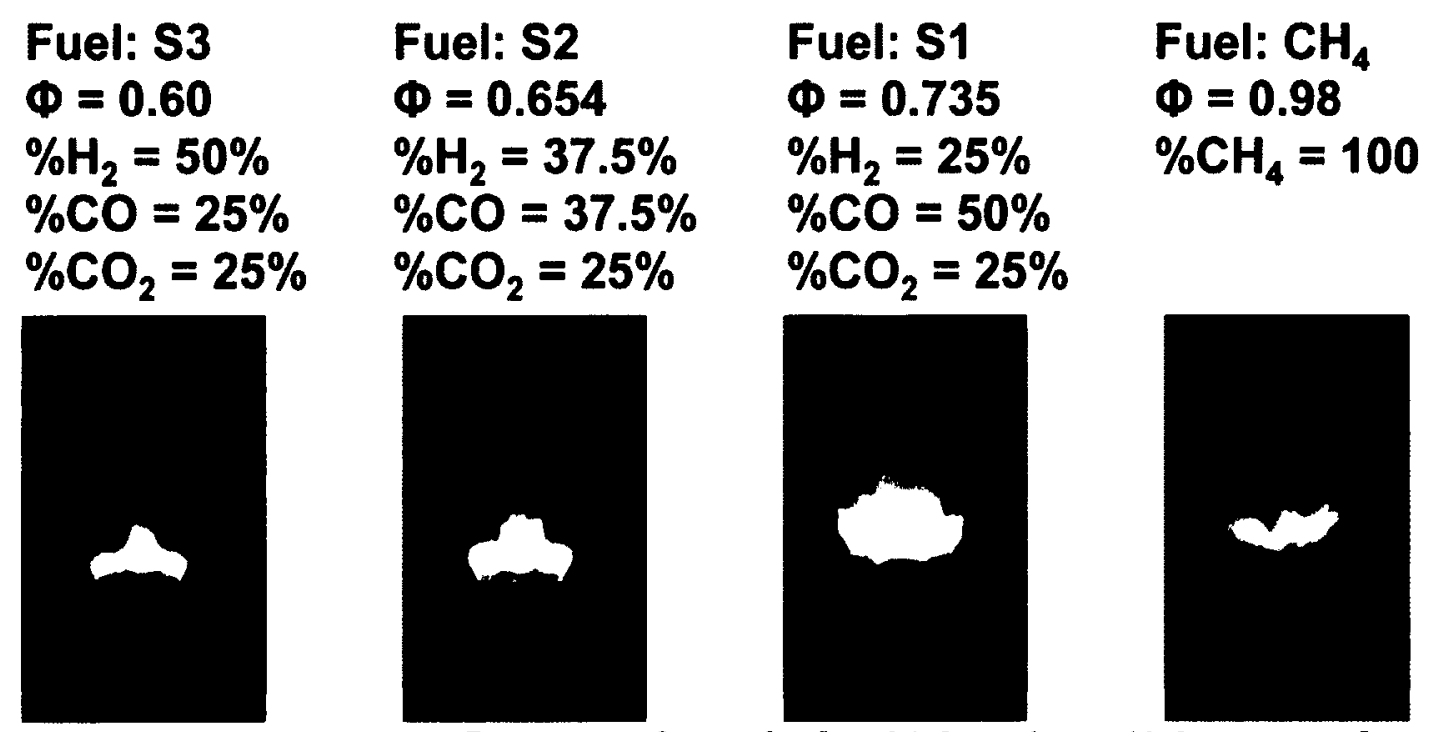

Figure 4.9: Laminar flame speed matched at $37.2 \mathrm{~cm} / \mathrm{s}$ on $50.8 \mathrm{~mm}$ nozzle with $S=0.43$ and $Q_{t o t}=400 \mathrm{SLPM} / U_{\text {ave }}=3.7 \mathrm{~m} / \mathrm{s}$ for $\mathrm{CH}_{4}, \mathrm{~S} 1, \mathrm{S2}$, and $\mathrm{S3}$

\subsubsection{Enclosure effects}

As part of the experiments for this thesis, the effects of adding a cylindrical enclosure to the flame were preliminarily tested to observe any potential changes in blowoff behavior of the LSB. A $195 \mathrm{~mm}$ diameter, quartz enclosure was mounted at the exit plane of the LSB to represent a generic enclosure of a "can-type" gas turbine combustor. Blowoff limits were measured with the LSB flame operating within the enclosure. As the swirl number was decreased (by increasing the \%IFF), the flame rose in height consistent with the non-enclosed open flame. However, with the 
enclosure in place, blowoff was delayed slightly as the swirl number was decreased. Past the point where blowoff would normally occur in the "unenclosed" case, the flame changed shape from the usual " $W$ " flame into a flatter flame and continued to rise in height above the burner exit until it reached the top of the $457 \mathrm{~mm}$ tube where it eventually extinguished at a very low swirl number. These preliminary tests suggest that an enclosure may further enhance the stability of the LSB flame, although the migration of the flame downstream could limit the utility of this enhanced stability in a practical combustor with finite volume.

Photos ( $10 \mathrm{~s}$ exposures) of the blowoff event with the enclosure present on the $50.8 \mathrm{~mm} \mathrm{LSB}$ nozzle burning $\mathrm{CH}_{4}$ at $\Phi=0.8\left(T_{a d}=1990 \mathrm{~K}\right)$ and $H R R_{H H V}=37 \mathrm{~kW}$ are documented in Figure 4.10. The same phenomenon was observed in experiments with the $38.1 \mathrm{~mm}$ nozzle at a lower flow rate, as well as further experiments on the $50.8 \mathrm{~mm}$ nozzle with the S5M50 fuel. Changing the fuel to S5 showed that the enclosure encouraged the flame attachment mode at conditions where no attachment was observed for the open flame. This is consistent with the results from Cheng (2008).

Figure 4.11 shows the enclosed flame heights as extracted along the centerline of the burner for each case tested. The flame height was defined as the brightest point in the image along the centerline. With the exception of the $\mathrm{S} 5$ case (where attachment occurs), it is obvious that when the swirl number is reduced beyond the value at which blowoff would occur in the unenclosed case, the flame uses the enclosure to sustain itself at a position much further downstream than is possible without the enclosure, and the flame continues to rise to the top of the enclosure as the swirl number is further reduced. 


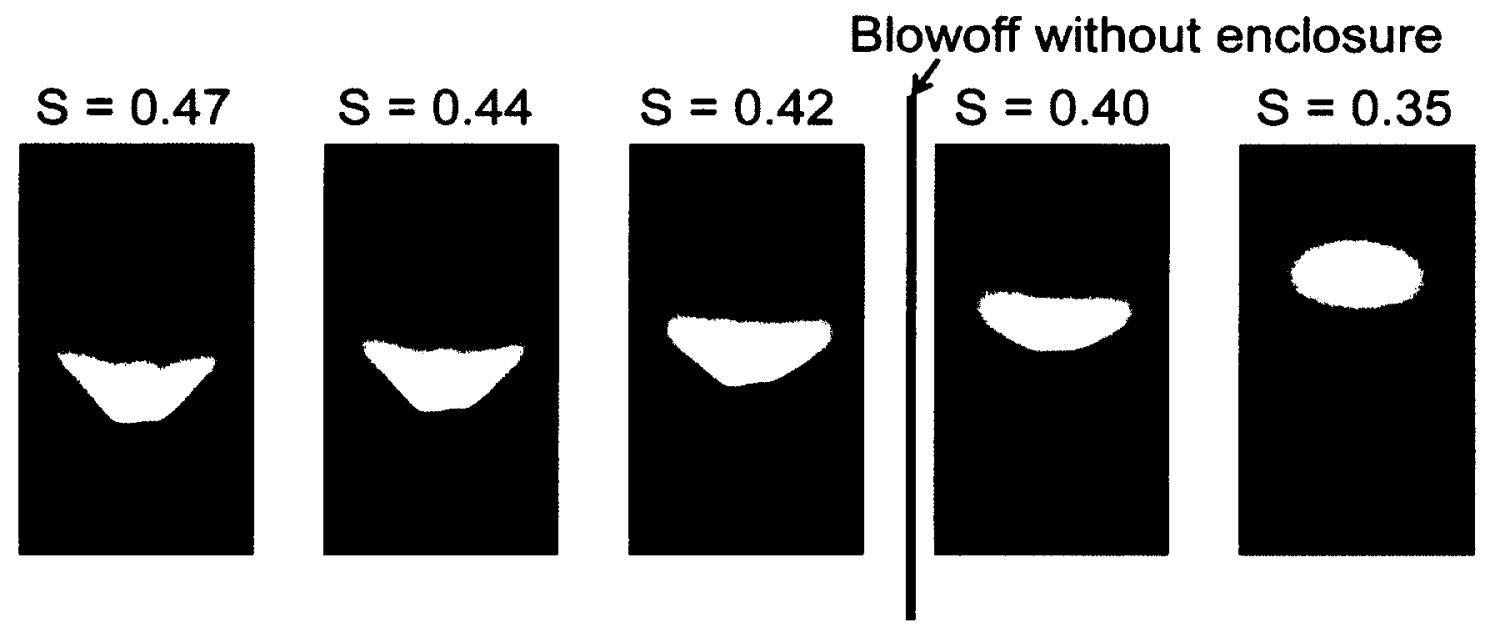

Figure 4.10: Enclosure effect on blowoff, $50.8 \mathrm{~mm}$ nozzle, $\mathrm{CH}_{4}, \Phi=0.8$, $H H R_{H H V}=37 \mathrm{~kW}$

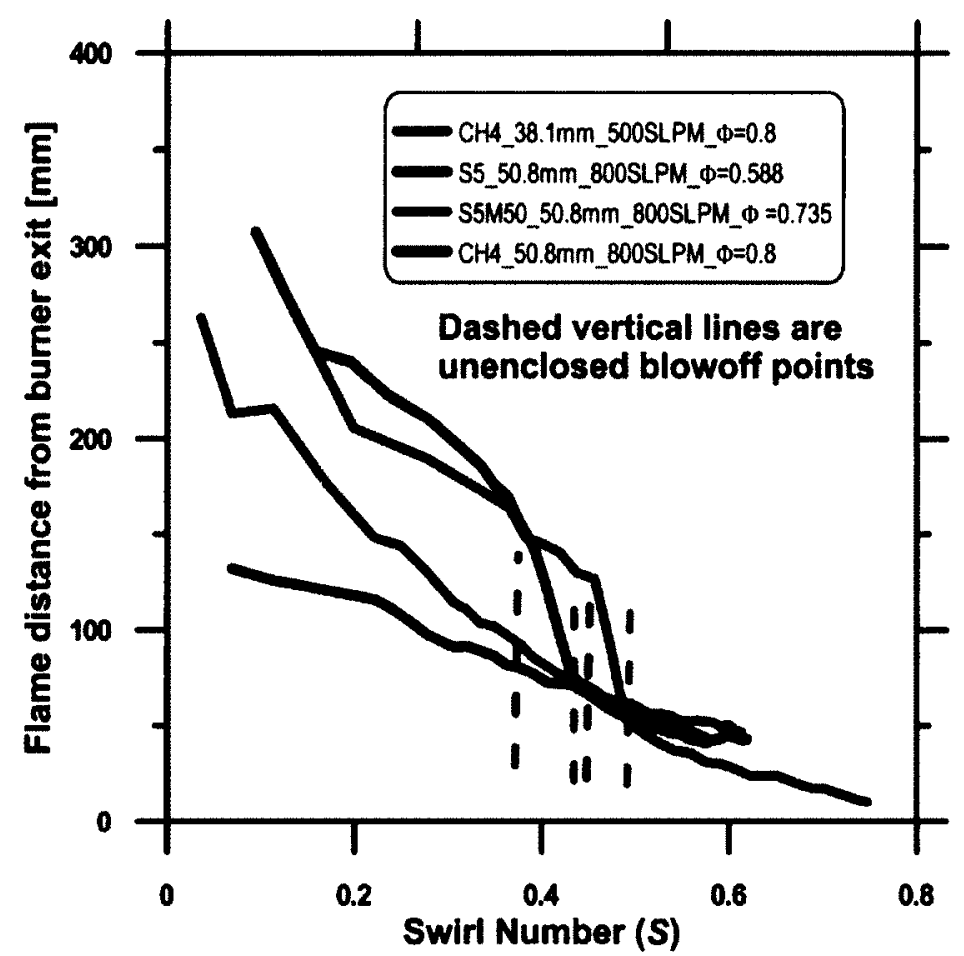

Figure 4.11: Vertical heights of enclosed LSB flames 


\section{Flowfield Measurements using Particle image velocimetry (PIV)}

\subsection{Comparison of Non-reacting and Reacting Flowfields}

Prior to discussing PIV results in detail, it is instructive to first briefly compare measurements of the non-reacting and reacting velocity fields. In the context of understanding the underlying physics of LSB stability, it is evident that the original proposed mechanism of Chan et al. (1992) of stability based on radial flow divergence is incomplete. Figure 5.1 shows the velocity fields from PIV measurements using olive-oil seeding for a non-reacting flow and a flowfield burning methane at $\Phi=0.8$ with matched $Q_{t o t}$ and $S$.
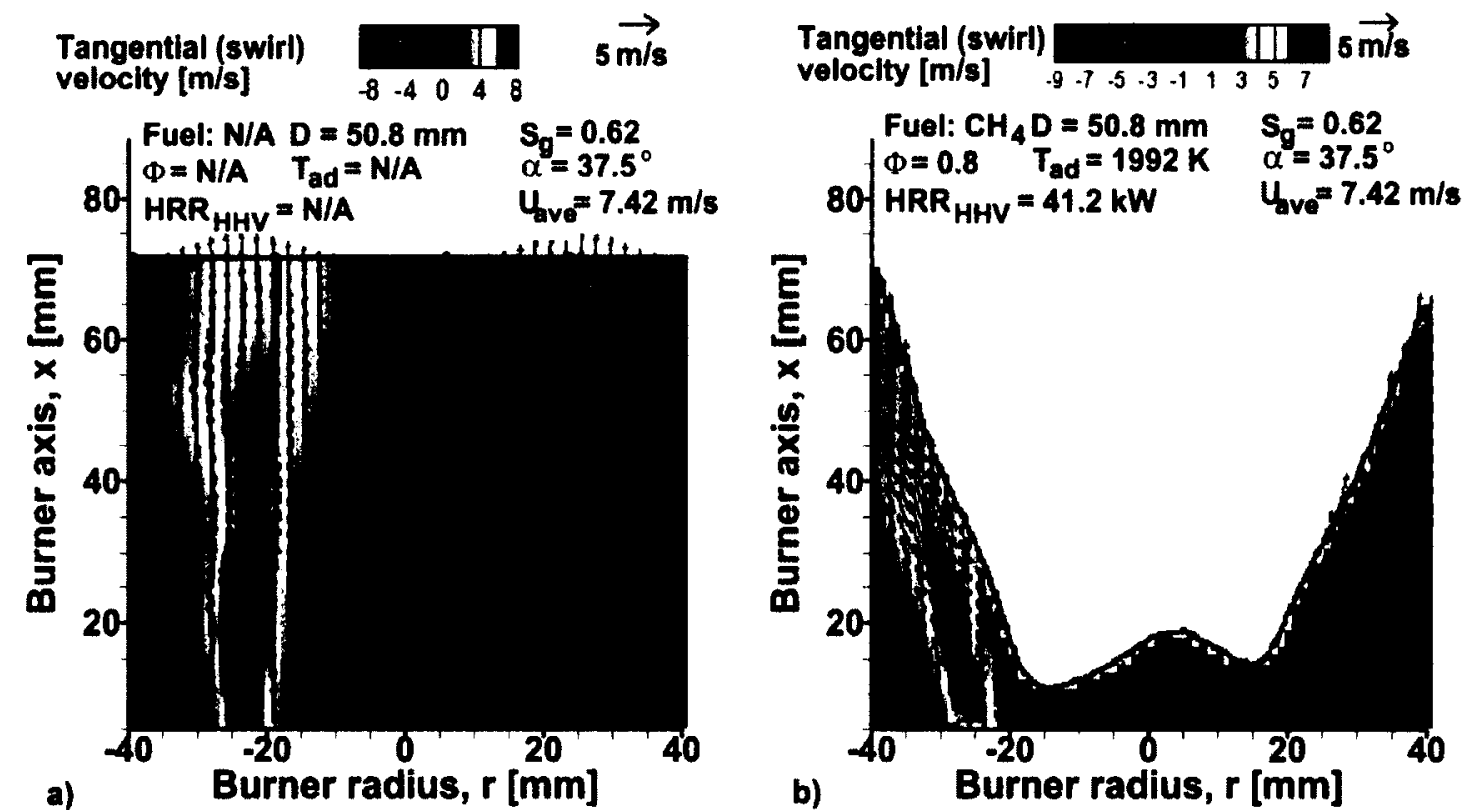

Figure 5.1: Velocity fields measured via PIV using olive oil seeding. Plots show data on the $50.8 \mathrm{~mm}$ nozzle at $Q_{t o t}=800 \mathrm{SLPM}$ and $S=0.62$. a) $\Phi=0$ (Non-reacting) b) Methane at $\Phi=0.8$

The non-reacting flowfield shows that in the absence of a reacting flame there is no significant radial divergence. When methane is added and the flame is lit, the olive oil seeding evaporates at the flame front, providing no velocity vectors beyond that point. The maximum measured radial divergence increases to $20^{\circ}$ for the reacting flowfield. This provides evidence to the contrary of Chan et al. (1992) 
where they concluded that the radial divergence provided by the swirling flow was responsible for stabilizing the flame. In fact, Figure 5.1 shows that the flame itself is responsible for the radial divergence of LSB flames, and thus radial divergence could be a result of the stable flame, and not necessarily the cause of it. Once the flame is lit, however; the radial divergence produced could still be a part of the stabilization process. Thus, as mentioned above, the evidence presented merely indicates that the original model for LSB stability is incomplete.

\subsection{Stabilization of Flames without using a Swirler}

Recognizing that the swirl alone is not causing the radial divergence, it is reasonable to question whether and LSB-type flame can be stabilized in the absence of a swirler. Figure 5.2a demonstrates that it is possible to stabilize a flame in the absence of the swirler, where the flame appears to stabilize in the shear layer of the coannular flow.
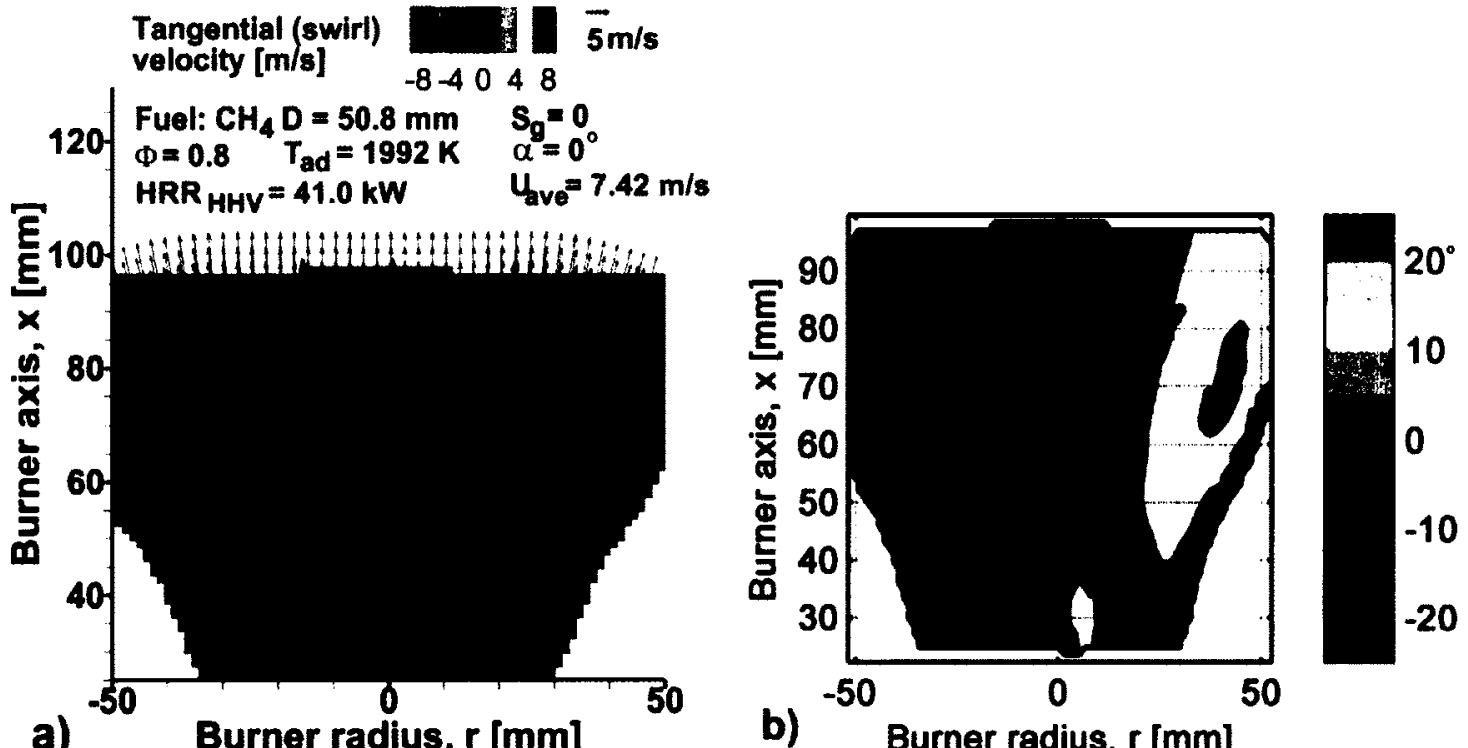

Figure 5.2: $\mathrm{CH}_{4}-\Phi=0.8-800$ SLPM near blowoff without swirl on $50.8 \mathrm{~mm}$ nozzle a) Measured PIV flowfield b) Radial divergence contour plot

For Figure 5.2, the swirler was removed from the $50.8 \mathrm{~mm}$ nozzle, effectively transforming the LSB into a purely co-annular premixed burner. This same experiment was repeated with a number of different fuel / flow combinations and although the stability regimes were narrower than with the swirler in place, the 
results clearly demonstrate that radial divergence from the swirl is not the key stabilization mechanism. Figure $5.2 \mathrm{~b}$ shows a similar maximum radial divergence of $20^{\circ}$ in the outer radial positions for the case without the swirler. This provides more evidence that it is not the swirling component of the flow that drives the divergence, but the expansion through the flame itself. The divergence may still be responsible for flame stability, but it is clearly not the result of the outer swirling flow. More extensive results from using the LSB without a swirler are discussed in the context of developing models to predict stability in Chapter 6 .

\subsection{Reference PIV Velocity Field Measurements for Methane}

Figure 5.3 shows mean velocity field measurements obtained via PIV for the $50.8 \mathrm{~mm}$ LSB burning methane fuel at $\Phi=0.8$ near blowoff conditions. Figure 5.3a-c reports data for total flow rates $\left(Q_{t o t}\right)$ of 400,800 , and $1200 \operatorname{SLPM}\left(U_{\text {ave }}=3.71,7.42\right.$, and $11.1 \mathrm{~m} / \mathrm{s}$ ) respectively. The flame front has a characteristic ' $W$ ' shape in all three cases with anchor points (lowest points of the ' $W$ '; Strahman, 2007) along the shear layer between the inner core flow and outer annular flow. The lowest point of the flame sits $40-50 \mathrm{~mm}$ from the burner exit plane meaning that over a three-fold increase in exit velocity, the flame still blows off at the same height. This illustrates the similarity features of the LSB over significant changes in exit velocity as originally documented by Littlejohn and Cheng (2007). The streamlines show that the LSB flames do indeed diverge radially in the vicinity of the flame, while the centerline velocity stays straight along the axis of symmetry.

To quantify the divergence, a contour plot of the radial divergence angle was created as shown in Figure 5.4. In this case, the radial flow divergence near the flame is estimated to be $20^{\circ}$ (corresponding to the maximum on both sides of the flame). This was consistent for all three flowrates. This method of quantifying radial divergence was used in the following sections, where the intermediate radial divergence angle contour plots have been omitted for brevity. 

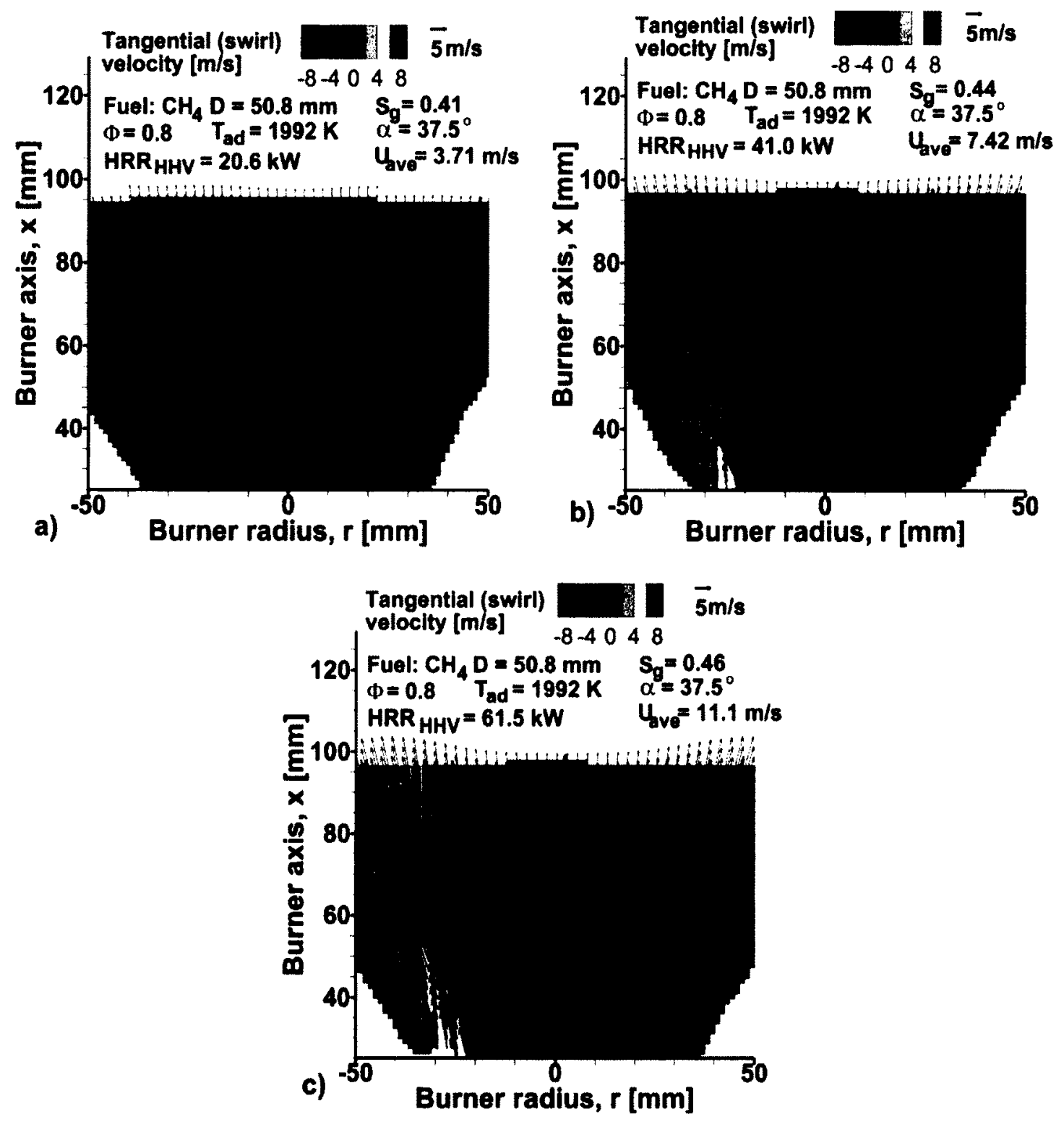

Figure 5.3: Velocity fields measured via PIV at near blowoff conditions. Plots show data for the $50.8 \mathrm{~mm}$ LSB burning methane at $\Phi=0.8$ and a total reactant flow rate $\left(Q_{t o t}\right)$ of a) 400 SLPM b) 800 SLPM c) 1200 SLPM 


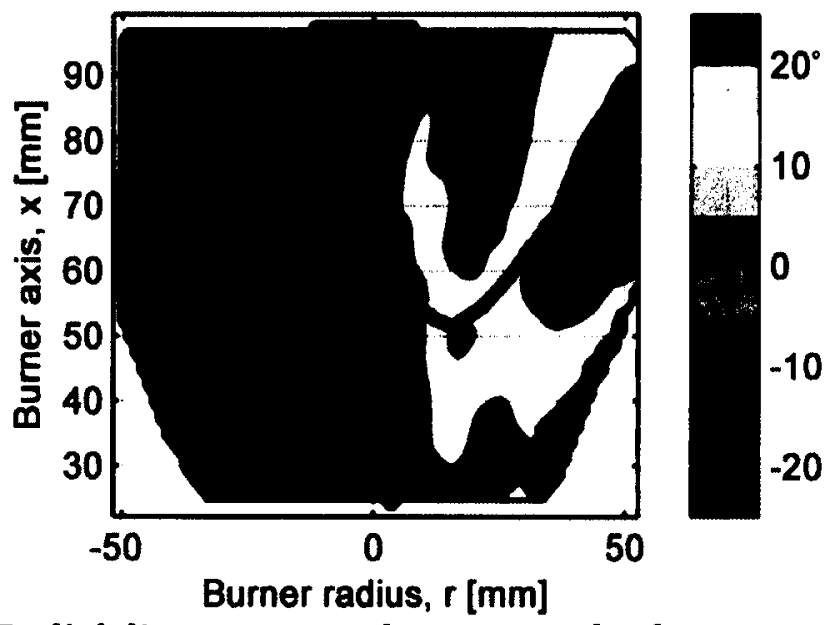

Figure 5.4: Radial divergence angle contour plot from PIV measurement for LSB burning methane near blowoff at $\Phi=0.8$ and $Q_{t o t}=800$ SLPM on $50.8 \mathrm{~mm}$ nozzle

Figure 5.5 compares flowfields at blowoff for methane flames at $\Phi=0.7$ for the three nozzle diameters of $38.1 \mathrm{~mm}, 50.8 \mathrm{~mm}$, and $76.2 \mathrm{~mm}$. The mean burner exit velocity was fixed at $U_{a v e}=6.70 \mathrm{~m} / \mathrm{s}$ for all three cases. The familiar ' $\mathrm{W}$ ' shape is clearly seen in the $38.1 \mathrm{~mm}$ and $50.8 \mathrm{~mm}$ flame fronts. The $76.2 \mathrm{~mm}$ flame front shows a weak ' $W$ ' shape while exhibiting some flame asymmetry toward the right side of the nozzle. This is symptomatic of PIV seeding effects as noted in Chapter 3. Even with the asymmetry, the $76.2 \mathrm{~mm}$ flame front still has a distinct anchor point on the right-hand nose of the ' $W$ ' shape. Radial divergence angles of $20^{\circ}$ are seen in all three cases. The $50.8 \mathrm{~mm}$ flowfield shows that the flame front again stabilizes approximately $50 \mathrm{~mm}$ downstream of the burner exit plane (closest point is $52 \mathrm{~mm}$ downstream), similar to the results from Figure 5.3. However the flame position appears to scale with the diameter of the burner; the anchor point of the flame sits at $27 \mathrm{~mm}$ for the $38.1 \mathrm{~mm} \mathrm{LSB}$ and $78 \mathrm{~mm}$ for the $76.2 \mathrm{~mm}$ LSB. 

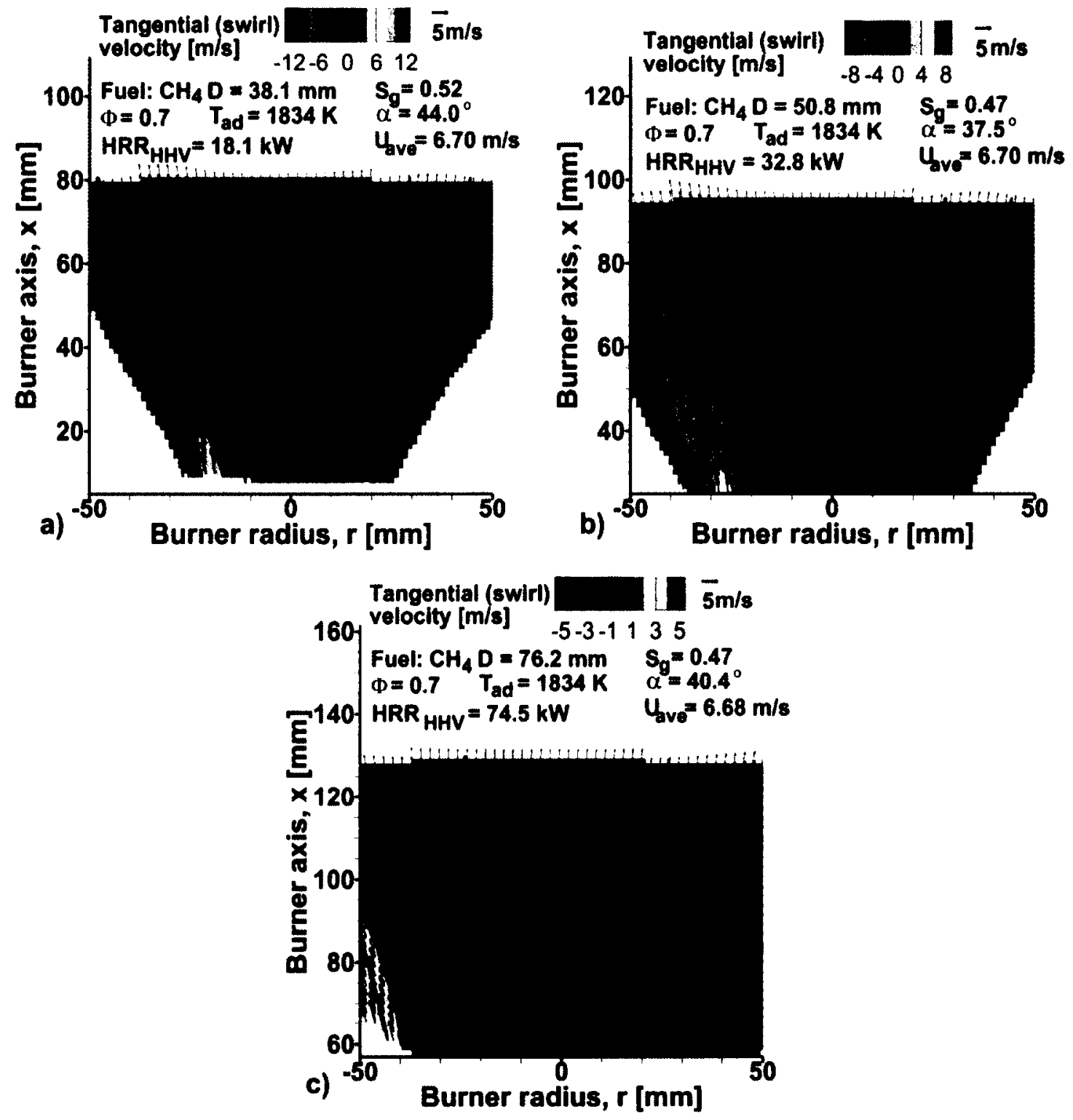

Figure 5.5: Velocity fields measured via PIV at near blowoff conditions. Plots show data for the LSB burning methane at $\Phi=0.7$ at an average exit velocity $\left(U_{\text {ave }}\right)$ of $6.7 \mathrm{~m} / \mathrm{s}$ on the a) $38.1 \mathrm{~mm}$ nozzle b) $50.8 \mathrm{~mm}$ nozzle c) $76.2 \mathrm{~mm}$ nozzle

Figure 5.6 presents similar results to Figure 5.5 but with $\Phi=0.8$. The flowfields are analogous to those seen in the $\Phi=0.7$ case, and the flame height at blowoff again scales with the burner exit diameter. Once again, radial divergence angles for all three measurements are at about $20^{\circ}$. The flame position does not change with $\Phi$ for the two smaller nozzles; at $\Phi=0.8$, the flame anchors at $27 \mathrm{~mm}$ for the $38.1 \mathrm{~mm} \mathrm{LSB}$ and $50 \mathrm{~mm}$ for the $50.8 \mathrm{~mm} \mathrm{LSB}$, as compared to $27 \mathrm{~mm}$ and $52 \mathrm{~mm}$ at $\Phi=0.7$. For the $76.2 \mathrm{~mm} \mathrm{LSB}$; however, the flame moves to $59 \mathrm{~mm}$ downstream of the burner exit plane at its lowest point for $\Phi=0.8$. This is much 
closer than its lowest position of $78 \mathrm{~mm}$ downstream for $\Phi=0.7$. However, the measured flame position is affected by the noticeable flame asymmetry in Figure $5.6 \mathrm{c}$ that is presumably related to an accumulation of PIV seed in the burner. Overall, the trend remains that flame height at blowoff scales with burner exit diameter. This is confirmed by additional measurements of the flame height along the centreline (where any potential effects of flame asymmetry are largely mitigated). For Figure 5.3, where the nozzle diameter is held constant at $50.8 \mathrm{~mm}$, the flame heights along the centerline at blowoff conditions were 60,62 , and $56 \mathrm{~mm}$, respectively. Figure 5.5 has centreline flame heights at blowoff for matched $U_{\text {ave }}$ at $\Phi=0.7$ for the LSB nozzle sizes of $38.1,50.8$, and $76.2 \mathrm{~mm}$ of 30,56 , and $87 \mathrm{~mm}$, respectively. Figure 5.6, which is the same as Figure 5.5 but with $\Phi=0.8$, shows centreline flame heights at blowoff of 30,60 , and $75 \mathrm{~mm}$, respectively.

\subsection{Matching biogas/syngas fuel mixtures to methane conditions}

To directly compare the performance of the LSB with biofuel mixtures versus pure methane, relevant operating parameters had to be matched. As mentioned in

Section 3.2.3, comparisons while matching $T_{a d}$ and $H R R_{H H V}$ are relevant to assessing the potential for substituting various fuels into an existing LSB such that energy output and temperature could be maintained approximately constant.

Figure 5.7 shows reference measured velocity fields for methane at $\Phi=0.7$ and $\Phi=0.8$ on the $50.8 \mathrm{~mm} \mathrm{LSB}$ burning pure $\mathrm{CH}_{4}$ at a fixed total flowrate of $Q_{t o t}=800$ SLPM. To match conditions of the methane at $\Phi=0.7$ case with $T_{a d}=1834 \mathrm{~K}$, the equivalence ratio of each of the biofuel mixtures was first adjusted to match $T_{a d}=1834 \mathrm{~K}$, and then $Q_{t o t}$ was varied until the $H R R_{H H V}$ was matched at $36.2 \mathrm{~kW}$. With these conditions held constant, the swirl number was subsequently lowered to the relevant near-blowoff condition, and the PIV measurement was taken. This same procedure was repeated to match conditions for the methane case at $\Phi=0.8$ where $T_{a d}=1992 \mathrm{~K}$ and $H R R_{H H V}=41.2 \mathrm{~kW}$. Both flame fronts look similar, with an obvious ' $W$ ' shape (though the $\Phi=0.7$ case is asymmetric). The flame heights are similar at about $50 \mathrm{~mm}$ from the burner exit and the maximum radial divergence of about $20^{\circ}$ in both cases. 

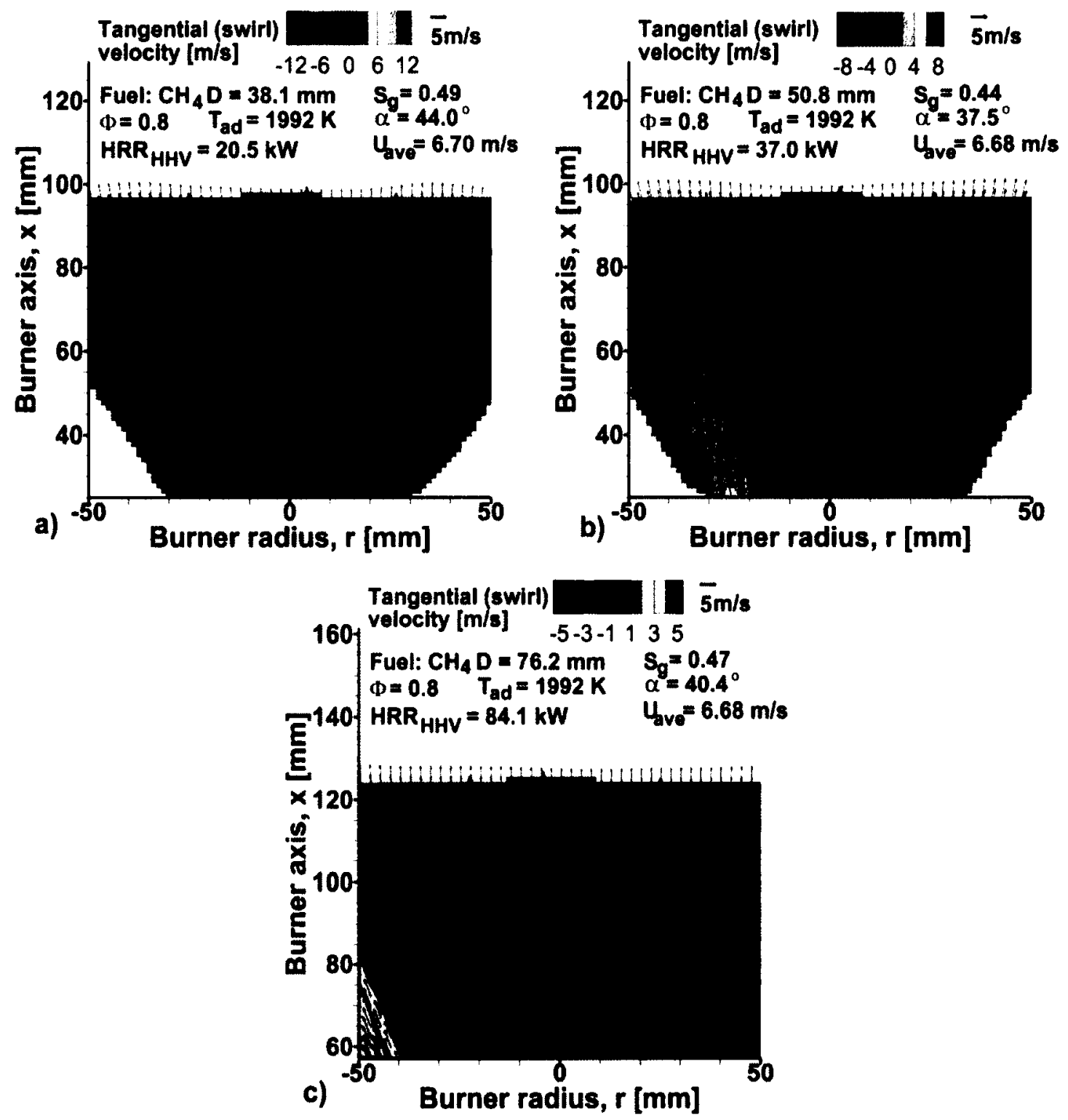

Figure 5.6: Velocity fields measured via PIV at near blowoff conditions. Plots show data for the LSB burning methane at $\Phi=0.8$ at an average exit velocity ( $\left.U_{\text {ave }}\right)$ of $6.7 \mathrm{~m} / \mathrm{s}$ on the a) $38.1 \mathrm{~mm}$ nozzle b) $50.8 \mathrm{~mm}$ nozzle c) $76.2 \mathrm{~mm}$ nozzle 

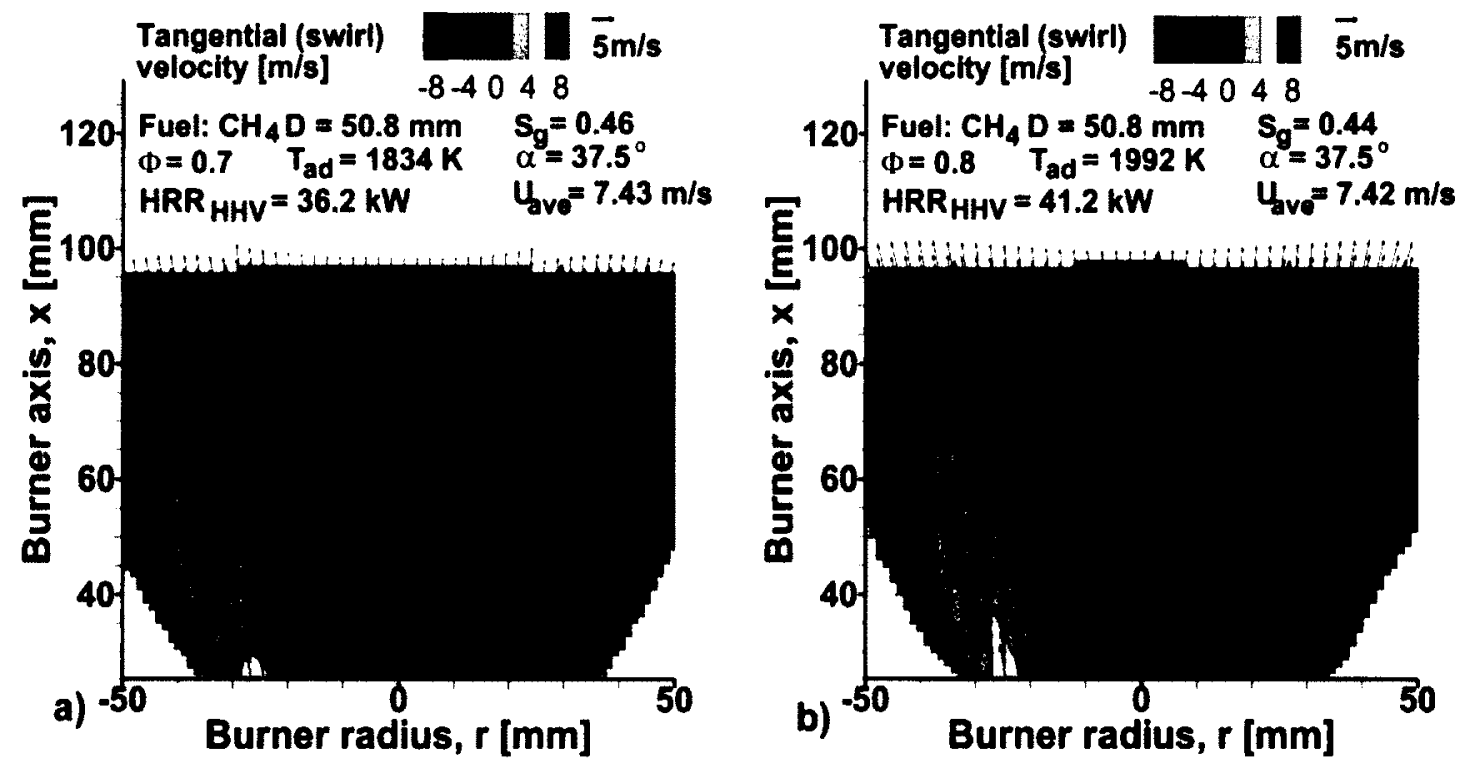

Figure 5.7: Velocity fields measured via PIV at near blowoff conditions. Plots show data for the LSB burning methane on the $50.8 \mathrm{~mm}$ nozzle to obtain conditions

for matching biofuel mixture $T_{a d}$ and $H R R_{H H V}$ to the methane case for direct comparison. a) $\Phi=0.7, Q_{t o t}=800$ SLPM and b) $\Phi=0.8, Q_{t o t}=800$ SLPM (repeated from Figure 5.3b)

Figure 5.8 shows the velocity field data for conditions where the $T_{a d}$ and $H R R_{H H V}$ for all of the biofuel mixtures were matched to the methane case at $\Phi=0.7$. The result from B1 is in Figure 5.8a where the flow field looks quite similar to the methane case with a ' $W$ ' shape (albeit asymmetric), a maximum radial divergence angle of $20^{\circ}$, and a similar flame front height at blowoff of $40 \mathrm{~mm}$ at its lowest point (the asymmetry obviously lowers this more than it should, as in Figure 5.6c). This isn't surprising as B1 is $60 \%$ methane, with balance carbon dioxide (a mostly inert gas in this case), and thus would be expected to behave similarly to pure methane. With fuel S1, which contains no methane (Figure 5.8b), the ' $W$ ' shape is similarly apparent and the flame front height at blowoff is similar ( $45 \mathrm{~mm}$ at lowest point). Despite the similarly of the $\mathrm{S} 1$ flowfield in terms of flame front shape, radial divergence angle $\left(20^{\circ}\right)$, and flame height at blowoff, there is a significant difference in the magnitude of the vectors past the flame front. With fuel S1, the vectors past the flame front are clearly much larger than with the reference methane case. This difference in the increase in velocity (denoted as $\Delta U$ ) past the flame front is considered further below. 
Figure 5.8c (fuel S2) again shows a ' $W$ ' flame and an even larger $\Delta U$ across the flame front relative to fuel $\mathrm{S} 1$, presumably related to the increased hydrogen content of the fuel and its correspondingly larger laminar flame speed. Overall, other than a fairly asymmetric ' $W$ ', the S2 flowfield is very similar to the S1 flowfield, with a lower overall flame height likely due to its higher hydrogen content causing it to get closer to the attached flame condition. For fuel S3 (Figure 5.8d) the situation is very different in that the flame has attached to the burner nozzle. The radial divergence of the S3 attached flame is even greater than the ' $W$ ' flames with vectors near the exit plane of the nozzle having radial divergence angles of up to $40^{\circ}$. The $\mathrm{S} 3$ vectors past the flame front are even greater than with $\mathrm{S} 1$ or $\mathrm{S} 2$, again suggesting that the increase in velocity is correlated with the $\mathrm{H}_{2}$ fraction and presumably the laminar flame speed, $S_{L}$.

Figure 5.8e-j (S4, S5, S6, S14, S5M50, S5M25) show the same properties as expected based on the results from the reference methane case and B1, S1-S3 (i.e. 'W' shaped flame, similar flame position at blowoff). Again, as $S_{L}$ increases (generally, with $\% \mathrm{H}_{2}$ in the fuel), so does $\Delta U$ across the flame front. For fuel $\mathrm{S} 6$ (Figure 5.8g), the flame does not attach as in the S3 case, but it appears to be getting close as evident by its asymmetry and lower overall flame height. This same occurrence of being "close" to the attached condition is seen in the S14 flowfield (Figure 5.8h), but not to the extent of the S6 flowfield. 

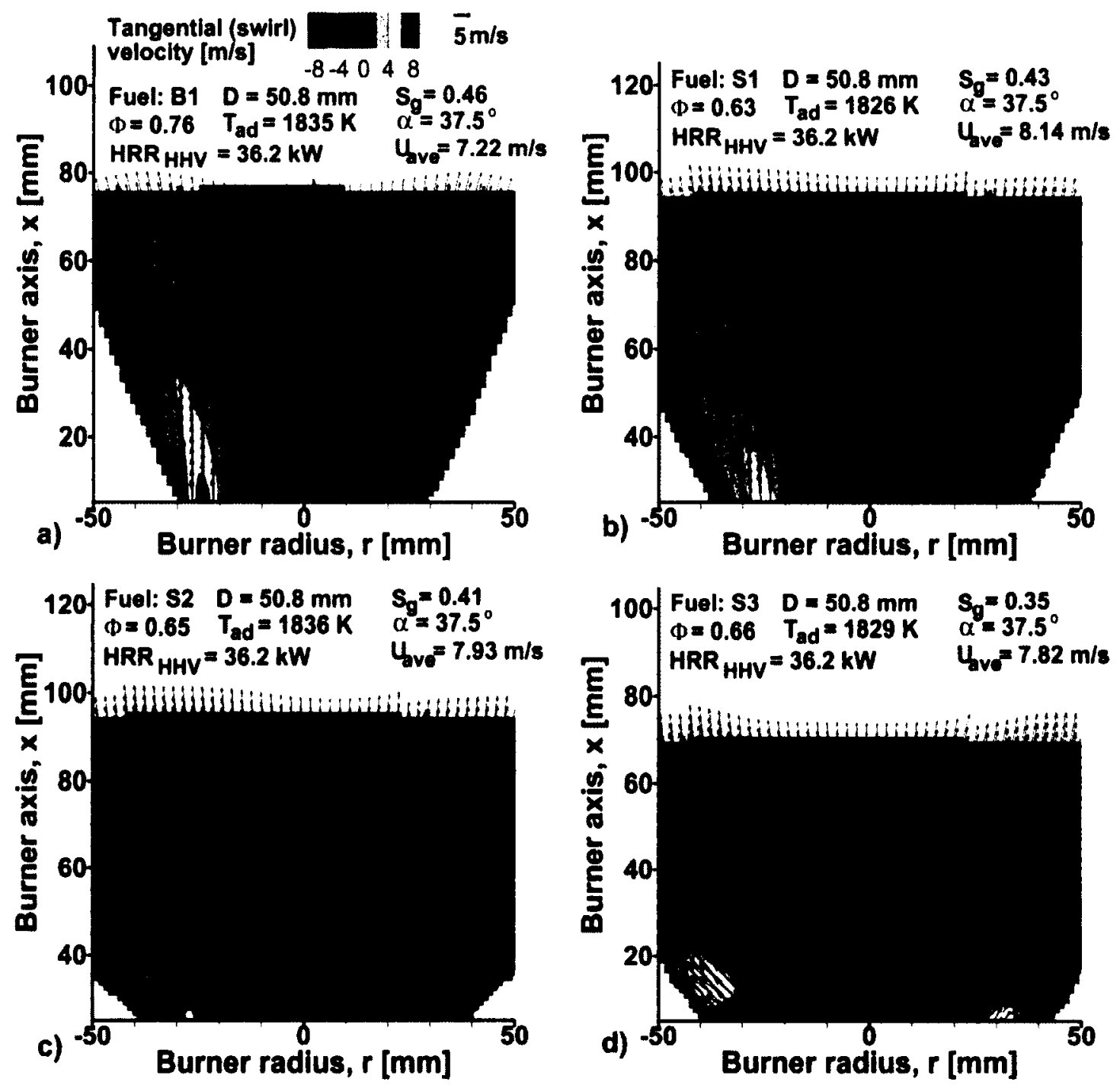

Figure 5.8: Velocity fields measured via PIV at near blowoff conditions. Plots show data for the LSB on the $50.8 \mathrm{~mm}$ nozzle with matched $T_{a d}$ and $H R R_{H H V}$ to the methane case of Figure 5.7a for direct comparison. a) B1 b) S1 c) S2 d) S3 e) S4 f) S5 g) S6 h) S14 i) S5M50 j) S5M25 

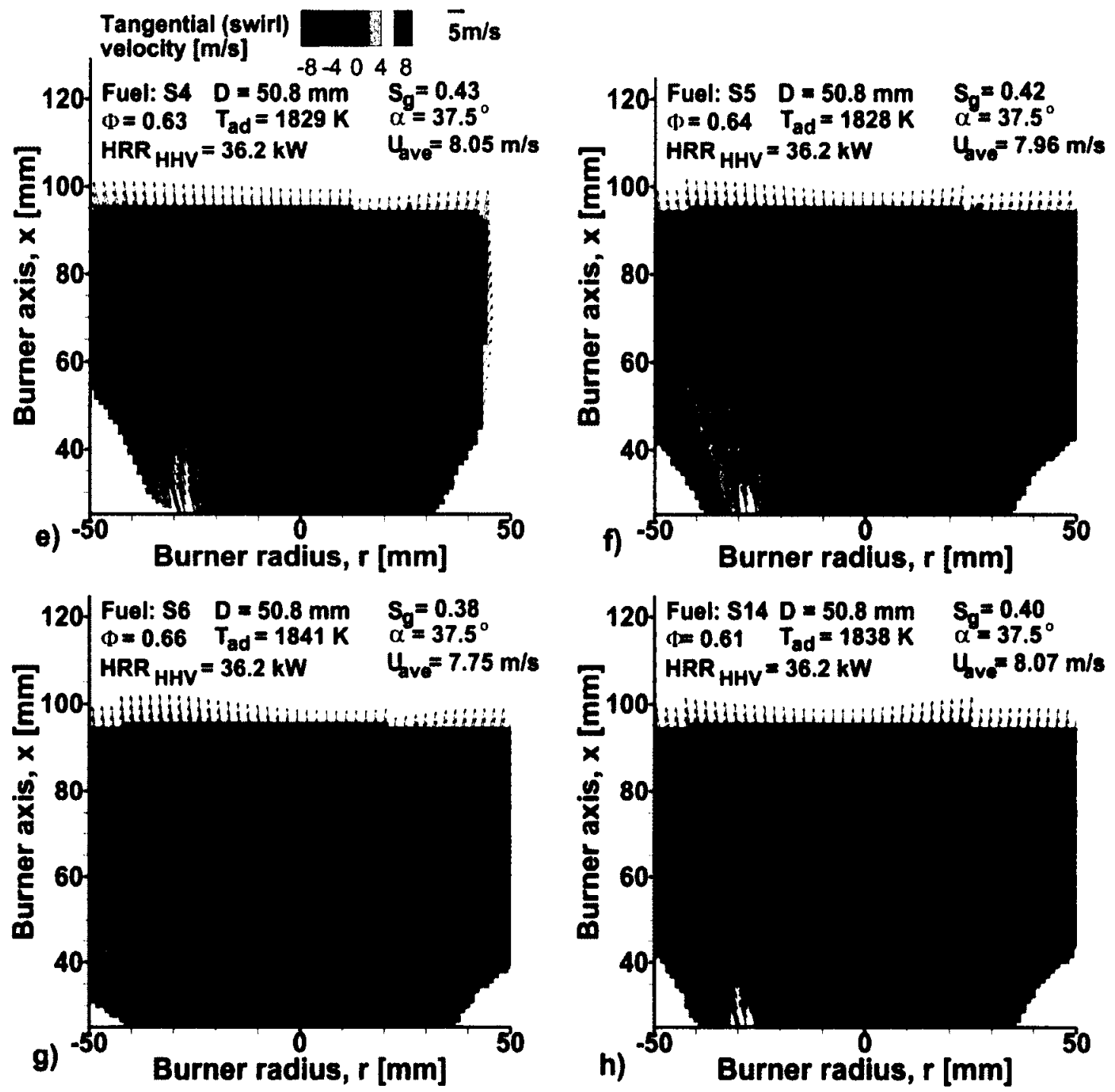

Figure 5.8: (continued) Velocity fields measured via PIV at near blowoff conditions. Plots show data for the LSB on the $50.8 \mathrm{~mm}$ nozzle with matched $T_{a d}$ and $H R R_{H H V}$ to the methane case of Figure 5.7a for direct comparison. a) B1 b) S1 c) S2 d) S3 e) S4 f) S5 g) S6 h) S14 i) S5M50 j) S5M25 

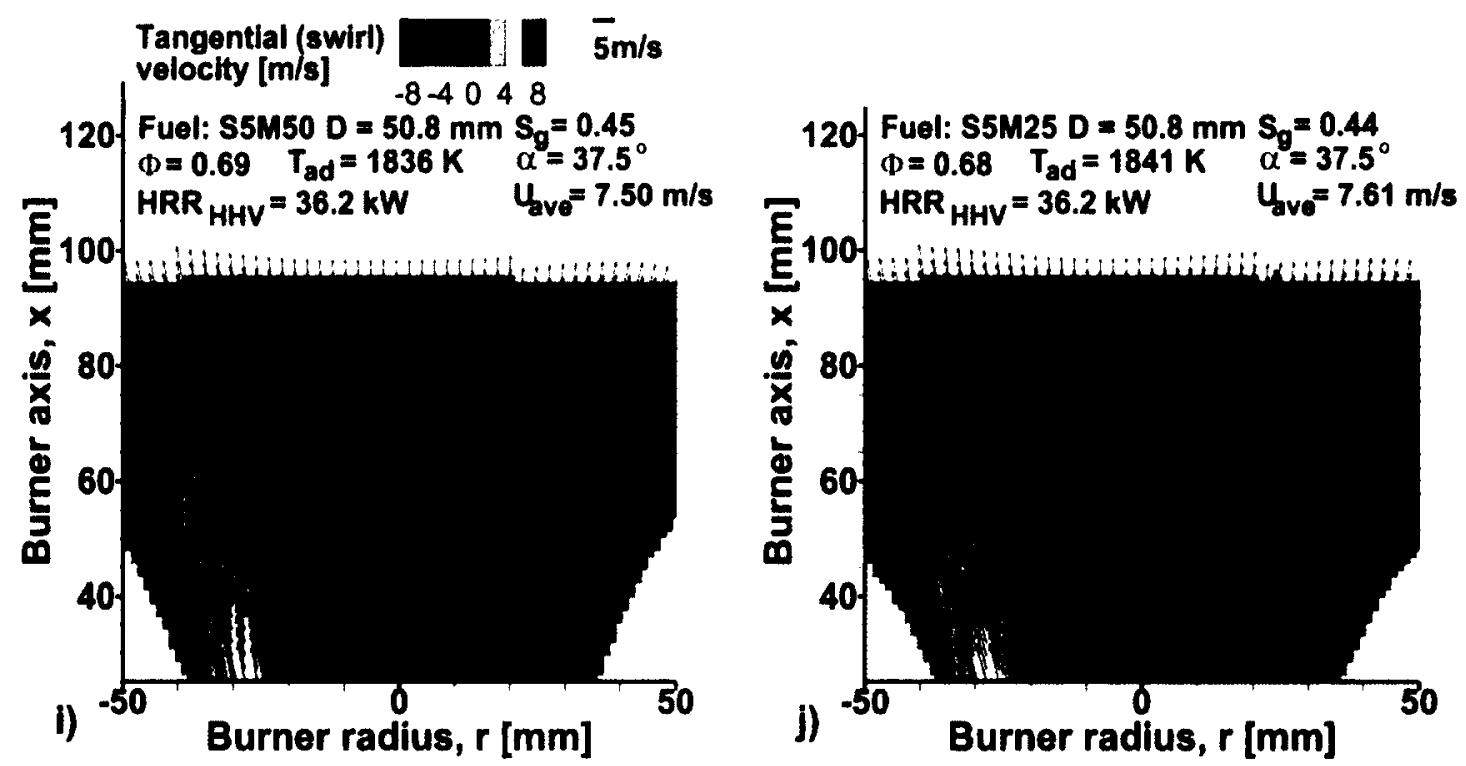

Figure 5.8: (continued) Velocity fields measured via PIV at near blowoff conditions. Plots show data for the LSB on the $50.8 \mathrm{~mm}$ nozzle with matched $T_{a d}$ and $H R R_{H H V}$ to the methane case of Figure 5.7a for direct comparison. a) B1 b) S1 c) S2 d) $S 3$ e) $S 4$ f) S5 g) $S 6$ h) $S 14$ i) $S 5 M 50$ j) $S 5 M 25$

Figure 5.9 shows the results of matching $T_{a d}$ and the $H R R_{H H V}$ to the methane case at $\Phi=0.8$ and $H R R_{H H V}=41.2 \mathrm{~kW}$. The trends are quite similar to the observations from the $\Phi=0.7$ matching case (Figure 5.8). The vectors past the flame fronts $(\Delta U)$ for the syngas fuels are again much larger than the methane or B1 cases, and increase with the $\% \mathrm{H}_{2}$. Again, this is likely due to the relatively higher laminar flame speeds for the syngas fuels as compared to methane at the same $T_{a d}$, as will be explored further below. All unattached flames have maximum radial divergence angles of $20^{\circ}$. The flame front height at blowoff for unattached flames is relatively constant between 40 and $50 \mathrm{~mm}$ from the burner exit plane at the lowest point for most cases with one exception. This exception is a lower flame front height for S14 (Figure 5.9h) due to asymmetry that is likely related to the flow condition being very close to the attached flame mode. In this case, with $T_{a d}=1994 \mathrm{~K}$ and a $H R R_{H H V}$ of $41.2 \mathrm{~kW}$, the flame is just above the area where attached flames occurred. As discussed in Section 4.1.3, the attachment phenomenon is highly correlated to the laminar flame speed, but not completely. A comparison of the flowfield properties of the matched biofuel mixtures and the reference methane cases is shown in Table 5.1. 

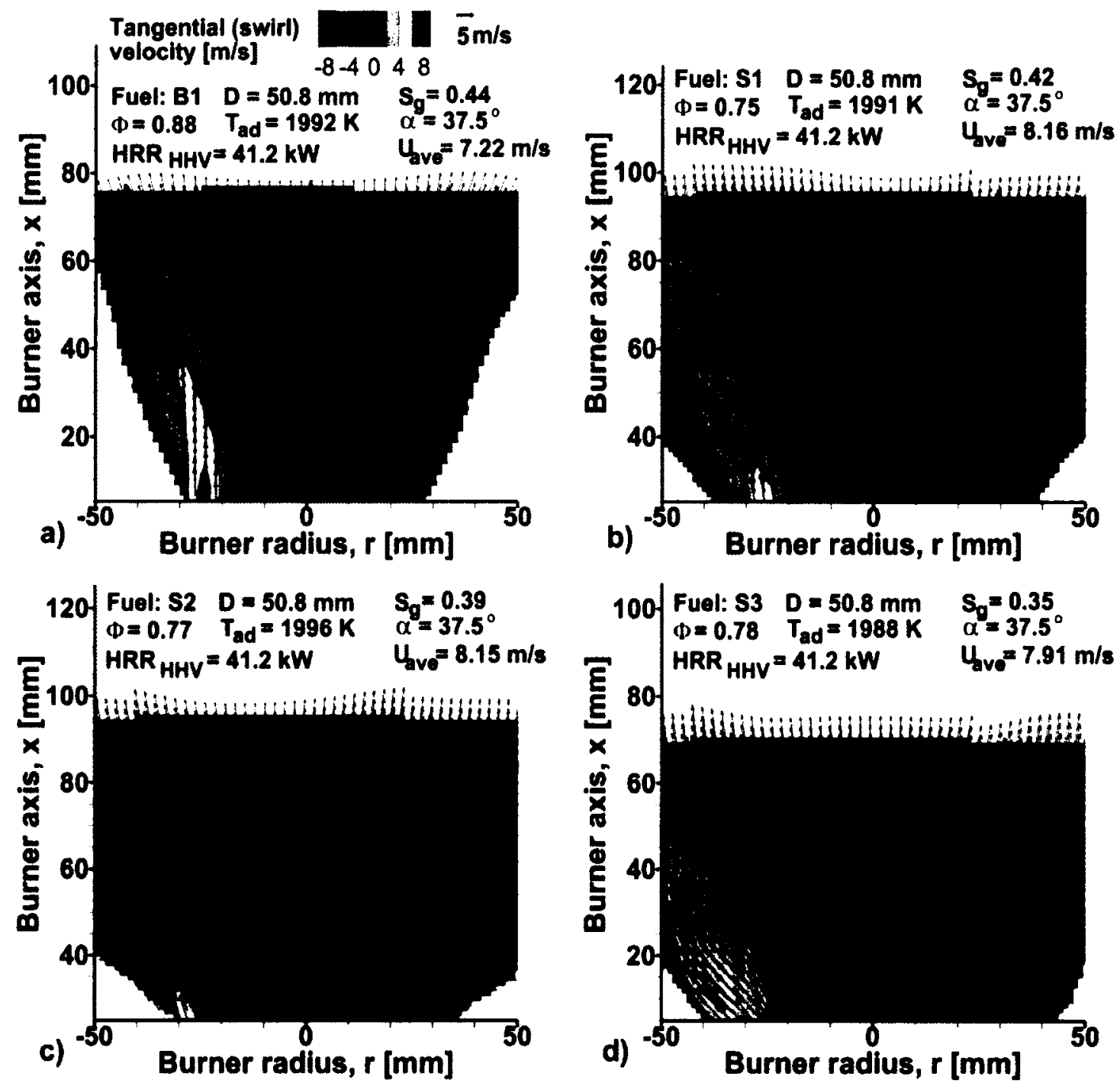

Figure 5.9: Velocity fields measured via PIV at near blowoff conditions. Plots show data for the LSB on the $50.8 \mathrm{~mm}$ nozzle with matched $T_{a d}$ and $H R R_{H H V}$ to the methane case of Figure $5.7 \mathrm{~b}$ for direct comparison. a) B1 b) S1 c) S2 d) S3 e) S4 f) S5 g) $S 6$ h) S14 i) S5M50 j) S5M25 

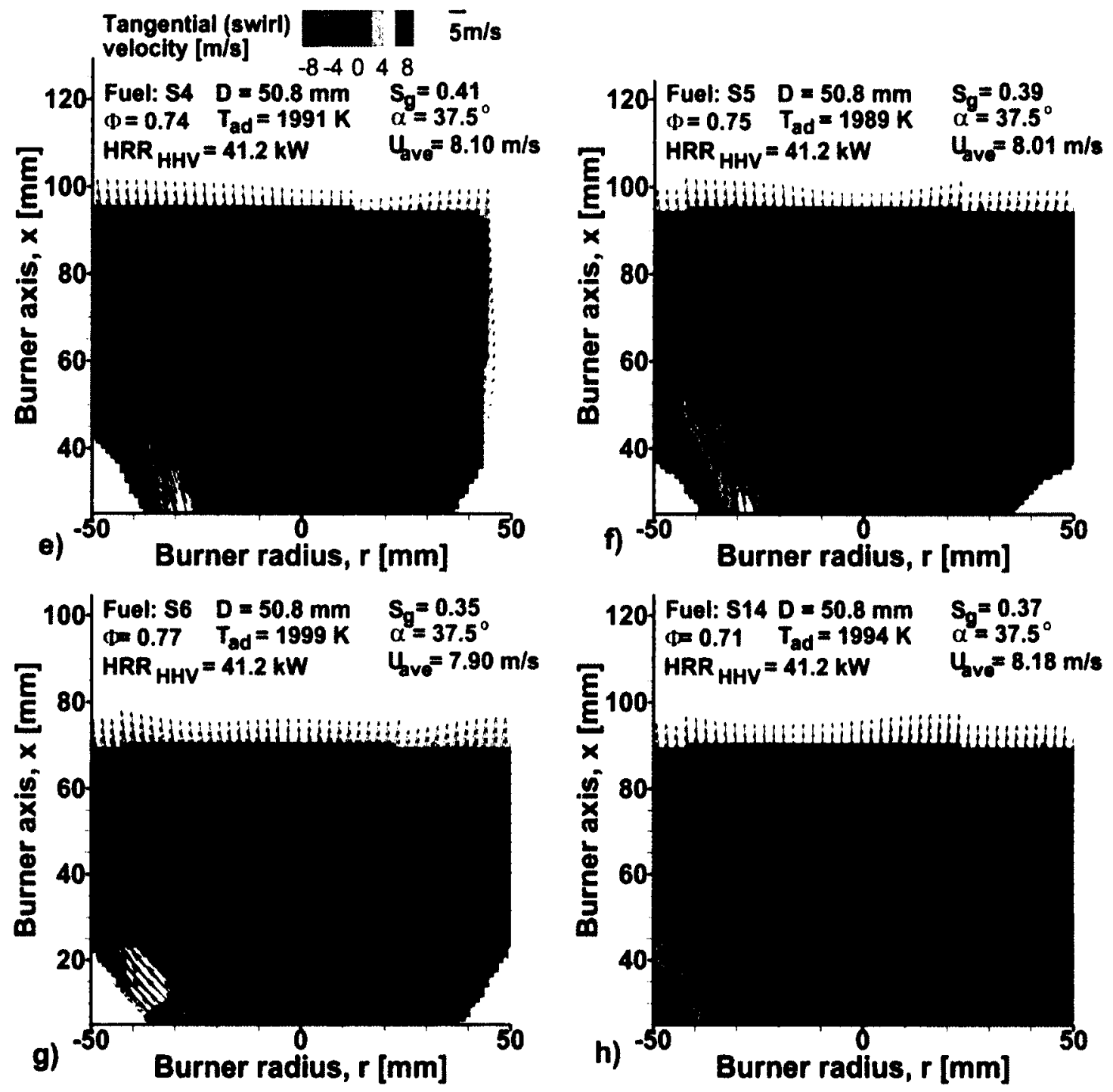

Figure 5.9: (continued) Velocity fields measured via PIV at near blowoff conditions. Plots show data for the LSB on the $50.8 \mathrm{~mm}$ nozzle with matched $T_{a d}$ and $H R R_{H H V}$ to the methane case of Figure 5.7b for direct comparison. a) B1 b) S1 c) S2 d) S3 e) S4 f) S5 g) S6 h) S14 i) S5M50 j) S5M25 

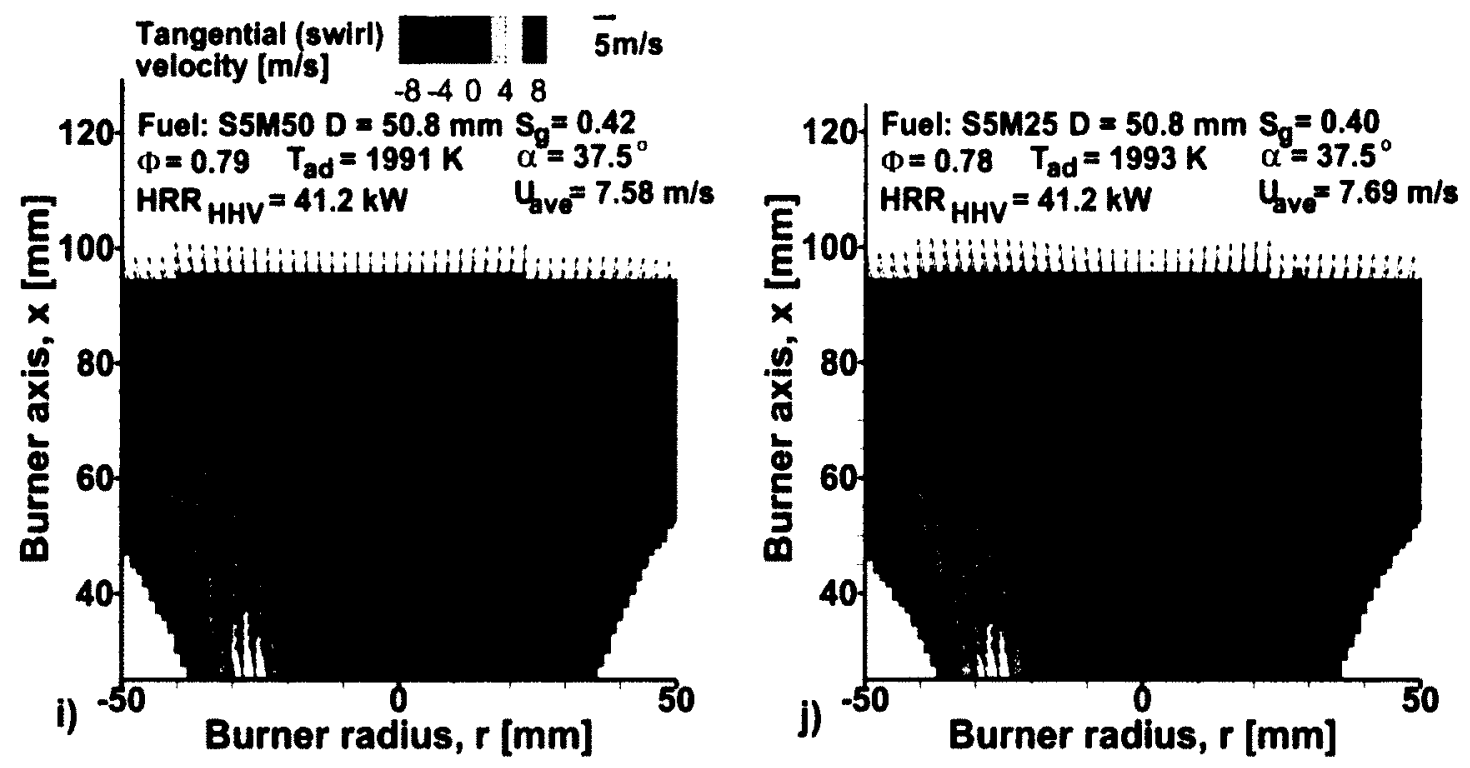

Figure 5.9: (continued) Velocity fields measured via PIV at near blowoff conditions. Plots show data for the LSB on the $50.8 \mathrm{~mm}$ nozzle with matched $T_{a d}$ and $H R R_{H H V}$ to the methane case of Figure 5.7b for direct comparison. a) B1 b) S1 c) S2 d) $S 3$ e) S4 f) $S 5$ g) S6 h) S14 i) S5M50 j) S5M25

\subsection{Flame height at blowoff}

Figure 5.10 shows the flame height for each PIV condition at blowoff measured along its centerline. Flame heights were calculated via image processing as explained in Chapter 4 as the height of the flame front above the burner exit plane along the centerline of the burner. Defining the height along the centerline mitigated any potential effects of asymmetries in the flame when present. There is a general trend of increasing height with LSB diameter as noted previously in Section 5.3 such that the flame sits approximately one burner exit diameter downstream at blowoff for all three nozzles. However, there are several exceptions to this trend that are labeled on the figure. One of these labeled conditions was for an S14 fuel case that was very close to becoming attached, and the rest were indicative of the Rrather than W-type blowoff mode, as partially inferred from the observed PIV flowfield (See Section 5.8 below for further discussion). 


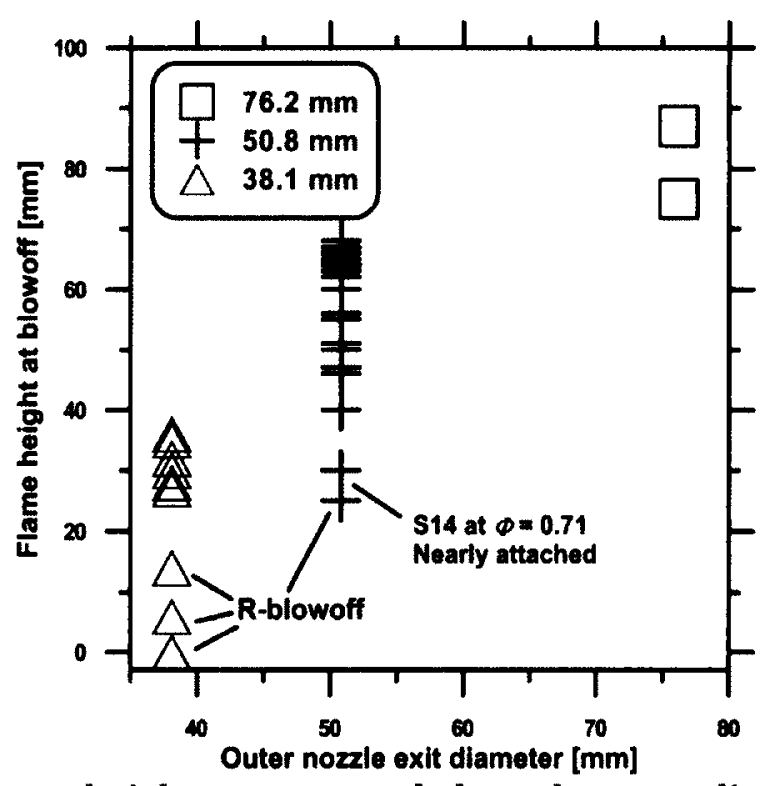

Figure 5.10: Flame height as measured along the centreline for all blowoff PIV measurements.

Neglecting flames in the R-type stabilization mode, the scaling of flame height at blowoff is consistent with the observations of Littlejohn and Cheng (2007), who noted that both reacting and non-reacting LSB flowfields exhibited similarity features in terms of the centerline axial velocity profiles. Figure 5.11a shows the centerline axial velocity profiles for the $50.8 \mathrm{~mm}$ nozzle burning methane fuel at $\Phi=0.8$ at three different average flow velocities (total volume flow divided by total area) for flames near W-type blowoff. The results show features consistent with the work of Littlejohn and Cheng (2007). Specifically, there is a linear axial velocity decay region approaching the flame front which is followed by a rapid acceleration as the flow crosses the flame front. For all three flow velocities, the minimum axial velocity point occurs just before the positions of the flame front measured along the burner centerline. For the $U_{\text {ave }}=3.72 \mathrm{~m} / \mathrm{s}$ case, the flame front height along the centerline was $60 \mathrm{~mm}$ from the burner exit plane, while the minimum axial velocity occurs at $49 \mathrm{~mm}$. The $U_{\text {ave }}=7.41$ and $11.1 \mathrm{~m} / \mathrm{s}$ cases have flame front heights of 60 and $55 \mathrm{~mm}$ and positions of minimum axial velocity of 59 and $49 \mathrm{~mm}$ respectively. These trends are also consistent with the suggestion by Littlejohn and Cheng (2007) that the overall effect of the flame is equivalent to an aerodynamic blockage to the flow supplied by the LSB. For all three flowrates, the minimum centerline axial 
velocity is relatively constant. This could explain why the flame height at blowoff remains fairly constant as the total flow rate changes.

Figure $5.11 \mathrm{~b}$ shows the axial velocity profiles for methane fuel near $\mathrm{W}$-type blowoff at $\Phi=0.7$ for all three nozzles where $U_{\text {ave }}$ is matched at $6.70 \mathrm{~m} / \mathrm{s}$.

Corresponding mean velocity fields were shown previously in Figure 5.5. The results show that the minimum axial velocities again occur right before the location of the flame front, approximately one nozzle diameter from the burner exit plane. As the average velocity is matched, each profile shows a nearly constant axial velocity at the flame front, though there is a slight decreasing trend with nozzle diameter. From these results, the following observations can be made:

- Increasing $U_{a v e}$ while holding the exit diameter constant does not significantly change the flame height at blowoff;

- Increasing $U_{a v e}$ does not significantly change the minimum axial velocity at blowoff

- Increasing the burner diameter with $U_{\text {ave }}$ held constant shifts the location of the flame at blowoff downstream; and

- Increasing the burner diameter with $U_{a v e}$ held constant does not significantly affect the axial velocity at blowoff.

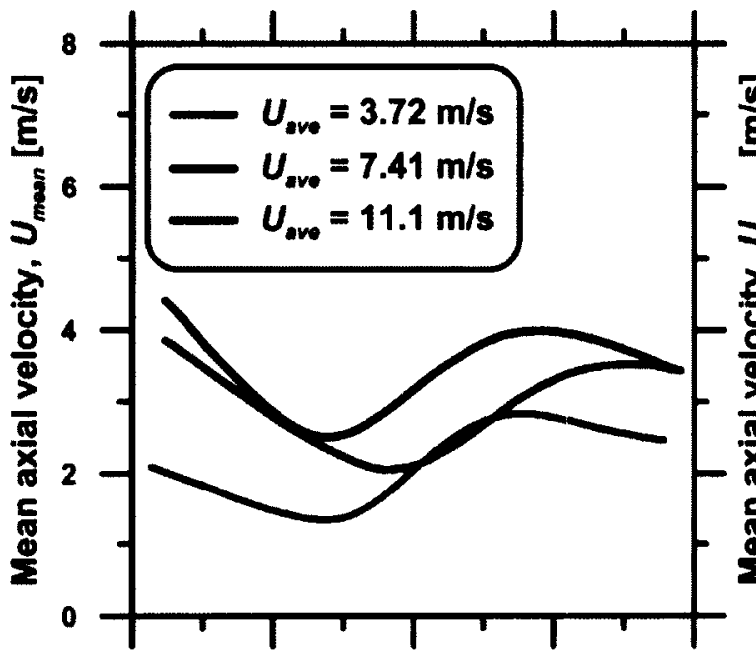

a) 20
100

b)

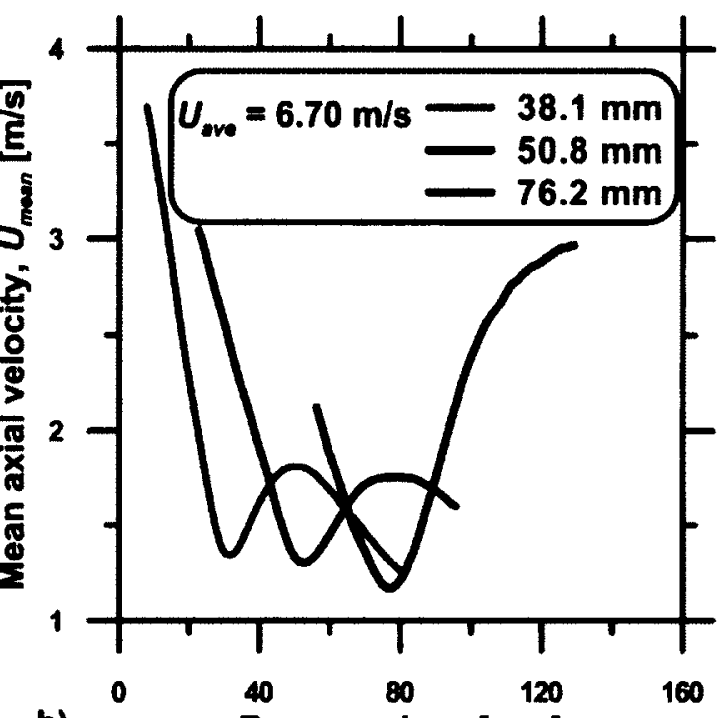
5ure 5.11: Centreline axial velocity profiles for $\mathrm{CH}_{4}$ at a) $\Phi=0.8$ for the $50.8 \mathrm{~mm}$ nozzle at $U_{\text {ave }}=3.72,7.41,11.1 \mathrm{~m} / \mathrm{s}$ b) $\Phi=0.7$ for all nozzles at

$$
U_{a v e}=6.70 \mathrm{~m} / \mathrm{s}
$$




\subsection{Measurements of Velocity Increase through the Flame Front}

According to Littlejohn et al. (2010), the velocity increase across a premixed flame, $\Delta U$, can be estimated as $\Delta U=S_{L}(\tau-1)$, where $\tau$ is the expansion ratio $T_{a d} / T_{0}$, where $T_{0}$ is the incoming premixed gas temperature. This formula assumes that the molar ratio of products to reactants is unity, which is not precisely the case for the matched biofuel conditions as presented in Table 5.1. Although the molar ratios are close to unity, for completeness $\tau$ will be calculated as $\left(T_{a d}{ }^{*} N_{P}\right) /\left(T_{0}{ }^{*} N_{R}\right)$ where $N_{P}$ and $N_{R}$ are the number of moles of products and reactants respectively. To test the validity of this approach for estimating $\Delta U$, a measurement of the velocity increase past the flame front was taken along the centerline axial velocity profiles of the flames, using the simple procedure as illustrated in Figure 5.12. Because the centerline streamline is essentially vertical in all cases, extraction of axial velocity profiles was straightforward. Figure 5.13 compares the measured and calculated velocity rise through the flame front for the all PIV measurement cases for the various bio- and syn-gas fuels referenced to methane. Numerical values are also included in Table 5.1. It is clear from this figure that the calculated $\Delta U$ completely underestimates the measured value at the $\Phi=0.7$ matched conditions, but a reasonably accurate estimate of the velocity increase is seen at the $\Phi=0.8$ matched conditions. This implies that the technique might be useful to estimate $\Delta U$ for a biogas or syngas fuel mixture relative to methane at higher flame temperatures, but not at lower flame temperatures.

\subsection{Estimates of Turbulent Flame Speed from Velocity Field Data}

As defined in the introduction, Cheng (2010) defines the turbulent flame speed for the LSB as the local displacement speed, $S_{T, L D}$ (Eq.(1.1))which is the minimum axial velocity along the centreline of the flame as in Figure 5.12. This generally occurs just before the flame front (See Figure 5.11). However, given the importance of the shear layer in stabilizing low-swirl flames (see Section 5.8) as further discussed in Strahman (2007) and Nogenmyr (2010), it is perhaps more relevant to define a turbulent flame speed at the lowest (farthest upstream) portion of the flame front. For a W-type flame, the point occurs at the shear layer between the 
inner core flow and outer annular flow, termed the anchor point by Strahman (2007). At the anchor point, the local slope of the 'W'shaped flame is horizontal in the plane of the PIV measurement, such that the flow velocity of the reactants in the axial direction balances the apparent turbulent flame speed. The location of the lowest anchor point is determined from PIV flame fronts, and then the minimum axial velocity along the profile at that radial location is taken to be the 'anchor point' turbulent flame speed, $S_{T, A P}$, as shown in Figure 5.12.

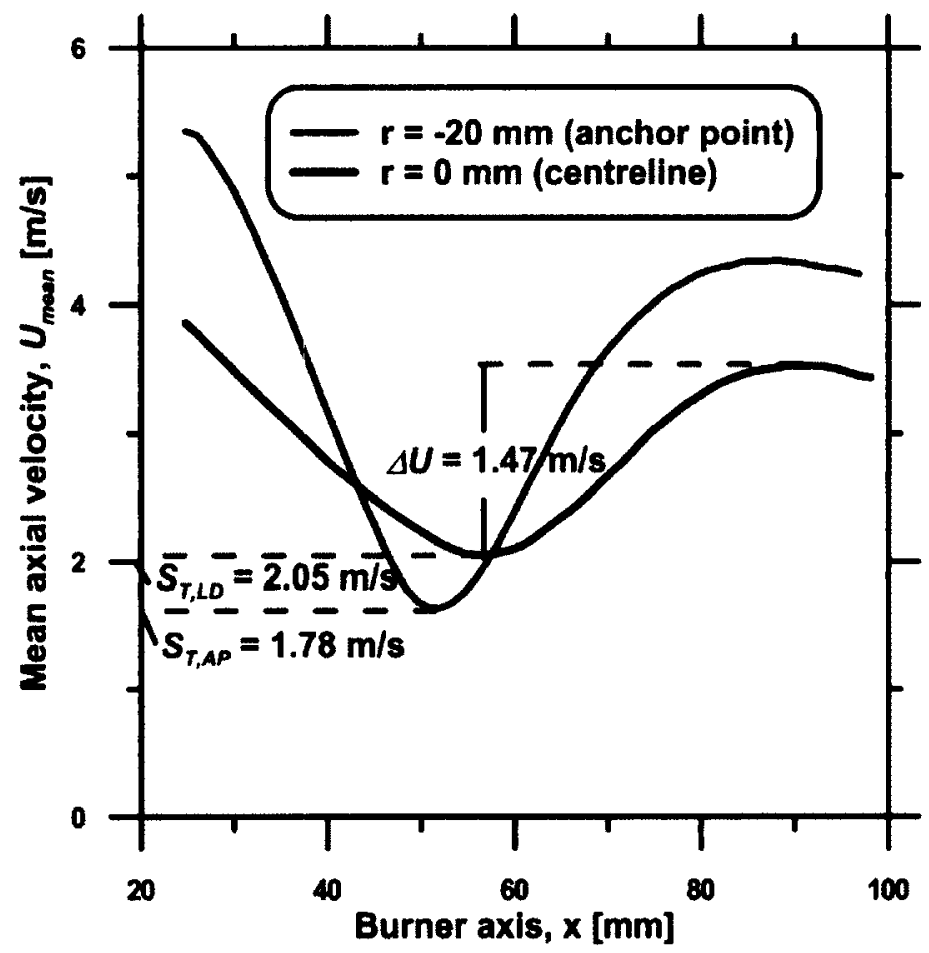

Figure 5.12: Centreline $(r=0 \mathrm{~mm})$ and anchor point $(r=-20 \mathrm{~mm})$ axial velocity profiles for the reference methane case at $\Phi=0.8$. Example for how the turbulent flame speeds, $S_{T, L D}$ and $S_{T, A P}$, and velocity increase past the flame front, $\Delta U$, are measured. 


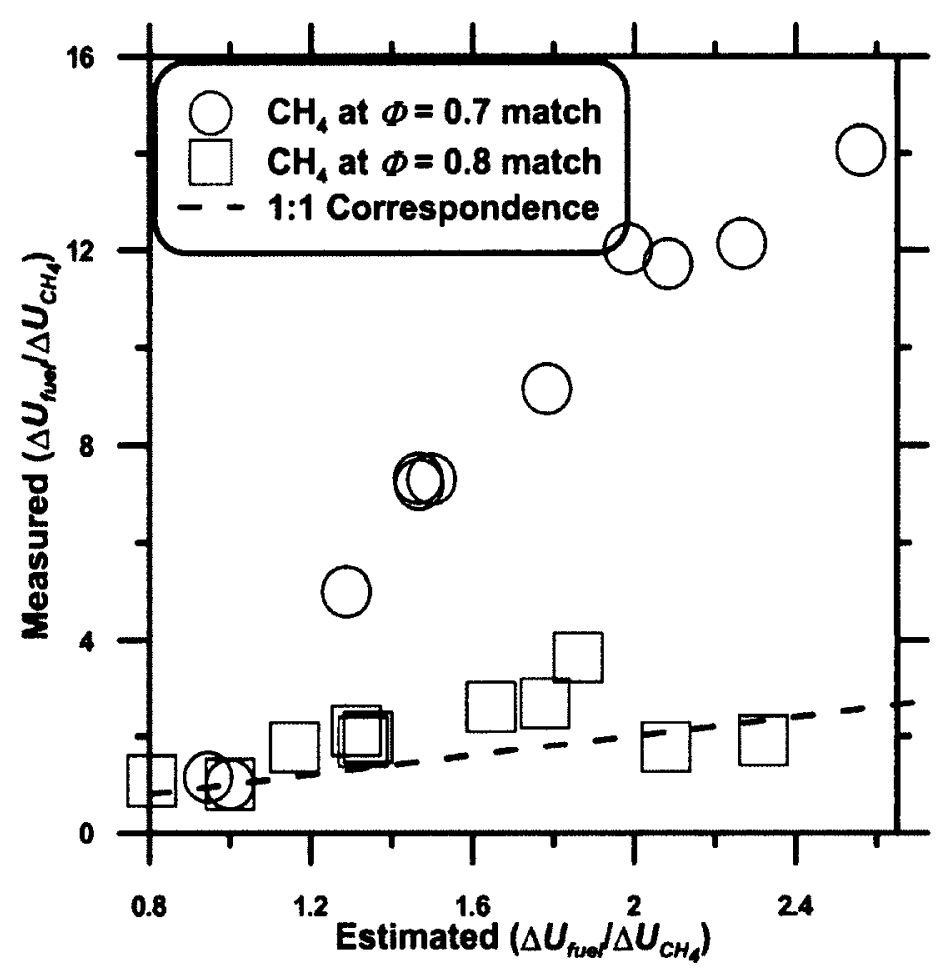

Figure 5.13: Measured velocity increase past flame front plotted against estimated velocity increase past flame front, both as compared to reference methane case

Using these procedures, the turbulent flame speeds for the reference methane and matched fuel mixture cases were measured, as summarized in Table 5.1. With the exception of fuel B1, every syngas fuel mixture has a significantly higher turbulent flame speed than the reference methane case at both the centreline and anchor point locations. They also have significantly higher laminar flame speeds, implying a correlation. Figure 5.14 shows the results from this study on the plot from Kido et al. (2002) testing the theory as to whether the hydrogen-containing biofuel mixtures have a higher sensitivity to turbulent fluctuations than methane. Along the centerline, there are no outliers. At the anchor point location, however, there are higher turbulent flame speeds, but only at higher turbulence fluctuations. This shows that no particular mixture appears to be more sensitive to turbulence fluctuations than any other. Thus, from the present results at least, the heightened sensitivities of $\mathrm{H}_{2}$ containing mixtures to turbulence seen by Kido et al. (2002) are not apparent. 
Table 5.1: Comparison of biofuels to methane at matched $T_{a d}$ and $H R R_{H H V}$ near blowoff

\begin{tabular}{|c|c|c|c|c|c|c|c|c|c|c|}
\hline Fuel & $\Phi$ & $T_{a d}[\mathrm{~K}]$ & $\begin{array}{c}H_{R R_{H H V}} \\
{[\mathrm{~kW}]}\end{array}$ & $N_{p} / N_{R}$ & $\begin{array}{c}S_{L} \\
{[\mathrm{~m} / \mathrm{s}]}\end{array}$ & $\begin{array}{c}S_{T, 10} \\
{[\mathrm{~m} / \mathrm{s}]}\end{array}$ & $\begin{array}{c}S_{T, A P} \\
{[\mathrm{~m} / \mathrm{s}]}\end{array}$ & $\left(\frac{\Delta U_{\text {fuel }}}{\Delta U_{C H_{4}}}\right)_{\text {est. }}$ & $\left(\frac{\Delta U_{f u e l}}{\Delta U_{C H_{4}}}\right)_{\text {meas }}$ & $\begin{array}{c}\text { Flame } \\
\text { comparison to } \\
\mathrm{CH}_{4}\end{array}$ \\
\hline $\mathrm{CH}_{4}$ & 0.7 & 1834 & 36.2 & 1 & 0.17 & 1.30 & 1.30 & 1 & 1 & \\
\hline B1 & 0.76 & 1835 & 36.2 & 1 & 0.15 & 1.31 & 1.11 & 0.95 & 1.15 & $\begin{array}{c}\text { Same height } \\
\text { and shape }\end{array}$ \\
\hline S1 & 0.63 & 1826 & 36.2 & 0.93 & 0.24 & 2.69 & 2.19 & 1.47 & 7.32 & $\begin{array}{l}\text { Same height } \\
\text { and shape }\end{array}$ \\
\hline S2 & 0.65 & 1836 & 36.2 & 0.95 & 0.32 & 3.03 & 2.82 & 1.98 & 12.0 & $\begin{array}{l}\text { Lower height, } \\
\text { same shape }\end{array}$ \\
\hline S3 & 0.66 & 1829 & 36.2 & 0.97 & 0.42 & 5.49 & $\mathrm{~N} / \mathrm{A}$ & 2.56 & 14.1 & $\begin{array}{l}\text { Attached } \\
\text { flame }\end{array}$ \\
\hline S4 & 0.63 & 1829 & 36.2 & 0.95 & 0.25 & 2.99 & 4.92 & 1.47 & 7.20 & $\begin{array}{l}\text { Same height } \\
\text { and shape }\end{array}$ \\
\hline S5 & 0.64 & 1828 & 36.2 & 0.96 & 0.30 & 2.93 & 4.86 & 1.78 & 9.16 & $\begin{array}{c}\text { Same height } \\
\text { and shape }\end{array}$ \\
\hline S6 & 0.66 & 1841 & 36.2 & 0.97 & 0.39 & 3.64 & 3.97 & 2.27 & 12.1 & $\begin{array}{l}\text { Lower height, } \\
\text { same shape }\end{array}$ \\
\hline $\mathrm{S} 14$ & 0.61 & 1838 & 36.2 & 0.95 & 0.33 & 3.15 & 3.93 & 2.08 & 11.7 & $\begin{array}{c}\text { Same height } \\
\text { and shape }\end{array}$ \\
\hline S5M50 & 0.69 & 1836 & 36.2 & 0.99 & 0.20 & 1.96 & 1.59 & 1.29 & 5.00 & $\begin{array}{l}\text { Same height } \\
\text { and shape }\end{array}$ \\
\hline S5M25 & 0.68 & 1841 & 36.2 & 0.98 & 0.24 & 2.20 & 2.23 & 1.50 & 7.30 & $\begin{array}{c}\text { Same height } \\
\text { and shape }\end{array}$ \\
\hline $\mathrm{CH}_{4}$ & 0.8 & 1992 & 41.2 & 1 & 0.25 & 2.05 & 1.78 & 1 & 1 & \\
\hline B1 & 0.88 & 1992 & 41.2 & 1 & 0.20 & 1.46 & 1.87 & 0.81 & 1.07 & $\begin{array}{l}\text { Same height } \\
\text { and shape }\end{array}$ \\
\hline S1 & 0.75 & 1991 & 41.2 & 0.93 & 0.34 & 2.99 & 2.53 & 1.31 & 2.11 & $\begin{array}{c}\text { Same height } \\
\text { and shape }\end{array}$ \\
\hline S2 & 0.77 & 1996 & 41.2 & 0.94 & 0.46 & 3.97 & 4.92 & 1.78 & 2.69 & $\begin{array}{c}\text { Lower height, } \\
\text { same shape }\end{array}$ \\
\hline S3 & 0.78 & 1988 & 41.2 & 0.96 & 0.59 & 5.57 & $\mathrm{~N} / \mathrm{A}$ & 2.32 & 1.91 & $\begin{array}{l}\text { Attached } \\
\text { flame }\end{array}$ \\
\hline S4 & 0.74 & 1991 & 41.2 & 0.94 & 0.35 & 3.36 & 4.51 & 1.34 & 1.97 & $\begin{array}{l}\text { Same height } \\
\text { and shape }\end{array}$ \\
\hline S5 & 0.75 & 1989 & 41.2 & 0.95 & 0.43 & 3.26 & 4.83 & 1.64 & 2.60 & $\begin{array}{l}\text { Same height } \\
\text { and shape }\end{array}$ \\
\hline S6 & 0.77 & 1999 & 41.2 & 0.97 & 0.56 & 5.53 & $\mathrm{~N} / \mathrm{A}$ & 2.08 & 1.77 & $\begin{array}{l}\text { Attached } \\
\text { flame }\end{array}$ \\
\hline $\mathrm{S} 14$ & 0.71 & 1994 & 41.2 & 0.94 & 0.47 & 3.81 & 4.26 & 1.86 & 3.65 & $\begin{array}{c}\text { Lower height, } \\
\text { same shape }\end{array}$ \\
\hline S5M50 & 0.79 & 1991 & 41.2 & 0.99 & 0.28 & 2.17 & 2.39 & 1.16 & 1.77 & $\begin{array}{c}\text { Same height } \\
\text { and shape }\end{array}$ \\
\hline $55 \mathrm{M} 25$ & 0.78 & 1993 & 41.2 & 0.98 & 0.33 & 2.68 & 3.20 & 1.33 & 1.88 & $\begin{array}{c}\text { Same height } \\
\text { and shape }\end{array}$ \\
\hline
\end{tabular}



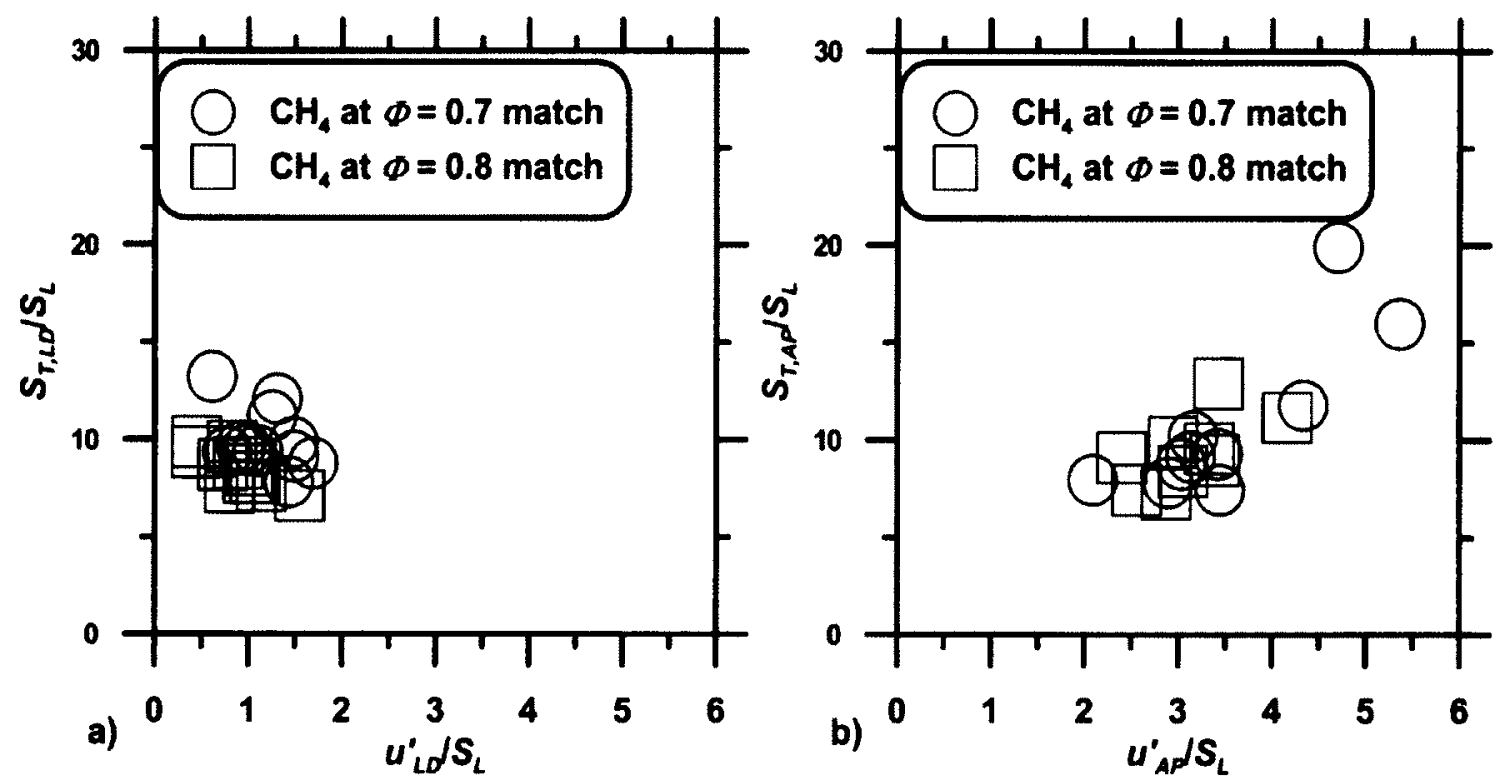

Figure 5.14: The sensitivity of the turbulent flame speeds of to turbulent fluctuations normalized by laminar flame speed. a) Turbulent flame speeds measured as defined by the local displacement speed (Cheng, 2010)b) Turbulent flame speeds measured at the anchor point

Figure 5.15 shows the both the local displacement turbulent flame speed and anchor point turbulent flame speed for all of the methane and bio/syngas ' $W$ '-type flames presented above. Both show a linear correlation with laminar flame speed. The high laminar flame speed of hydrogen is thus responsible for both the high velocity increase past the flame front, and high turbulent flame speeds. These data support the notion that the flame attachment phenomenon observed with certain $\mathrm{H}_{2}$ containing mixtures is predominantly related to enhancement of $S_{L}$, even though the results of Figure 4.9 suggest that some unknown secondary factors are likely also relevant. The exact mechanisms of flame attachment with $\mathrm{H}_{2}$ containing mixtures are a possible topic for future work. 


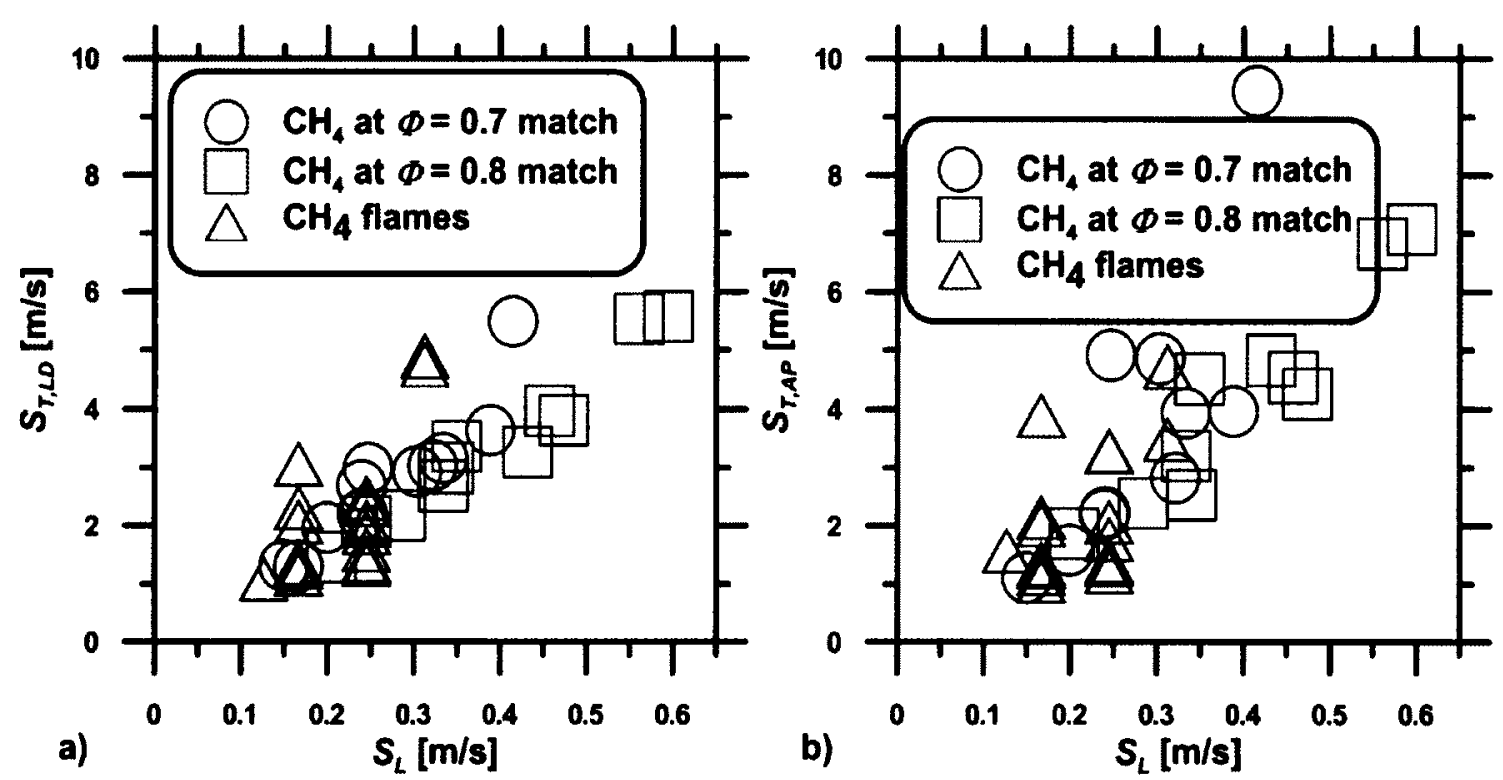

Figure 5.15: Turbulent flame speeds for all ' $W$ '-methane flames and all biofuel cases a) The local displacement turbulent flame speed b) Anchor point turbulent

flame speed

\subsection{Comparison of Flowfields for Apparent Different Stability/Blowoff Modes}

As first noted in the discussion of the blowoff stability limit measurements presented in Chapter 4, it is apparent that there are at least two different types of blowoff mechanisms in the LSB. R-type blowoff occurs for high flowrates and low $\Phi$ and is observed at higher $S$. W-type blowoff occurs at low flowrates for low $\Phi$, and at all tested flowrates for higher $\Phi$. Figure 5.16 shows blowoff curves for the $38.1 \mathrm{~mm}$ LSB nozzle burning methane at $\Phi=0.65$ or 0.7 . These curves are $2 \mathrm{D}$ slices at fixed $\Phi$ of the stability volumes shown previously in Figure 4.4. The labeled asterisks in the figure show conditions for which the PIV measurements were taken to document the different $R$ - and $W$-type blowoff events, as shown in Figure 5.17 to Figure 5.19. 


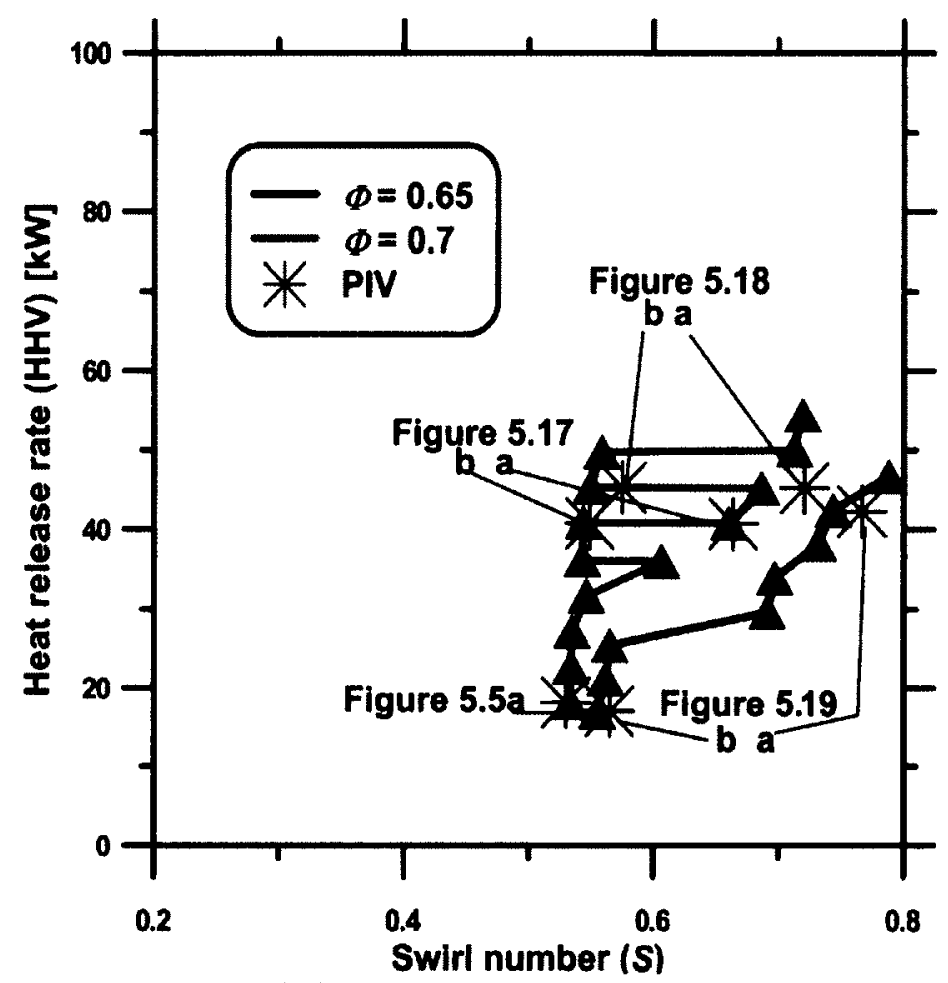

Figure 5.16: 2D stability map showing PIV measurement locations

As seen in Figure 5.17a, the flame front for conditions near R-type blowoff exhibits a rounded tulip-like shape rather than an obvious $W$-shape, which sits lower than the typical flame. The flowfield contains some axial recirculation, and the strong in- and out-of plane swirling action of the flow is still evident downstream of the flame front, curling in radially toward the center of the flame. The flame front near W-type blowoff (Figure 5.17b) is still not quite a typical 'W' shape, but it is wider and obviously further downstream than the flame front at Rtype blowoff conditions. The $\mathrm{W}$-type blowoff flowfield does not show any explicit recirculation, but there is an obvious deceleration in terms of axial velocity along the slightly deflected centerline streamline.

Figure 5.18 shows the same analogous velocity fields near $\mathrm{R}$ - and $\mathrm{W}$-type blowoff, but at a higher heat release rate (increased flowrate). The flame front near R-type blowoff is similar in shape to the lower flowrate condition, but has moved upstream almost to the exit plane. The flowfield shows the swirling flow is even more obviously curling in radially towards the centre of the flame, where there is obviously strong axial recirculation. By contrast, the flame front at conditions near 
W-type blowoff shows a somewhat ' $W$ '-shaped flame front that is downstream of the flame height location near R-type blowoff, and has only a small amount of axial recirculation near the centerline, downstream of the flame front.
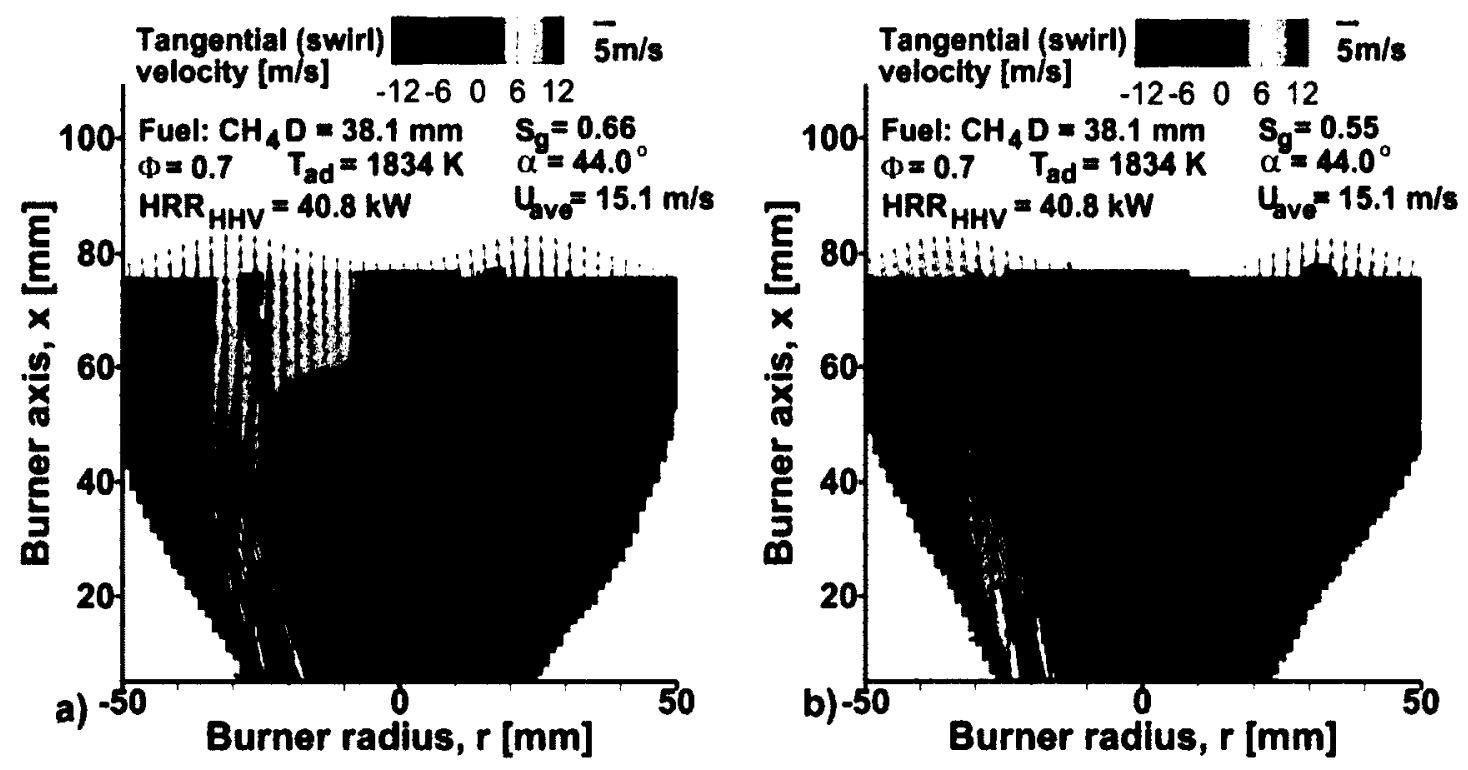

Figure 5.17: Near blowoff for $38.1 \mathrm{~mm}$ nozzle at $\Phi=0.7$ and $H R R_{H H V}=40.8 \mathrm{~kW}$ for a) $S=0.66$ b) $S=0.55$
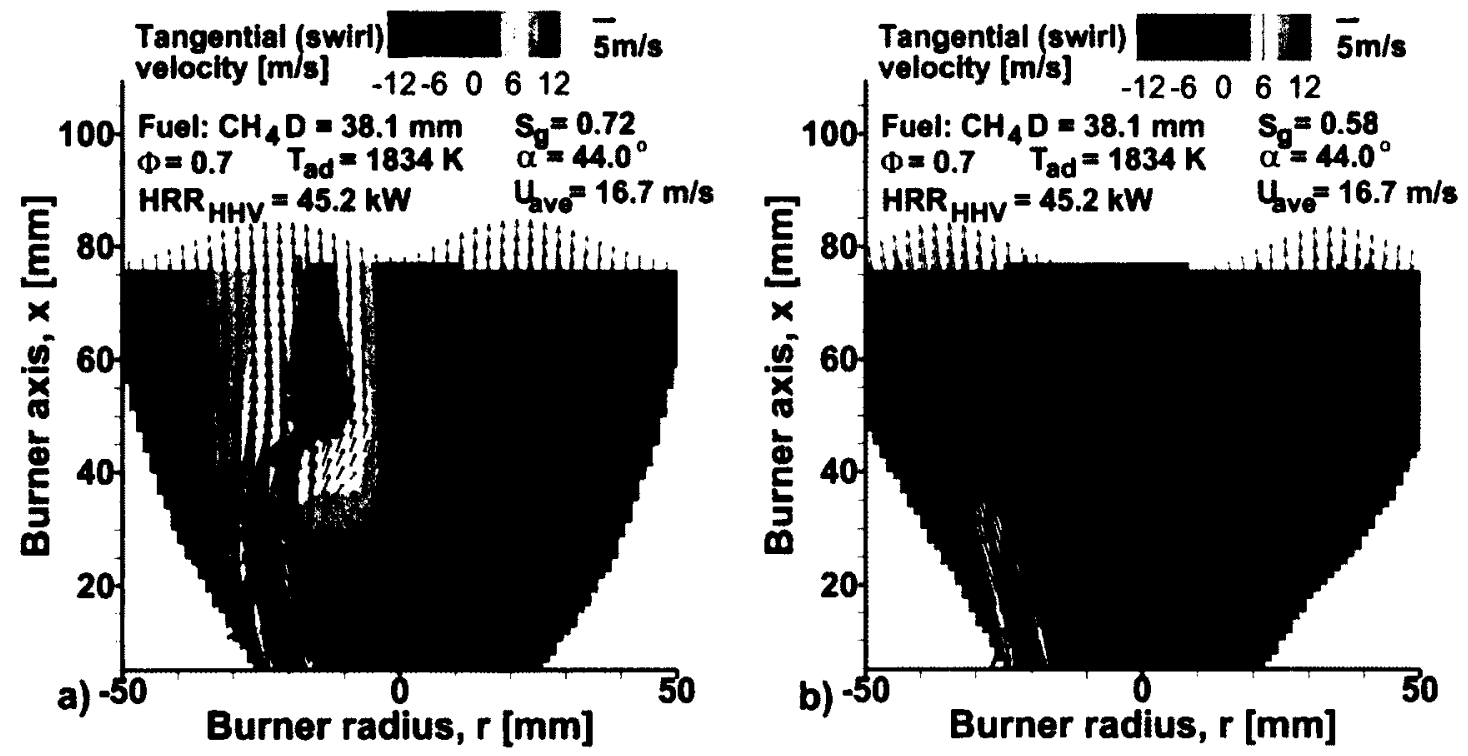

Figure 5.18: Near blowoff for $38.1 \mathrm{~mm}$ nozzle at $\Phi=0.7$ and $H R R_{H H V}=45.2 \mathrm{~kW}$ for a) $S=0.72$ b) $S=0.58$ 
At a lower flame temperature ( $\Phi=0.65$ ), the same basic features of the velocity fields near R- and W-type blowoff are present, as shown in Figure 5.19. Curiously, Figure 5.19a shows a flame front that is closed off at the top, a phenomenon that was only observed in this one measurement. In this case, the bottom of the flame front also sits slightly inside the nozzle and is obscured from the view of the PIV cameras. Although at first glance, the apparent flame contour resembles that of an attached flame, the flame is not stabilized on the burner rim in this case. The swirling flow strongly curls in toward the centerline following the flame contour in this R-type blowoff flowfield. Similar flowfields were observed with the $50.8 \mathrm{~mm}$ LSB nozzle as shown in Figure 5.20a below. By contrast, the W-type blowoff flowfield of the $38.1 \mathrm{~mm}$ LSB nozzle (Figure $5.19 \mathrm{~b}$ ) shows a small amount of axial recirculation along with a flattened ' $W$ '-shaped flame.
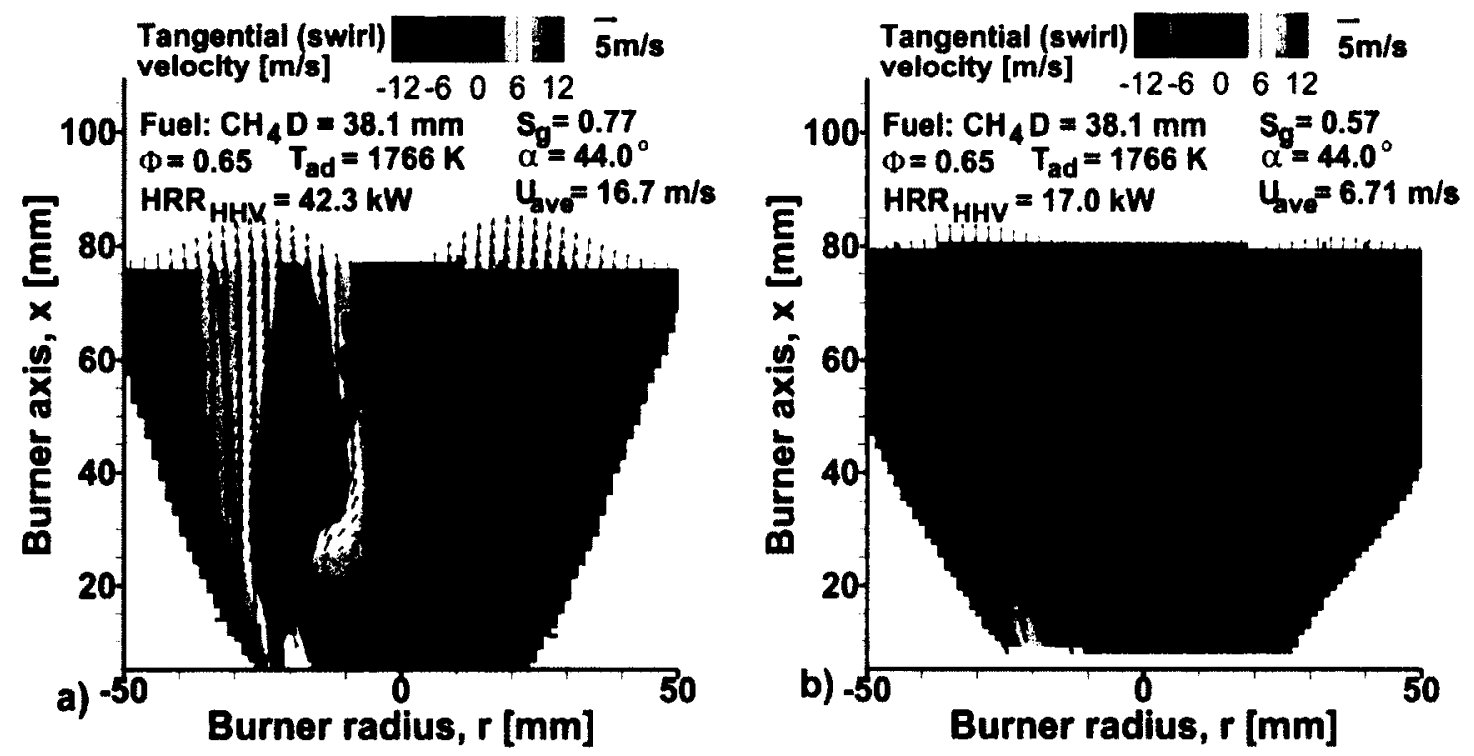

Figure 5.19: Near blowoff for $38.1 \mathrm{~mm}$ nozzle at $\Phi=0.65$ and a) $H R R_{H H V}=17.0 \mathrm{~kW}$ b) $H R R_{H H V}=42.3 \mathrm{~kW}$

The flowfields presented in this section provide clear evidence for two distinct blowoff mechanisms within the regime of the low-swirl burner. The first (R-type blowoff) is characterized by a combination of the swirling outer flow radially curling into towards the center of the flame, a significant amount of axial recirculation downstream of the flame front, and a lower than normal flame front height at 
blowoff (compared to the $\mathrm{W}$ - blowoff flame heights). The dominant recirculation in the R-type flames is the reason for the label R-type (i.e. recirculation type). R-type blowoff occurs at lower flame temperatures and higher flowrates (and at higher velocities, as evidenced by the higher likelihood of it occurring with the $38.1 \mathrm{~mm}$ nozzle).

W-type blowoff is characterized by the flame front stabilizing at a higher axial location (as compared to the R-type blowoff heights) and tending towards a ' $\mathrm{W}$ 'shape which is anchored along the shear layer between the inner core flow and outer annular flow. In addition, there is a lack of significant axial recirculation within the flame zone, and the outer swirling motion diverging out radially as opposed to curling in as in the R-type blowoff case. W-type blowoff is named for the obviously W-shaped flames. A summary of the observed stabilization modes of the LSB is presented in Table 5.2.

Table 5.2: Summary of observed stabilization modes

\begin{tabular}{|c|c|c|}
\hline Stabilization mode & Conditions for occurrence & Flame and flowfield properties \\
\hline $\begin{array}{c}\text { Shear-layer stabilization (leads to } \\
\text { W-type blowoff) }\end{array}$ & $\begin{array}{c}\text { Higher } S_{L} \text { (via higher } \Phi \text { ) and lower } \\
\text { flowrates. Can also occur at high } \\
\text { flow rates with high enough } S_{L} . \\
\text { Most common type of LSB blowoff. }\end{array}$ & $\begin{array}{c}\text { At blowoff: Anchor point located } \\
\text { along shear-layer. Generally a 'W'- } \\
\text { shaped flame. A radially divergent } \\
\text { flowfield with no significant axial } \\
\text { recirculation (though some might } \\
\text { still be present) }\end{array}$ \\
\hline $\begin{array}{c}\text { Recirculation-based stabilization } \\
\text { (R-type blowoff) }\end{array}$ & $\begin{array}{c}\text { Lower } S_{L} \text { (via lower } \Phi \text { ) and higher } \\
\text { flow rates. Only observed with } \mathrm{CH}_{4} \\
\text { fuel at } \Phi \leq 0.7 . \text { Blowoff occurs at } \\
\text { higher swirl numbers than W-type } \\
\text { blowoff.. }\end{array}$ & $\begin{array}{c}\text { At blowoff: Flame height } \\
\text { considerably lower than at } W \text {-type } \\
\text { blowoff. Outer swirling flow curls } \\
\text { radially inwards with significant } \\
\text { axial recirculation. }\end{array}$ \\
\hline Attached flame & $\begin{array}{c}\text { Hz must be present in fuel. More } \\
\text { likely with increasing \% } \mathrm{H}_{2} \text { in fuel, } \\
\text { and higher } \Phi \text { when } \mathrm{H}_{2} \text { is present. } \\
\text { More likely at lower flow rates. }\end{array}$ & $\begin{array}{c}\text { Flame attaches to nozzle rim and } \\
\text { produces a stable cone-shaped } \\
\text { flame that does not easily flash } \\
\text { back. Radially divergent flowfield. }\end{array}$ \\
\hline
\end{tabular}

It might be suggested that the recirculation for the R-type flames is simply related to swirl number, occurring at $S \sim 0.6$ or higher, the typical rule of thumb demarcation between low- and high-swirl flames. Figure 5.20a shows a methane flame at $\Phi=0.6$ on the $50.8 \mathrm{~mm} \mathrm{LSB}$ at R-type blowoff $(S=0.60)$. A distinct amount of axial recirculation is observed in this case. By contrast Figure $5.20 \mathrm{~b}$ shows a similar case for methane at $\Phi=0.9$ on the $50.8 \mathrm{~mm}$ nozzle at a high-swirl number of $S=0.62$ where there is no apparent recirculation. These figures demonstrate that the swirl number alone is not a sufficient predictor for the occurrence of axial 
recirculation for LSB flames. In the latter case, the flame front sits stably just slightly below the exit plane of the burner. The volume expansion from the methane flame at $\Phi=0.9$ is presumably sufficient to overcome the adverse pressure gradient that might usually result in axial recirculation. Thus, the presence of axial recirculation seems to be a product of both the amount of swirl present and the volume expansion through the flame. This is likely why the R-type blowoff condition is only seen at low equivalence ratios ( $\Phi=0.7$ or lower) where the volume expansion is low, and at high flow rates where there is a strong adverse pressure gradient caused by the extremely high swirl velocity, and relatively low inner core flow velocity.
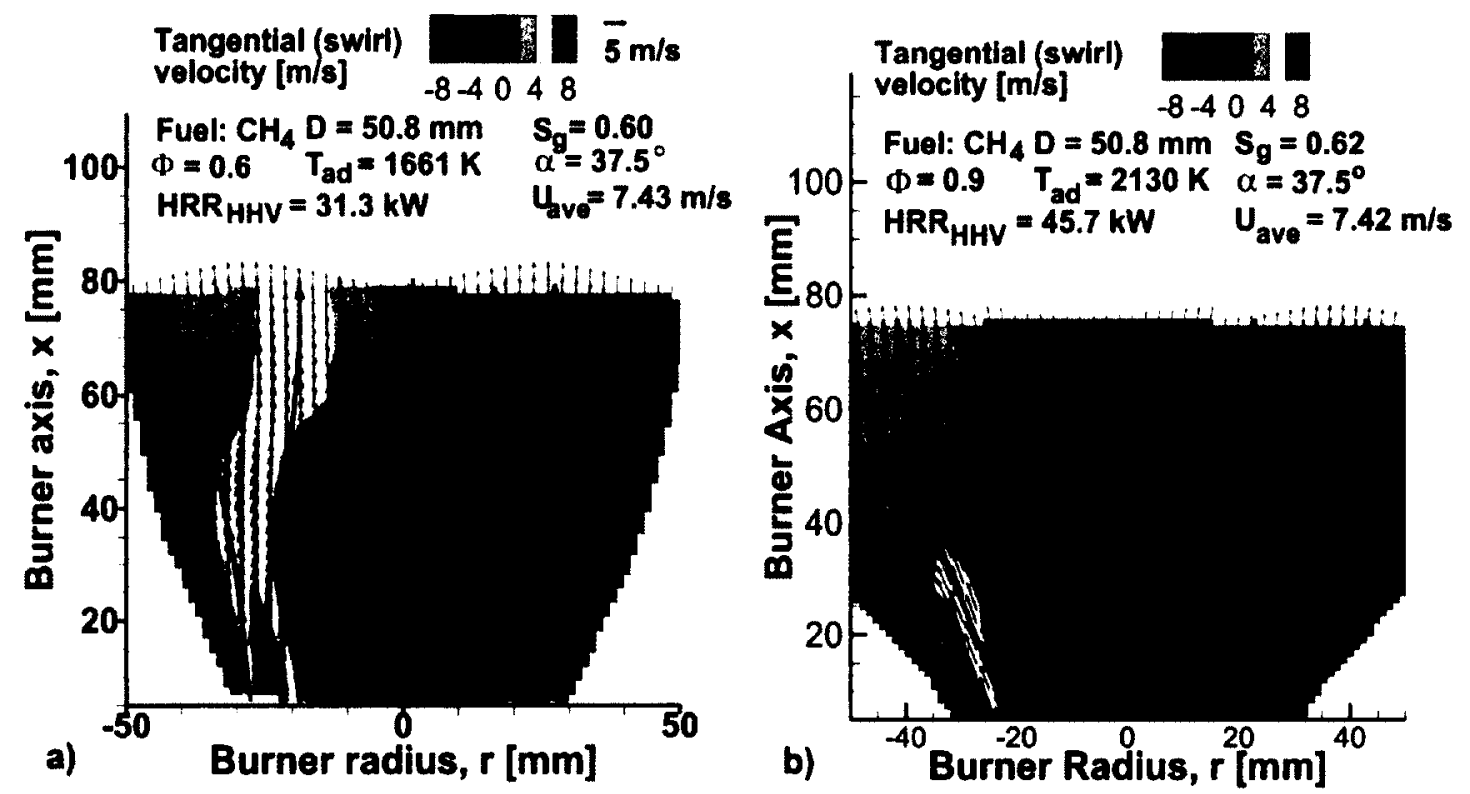

Figure 5.20: PIV flowfield and flame front contour for the $50.8 \mathrm{~mm} \mathbf{~ L S B}$ nozzle with $\mathrm{CH}_{4}$ at a) $\Phi=0.6, Q_{t o t}=800$ SLPM, near blowoff at $S=0.60$, and b) $\Phi=0.9$, $Q_{t o t}=800$ SLPM, at a stable condition at $S=0.62$ 


\section{Discussion}

\subsection{Theoretical analysis}

As mentioned in the introduction, Glassman and Yetter (2008) mention that most studies on developing blowoff correlations for premixed gases relate the blowoff conditions to a Damköhler number. Zhang (2008), using his premixed high-swirl burner, shows that Damköhler number scaling can be used at blowoff for mixtures with up to $50 \% \mathrm{H}_{2}$ without modification to the Damköhler number based on the unique diffusion properties of hydrogen (See Section 2.2.1). Since no fuel mixture in this study contains more than $50 \% \mathrm{H}_{2}$, an attempt at using Damköhler numbers in the blowoff analysis was conducted. From Eq.(1.3) we see that the Damköhler number relates a characteristic flow time to a characteristic chemical time. There are nearly endless ways to calculate Damköhler numbers with advantages and drawbacks for each method. For this study, the characteristic flow time will be calculated from the turbulence statistics from the PIV measurements (See Appendix E), and thus will be labelled $\tau_{\text {turb }}$, a characteristic turbulence time. From Turns (2000), $\tau_{\text {turb }}$ can be estimated as:

$$
\tau_{\text {turb }}=\frac{l_{0}}{u_{r m s}^{\prime}}
$$

where $l_{0}$ is the integral length scale in the axial direction, and $u_{r m s}^{\prime}$ are the axial RMS turbulence fluctuations. The axial direction is chosen here since it is the dominant flow direction. The characteristic chemical time, $\tau_{c h e m}$, can be estimated as (e.g. Zhang, 2008):

$$
\tau_{\text {chem }}=\frac{\alpha}{S_{L}^{2}}
$$

where $\alpha$ is the thermal diffusivity of the fuel/air mixture. Since $\alpha$ is temperature and species dependent, it is important to be consistent on how it is defined. For the present analysis, $\alpha$ was calculated from simulations of premixed 1D laminar flames performed using the software program Cantera (Cantera 2011) by Abhishek Barnwal at the University of Toronto. The reactant inlet conditions were $300 \mathrm{~K}$ and $1 \mathrm{~atm}$ for all simulations. A representative thermal diffusivity of the reacting 
mixture was calculated at the center of the spatial range of the simulation between pure products and pure reactants.

The Damköhler number can then be calculated as follows:

$$
D a=\left(\frac{l_{0}}{u_{r m s}^{\prime}}\right)\left(\frac{S_{L}^{2}}{\alpha}\right)
$$

With this type of Damköhler number, there is obviously going to be significant uncertainty. For this study; however, only trends were sought, so consistency in the definition of the Damköhler number was decided to be more important than the definition itself (beyond the reasonable choice of variables within the definition). When accurately defined, a Damköhler number greater than one implies the chemical time scale is shorter than the turbulent time scale (chemistry faster than turbulence), while a Damköhler number less than unity implies the opposite (turbulence faster than chemistry). With the above defined Damköhler number, this type of inference can only be made in a relative sense; comparing one flame to another without placing any importance on the absolute values.

Figure 6.1 shows the $D a$ contour plot for a flame near W-type blowoff, with the flame front superimposed in magenta. The figure shows reference data for the $50.8 \mathrm{~mm}$ nozzle burning methane at $\Phi=0.8$ and $Q_{t o t}=800$ SLPM(see Figure 5.3b for a plot of the corresponding velocity field). Here we see that $D a$ is greater than unity everywhere past the flame front, suggesting that the chemistry outpaces the turbulence at these conditions (keeping in mind the above caveats). 


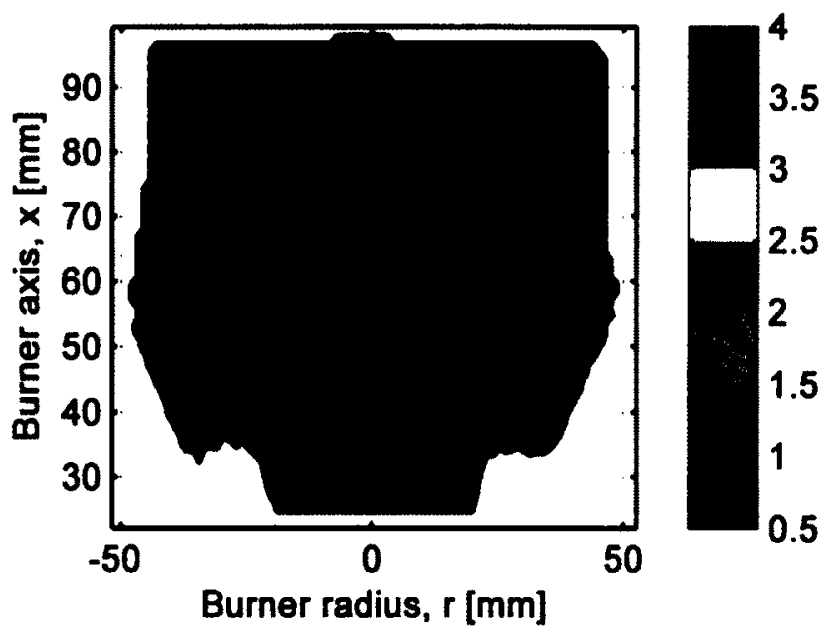

Figure 6.1: $D a$ contour of $L S B$ burning methane at $\Phi=0.8$ on $50.8 \mathrm{~mm}$ nozzle near W-type blowoff, $U_{\text {ave }}=7.42 \mathrm{~m} / \mathrm{s}\left(Q_{\text {tot }}=800 \mathrm{SLPM}\right.$ ) (See Figure $5.3 \mathrm{~b}$ for corresponding velocity field)

Figure 6.2 shows a corresponding $D a$ contour plot for fuel $\mathrm{S} 1$ at equivalent $T_{a d}$ and $H R R_{H H V}$ conditions. At the flame front, $D a=3-4$, which is even higher that for the reference methane case, implying faster chemistry for equivalent turbulence levels. This is expected given the faster laminar flame speed of $S 1$ at $\Phi=0.75$ of $0.34 \mathrm{~m} / \mathrm{s}$ as compared to methane at $\Phi=0.8$ with $S_{L}=0.25 \mathrm{~m} / \mathrm{s}$. Thus, for both of these shear layer stabilized flames near W-type blowoff, the chemistry is much faster than the turbulence as seen in the Damköhler numbers. This suggests that for W-type blowoff, the flows are aerodynamically controlled by the comparatively slower turbulence (although little importance should be placed on the absolute values of $D a$ ). 


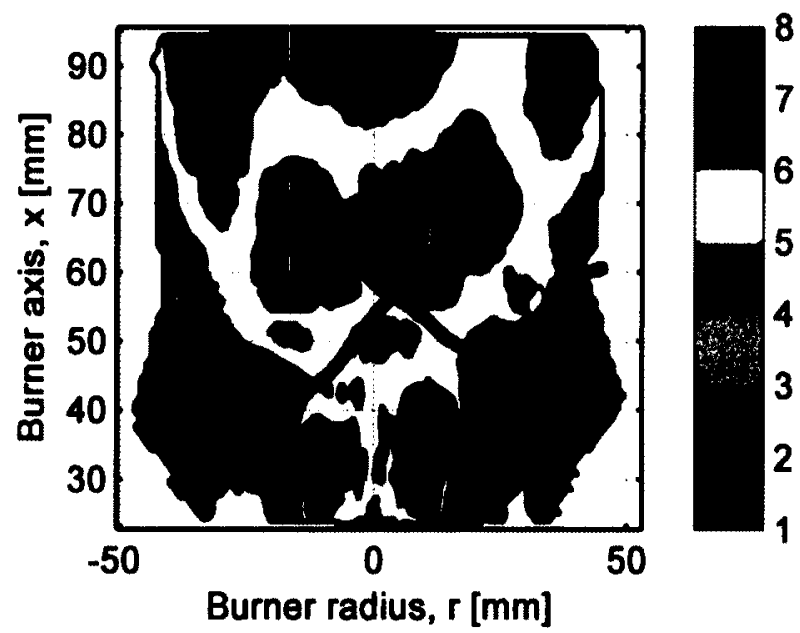

Figure 6.2: $D a$ contours of LSB burning $S 1$ fuel mixture methane at $\Phi=0.75$ on $50.8 \mathrm{~mm}$ nozzle near W-type blowoff, $U_{\text {ave }}=8.16 \mathrm{~m} / \mathrm{s}\left(Q_{t o t}=881 \mathrm{SLPM}\right)$ (adiabatic flame temperature and heat release rate are matched to Figure 6.1; See Figure 5.9b for corresponding velocity field)

Figure 6.3 shows the Damköhler number contour plot for a flame burning methane on the $50.8 \mathrm{~mm}$ nozzle at $\Phi=0.6$ with the same average exit velocity as Figure 6.1, but now near conditions of R-type blowoff (refer to Figure 5.20a for a plot of the velocity field). Damköhler numbers are markedly lower in this case, with $D a=0.5$ at the flame front. This implies that the turbulent time scales are shorter than the chemical time scales at conditions of R-type blowoff (as compared to Wtype blowoff). Thus, for R-type blowoff, the longer chemical time scales could be the controlling factor for stability. High amounts of swirl are needed to stabilize recirculation based flames, and this is likely due to the chemistry being so slow as to require longer residence times enabled by a recirculation zone to keep the flame lit.

Another example of this is shown in Figure 6.4 where $D a$ contour plots for an $\mathrm{R}$-type blowoff and a $\mathrm{W}$-type blowoff are shown. This time, the $38.1 \mathrm{~mm}$ nozzle at $\Phi=0.65$ at high flow rate (R-type blowoff) and a low flow rate (W-type blowoff) are compared. As mentioned in Section 5.8, the flame front in Figure 6.4a was below the exit of the nozzle. Again the same result is seen where the R-type blowoff has a very low $(\sim 0)$ Damköhler number at the flame front implying faster turbulence time scales than chemistry timescales. The W-type blowoff has a higher $D a$ at the flame front of 0.32 , which is still low, but obviously higher than the R-type blowoff case. 
Though both of these Damköhler numbers are low, it's obvious that the W-type blowoffs have relatively higher Damköhler numbers than the R-type blowoffs. This further reinforces the idea that the R-type blowoffs are chemistry limited, and the W-type blowoffs are turbulence limited. Some W-type blowoffs, however, may have low Damköhler numbers at the flame front, but still exhibit W-type blowoff flowfield properties. Figure $6.4 \mathrm{~b}$ shows a $\mathrm{W}$-type blowoff very near transition to a recirculation-stabilized flame (see Figure 5.16), so it may be more accurate to label it as a 'transitional' W-type flame.
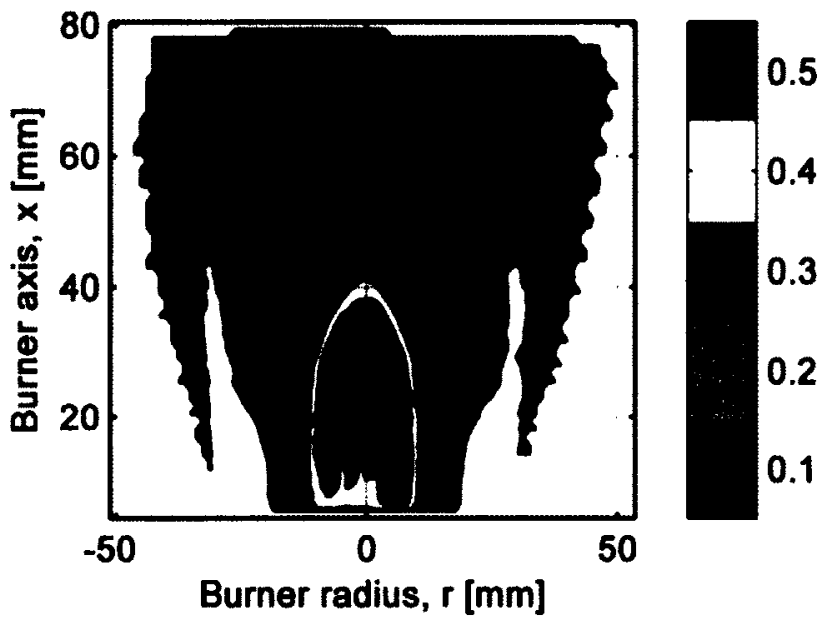

Figure 6.3: $D a$ contour of $L S B$ burning methane at $\Phi=0.6$ on $50.8 \mathrm{~mm}$ nozzle near R-type blowoff, $U_{a v e}=7.42 \mathrm{~m} / \mathrm{s}\left(Q_{t o t}=800\right.$ SLPM) (See Figure 5.20a for corresponding velocity field)

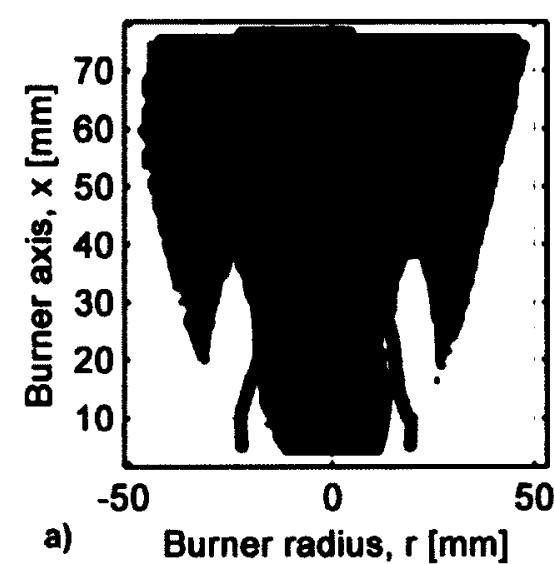

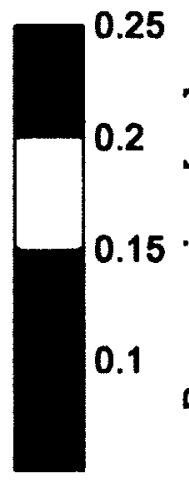

50

Burner radius, $r$ [mm]

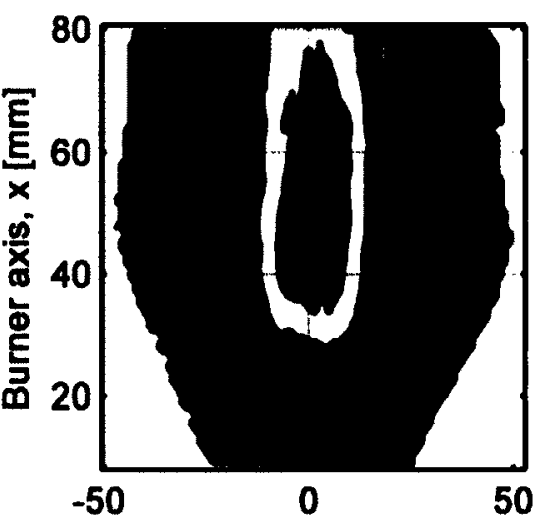

b) Burner radius, $r$ [mm]

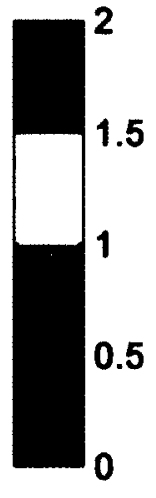

0.5

Figure 6.4: $D a$ contours for $\mathrm{CH}_{4}$ on $38.1 \mathrm{~mm}$ nozzle at $\Phi=0.65$ near a) R-type blowoff- $U_{\text {ave }}=16.7 \mathrm{~m} / \mathrm{s}\left(Q_{t o t}=1000\right.$ SLPM $)$ b) $W$-type blowoff $-U_{\text {ave }}=6.70 \mathrm{~m} / \mathrm{s}$ $\left(Q_{t o t}=400\right.$ SLPM) (See Figure 5.19 for corresponding velocity fields) 
Figure 6.5 similarly compare R- and W-type blowoff condition on the $38.1 \mathrm{~mm}$ nozzle with methane as a fuel. Here the average exit velocity and equivalence ratio have been fixed at $U_{\text {ave }}=16.7 \mathrm{~m} / \mathrm{s}$ at $\Phi=0.7$ (refer to Figure 5.18 for corresponding velocity fields], while the swirl number is varied to produce both an R-type and Wtype blowoff. Figure 6.5a again shows that near R-type blowoff conditions, $D a$ is quite low at the flame front with a value of 0.43 . Figure $6.5 \mathrm{~b}$ shows that for the case near W-type blowoff, $D a$ is also very low with a value at the lowest point of the flame front of 0.30 . Judging by the flatter contour of the flame front, this is likely similar to the situation of Figure $6.4 \mathrm{~b}$ where the flow conditions could be near a transition between the $\mathrm{W}$-and $\mathrm{R}$-type regimes. This is supported by velocity field data of Figure 5.18b, which shows that there is some flow recirculation occurring, although the flame is still weakly anchored in the shear-layer. It is reasonable to expect a transitional flame at these conditions (high flow rates on $38.1 \mathrm{~mm}$ nozzle at low $\Phi$ ) since this is where the blowoff data (see Figure 4.5) showed an obvious break from the trends at lower flow rates and higher $\Phi$.

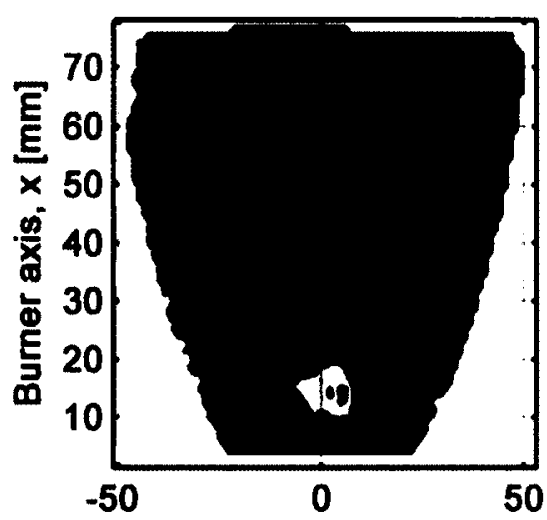

a) Burner radius, $r$ [mm]

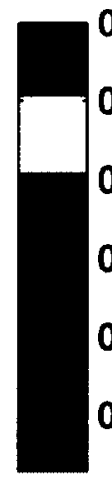

0.1

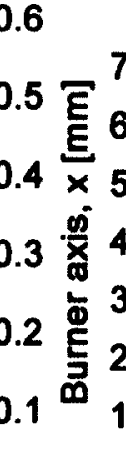

b)

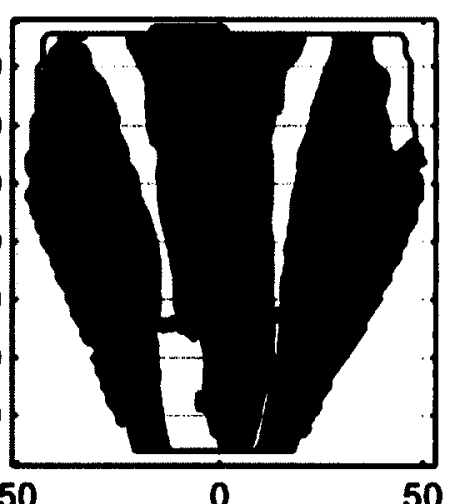

Burner radius, $r$ [mm]

50

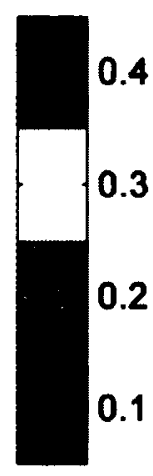

Figure 6.5: $\mathrm{Da}$ contours for $\mathrm{LSB}$ burning $\mathrm{CH}_{4}$ on $38.1 \mathrm{~mm}$ nozzle at $\Phi=0.7$ at $U_{\text {ave }}=16.7 \mathrm{~m} / \mathrm{s}\left(Q_{\text {tot }}=1000\right.$ SLPM $)$ near a) R-type blowoff $-S=0.72$ and b) $W$-type blowoff $-S=0.58$ (See Figure 5.18 for corresponding velocity fields)

The preceding results provide useful insight into the $\mathrm{R}$ - and $\mathrm{W}$-type blowoff regimes. For the R-type blowoff, the intense turbulence is too much for the weaker chemistry, and the outer annular layer does not readily ignite (where the turbulence is the strongest). This creates a weak flame in the low-speed inner core region of 
the flow, where due to the low amount of volume expansion, significant axial recirculation takes place such that the outer swirling flow curls inward around the flame and at least partially recirculates. This recirculation maintains the combustion of the weak flame, but generally requires operation at higher swirl numbers.

Flames stabilized near W-type blowoff are much stronger and appear to anchor in the high-turbulence shear layer. Since the chemistry is fast enough for these flames, the turbulence in the shear layer acts to encourage the combustion as opposed to extinguishing it. The shear layer becomes the most upstream location of the flame (anchor points), and it is when this shear layer is weakened by lowering the swirl number that the flame rises and eventually blows off as illustrated previously in Figure 5.10.

Table 6.1 lists the measured $D a$ at the lowest flame position for all available cases in this study (anchor points for W-type blowoff flames, generally the centreline for R-type blowoff conditions). For the R-type flames at $\Phi=0.65$, the lowest position was inside the nozzle, so the $D a$ at the exit of the nozzle at the centreline was instead reported. The overall results support the above assessment that R-type blowoff occurs when the Damköhler number is very low, implying that for an R-type flame the turbulence at the lowest point in the measured flame front is faster than the chemistry.

By contrast most of the results for the W-type blowoff conditions show that the Damköhler number is relatively higher at the leading edge of the flame as compared to R-blowoff type flames. There are four examples (shown in bold in Table 6.1) where the flowfield properties suggest a $\mathrm{W}$-type blowoff ( $\mathrm{W}$-shaped flame front, radially divergent flowfield), but the $D a$ has a low value comparable to the R-type blowoff Damköhler numbers. Closer inspection of the PIV velocity field data suggests that these conditions correspond to a transition between the two stability modes in which the flame is just barely able to anchor along the shear-layer to produce a W-type flame, but flow recirculation is beginning to appear and the timescale of the chemistry is apparently slow relative to the intense turbulence in the shear layer. With the data currently available and the obvious challenges in 
accurately calculating $D a$, it is not possible to precisely define the conditions for this transition, however, for the definition of the Damköhler number employed here, it appears that transition can occur roughly in the region of $0.3<D a<0.65$. 
Table 6.1: Damköhler numbers at lowest flame position (anchor points) at blowoff (blowoff points denoted as transitional highlighted in bold)

\begin{tabular}{|c|c|c|c|c|c|c|c|}
\hline $\begin{array}{c}\text { Blowoff } \\
\text { type }\end{array}$ & Fuel & $\begin{array}{l}\text { Nozzle } \\
{[\mathrm{mm}]}\end{array}$ & $\Phi$ & $\begin{array}{c}Q_{\text {tot }} \\
{[S L P M]}\end{array}$ & $U_{\text {ove }}[\mathrm{m} / \mathrm{s}]$ & $s$ & $D a$ \\
\hline \multirow{5}{*}{$\begin{array}{l}\text { R-type } \\
\text { blowoff }\end{array}$} & $\mathrm{CH}_{4}$ & 38.1 & 0.65 & 900 & 15.1 & 0.75 & 0.15 \\
\hline & $\mathrm{CH}_{4}$ & 38.1 & 0.65 & 1000 & 16.7 & 0.77 & 0.09 \\
\hline & $\mathrm{CH}_{4}$ & 38.1 & 0.70 & 900 & 15.1 & 0.66 & 0.62 \\
\hline & $\mathrm{CH}_{4}$ & 38.1 & 0.70 & 1000 & 16.7 & 0.72 & 0.43 \\
\hline & $\mathrm{CH}_{4}$ & 50.8 & 0.60 & 800 & 7.44 & 0.60 & 0.23 \\
\hline \multirow{35}{*}{$\begin{array}{l}\text { W-type } \\
\text { blowoff }\end{array}$} & $\mathrm{CH}_{4}$ & 38.1 & 0.65 & 400 & 6.71 & 0.56 & 0.32 \\
\hline & $\mathrm{CH}_{4}$ & 38.1 & 0.7 & 400 & 6.68 & 0.52 & 0.65 \\
\hline & $\mathrm{CH}_{4}$ & 38.1 & 0.7 & 900 & 15.1 & 0.55 & 0.50 \\
\hline & $\mathrm{CH}_{4}$ & 38.1 & 0.7 & 1000 & 16.7 & 0.58 & 0.30 \\
\hline & $\mathrm{CH}_{4}$ & 38.1 & 0.8 & 400 & 3.72 & 0.41 & 0.98 \\
\hline & $\mathrm{CH}_{4}$ & 38.1 & 0.9 & 1000 & 16.7 & 0.53 & 1.13 \\
\hline & $\mathrm{CH}_{4}$ & 38.1 & 0.9 & 1200 & 20.1 & 0.53 & 1.67 \\
\hline & $\mathrm{CH}_{4}$ & 50.8 & 0.7 & 720.6 & 6.68 & 0.47 & 1.53 \\
\hline & $\mathrm{CH}_{4}$ & 50.8 & 0.7 & 800 & 7.43 & 0.46 & 0.73 \\
\hline & $\mathrm{CH}_{4}$ & 50.8 & 0.7 & 1200 & $\begin{array}{l}11.1 \\
\end{array}$ & 0.48 & 0.85 \\
\hline & $\mathrm{CH}_{4}$ & 50.8 & 0.8 & 400 & 3.72 & 0.41 & 3.43 \\
\hline & $\mathrm{CH}_{4}$ & 50.8 & 0.8 & 720.6 & 6.68 & 0.44 & 2.86 \\
\hline & $\mathrm{CH}_{4}$ & 50.8 & 0.8 & 800 & 7.41 & No Swirl & 0.79 \\
\hline & $\mathrm{CH}_{4}$ & 50.8 & 0.8 & 800 & 7.41 & 0.44 & 1.15 \\
\hline & $\mathrm{CH}_{4}$ & 50.8 & 0.8 & 1200 & 11.3 & 0.46 & 0.98 \\
\hline & $\mathrm{CH}_{4}$ & 76.2 & 0.7 & 1639.9 & 6.68 & 0.47 & 2.49 \\
\hline & $\mathrm{CH}_{4}$ & 76.2 & 0.8 & 1639.9 & 6.68 & 0.47 & 4.61 \\
\hline & B1 & 50.8 & 0.76 & 778 & 7.22 & 0.46 & 0.59 \\
\hline & B1 & 50.8 & 0.80 & 800 & 7.43 & 0.48 & 0.81 \\
\hline & B1 & 50.8 & 0.88 & 778 & 7.23 & 0.44 & 1.09 \\
\hline & S1 & 50.8 & 0.63 & 878 & 8.14 & 0.43 & 1.81 \\
\hline & S1 & 50.8 & 0.75 & 881 & 8.16 & 0.42 & 3.87 \\
\hline & $\mathrm{S} 2$ & 50.8 & 0.65 & 856 & 7.93 & 0.41 & 3.57 \\
\hline & $\mathrm{S} 2$ & 50.8 & 0.77 & 879 & 8.15 & 0.38 & 6.36 \\
\hline & 54 & 50.8 & 0.63 & 869 & 8.05 & 0.43 & 0.89 \\
\hline & S4 & 50.8 & 0.74 & 874 & 8.10 & 0.41 & 2.39 \\
\hline & S5 & 50.8 & 0.64 & 858 & 7.96 & 0.42 & 3.59 \\
\hline & S5 & 50.8 & 0.75 & 865 & 8.01 & 0.39 & 5.69 \\
\hline & 56 & 50.8 & 0.77 & 847 & 7.88 & 0.38 & 3.24 \\
\hline & S14 & 50.8 & 0.61 & 871 & 8.07 & 0.40 & 3.52 \\
\hline & S14 & 50.8 & 0.71 & 884 & 8.18 & 0.37 & 5.09 \\
\hline & S5M50 & 50.8 & 0.69 & 810 & 7.50 & 0.44 & 1.56 \\
\hline & S5M50 & 50.8 & 0.79 & 817 & 7.59 & 0.42 & 2.45 \\
\hline & S5M25 & 50.8 & 0.68 & 820 & 7.59 & 0.44 & 2.59 \\
\hline & S5M25 & 50.8 & 0.78 & 830 & 7.69 & 0.40 & 3.29 \\
\hline
\end{tabular}

\subsubsection{Turbulent Premixed Combustion Regimes of the LSB}

Peters' turbulent premixed combustion regime diagram (Peters, 2000) is plotted in Figure 6.6 with superimposed points corresponding to the present measurements listed in Table 6.1. In this diagram, $u$ ' is the RMS of the turbulence fluctuations in 
the axial direction, $l_{0}$ is the axial integral length scale, and $\delta_{L}$ is the laminar flame thickness. From Turns (2000), the laminar flame thickness can be estimated by:

$$
\delta_{L}=\frac{2 \alpha}{S_{L}}
$$

The results show that the estimated locations within Peters' regime diagram suggest that all LSB operation near-blowoff lies within the thin-reaction zones regime where the smallest turbulence scales $\left(l_{k}\right)$ are smaller than the laminar flame thickness. The $\mathrm{W}$-type blowoff flames are located further to the right on this diagram, which implies larger turbulence scales as compared to the laminar flame thickness. The R-type blowoff flames are located higher and further to the left, which implies smaller turbulence scales as compared to the laminar flame thickness and weaker chemistry as compared to the turbulence consistent with the previous analysis.

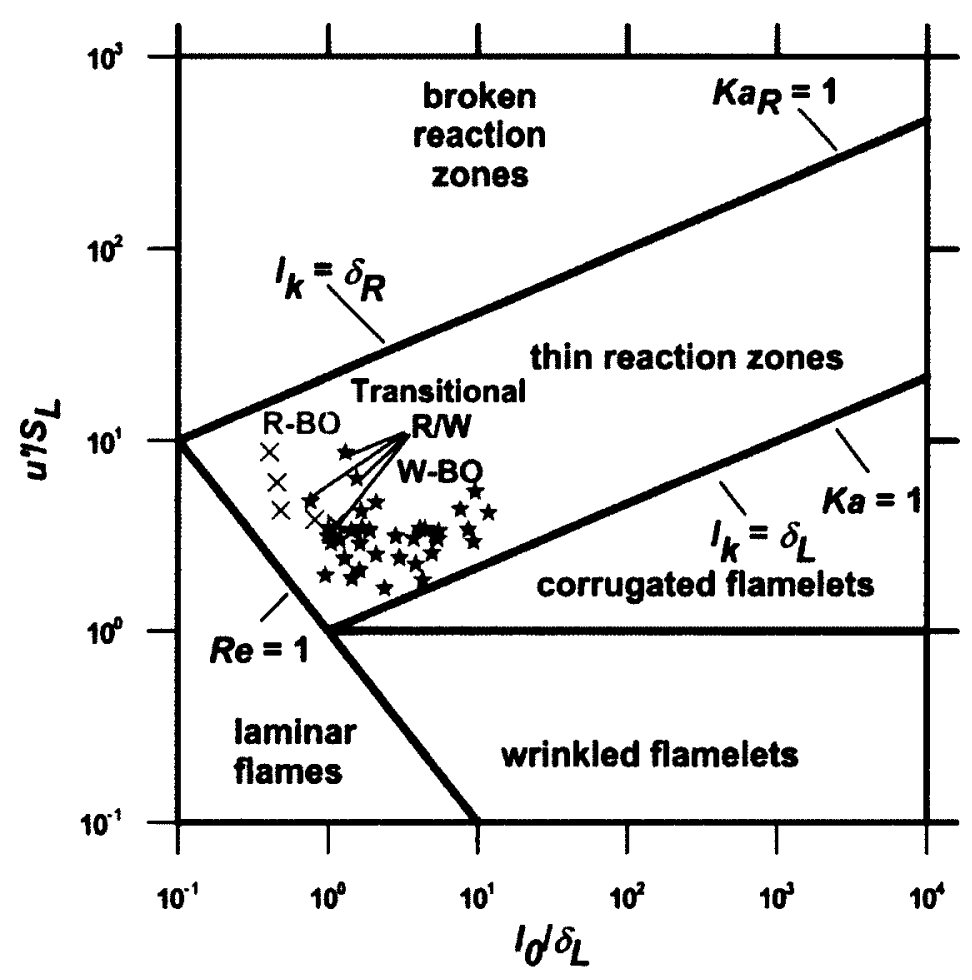

Figure 6.6: Peter's premixed turbulent combustion regime diagram with $\mathrm{CH}_{4}$ LSB blowoff points

Several of the W-type blowoff flames have been labeled as transitional on the diagram corresponding to conditions identified as transitional in the preceding Damköhler number analysis. Plotted in this manner, it is apparent that the 
transitional W-type flames exhibit more intense turbulence than chemistry $\left(u^{\prime} / S_{L}\right.$ $>>1$ ), but that the integral length scales are larger as compared to the laminar flame thickness (further right than R-type blowoff conditions). From this analysis, the transitional region becomes more obvious, but still more measurements would be required to develop a clear criterion for this transition. Nevertheless, the existence of at least two stability regimes within the domain classically known as low swirl has been confirmed. These two regimes lead to different blowoff mechanisms with flowfield characteristics.

Practically speaking, these results suggest that if it is desired to operate the LSB at extremely low flame temperatures with mixtures with very slow chemistry, the flowfield and/or turbulence levels should be monitored to ensure sure that the flame stays as a predictable $\mathrm{W}$-type flame, to avoid significant recirculation to the point where the flame no longer anchors along the shear layer. As discussed in the introduction of this thesis, longer flame residence times associated with a recirculating flowfield can adversely affect NOx emissions. Thus, for these weak mixtures, the swirl number must be low when the flame is lit (still high enough for stable operation however), and average exit velocity must be kept low by either increasing the nozzle diameter, or by lowering the total flow rate.

\subsection{Empirical correlations}

The goals of this thesis were not only to characterize the different types of flames in the LSB, but also to attempt to develop reliable means for predicting when blowoff will occur. As discussed in Section 2.3, Mansour and Chen (2008) recently suggested a simple blowoff correlation for methane/air jet-type LSB flames in which they observed $U D / u=5.08 \mathrm{~mm}$ at blowoff conditions, where $U$ refers to the central jet velocity, $D$ refers to the burner diameter, and $u$ is the tangential jet velocity. This can be extended to a vane-type LSB, where the burner diameter at the location of the central nonswirling jet $(D)$ in Mansour and Chen (2008) is equivalent to the inner flow diameter ( $0.8 \times$ the outer diameter) in the vane-type LSB; the central jet velocity, $U$, is equivalent to the inner flow velocity; and the tangential jet velocity, $u$, 
is equivalent to the outer flow exit velocity including the tangential component, which is calculated as:

$$
u=U_{\text {o, axial }} \tan (\alpha)
$$

In Eq.(6.5), $U_{0, a x i a l}$ is the outer axial velocity (measured as outer flow rate divided by outer area), and $\alpha$ is the vane exit-angle (this assumes there is no fluid deviation from this angle).

Figure 6.7 tests the Mansour and Chen (2008) correlation with methane-only blowoff curves for the three LSB nozzle sizes. While the correlation clearly does not align with the present data, there is a common linear trend for the majority of the $38.1 \mathrm{~mm}$ and $50.8 \mathrm{~mm}$ LSB data. The $76.2 \mathrm{~mm} \mathrm{LSB}$ data also show a linear trend but with a different slope than the $38.1 \mathrm{~mm}$ and $50.8 \mathrm{~mm}$ data. It is noteworthy, however, that for the $38.1 \mathrm{~mm}$ and $50.8 \mathrm{~mm}$ LSB data, exceptions to the common linear trend were previously identified as R-type rather than W-type blowoff conditions.

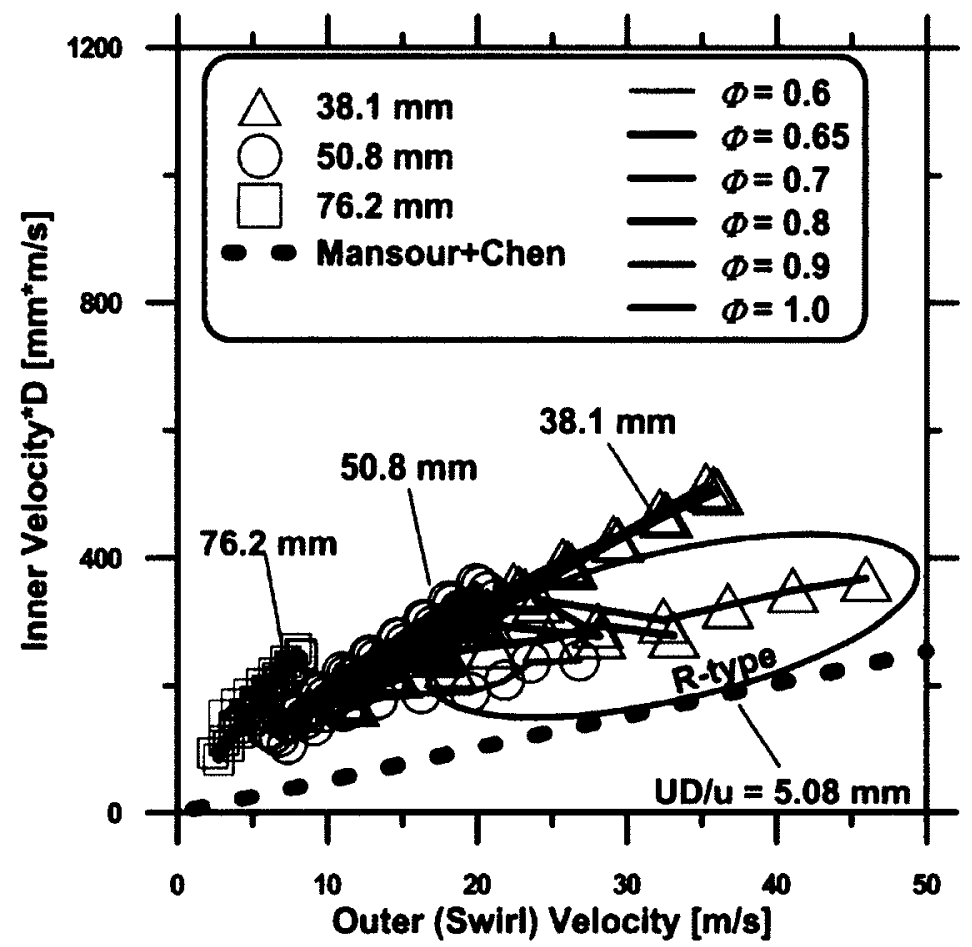

Figure 6.7: Comparison of methane blowoff curves to Mansour and Chen (2008) correlation 


\subsubsection{Horizontal Profiles of Measured Flow Turbulence}

As mentioned in the literature review, the work of Strahman (2007) led to the conclusion that the major effect of swirl is a change of mean axial velocities and turbulence intensities, which directly influences the position of the flame and its stability limits. Strahman further suggested that the induced shear layer between the central core flow and the outer annular flow causes the high levels of turbulence that allow the flame to stabilize in this region. The so-called "anchor points" of the LSB flame in the shear-layer, produce the characteristic ' $W$ '-shaped flame as shown in Figure 6.8 (Strahman, 2007). Anchor point II is right on the radial location of the shear layer between the inner core flow and the outer annular flow. This suggests that the strength of the shear layer, which is directly influenced by the amount of swirl, is what actually causes the flame to anchor. Nogenmyr (2010) similarly noted W-shaped LSB flames in their experiments and simulations, and attributed stability of the flame to large-scale vertical motion in the shear layer that continuously transports hot products down to ignite fresh reactants. As noted previously, this explanation for LSB flame stability is in contrast to the original explanation proposed by Chan et al. (1992) who suggested that the main effect of swirl was to provide radial divergence of the flowfield to lower the flow velocity to the point of the flame speed where the stable flame would then settle.

To further evaluate the role of the 3D shear layer between the inner core flow and the outer annular flow in determining flame stability, turbulence statistics calculated from the instantaneous PIV images (2000 per data set) were analyzed (See Appendix E). Figure 6.9a shows the 3D turbulence intensity contour plot for an LSB flame near W-type blowoff on the $50.8 \mathrm{~mm}$ nozzle at $\Phi=0.8$ and $Q_{t o t}=800$ SLPM. The annular anchor points are positioned in local spots of higher normalized turbulence intensity than the surrounding region, which is in agreement with the ideas of Strahman (2007) and Nogenmyr (2010). Figure 6.9b shows the absolute 3D turbulence fluctuations, and the anchor points are situated where the low turbulence from the inner core begins to mix with the higher turbulence from the outer annular layer. 


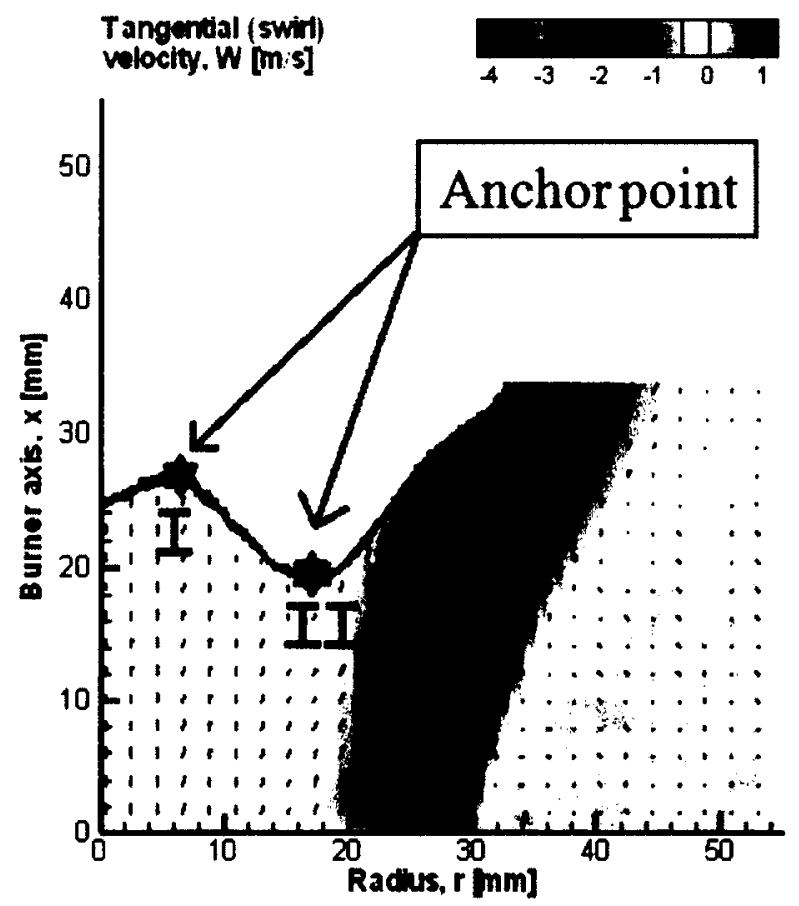

Figure 6.8: Mean flame contour superimposed on velocity field, for $\Phi=0.8$, $S=0.55$, and $Q_{t o t}=400$ SLPM (from Strahman (2007))

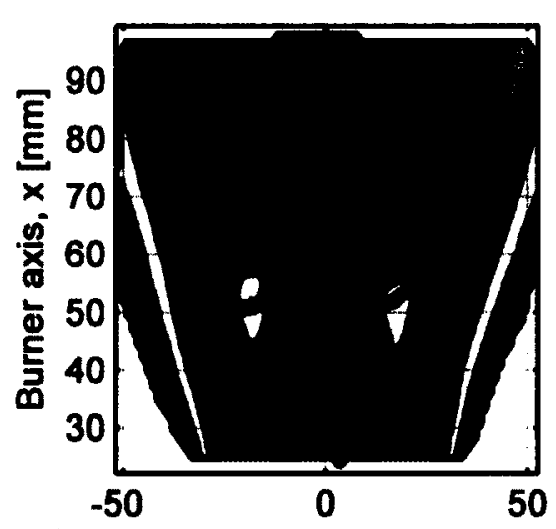

a) Burner radius, $\mathrm{r}[\mathrm{mm}]$

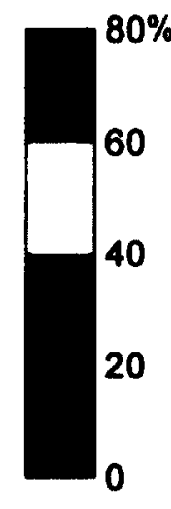

Figure 6.9: Turbulence contours for the $50.8 \mathrm{~mm} \mathrm{LSB} \mathrm{nozzle} \mathrm{burning} \mathrm{CH}_{4}$ at $\Phi=0.8, Q_{t o t}=800$ SLPM, near blowoff (W-type blowoff $\left.-S=0.44\right)$ for a) $3 D$ turbulence intensity b) 3D RMS turbulence fluctuations, $V^{\prime}$

Figure 6.10a shows the same 3D turbulence intensity contour plot for corresponding more stable conditions removed from blowoff at higher $S=0.60$. Unfortunately, asymmetries in the flowfield were present during this PIV measurement (right-side of the flame sites lower than the left-side), but it is still apparent that the flame anchors in regions of locally high turbulence intensity. Note 
that the overall vertical location of the stable flame is lower relative to the flame near blowoff conditions.

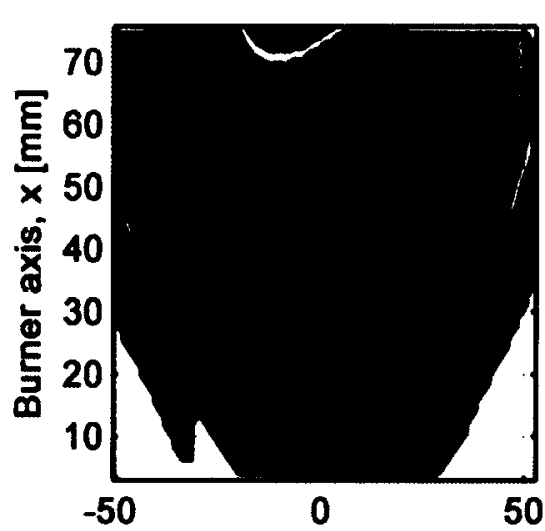

a) Burner radius, $\mathrm{r}$ [mm]

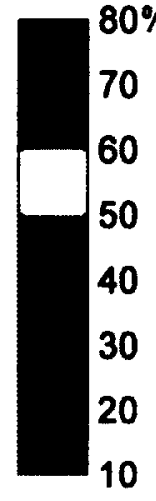

10

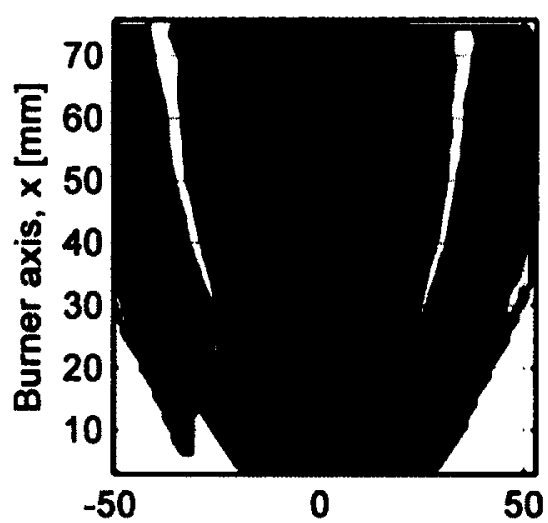

b) Burner radius, $r[\mathrm{~mm}]$

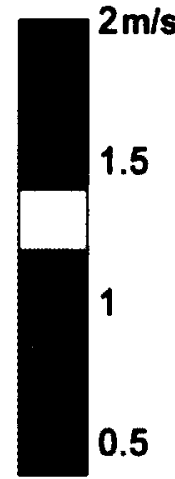

50

Figure 6.10: Turbulence contours for the $50.8 \mathrm{~mm} \mathrm{LSB} \mathrm{nozzle} \mathrm{burning} \mathrm{CH}_{4}$ at $\Phi=0.8, Q_{t o t}=800$ SLPM, at a stable condition $(S=0.60)$. a) 3D turbulence normalized intensity b) 3D RMS turbulence fluctuations, $V^{\prime}$

For both the flame near blowoff and the stable flame, the gradient of the 3D turbulence fluctuations in the radial direction (from left to right) was calculated using a built in function in MATLAB, and results are plotted in Figure 6.11. The different line colours refer to different heights from the nozzle exit plane. For the flame at blowoff, all heights have the same basic trends. Through the core flow, the gradient is negligible as would be expected. However, at the boundaries of the swirling annular flow, the gradients spike (positive on right, negative on the left consistent with the sense of the rotation). For both the flame near blowoff, and the stable flame, relative to the location of the core flow, the closest local minimum/maximum in the radial gradient of the 3D turbulent fluctuations corresponds almost perfectly to the anchor position of the flame in the shear layer.

Figure 6.12 shows representative turbulence contour plots for a $\mathrm{CH}_{4}$ flame near R-type blowoff conditions ( $\Phi=0.7, Q_{t o t}=1000 \mathrm{SLPM}, S=0.72$ ). This is an example of the situation where after blowoff the swirl number could be lowered further, and the flame could be relit in a W-type stability mode. Figure 6.12a shows that the contour of the 'tulip' shaped flame front corresponds almost exactly to the measured turbulence intensity contours. Figure $6.12 \mathrm{~b}$ shows that in this case the flame does 
not anchor along the shear layer, but in fact reaches its lowest point almost at $r=0$. This further supports the idea that the stability mechanism leading up to an R-type blowoff event is based upon axial recirculation in the inner core flow.
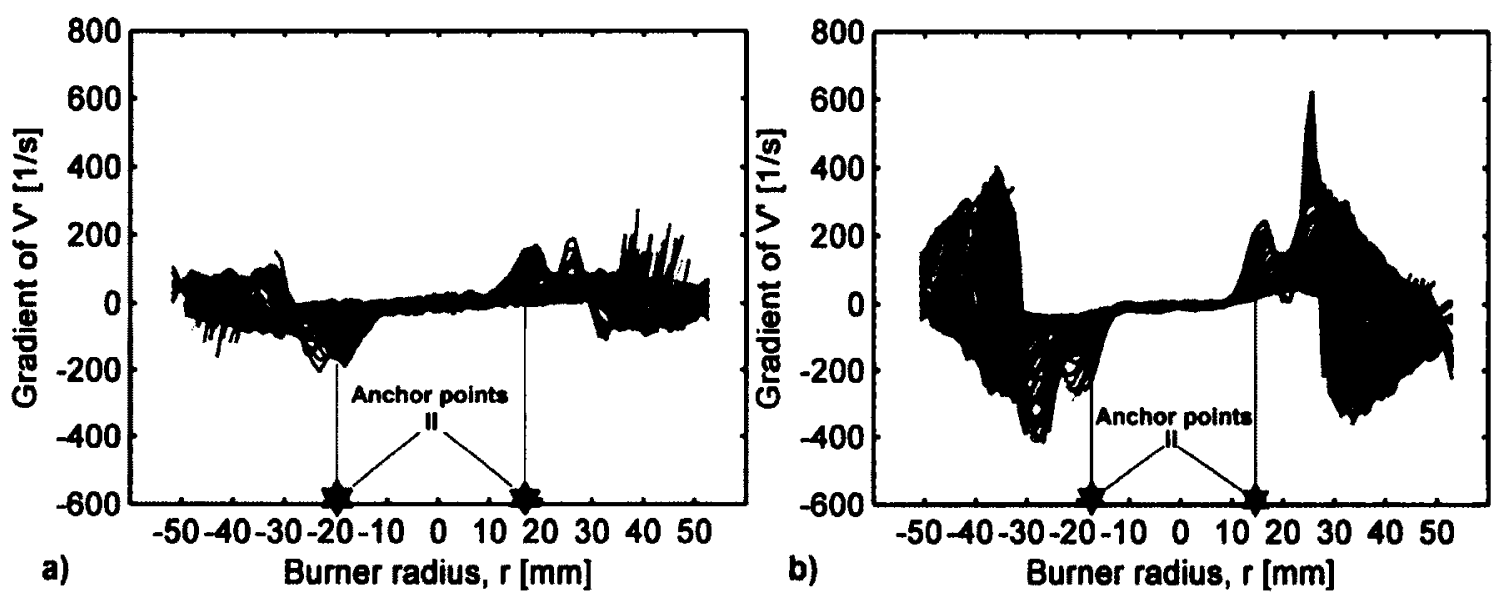

Figure 6.11: Radial 3D RMS turbulence fluctuation gradients for the $50.8 \mathrm{~mm}$ LSB nozzle burning $\mathrm{CH}_{4}$ at $\Phi=0.8$ and $Q_{\text {tot }}=800$ SLPM. a) Conditions near blowoff $(S=0.44)$ b) Stable conditions $(S=0.60)$

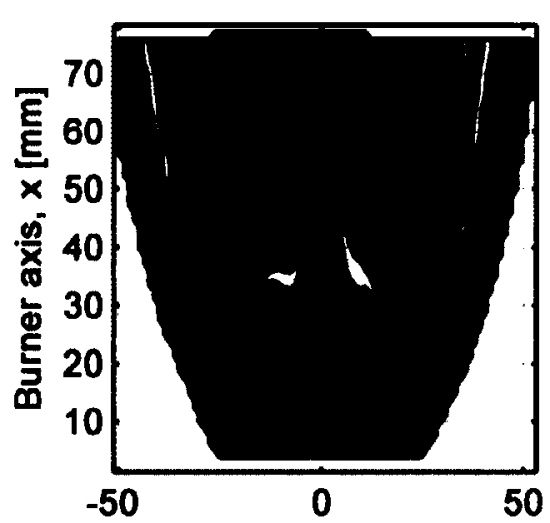

a) Burner radius, $r$ [mm]

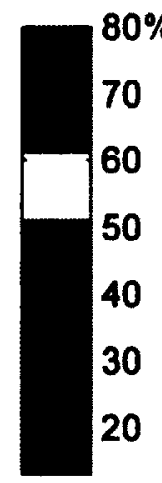

20

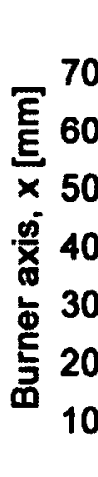

b)

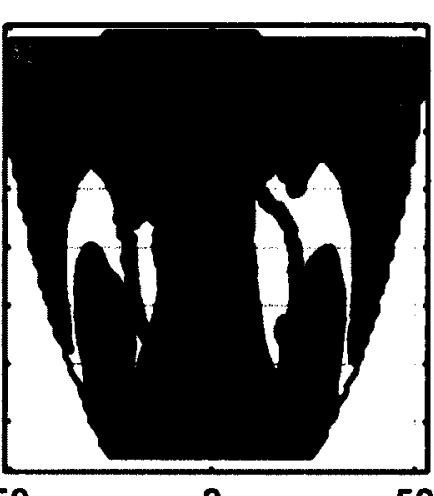

0

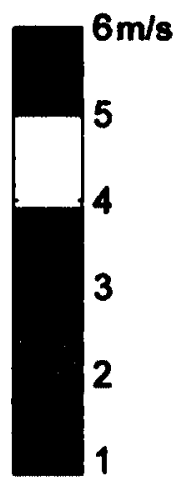

50

Figure 6.12: Turbulence contours for the $38.1 \mathrm{~mm} \mathrm{LSB} \mathrm{nozzle} \mathrm{burning} \mathrm{CH}_{4}$ at $\Phi=0.7, Q_{\text {tot }}=1000$ SLPM, near blowoff (R-type blowoff $-S=0.72$ ) for a) 3D turbulence intensity b) 3D RMS turbulence fluctuations, $V^{\prime}$

After blowoff occurred, when the swirl number was lowered from the conditions in Figure 6.12, the flame could be relit in a W-type stability mode as shown in Figure 6.13. Figure 6.13a shows that the flame front for this $\mathrm{W}$-type blowoff condition no longer follows the apparent weak recirculation region, implying that it is not essential for the stability of the flame as it is for the R-type blowoff condition. Although the flame front is quite flat, the flame again appears to be anchored in the shear layer where the 3D turbulence fluctuations begin to 
increase. This observation provides evidence for the situation where a shear-layer stabilized flame (which leads to W-type blowoff) can still have some recirculation, but the stability of the flame does not depend on the recirculation as it would for Rtype blowoff condition. Given the conditions for these measurements corresponded to where the relighting phenomenon was observed for the $38.1 \mathrm{~mm} \mathrm{LSB}$, it is evident that these are the conditions of transitional flames between the R- and Wtype stability modes.

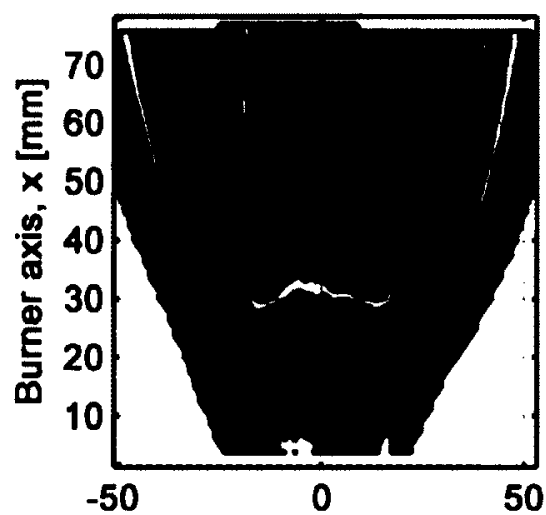

a) Burner radius, $r[\mathrm{~mm}]$

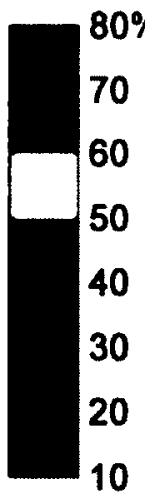

10

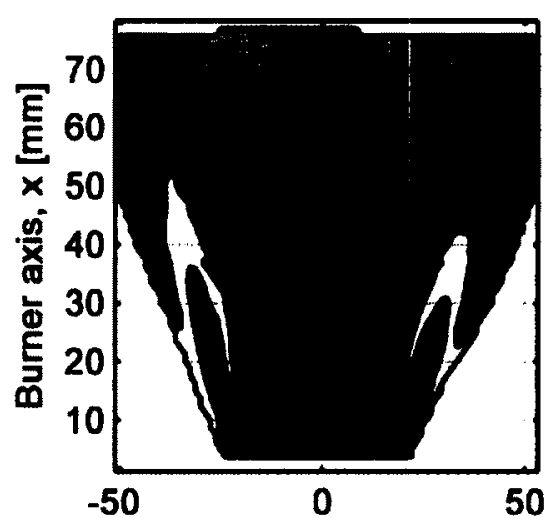

b) Burner radius, $r$ [mm]

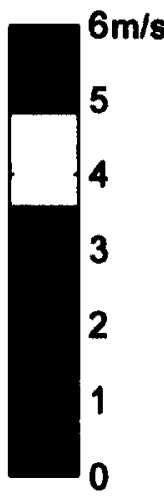

50

Figure 6.13: Turbulence contours for the $38.1 \mathrm{~mm} \mathrm{LSB} \mathrm{nozzle} \mathrm{burning} \mathrm{CH}_{4}$ at $\Phi=0.7, Q_{t o t}=1000$ SLPM, near blowoff (transitional $W$-type blowoff $-S=0.58$ ) for a) 3D turbulence intensity b) 3D RMS turbulence fluctuations, $V^{\prime}$

Table 6.2 list the calculated radial gradients of the axial velocity and fluctuating component of the axial velocity as determined from PIV data at the leading edge anchor position of the flame for all available conditions. It was postulated that there may be a maximum velocity gradient in which the flame can sustain itself that might correspond to the transition between $\mathrm{W}$ - and $\mathrm{R}$-type blowoff regimes. This notion would be consistent with the basic theory of premixed flames and strain induced flame extinction and would imply that there is a practical upper limit to the amount of swirl that can usefully be used to stabilize a W-type flame. In situations where the velocities are extremely high and the radial gradients are very large, the flame may not be able to exist in the shear layer region and flames can only then stabilize in an R-type mode in the presence of flow recirculation. However, the available data in Table 6.2 show no definitive trends sufficient to confirm this hypothesis. 
Table 6.2: Magnitude of $u_{R M S}^{\prime}$ and $U_{\text {mean }}$ radial gradients at anchor points of all flames at blowoff

\begin{tabular}{|c|c|c|c|c|c|c|c|c|}
\hline $\begin{array}{c}\text { Blowoff } \\
\text { type }\end{array}$ & Fuel & $\begin{array}{c}\text { Nozzle } \\
{[\mathrm{mm}]}\end{array}$ & $\phi$ & $\begin{array}{c}Q_{\text {tot }} \\
{[S L P M]}\end{array}$ & $\begin{array}{c}U_{\text {ave }} \\
{[\mathrm{m} / \mathrm{s}]}\end{array}$ & $S$ & $\begin{array}{c}U_{\text {mean }} \\
\text { gradient }\end{array}$ & $\begin{array}{c}\boldsymbol{u}_{R M S}^{\prime} \\
\text { gradient }\end{array}$ \\
\hline \multirow{5}{*}{$\begin{array}{l}\text { R-type } \\
\text { blowoff }\end{array}$} & $\mathrm{CH}_{4}$ & 38.1 & 0.65 & 900 & 15.1 & 0.75 & 128 & 34 \\
\hline & $\mathrm{CH}_{4}$ & 38.1 & 0.65 & 1000 & 16.7 & 0.77 & 152 & 11 \\
\hline & $\mathrm{CH}_{4}$ & 38.1 & 0.70 & 900 & 15.1 & 0.66 & 43 & 15 \\
\hline & $\mathrm{CH}_{4}$ & 38.1 & 0.70 & 1000 & 16.7 & 0.72 & 29 & 7.7 \\
\hline & $\mathrm{CH}_{4}$ & 50.8 & 0.60 & 800 & 7.44 & 0.60 & 149 & 96 \\
\hline \multirow{35}{*}{$\begin{array}{l}\text { W-type } \\
\text { blowoff }\end{array}$} & $\mathrm{CH}_{4}$ & 38.1 & 0.65 & 400 & 6.71 & 0.56 & 266 & 104 \\
\hline & $\mathrm{CH}_{4}$ & 38.1 & 0.7 & 400 & 6.68 & 0.52 & 176 & 77 \\
\hline & $\mathrm{CH}_{4}$ & 38.1 & 0.7 & 900 & 15.1 & 0.55 & 54 & 73 \\
\hline & $\mathrm{CH}_{4}$ & 38.1 & 0.7 & 1000 & 16.7 & 0.58 & 1.25 & 67 \\
\hline & $\mathrm{CH}_{4}$ & 38.1 & 0.8 & 400 & 3.72 & 0.41 & 18 & 18 \\
\hline & $\mathrm{CH}_{4}$ & 38.1 & 0.9 & 1000 & 16.7 & 0.53 & 58 & 34 \\
\hline & $\mathrm{CH}_{4}$ & 38.1 & 0.9 & 1200 & 20.1 & 0.53 & 38 & 59 \\
\hline & $\mathrm{CH}_{4}$ & 50.8 & 0.7 & 720.6 & 6.68 & 0.47 & 24 & 34 \\
\hline & $\mathrm{CH}_{4}$ & 50.8 & 0.7 & 800 & 7.43 & 0.46 & 10 & 54 \\
\hline & $\mathrm{CH}_{4}$ & 50.8 & 0.7 & 1200 & 11.1 & 0.48 & 25 & 39 \\
\hline & $\mathrm{CH}_{4}$ & 50.8 & 0.8 & 400 & 3.72 & 0.41 & 29 & 4.2 \\
\hline & $\mathrm{CH}_{4}$ & 50.8 & 0.8 & 720.6 & 6.68 & 0.44 & 6.5 & 31 \\
\hline & $\mathrm{CH}_{4}$ & 50.8 & 0.8 & 800 & 7.41 & No Swirl & 531 & 102 \\
\hline & $\mathrm{CH}_{4}$ & 50.8 & 0.8 & 800 & 7.41 & 0.44 & 277 & 91 \\
\hline & $\mathrm{CH}_{4}$ & 50.8 & 0.8 & 1200 & 11.3 & 0.46 & 270 & 145 \\
\hline & $\mathrm{CH}_{4}$ & 76.2 & 0.7 & 1639.9 & 6.68 & 0.47 & 15 & 11 \\
\hline & $\mathrm{CH}_{4}$ & 76.2 & 0.8 & 1639.9 & 6.68 & 0.47 & 11 & 2.9 \\
\hline & $\mathrm{B} 1$ & 50.8 & 0.76 & 778 & 7.22 & 0.46 & 190 & 70 \\
\hline & $\mathrm{B} 1$ & 50.8 & 0.80 & 800 & 7.43 & 0.48 & 124 & 81 \\
\hline & $\mathrm{B} 1$ & 50.8 & 0.88 & 778 & 7.23 & 0.44 & 181 & 75 \\
\hline & S1 & 50.8 & 0.63 & 878 & 8.14 & 0.43 & 161 & 69 \\
\hline & S1 & 50.8 & 0.75 & 881 & 8.16 & 0.42 & 104 & 64 \\
\hline & S2 & 50.8 & 0.65 & 856 & 7.93 & 0.41 & 74 & 43 \\
\hline & S2 & 50.8 & 0.77 & 879 & 8.15 & 0.38 & 199 & 26 \\
\hline & 54 & 50.8 & 0.63 & 869 & 8.05 & 0.43 & 408 & 66 \\
\hline & 54 & 50.8 & 0.74 & 874 & 8.10 & 0.41 & 332 & 55 \\
\hline & $S 5$ & 50.8 & 0.64 & 858 & 7.96 & 0.42 & 206 & 23 \\
\hline & 55 & 50.8 & 0.75 & 865 & 8.01 & 0.39 & 172 & 18 \\
\hline & S6 & 50.8 & 0.77 & 847 & 7.88 & 0.38 & 320 & 36 \\
\hline & S14 & 50.8 & 0.61 & 871 & 8.07 & 0.40 & 104 & 33 \\
\hline & S14 & 50.8 & 0.71 & 884 & 8.18 & 0.37 & 62 & 22 \\
\hline & S5M50 & 50.8 & 0.69 & 810 & 7.50 & 0.44 & 14 & 65 \\
\hline & S5M50 & 50.8 & 0.79 & 817 & 7.59 & 0.42 & 115 & 50 \\
\hline & S5M25 & 50.8 & 0.68 & 820 & 7.59 & 0.44 & 49 & 44 \\
\hline & S5M25 & 50.8 & 0.78 & 830 & 7.69 & 0.40 & 160 & 48 \\
\hline
\end{tabular}




\subsection{Blowoff Stability Correlation Based on Shear-layer Strength}

All of the results presented in this thesis highlight the importance of the annular shear layer in determining flame stability, especially for flame in a W-type mode. The strength of the 3D shear layer is a function of the magnitude of the velocity vector difference between the inner core flow and outer annular flows. Termed $V_{\text {diff, }}$ this velocity magnitude difference is calculated as follows:

$$
V_{\text {diff }}=\sqrt{\left(U_{o, x}-U_{i, x}\right)^{2}+\left(U_{o, x} \tan (\alpha)\right)^{2}}
$$

An attempt at using $V_{\text {diff }}$ as a correlating parameter is shown below. Figure 6.14 shows the methane blowoff curves for the three different sized LSB nozzles at equivalence ratios of $\Phi=0.6-1.0$. For the $50.8 \mathrm{~mm}$ LSB nozzle, the $37.5^{\circ}$ swirler was used in this case. The results show an obvious linear trend that tightly correlates the majority of the blowoff points. More intriguing is the fact that the blowoff points that obviously deviate from the linear trend can all be inferred as operating near an R-type blowoff mode based on available PIV flowfield data and their occurrence at higher swirl numbers, low $\Phi$, and higher flowrates. All of the remaining blow-off points follow a common linear trend with average exit velocity. This clearly implies that for flames in a W-type blowoff regime, the strength of the shear layer is paramount in determining stability and $V_{\text {diff }}$ is a remarkably useful parameter for quantifying this effect. 


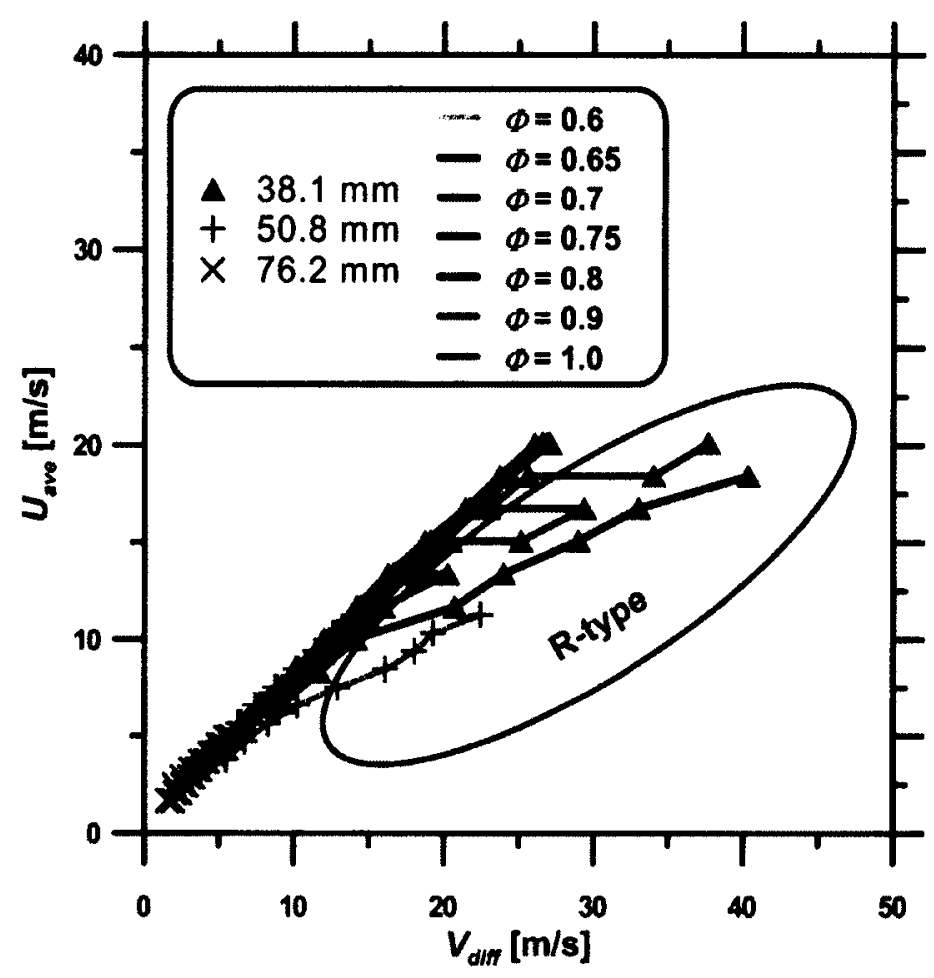

Figure 6.14: $\mathrm{CH}_{4}$ blowoff curves for all three nozzles plotted with $U_{\text {ave }}$ vs. $V_{\text {diff }}$

The notion that it is simply the strength of the shear layer that determines stability as opposed to something specific to the swirling flow can be tested by considering stability data for the LSB operating without a swirler in place. As discussed briefly in Section 5.2, with the swirler removed the LSB can operate as a simple co-annular burner and produce stable lifted flames (although with a narrower stability range that is possible with the swirler in place). Figure 6.15 shows two different blowoff curves for methane fuel at $\Phi=0.8$ on the $50.8 \mathrm{~mm}$ nozzle achieved with and without the use of the $37.5^{\circ}$ swirler. The curves are plotted against the fraction of the total flow directed to the inner core flow $(\% I F F)$, since the swirl number is ill-defined (always equal to zero) for the co-annular burner without a swirler in place. Blowoff occurs when the $\% I F F$ is raised to a high enough location, meaning that the area to the left of both blowoff curves is considered stable (bounded by flashback at lower \%IFF). The spacing between the two curves is indicative of the enhanced stability that is possible with the swirler in place. 


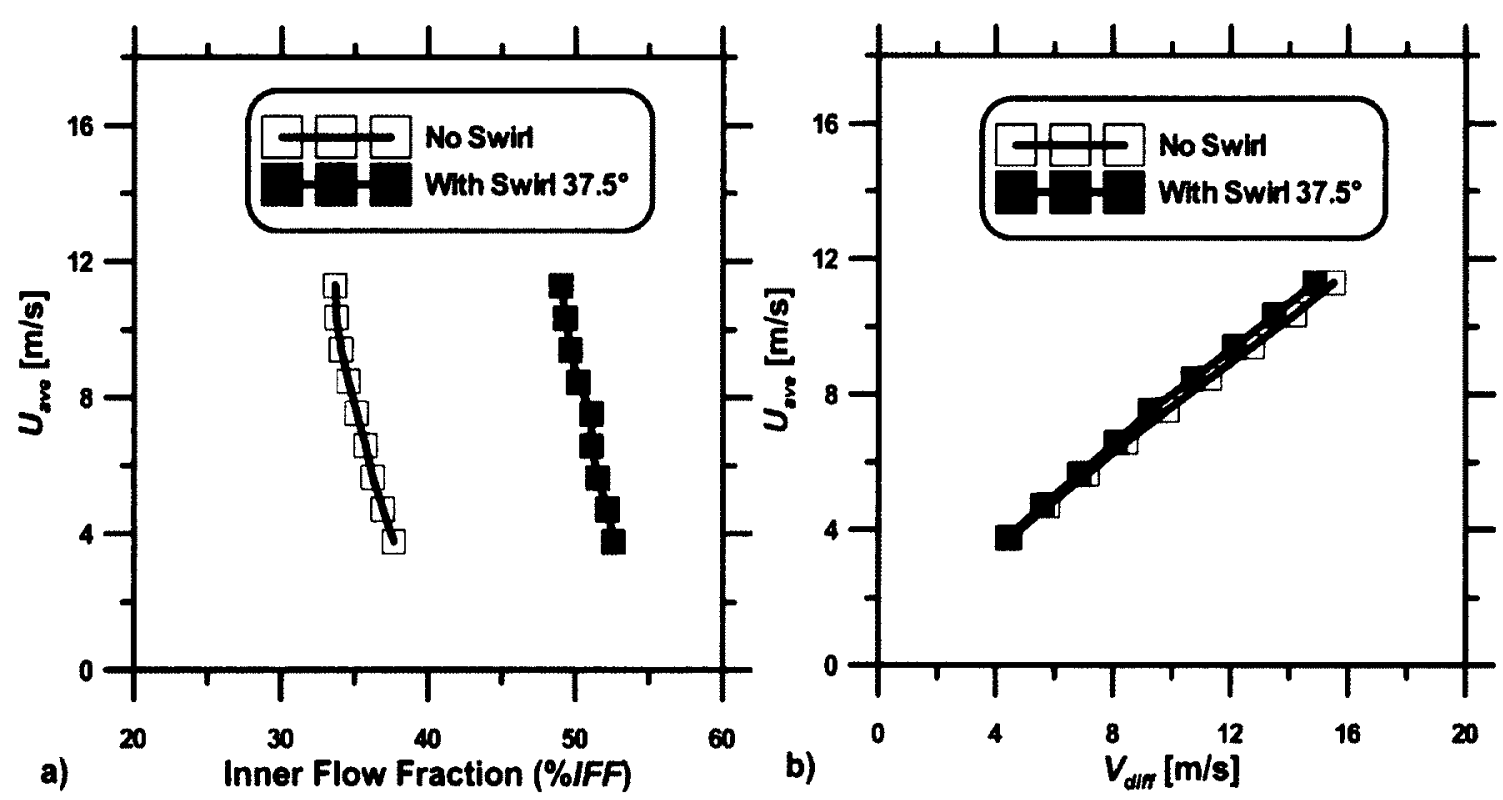

Figure 6.15: $50.8 \mathrm{~mm}$ nozzle with $\mathrm{CH}_{4}$ at $\Phi=0.8$, at blowoff ( $W$-type blowoff) with and without swirl plotted with a) Inner flow fraction (\%) and b) $V_{\text {diff }}$

Figure $6.15 \mathrm{~b}$ shows that when the blowoff curves are plotted using $V_{\text {diff }}$ on the horizontal axis, the blowoff curves for the with and without swirl cases essentially coincide. This effectively proves that it is the magnitude of the 3D shear layer that determines whether or not $\mathrm{W}$-type blowoff will occur, regardless of the amount of swirl present. Consistent with previous observations, increasing the amount of swirl increases $V_{\text {diff }}$ by adding a tangential component to the velocity difference. This in turn would increase the turbulence produced in the shear layer which directly affects the flame. However, with or without swirl, shear-layer stabilized LSB flames appear to be fundamentally the same.

To test the limits of this relation Figure 6.16 plots all available data for W-type blowoff in this study (all nozzle diameters, all fuel mixtures, all equivalence ratios, all swirl angles including no-swirl for the $50.8 \mathrm{~mm}$ nozzle). A surprisingly tight correlation is apparent, which underscores the importance of the magnitude of the 3D shear layer for all shear layer stabilized LSB flames.

There is some spread in the data that empirically seems linked to the fuel composition. Typically, fuels with a higher laminar flame speed blow off at a lower $V_{\text {diff }}$ (lower swirl number). Several attempts were made to develop a useful nondimensional relationship to describe this behaviour but none could be found. 
However, as shown in Figure 6.17a, an empirical scaling using $V_{\text {diff }}{ }^{*} S_{L}^{0.15}$ removes much of the remaining spread in the data. It must be stressed that the exponent used for the laminar flame speed is purely empirical where the exponent that produced the closest observed fit was chosen. This empirical relationship effectively summarizes key observed behaviour of the LSB in a W-type stabilization mode. With increasing average exit velocity (due to smaller diameter nozzle or increased flowrate), the shear layer strength needed to stabilize the flame increases. Figure $6.17 \mathrm{~b}$ shows a histogram of $V_{\text {diff }}{ }^{*} S_{L}^{0.15}$ normalized by $U_{\text {ave. }}$. All data fall within approximately $\pm 20 \%$ of unity.

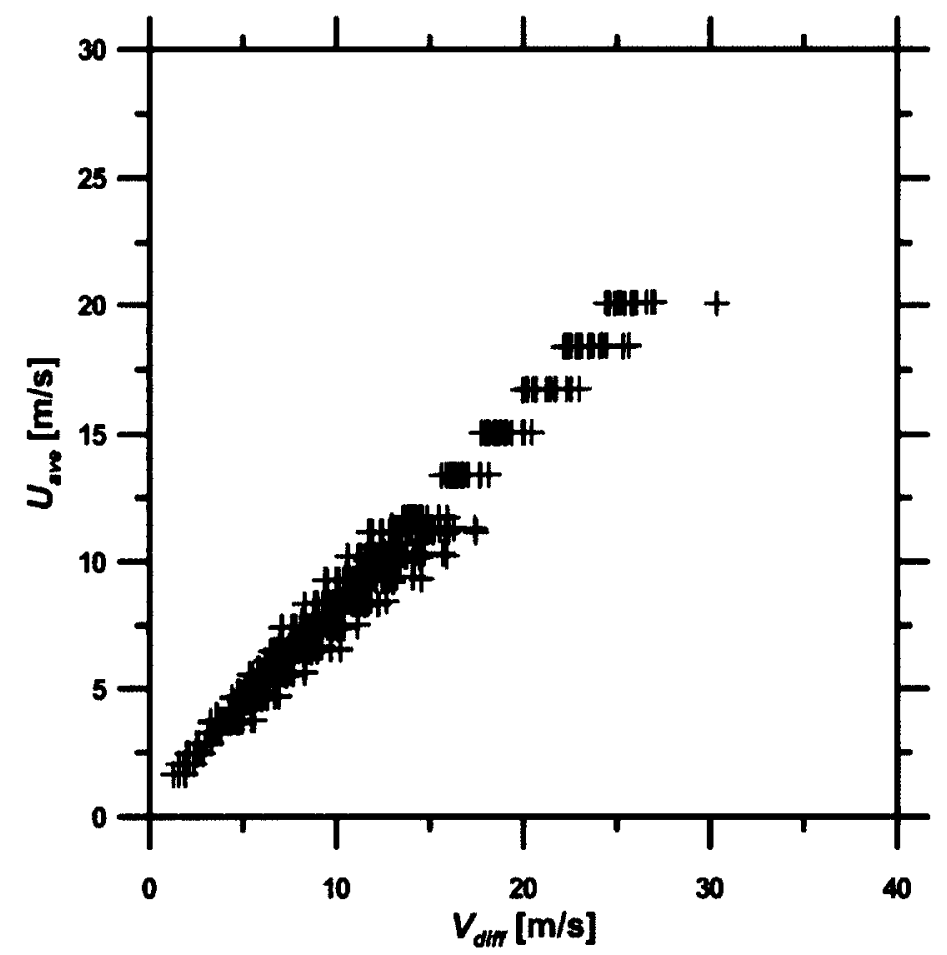

Figure 6.16: All blowoff points ( $W$-type blowoff only) for all fuel mixtures, all $\Phi$, all nozzles $\left(35^{\circ}, 37.5^{\circ}, 47^{\circ}\right.$ and no swirl for $50.8 \mathrm{~mm}$ nozzle $)$ 


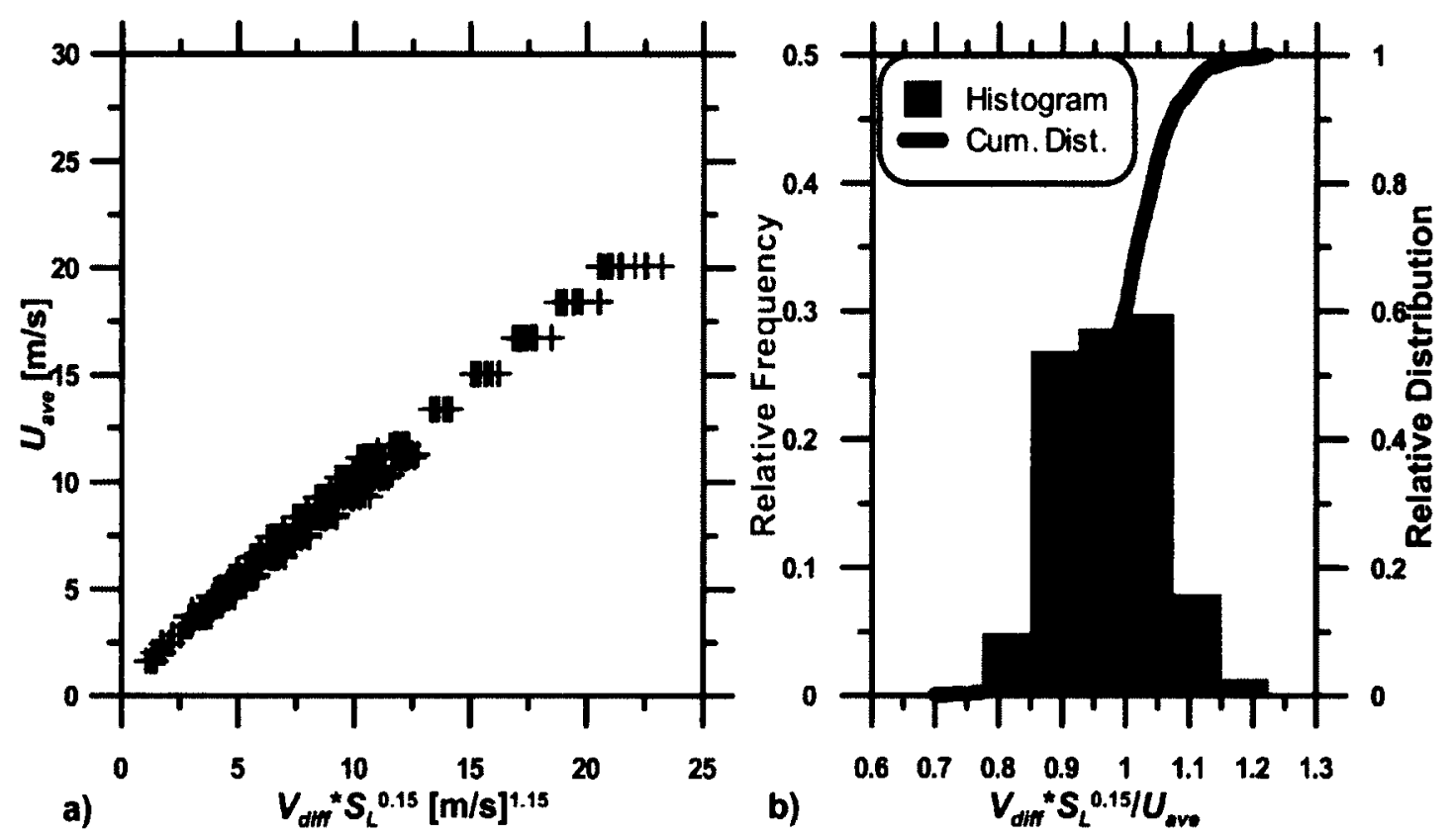

Figure 6.17: Empirical correlation for blowoff points (W-type blowoff only) for all fuel mixtures, all $\Phi$, all nozzles, all swirl angles $\left(35^{\circ}, 37.5^{\circ}, 47^{\circ}\right.$ and no swirl for $50.8 \mathrm{~mm}$ nozzle) a) Average exit velocity vs. 3D shear layer strength ( $\left.V_{\text {diff }}\right)$ times $S_{L}{ }^{0.15}$ b) Histogram $\left(V_{\text {diff }}{ }^{*} S_{L}^{0.15} / U_{\text {ave }}\right)$

The correlation presented in Figure 6.17 provides a useful way of determining whether a flame will blowoff or not for a given fuel mixture, equivalence ratio, average exit velocity, and strength of the 3D shear layer within the LSB. This result also demonstrates that the LSB is extremely fuel flexible so long as the attached flame mode is avoided (i.e. by limiting the $\mathrm{H}_{2}$ content of the fuel or by increasing the exit velocity of the reactants accordingly) and the swirl number is kept sufficiently low and/or equivalence ratio is kept sufficiently high to avoid R-type blowoff. Otherwise, the open- atmosphere LSB requires no significant redesign to implement the tested gaseous biofuels immediately. 


\section{Conclusions and Recommendations}

\subsection{Conclusions}

Blowoff and flashback stability limits of a low-swirl burner (LSB) were measured for a range of scales ( $38.1 \mathrm{~mm}, 50.8 \mathrm{~mm}$, and $76.2 \mathrm{~mm}$ LSB nozzles) using 11 different biogas and syngas fuel mixtures (methane, B1, S1, S2, S3, S4, S5, S6, S14, S5M50, S5M25). The LSB used in these experiments permitted full independent control over the flows directed to the inner core and annular regions for the burner, and stability measurements were performed over a wide parametric range of flowrates, heat release rates, equivalence ratios, adiabatic flame temperatures, and swirl numbers. Stability 'volumes' were produced in heat release rate-swirl-numberadiabatic flame temperature space, and the stability limits between the fuel mixtures were compared. Stereoscopic particle image velocimetry (PIV) was employed to measure the 3D velocity fields of selected conditions (mostly near blowoff) along the midplane of the burner exit nozzle. The instantaneous PIV velocity fields were used to calculate turbulence statistics of the LSB flames.

The results showed that the LSB is capable of stable operation at lean premixed conditions over a significant turndown ratio. In general, it was found that increasing $\Phi$ makes the flame blowoff and flashback at lower swirl numbers, while increasing the flowrate had the opposite effect. Two different blowoff regimes were observed at swirl numbers traditionally associated with low-swirl operation $(S \leq 0.65)$. The dominant "W-type" blowoff mode was characterized by a W-shaped flame that stabilized in the shear layer between the inner non-rotating core flow and annular swirling flow. The secondary "R-type" blowoff mode was characterized by a weak tulip-shaped flame stabilized by a central recirculation zone. Investigation using PIV confirmed that the flowfield and stability mechanisms for these two types of flames were inherently different. A third attached flame mode was observed with certain hydrogen-containing fuel mixtures that was closely correlated with the laminar flame speed of the mixture. 
The stability volumes for the syngas fuel mixtures show that the LSB is amenable to alternative gaseous fuels immediately with certain caveats. Namely, with the exception of $\mathrm{B} 1$, all biofuel mixtures tested in this study were less prone to blowoff, but more prone to flashback. Also, when hydrogen was present in the fuel mixture there was the possibility of the attached flame mode where the flame stabilized on the burner rim, and blowoff did not occur for any swirl number.

A Damköhler number $(D a)$ analysis was performed on all PIV measured blowoff conditions. In general, the flames near R-type blowoff had Damköhler numbers less than unity at the lowest point on the flame front, implying chemically limited blowoff. Most flames at W-type blowoff had Damköhler numbers at the lowest point in the flame front of either close to or greater than unity, aerodynamically controlled blowoff. Transitional flames were observed that had flowfield properties consistent with W-type blowoff flames, but where weak recirculation was evident or becoming evident in the flowfields. Damköhler numbers in these cases were less than unity.

For the flames that led to W-type blowoff (including transitional W-type flames), an empirical parameter was found that successfully correlated blowoff data for all nozzle diameters, swirl angles (including no-swirl), and fuel mixtures. This simple correlation was based upon the magnitude of the vector difference $\left(V_{d i f f}\right)$ between the inner core flow and outer annular flow. When multiplied by the laminar flame speed raised to the 0.15 power $\left(V_{\text {diff }}^{*} S_{L}^{0.15}\right)$ blowoff data for all available fuel mixtures were linearly related to the average exit velocity, $U_{\text {ave, }}$, such that $0.8<V_{\text {diff }}{ }^{*} S_{L}{ }^{0.15} / U_{\text {ave }}<1.2$ for all data at $W$-type blowoff. This result provides a useful empirical tool for designing a low-swirl burner to operate at any exit velocity with a wide variety of fuels and equivalence ratios. Special care must be taken at conditions of low $\Phi$ and high flowrate to avoid the R-type blowoff situation. For this situation, the flowrate must be lowered, the equivalence ratio must be raised, or a high enough swirl number must be provided to stabilize these flames to avoid Rtype blowoff. If an attached flame is to be avoided when hydrogen is present in the fuel mixture, then the equivalence ratio must be kept low, the flowrate must be raised, or a combination of these two strategies must be employed. 


\subsection{Recommendations for future work}

Further studies could focus on elucidating the exact physical basis for the observed $S_{L}{ }^{0.15}$ in the empirical correlation for W-type blowoff. In addition, flames near Rtype blowoff should be more broadly explored since it is anticipated that R-type blowoff may be more relevant at higher $\Phi$ with higher flow rates than were possible to achieve in the present study.

All of the experiments presented in this thesis were for atmospheric flames. If gas turbine applications are to be targeted, then future work must consider elevated pressures and temperatures. Enclosure effects should also be investigated in greater detail.

Correlating flashback points could similarly be a focus of future work. The same chemical properties which make a fuel blowoff resistant (namely, laminar flame speed) also make the fuel more prone to flashback. A study on flashback behavior with the goal of obtaining tools for the prediction of flashback would be another useful result for the design of fuel-flexible low-swirl burners.

Finally, the exact combination of chemical and/or physical properties of hydrogen that make the attached flame possible should be identified. With these properties, another tool for the prediction of the onset of the attached flame could be created to aid in future designs as well. 


\section{References}

Abdel-Gayed, R.G., D. Bradley, and FKK Lung. 1989. "Combustion regimes and the straining of turbulent premixed flames." Combustion and Flame 76 (2): 213-218.

Agency, International Energy. 2010. Key World Energy Statistics 2010. Statistics. OECD Publishing, August. doi:10.1787/9789264039537-en. http://www.oecdilibrary.org/energy/key-world-energy-statistics-2009_9789264039537-en.

Antal, Michael J., William E. Edwards, Henry L. Friedman, and Frank E. Rogers. 1984. A Study of the Steam Gasification of Organic Wastes. EPA, March.

Bedat, B, and R.K. Cheng. 1995. "Experimental study of premixed flames in intense isotropic turbulence." Combustion and Flame 100 (3) (February): 485-494.

Bender, Bill. 2006. Lean Pre-mixed Combustion. In The Gas Turbine Handbook, ed. Richard Dennis.

Beér, J.M., and N.A. Chigier. 1972. Combustion aerodynamics. London: Krieger Pub Co.

Bicen, A.F., D.G.N. Tse, and J.H. Whitelaw. 1990. "Combustion characteristics of a model can-type combustor." Combustion and flame 80 (2) (May): 111-125.

Boillot, A, and A K Prasad. 1996. "Optimization procedure for pulse separation in crosscorrelation PIV." Experiments in Fluids 21 (Adrian 1991): 87-93.

Borghi, R. 1985. "On the structure and morphology of turbulent premixed flames." Recent advances in the aerospace sciences: 117-138.

Bowman, C.T. 1992. Control of combustion-generated Nitrogen oxide emissions: Technology driven by regulations. In Symposium (International) on Combustion,

Broadwell, J.E., W.J.A. Dahm, and M.G. Mungal. 1985. Blowout of turbulent diffusion flames. In Symposium (International) on Combustion, 20:303-310. Elsevier.

Canadian Council of Ministers of the Environment. 1992. CCME_NationlaEmissionGuidelinesforStationaryCombustionTurbines.pdf. Winnipeg, MB. http://www.ccme.ca/assets/pdf/pn_1072_e.pdf.

Cantera: An object-oriented software toolkit for chemical kinetics, thermodynamics, and transport processes", Caltech, Pasadena, 2011. [Online]. Available: http://code.google.com/p/cantera 
Casleton, Kent, Ronald Breault, and George Richards. 2008. "System Issues and Tradeoffs Associated with Syngas Production and Combustion." Combustion Science and Technology 180 (6) (June): 1013-1052.

Chan, C.K., K.S. Lau, W.K. Chin, and R.K. Cheng. 1992. Freely propagating open premixed turbulent flames stabilized by swirl. In Symposium (International) on Combustion, 24:511-518. Elsevier.

Chaudhuri, Swetaprovo, Stanislav Kostka, Michael W. Renfro, and Baki M. Cetegen. 2010. "Blowoff dynamics of bluff body stabilized turbulent premixed flames." Combustion and Flame 157 (4) (April): 790-802.

Cheng, R.K., D. Littlejohn, P.A. Strakey, and T. Sidwell. 2009. "Laboratory investigations of a low-swirl injector with $\mathrm{H} 2$ and $\mathrm{CH} 4$ at gas turbine conditions." Proceedings of the Combustion Institute 32 (2): 3001-3009.

Cheng, R.K., D.T. Yegian, M.M. Miyasato, G.S. Samuelsen, C.E. Benson, R. Pellizzari, and P. Loftus. 2000. "Scaling and development of low-swirl burners for lowemission furnaces and boilers." Proceedings of the Combustion Institute 28 (1): 1305-1313.

Cheng, RK, and D. Littlejohn. 2008. Effects of Combustor Geometry on the Flowfields and Flame Properties of a Low-Swirl Injector. In ASME.

Cheng, Robert K. 1995. "Velocity and scalar characteristics of premixed turbulent flames stabilized by weak swirl." Combustion and Flame 101 (1-2) (April): 1-14.

Cheng, Robert K.. 2006. Low Swirl Combustion. In The Gas Turbine Handbook, ed. Richard Dennis.

Cheng, Robert K. 2010. Turbulent Combustion Properties of Premixed Syngas. In Synthesis Gas Combustion: Fundamentals and Applications, ed. Timothy C. Lieuwen, Vigor Yang, and Richard A. Yetter, 129-168. Boca Raton, FL: CRC Press, Taylor \& Francis Group.

Ciferno, J.P., and J.J. Marano. 2002. Benchmarking biomass gasification technologies for fuels, chemicals and hydrogen production. US Dep of Energy. Citeseer, June. http:/citeseerx.ist.psu.edu/viewdoc/download?doi=10.1.1.140.8405\&amp;rep=rep 1 \&amp;type=pdf.

Co, North American Manufacturing. 1952. North American Combustion Handbook. Cleveland, $\mathrm{OH}$ : The North American Manufacturing Co.

Crosland, Brian Michael. 2008. An Experimental Characterisation of the Velocities of the Spray Issued from a Pressurised Metered-Dose Inhaler By. Carleton University. 
Curran, H J, P Gaffuri, W J Pitz, and C K Westbrook. 2002. "A Comprehensive Modeling Study of iso-Octane Oxidation." Combustion and Flame 2180 (01).

Damköhler, G. 1940. "Der Einfluss der Turbulenz auf die Flammengeschwindigkeit in Gasgemischen" (The effect of turbulence on the combustion rate in gas compounds) Zeitschrift fur Elektrochemie und Angewandte Physikalische Chemie 46: 601-626. (cited in Peters, 2000).

Davis, S.G., A.V. Joshi, H Wang, and F Egolfopoulos. 2005. "An optimized kinetic model of $\mathrm{H} 2 / \mathrm{CO}$ combustion." Proceedings of the Combustion Institute 30 (1): 1283-1292.

Dixon, S.L. 2005. "Fluid mechanics, thermodynamics of turbomachinery": 88-89.

Edmondson, H, and MP Heap. 1970. "The correlation of burning velocity and blowoff data by the flame stretch concept." Combustion and Flame 15 (2) (October): 179187.

Feikema, D. 1990. "Enhancement of flame blowout limits by the use of swirl." Combustion and Flame 80 (2) (May): 183-195.

Glassman, Irvin, and Richard Yetter. 2008. Combustion. 4th ed. Amsterdam; Boston: Academic Press.

Hasegawa, Tatsuya, Ryosuke Nakamichi, and Shinnosuke Nishiki. 2002. "Mechanism of flame evolution along a fine vortex." Combustion Theory and Modelling 6 (3): 413424.

Hermanson, J. C., M. B. Colket, and J. J. Sangiovanni. 1997. "Stability and Emissions of Lean, Turbulent, Premixed Flames with Very Lean Coflow." AIAA Journal 35 (11) (November): 1705-1711.

Howell, AR. 1945. "Fluid dynamics of axial compressors." ARCHIVE: Proceedings of the Institution of Mechanical Engineers 1847-1982 (vols 1-196) 153 (1945): 441452.

Hsieh, T.-C.Adrian, Werner J.a. Dahm, and James F. Driscoll. 1998. "Scaling Laws for NOx Emission Performance of Burners and Furnaces from $30 \mathrm{~kW}$ to $12 \mathrm{MW}$." Combustion and Flame 114 (1-2) (July): 54-80.

Jeffs, RA. 1961. The Flame Stability and Heat Release Rates of Some Can-Type Combustion Chambers. In Symposium (International) on Combustion, 8:1014-1027. Elsevier.

Ji, Jun, and Jay P. Gore. 2002. "Flow structure in lean premixed swirling combustion." Proceedings of the Combustion Institute 29 (1): 861-867. 
Johnson, M.R., D. Littlejohn, W.A. Nazeer, K.O. Smith, and R.K. Cheng. 2005. "A comparison of the flowfields and emissions of high-swirl injectors and low-swirl injectors for lean premixed gas turbines." Proceedings of the Combustion Institute 30 (2): $2867-2874$.

Johnson, MR, LW Kostiuk, and RK Cheng. 1998. "A Ring Stabilizer for Lean Premixed Turbulent Flames." Combustion and flame 114 (3): 594-596.

Kalghatgi, G.T. 1981. "Blow-out stability of gaseous jet diffusion flames. Part I: In still air." Combustion Science and Technology 26 (5): 233-239.

Kang, D, F Culick, and a Ratner. 2007. "Combustion dynamics of a low-swirl combustor." Combustion and Flame 151 (3) (November): 412-425.

Karlovitz, B, DW Jr. Denniston, DH Knapschaefer, and FE Wells. 1953. "Studies on Turbulent Flames: A. Flame Propagation Across Velocity Gradients. B. Turbulence Measurement in Flames." Symposium (International) on Combustion 4 (1): 613-620.

Kiameh, Philip. 2003. Power generation handbook: selection, applications, operation, and maintenance. McGraw-Hill Professional.

Kido, H, M Nakahara, K Nakashima, and J Hashimoto. 2002. "Influence of local flame displacement velocity on turbulent burning velocity." Proceedings of the Combustion Institute 29 (2): 1855-1861

Konle, M, and T Sattelmayer. 2009. "Time Scale Model for the Prediction of the Onset of Flame Flashback Driven by Combustion Induced Vortex Breakdown (CIVB)." Proceedings of ASME Turbo Expo 2009.

Konle, Marco, and Thomas Sattelmayer. 2009. "Interaction of heat release and vortex breakdown during flame flashback driven by combustion induced vortex breakdown." Experiments in Fluids 47 (4-5) (May): 627-635.

Kuo, KK. 2005. Principles of combustion. 2nd ed. Hoboken, NJ: John Wiley $\backslash \&$ Sons.

LaVision Inc. 2010. LaVision FlowMaster 7.2 Product-Manual. Gottingen, GE: LaVision.

Lefebvre, Arthur H. 1999. Gas Turbine Combustion. 2nd ed. Ann Arbor, MI: Taylor \& Francis.

Legrand, Mathieu, José Nogueira, Antonio Lecuona, Sara Nauri, and Pedro a. Rodriguez. 2010. "Atmospheric low swirl burner flow characterization with stereo PIV." Experiments in Fluids 48 (5) (November): $901-913$ 
Leonard, G., and J. Stegmaier. 1994. "Development of an Aeroderivative Gas Turbine Dry Low Emissions Combustion System." Journal of Engineering for Gas Turbines 116 (3): 542-546.

Lieuwen, Tim, Vince McDonell, Eric Petersen, and Domenic Santavicca. 2008. "Fuel flexibility influences on premixed combustor blowout, flashback, autoignition, and stability." Journal of Engineering for Gas Turbines and Power 130: 011506.

Lieuwen, Tim, Vince McDonell, Domenic Santavicca, and Thomas Sattelmayer. 2008. "Burner Development and Operability Issues Associated with Steady Flowing Syngas Fired Combustors." Combustion Science and Technology 180 (6) (June): 1169-1192.

Lieuwen, Timothy C. 2006. Static and Dynamic Combustion Stability. In The Gas Turbine Handbook, ed. Richard Dennis.

Lieuwen, Timothy C., Vince McDonell, Domenic Santavicca, and Thomas Sattelmayer. 2010. Operability Issues Associated with Steady Flowing Combustors. In Synthesis Gas Combustion: Fundamentals and Applications, ed. Timothy C. Lieuwen, Vigor Yang, and Richard A. Yetter, 261-288. Boca Raton, FL: Taylor \& Francis.

Littlejohn, D, RK Cheng, DR Noble, and T. 2010. "Laboratory Investigations of LowSwirl Injectors Operating With Syngases." Journal of Engineering for Gas Turbines and Power 132 (1).

Littlejohn, D., and R.K. Cheng. 2007. "Fuel effects on a low-swirl injector for lean premixed gas turbines." Proceedings of the Combustion Institute 31 (2): 3155 3162.

Littlejohn, David, Adrian J. Majeski, Shaheen Tonse, Carlo Castaldini, and Robert K. Cheng. 2002. "Laboratory investigation of an ultralow NOx premixed combustion concept for industrial boilers." Proceedings of the Combustion Institute 29 (1): 1115-1121

Mansour, Mohy, and Y.C. Chen. 2008. "Stability characteristics and flame structure of low swirl burner." Experimental Thermal and Fluid Science 32 (7): 1390-1395.

Miller, J.A., and C.T. Bowman. 1989. "Mechanism and modeling of nitrogen chemistry in combustion." Progress in Energy and Combustion Science 15 (4): 287-338.

Natarajan, J., Y. Kochar, T. Lieuwen, and J. Seitzman. 2008. "Laminar Flame Speed Measurements of $\mathrm{H} 2 / \mathrm{CO} / \mathrm{CO} 2$ Mixtures Up to $15 \mathrm{~atm}$ and $600 \mathrm{~K}$ Preheat Temperature." ASME Paper.

Natarajan, Jayaprakash, and Jerry M. Seitzman. 2010. Laminar Flame Properties of H2/CO Mixtures. In Synthesis Gas Combustion: Fundamentals and Applications, 
ed. Timothy C. Lieuwen, Vigor Yang, and Richard A. Yetter, 71-98. Boca Raton, FL: CRC Press, Taylor \& Francis Group.

Nauert, A., P. Petersson, M. Linne, and A. Dreizler. 2007. "Experimental analysis of flashback in lean premixed swirling flames: conditions close to flashback." Experiments in Fluids 43 (1): 89-100.

Noble, D.R., Q. Zhang, Akbar Shareef, J. Tootle, Andrew Meyers, and Tim Lieuwen. 2006. Syngas mixture composition effects upon flashback and blowout. In Proceedings of ASME Turbo Expo, 8-11.

Nogenmyr, K.-J., P. Petersson, X.S. Bai, C. Fureby, R. Collin, a. Lantz, M. Linne, and M. Aldén. 2010. "Structure and stabilization mechanism of a stratified premixed low swirl flame." Proceedings of the Combustion Institute 33 (August): 1567-1574.

Pereira, P., G.A. Somorjai, and H. Heinemann. 1992. "Catalytic steam gasification of coals." Energy \& Fuels 6 (4): 407-410..

Peters, Norbert. 1986. Laminar flamelet concepts in turbulent combustion. In TwentyFirst Symposium (International) on Combustion, 1231-1250. Pittsburgh, PA: The Combustion Institute.

Peters, Norbert 2000. Turbulent combustion. Applied Mechanics Reviews. 1st ed. Vol. 54. Cambridge Univ Pr.

Plessing, T., C. Kortschik, N. Peters, M.S. Mansour, and R.K. Cheng. 2000. "Measurements of the turbulent burning velocity and the structure of premixed flames on a low-swirl burner." Proceedings of the Combustion Institute 28 (1): 359366

Poinsot, T.J., D. Veynante, and S. Candel. 1990. Diagrams of premixed turbulent combustion based on direct simulation. In Twenty-Third Symposium (International) on Combustion, 613-619. Pittsburgh, PA: The Combustion Institute.

Ponizy, B, and J.C Leyer. 1999. "Flame dynamics in a vented vessel connected to a duct: 1. Mechanism of vessel-duct interaction." Combustion and Flame 116 (1-2) (January): 259-271.

Prasad, a. K. 2000. "Stereoscopic particle image velocimetry." Experiments in Fluids 29 (2) (August 7): 103-116. doi:10.1007/s003480000143.

Presser, C, J B Greenberg, Y Goldman, and Y M Timnat. 1982. "A Numerical Study of Furnace Flame Root Stabilization Using Conical Burner Tunnels." Combustion: 519-527. 
Ramasamy, Manikandan, and J. Gordon Leishman. 2007. "Benchmarking Particle Image Velocimetry with Laser Doppler Velocimetry for Rotor Wake Measurements." AIAA Journal 45 (11) (November): 2622-2633.

Rasi, Saija. 2009. Biogas Composition and Upgrading to Biomethane. Jyv|"askyl"a Studies in Biological and Environmental Science. University of Jyvaskyla.

Ribert, Guillaume, Piyush Thakre, Zhe Wang, Richard A. Yetter, and Vigor Yang. 2010. Fundamental Combustion Characterisitics of Syngas. In Synthesis Gas Combustion: Fundamentals and Applications, ed. Timothy C. Lieuwen, Vigor Yang, and Richard Yetter, 99-126. Boca Raton, FL: CRC Press, Taylor \& Francis Group.

Richards, Geo A., and Kent H. Casleton. 2010. Gasification Technology to Produce Synthesis Gas. In Synthesis Gas Combustion: Fundamentals and Applications, ed. Timothy C. Lieuwen, Vigor Yang, and Richard A. Yetter, 1-28. Boca Raton, FL: Taylor \& Francis.

Schefer, R. 2003. "Hydrogen enrichment for improved lean flame stability." International Journal of Hydrogen Energy 28 (10) (October): 1131-1141.

Shepherd, I, R Cheng, T Plessing, C Kortschik, and N Peters. 2002. "Premixed flame front structure in intense turbulence." Proceedings of the Combustion Institute 29 (2): 1833-1840.

Strahman, J.G. 2007. Flame Stability of an Ultra-Lean Premixed Low-Swirl Burner. Carleton University.

Tavoularis, Stavros. 2005. Measurement in fluid mechanics. Cambridge Univ Pr.

Tillman, David A., and N.S. Harding. 2004. Fuels of opportunity: characteristics and uses in combustion systems. 1st ed. Kidlington, Oxford: Elsevier Ltd.

Tropea, C., A.L. Yarin, and J.F. Foss. 2007. Springer handbook of experimental fluid mechanics. Vol. 1. Springer Verlag.

Turns, S.R. 2000. An introduction to combustion. 2nd ed. McGraw-Hill New York.

Vagelopoulos, C. 1994. "Laminar flame speeds and extinction strain rates of mixtures of carbon monoxide with hydrogen, methane, and air." Symposium (International) on Combustion 25 (1): 1317-1323.

Whitty, Kevin J., Hongzhi R. Zhang, and Eric G. Eddings. 2010. Pollutant Formation and Control. In Synthesis Gas Combustion: Fundamentals and Applications, ed. Timothy C. Lieuwen, Vigor Yang, and Richard A. Yetter, 169-191. Boca Raton, FL: CRC Press, Taylor \& Francis Group. 
Widmann, John F, S Rao Charagundla, and Cary Presser. 2000. "Aerodynamic study of a vane-cascade swirl generator." Chemical Engineering Science 55: 5311-5320.

Yegian, D. T., and R. K. Cheng. 1998. "Development of a Lean Premixed Low-Swirl Burner for Low NOx Practical Applications." Combustion Science and Technology 139 (1) (October): 207-227.

Yilmaz, Illker, Albert Ratner, Mustafa Ilbas, and Yun Huang. 2010. "Experimental investigation of thermoacoustic coupling using blended hydrogen-methane fuels in a low swirl burner." International Journal of Hydrogen Energy 35 (1) (January): 329-336.

Zhang, Qingguo. 2008. Lean Blowoff Characteristics of Swirling H2/CO/CH4 Flames. Fuel. Georgia Institute of Technology. 


\section{Appendix A Biofuel Compositions}

\section{A.1 Syngas/Biogas Compositions}

Gaseous biofuels can be separated into two main categories. Syngas, or synthesis gas, is produced via gasification of coal or biomatter resulting in a combustible gas mixture of widely varying composition. Typically, the principal constituents of syngas are carbon monoxide, hydrogen, carbon dioxide, methane, and nitrogen along with trace amounts of higher hydrocarbons and other impurities. The other main category of gaseous biofuels is biogas, which is produced via anaerobic digestion of biomatter by microorganisms. Biogas consists mainly of methane and carbon dioxide (Lieuwen et al. 2008). These two main categories can be further sub-divided as discussed below. In this brief review, reported syngas and biogas compositions are analyzed and categorized in an attempt to determine optimal mixtures for investigating the various influences of fuel composition on flame behaviour.

\section{A.2 Syngas Composition}

Syngas compositions are extremely variable and depend primarily on 3 factors: feedstock type, gasification configuration, and syngas purification methods. Feedstock can range from all varieties of coal (lignite, sub-bituminous, bituminous, and anthracite) and other solid fossil fuels to many types of biomass (bark, wood, switchgrass, etc) and refuse. The relative proportions of carbon, hydrogen, nitrogen, moisture, and impurities (sulfur, metals, halogens, etc) in the feedstock have an obvious impact on the product syngas composition, and will be explored in this report further below. Different gasification configurations (fixed bed, fluidized bed, etc) and methods (directly heated and indirectly heated) currently in use in industry are explored in high detail in (Casleton et al. 2008), (Richards and Casleton, 2010), and (Ciferno and Marano, 2002). Gasification occurs at elevated temperatures, $500-1400{ }^{\circ} \mathrm{C}$, and at atmospheric or elevated pressures. The oxidant used can be air, pure $\mathrm{O}_{2}$, steam or a mixture of these gases. Essentially, there are 
two main steps: pyrolysis and gasification. Pyrolysis uses heat to decompose the feedstock into primarily volatile gaseous and liquid hydrocarbons. Any remaining nonvolatile compounds that still contain high carbon content are referred to as char. The gasification step converts the volatile hydrocarbons and char into syngas. This can be seen graphically in Figure A.1:

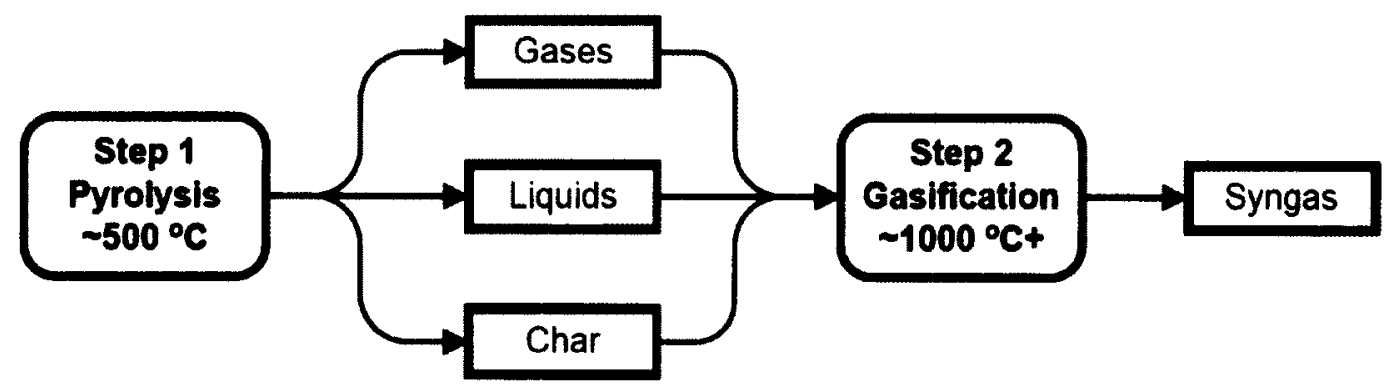

Figure A.1: Gasification steps, from (Ciferno and Marano, 2002)

There are both exothermic and endothermic reactions in the syngas-producing chemistry. A few of the major reactions are listed below (Ciferno and Marano, 2002):

Exothermic reactions:

Combustion

Partial Oxidation

Methanation

Water-Gas Shift

CO Methanation

$$
\begin{aligned}
& \{\text { volatiles/char }\}+\mathrm{O}_{2} \rightarrow \mathrm{CO}_{2} \\
& \{\text { volatiles/char }\}+\mathrm{O}_{2} \rightarrow \mathrm{CO} \\
& \{\text { volatiles/char }\}+\mathrm{H}_{2} \rightarrow \mathrm{CH}_{4} \\
& \mathrm{CO}+\mathrm{H}_{2} \mathrm{O} \rightarrow \mathrm{CO}_{2}+\mathrm{H}_{2} \\
& \mathrm{CO}+3 \mathrm{H}_{2} \rightarrow \mathrm{CH}_{4}+\mathrm{H}_{2} \mathrm{O}
\end{aligned}
$$

Endothermic Reactions:

Steam-Carbon reaction

$$
\begin{aligned}
& \{\text { volatiles/char }\}+\mathrm{H}_{2} \mathrm{O} \rightarrow \mathrm{CO}+\mathrm{H}_{2} \\
& \{\text { volatiles/char }\}+\mathrm{CO}_{2} \rightarrow 2 \mathrm{CO}
\end{aligned}
$$

Boudouard reaction

To supply heat for the endothermic gasification reactions, either directlyheated gasification or indirectly-heated gasification is employed. Directly-heated gasification, the most common type of gasification, conducts the pyrolysis (and combustion required for pyrolysis) and gasification in a single vessel. It uses an 
oxidant (in this case air or 02 only) to combust a portion of the biomass exothermically to provide heat for the endothermic reactions. Indirectly-heatedgasification aims to separate the combustion reaction required for pyrolysis from the rest of the gasification reactions for reasons explained later in this report. An example of this is reported in Ciferno and Marano (2002) from Battelle Columbus Laboratory. It consists of a steam-fluidized bed of sand particles, which are initially mixed with the feedstock. Sand particles mixed with char created via pyrolysis are separated and transported to a second fluidized bed reactor. This second bed is airblown and acts as a char combustor generating a flue gas exhaust stream and a stream of hot sand particles. These hot sand particles are separated from the flue gas and recirculated back to the gasifier to provide the heat necessary for further pyrolysis, and the cycle continues. Of the 35 compositions reported in Casleton et al. (2008) and Ciferno and Marano (2002), only 2 are produced via indirectly heated gasification showing that directly heated gasifiers are by far the most common.

Another significant factor in the product syngas composition is the raw syngas purification method used, if any. Impurities can be present in raw syngas (ie: before any purification), and thus different "cleanup" methods can be used to tailor a syngas for a particular application or to meet a specific emissions target. As described in Richards and Casleton (2010), a "cold gas cleanup" is typically used to purify the raw syngas. The gas is first cooled (through many possible different methods), and sent through cyclones or filters to remove slag, particulates, and alkali materials which are condensed out of solution upon cooling. A water wash can then be used to get the finest particulates and the majority of the water-soluble impurities (ammonia, $\mathrm{HCN}, \mathrm{HCl}$, etc.). For sulfur removal, $\mathrm{COS}$ present in the raw syngas is generally "shifted" to $\mathrm{H}_{2} \mathrm{~S}$ via $\mathrm{COS}$ hydrolysis, which consumes moisture present in the raw syngas. If more hydrogen is desired in the product syngas, the water-gas shift reaction can also be exploited to further consume moisture present in the raw syngas. Following these shifts, a "water knockout" is usually employed, which is typically implemented as a further reduction in temperature resulting in significant water condensation for the purpose of capturing even more watersoluble trace species. There are several other possible steps explained in Richards 
and Casleton (2010) that aren't explained here due to their minimal effect on final composition (i.e. further removal of trace species).

Although water vapour content in the product syngas can vary from $0-40 \%$ (Lieuwen et al. 2008), the most common method for reporting these compositions is to report the composition were it dry. Of the 35 syngas compositions reported in Casleton et al. (2008) and Ciferno and Marano (2002), 31 were reported as vol. \%, dry. Water vapour can be added back into clean syngas prior to combustion to lower flame temperatures as a proven method for emissions reductions, but this will not be analyzed here. The following analysis will thus ignore the moisture content, and in the cases of the four mixtures that included moisture content as part of the composition, the compositions were re-calculated excluding the water vapour.

Figure A.2 shows the variability of all the syngas mixtures reported in the above-mentioned literature. As is obvious in the figure, each constituent gas has a very wide range of possible values resulting from the variables in syngas production discussed above. Of the variables discussed, the choice of oxidant (i.e. Air, pure $\mathrm{O}_{2}$, or steam) is especially critical and directly affects the nitrogen content of the product syngas. Figure A.3 shows that when air is used as the oxidant, the product syngas is on the order of $50 \% \mathrm{~N}_{2}$, and when $\mathrm{O}_{2}$ is the oxidant there is a negligible amount of $\mathrm{N}_{2}$ and often $<1 \%$. This is the most obvious and useful sub-category for syngas mixtures. Gasification can occur with steam only as a reactant as described above in the discussion on indirectly-heated gasification, but only when air $/ \mathrm{O}_{2}$ is used in a separate combustor to burn char as a means of heating particles to be recirculated back into the gasifier for the heat necessary to induce pyrolysis. This occurs in only two of the mixtures presented here which were not included in Figure A.3 since they were not either air or $\mathrm{O}_{2}$ blown like the vast majority of syngas. The compositions of the two indirectly heated and steam-blown syngases are presented in Figure A.4. The indirectly-heated and steam-blown syngas mixtures show their own variability. In this case, one of the mixtures is from a wood feedstock (Battelle Columbus Laboratory), while the other is from a pulp mill sludge feedstock which could explain the difference. It is noted however, that both the indirectly-heated 
mixtures have zero $\mathrm{N}_{2}$ content since the combustion part of the process, which is air-blown, is separate from the pyrolysis/gasification. This provides a low- $\mathrm{N}_{2}$ syngas mixture without having to use pure $\mathrm{O}_{2}$ as an oxidant. As explained before,

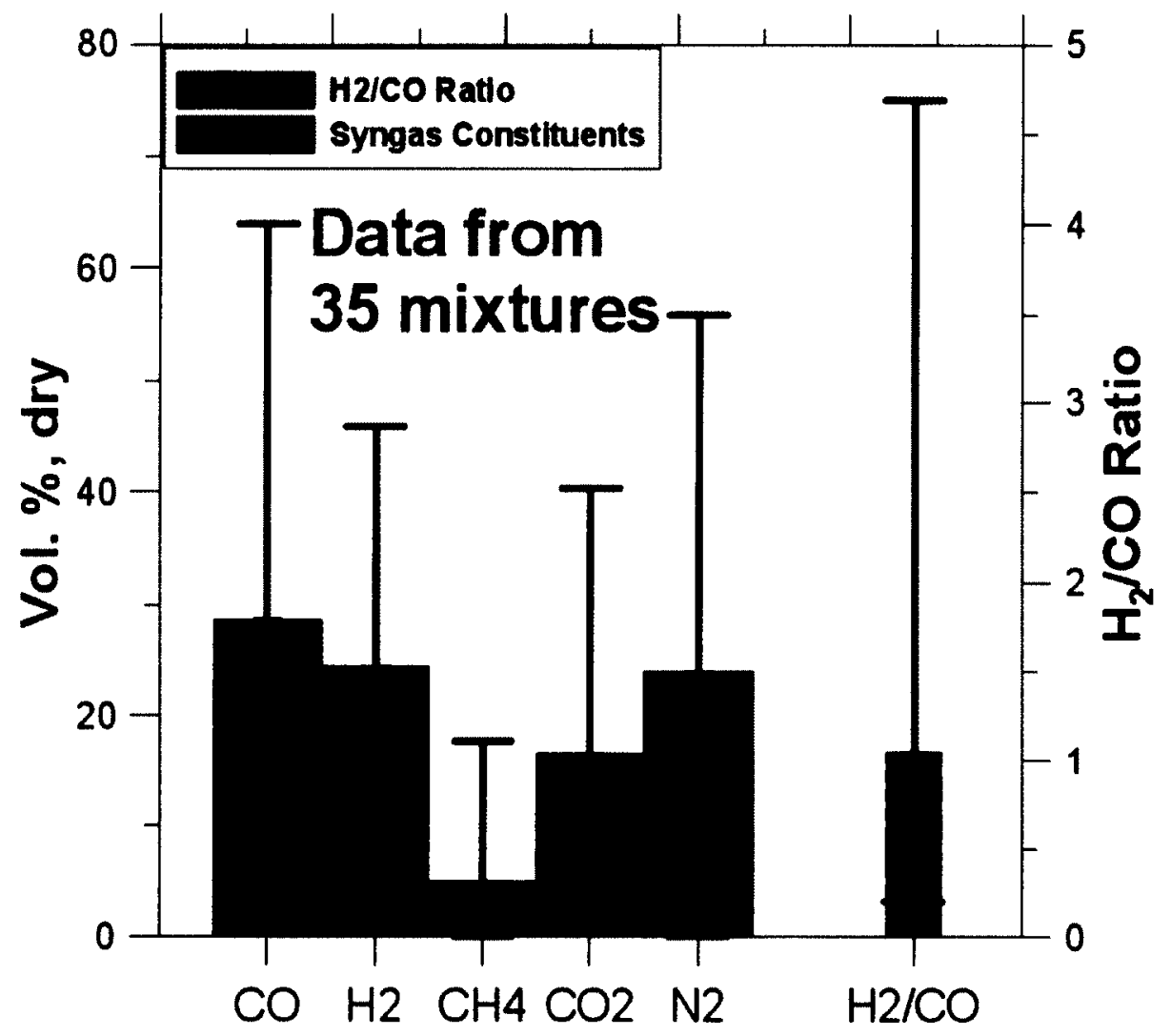

this is a rare case. Steam-blown gasification is explained in much higher detail in Antal et al. (1984) and Pereira et al. (1992).

Figure A.2: Mean composition and ranges for all syngas mixtures 


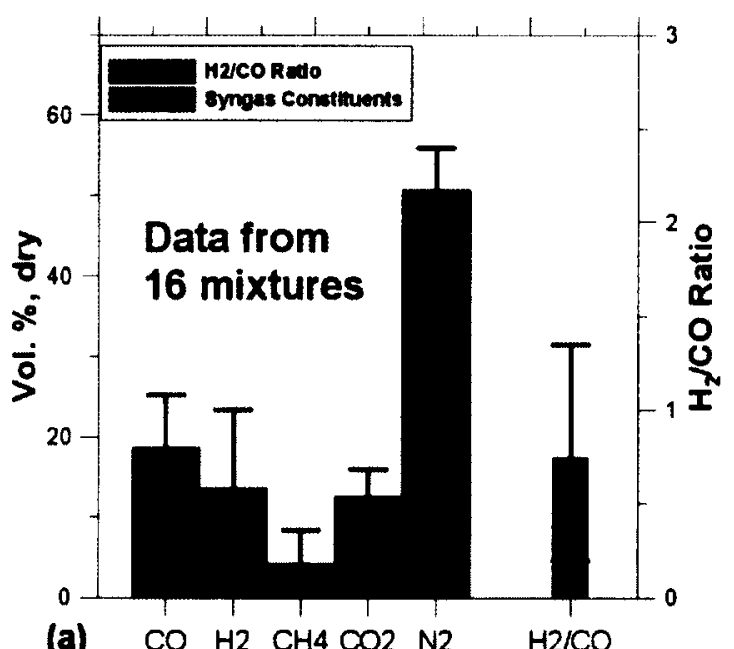

(a) $\mathrm{CO} \mathrm{H}_{2} \quad \mathrm{CH} 4 \mathrm{CO}_{2} \mathrm{~N} 2 \mathrm{H} / \mathrm{CO}$

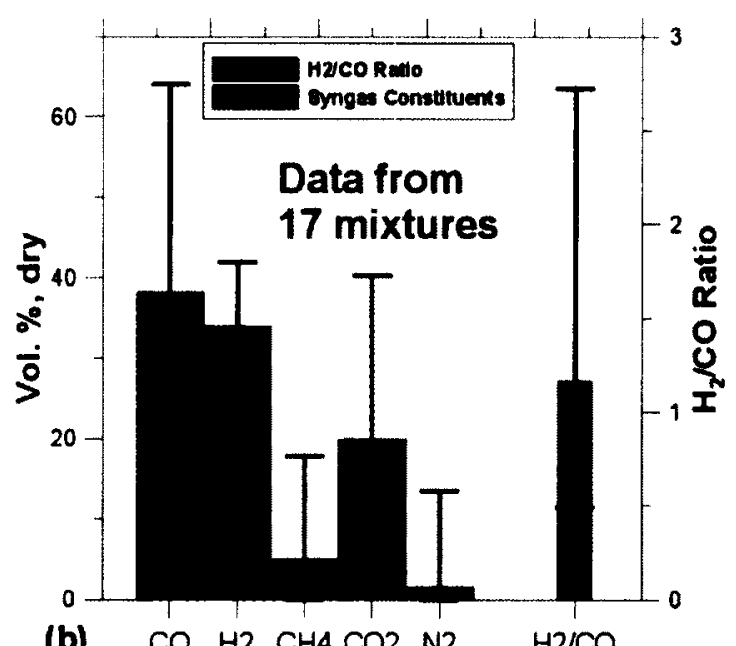

(b) $\mathrm{CO} \quad \mathrm{H} 2 \quad \mathrm{CH} 4 \mathrm{CO}_{2} \mathrm{~N} 2 \quad \mathrm{H} 2 / \mathrm{CO}$

Figure A.3: Directly heated and (a) airblown syngas (b) oxygen blown syngas

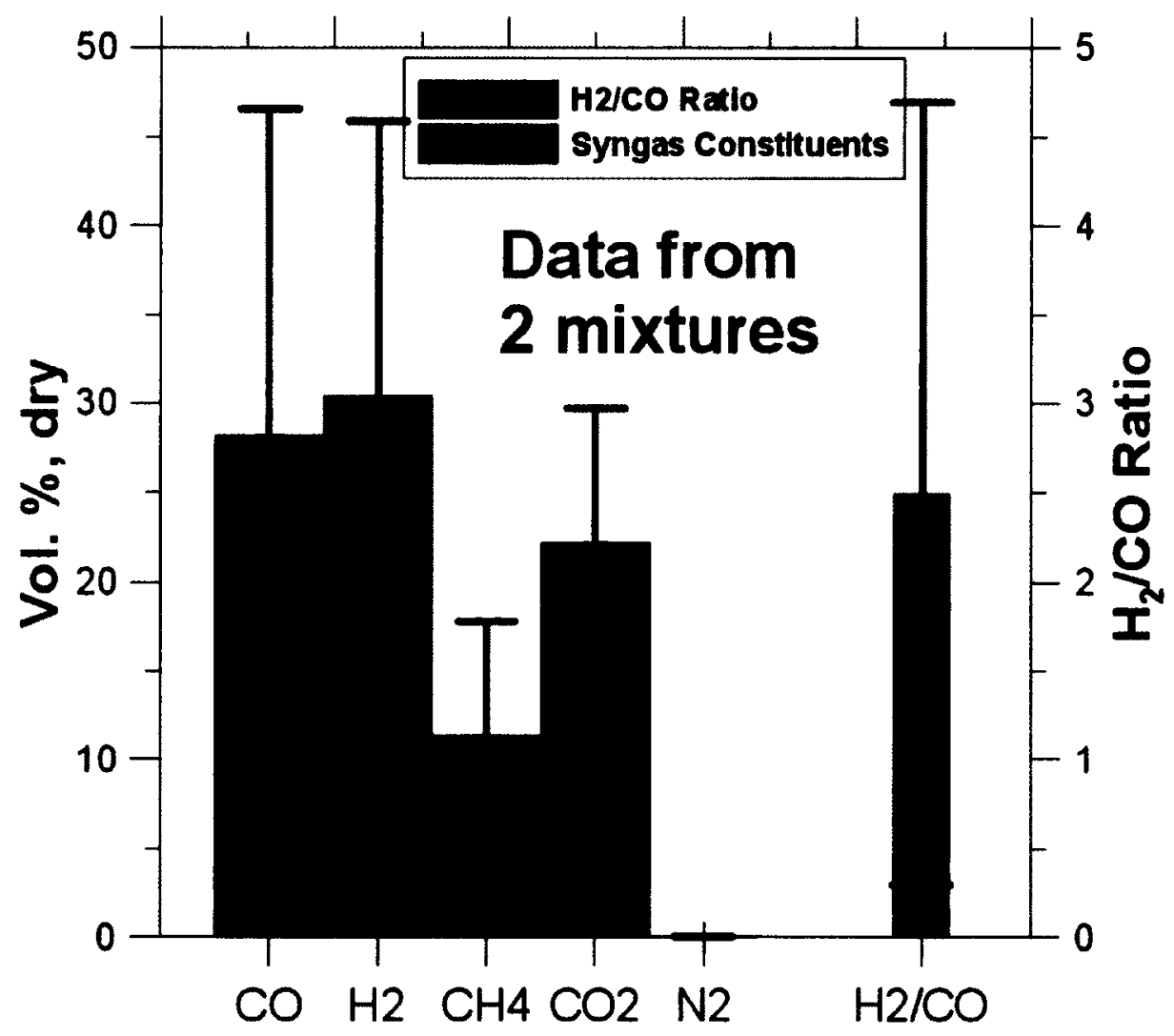

Figure A.4: Mean composition and ranges for indirectly-heated steam-blown syngas

Syngas can be further separated by feedstock. Syngas compositions reported in Casleton et al. (2008) result from entirely coalfed mixtures, and the compositions reported in Ciferno and Marano (2002) are entirely biomass fed with both reports 
differentiating between airblown and oxygen-blown gasification methods, and the biomass fed report differentiating further with the directly/indirectly-heated (and even steam-blown) gasifiers. Figure A.5 and Figure A.6 illustrate the similarity in compositions between coalfed and biomass fed syngas mixtures as long as the oxidant is held constant as either air or $\mathrm{O}_{2}$ (the indirectly-heated steam-blown mixtures were not included here). Biomass fed syngas mixtures typically have slightly higher levels of methane with corresponding lower levels of hydrogen, and the $\mathrm{H}_{2} / \mathrm{CO}$ ratio is higher for coalfed for both oxidants. This provides evidence that choice of oxidant (meaning primarily air or oxygen) has a much greater impact on final syngas composition than choice of feedstock. This might not be the case if impurities and moisture content in raw syngas were considered, but as explained above those factors will not be explored here.

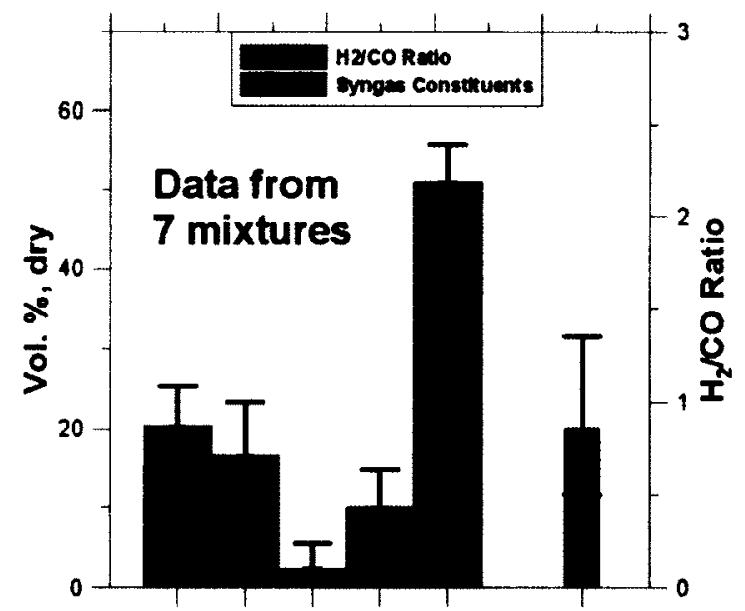

(a) $\mathrm{CO} \mathrm{H}_{2} \mathrm{CH}_{4} \mathrm{CO} 2 \mathrm{~N} 2 \mathrm{H} 2 / \mathrm{CO}$

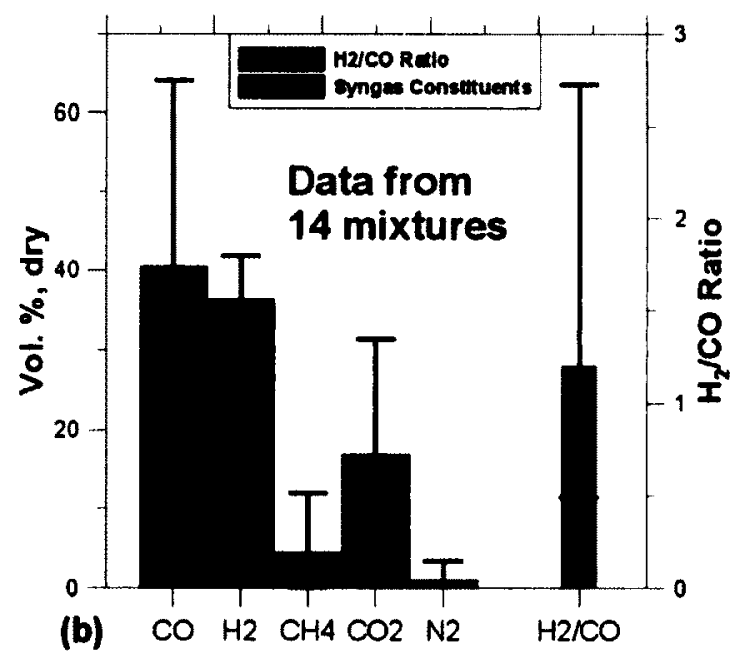

(b) $\mathrm{CO} \mathrm{H}_{2} \quad \mathrm{CH}_{4} \mathrm{CO}_{2} \quad \mathrm{~N} 2 \quad \mathrm{H} 2 / \mathrm{CO}$

Figure A.5: Directly-heated and (a) airblown coalfed syngas (b) $\mathrm{O}_{2}$ blown coalfed syngas 

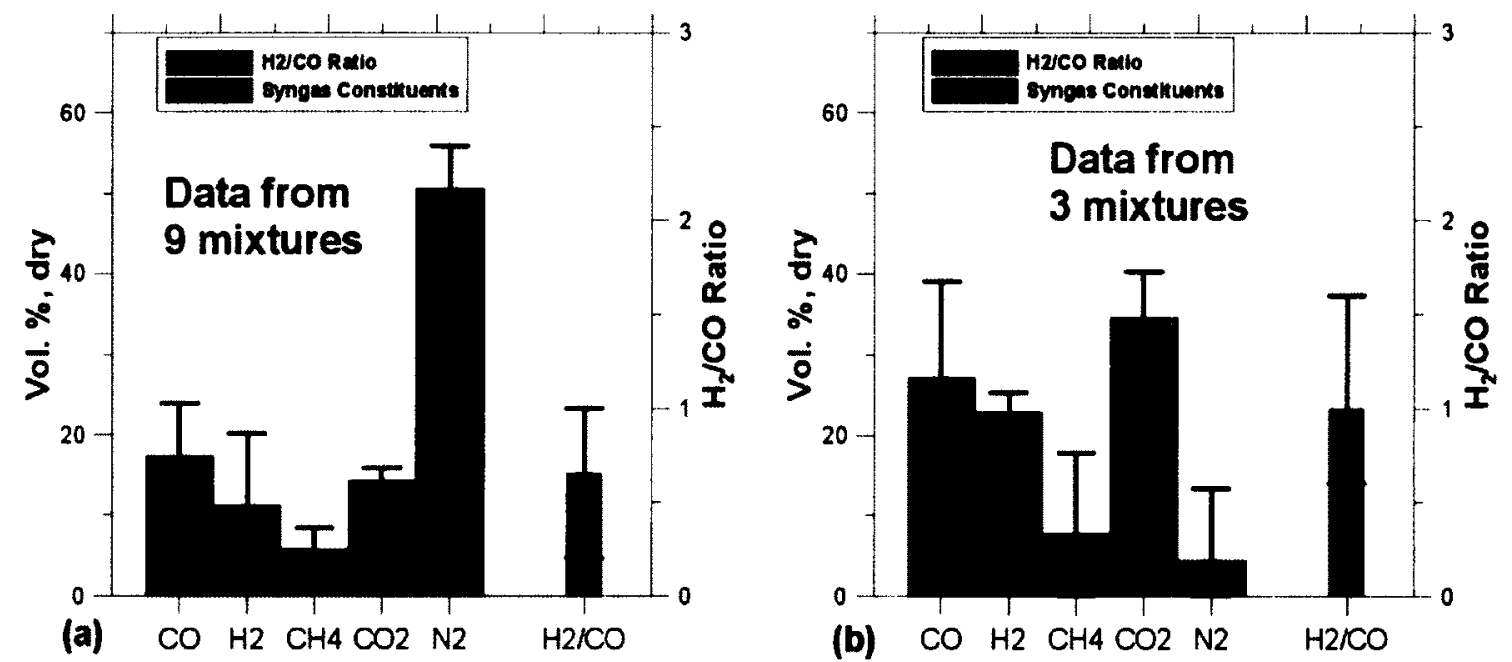

Figure A.6: Directly-heated and (a) airblown biomass-fed syngas (b) $\mathrm{O}_{2}$-blown biomass-fed syngas

To design relevant experimental syngas compositions, it was decided that a range of mixtures representing the variation in the common syngas mixtures should be used. Laminar flame speed has already been discussed as a major parameter for flame stability, and exploring its full range within syngas mixtures was considered a priority. Experimental measurements and model-based predictions for laminar flame speed for syngas mixtures are explored in depth in Natarajan and Seitzman (2010), Ribert et al. (2010), and Davis et al. (2005). According to Richards et al. (2010), $\mathrm{H}_{2} / \mathrm{CO}$ ratios go from 0.33-2.36 for both airblown and $\mathrm{O}_{2}$-blown directlyheated gasifiers, with very few outside of this range. For the rare case of indirectlyheated, steam-blown mixtures, the two reported mixtures have $\mathrm{H}_{2} / \mathrm{CO}$ ratios of 0.3 and 4.7. Hydrogen has by far the highest laminar flame speed of any species within syngas mixtures, and diluting with nitrogen or carbon dioxide tends to significantly lower this burning velocity somewhat predictably. So, to fully explore the range of possible syngas mixtures, a high $\mathrm{H}_{2} / \mathrm{CO}$ ratio, an equal $\mathrm{H}_{2} / \mathrm{CO}$ ratio, and a low $\mathrm{H}_{2} / \mathrm{CO}$ ratio was deemed necessary. The extreme level of the indirectly-heated, steamblown mixture whose $\mathrm{H}_{2} / \mathrm{CO}$ ratio was 4.7 will not be considered here due to the overwhelming prevalence of directly-heated gasifiers. Even though both of the diluents in syngas, $\mathrm{CO}_{2}$ and $\mathrm{N}_{2}$, should be studied separately, it was decided that since in these experiments air would be the oxidant, it was unnecessary to study the effects of nitrogen in the fuel since it would be present in the fuel-oxidant mixture 
anyway. Thus, for these experiments, only $\mathrm{CO}_{2}$ was considered as a diluent in syngas. Though methane concentration is generally quite low, its effect on flame behaviour cannot be ignored, so it was decided that methane would be present in a small amount for all the $\mathrm{H}_{2} / \mathrm{CO}$ ratios chosen. Along with this "natural" methane in the syngas fuels, higher levels of methane were also chosen to simulate syngas/natural gas blends. Based on this above analysis and the compromises discussed, the final decisions for experimental syngas mixtures are presented in Table 1.1.

Table A.1: Chosen Experimental Syngas Compositions

\begin{tabular}{|c|c|c|c|c|c|c|}
\hline Label & $\mathrm{H}_{2} / \mathrm{CO}$ ratio & $\mathrm{CO}(\%$ vol $)$ & $\% \mathrm{H}_{2}(\% \mathrm{vol})$ & $\% \mathrm{CH}_{4}(\%$ vol $)$ & $\% \mathrm{CO}_{2}(\% \mathrm{vol})$ & $\% \mathrm{~N}_{2}(\% \mathrm{vol})$ \\
\hline S1 & 0.5 & 50 & 25 & 0 & 25 & 0 \\
\hline S2 & 1.0 & 37.5 & 37.5 & 0 & 25 & 0 \\
\hline S3 & 2.0 & 25 & 50 & 0 & 25 & 0 \\
\hline S4 & 0.5 & 50 & 25 & 5 & 20 & 0 \\
\hline 55 & 1.0 & 37.5 & 37.5 & 5 & 20 & 0 \\
\hline 56 & 2.0 & 25 & 50 & 5 & 20 & 0 \\
\hline 514 & 1.0 & 42.5 & 42.5 & 0 & 15 & 0 \\
\hline S5M50 & 1.0 & 18.75 & 18.75 & 52.5 & 10 & 0 \\
\hline S5M25 & 1.0 & 28.125 & 28.125 & 28.75 & 15 & 0 \\
\hline
\end{tabular}

\section{A.2 Biogas Composition}

Biogas is produced from the decomposition of biomatter via anaerobic digestion from bacteria. Its primary constituents are $\mathrm{CH}_{4}$ and $\mathrm{CO}_{2}$ with balance $\mathrm{N}_{2}$. Biogas can be separated into two main groups: landfill gas (i.e. gas produced by a combination of aerobic and anaerobic decomposition of solid waste in landfills) and digester biogas (i.e. gas produced in mechanically controlled digesters). If significant oxygen from air penetrates a landfill, then decomposition proceeds aerobically and mostly $\mathrm{CO}_{2}$ is produced. However, as oxygen is consumed and/or if oxygen diffusion rates are low, then reactions proceed anaerobically and $\mathrm{CH}_{4}$ is the dominant product. Typical landfill gas is 45 to $55 \% \mathrm{CH}_{4}, 30$ to $40 \% \mathrm{CO}_{2}$, with balance $\mathrm{N}_{2}$ ranging from 5 to $15 \%$ (Rasi, 2009).

Biogas from a mechanically controlled digester is produced in a completely anaerobic environment and is therefore rarely if ever exposed to air (Chynoweth and Isaacson, 1987), which reduces the nitrogen concentration to negligible 
amounts. The product biogas from these digesters is typically composed of $55-70 \%$ $\mathrm{CH}_{4}, 30-45 \% \mathrm{CO}_{2}$ and $<1 \% \mathrm{~N}_{2}$ (Lieuwen, 2008)(Tillman and Harding, 2004)(Rasi, 2009). Figure A.7 shows the variability of biogas in general, and Figure A.8 shows plots of typical landfill and digester biogas compositions.

Similarly to the syngas composition decisions, it was decided having nitrogen in the fuel itself was unnecessary since the nitrogen in the air would dominate the mixture anyway. Thus, only one biogas mixture was chosen to represent the entire category. The mixture chosen is presented in Table A.2.

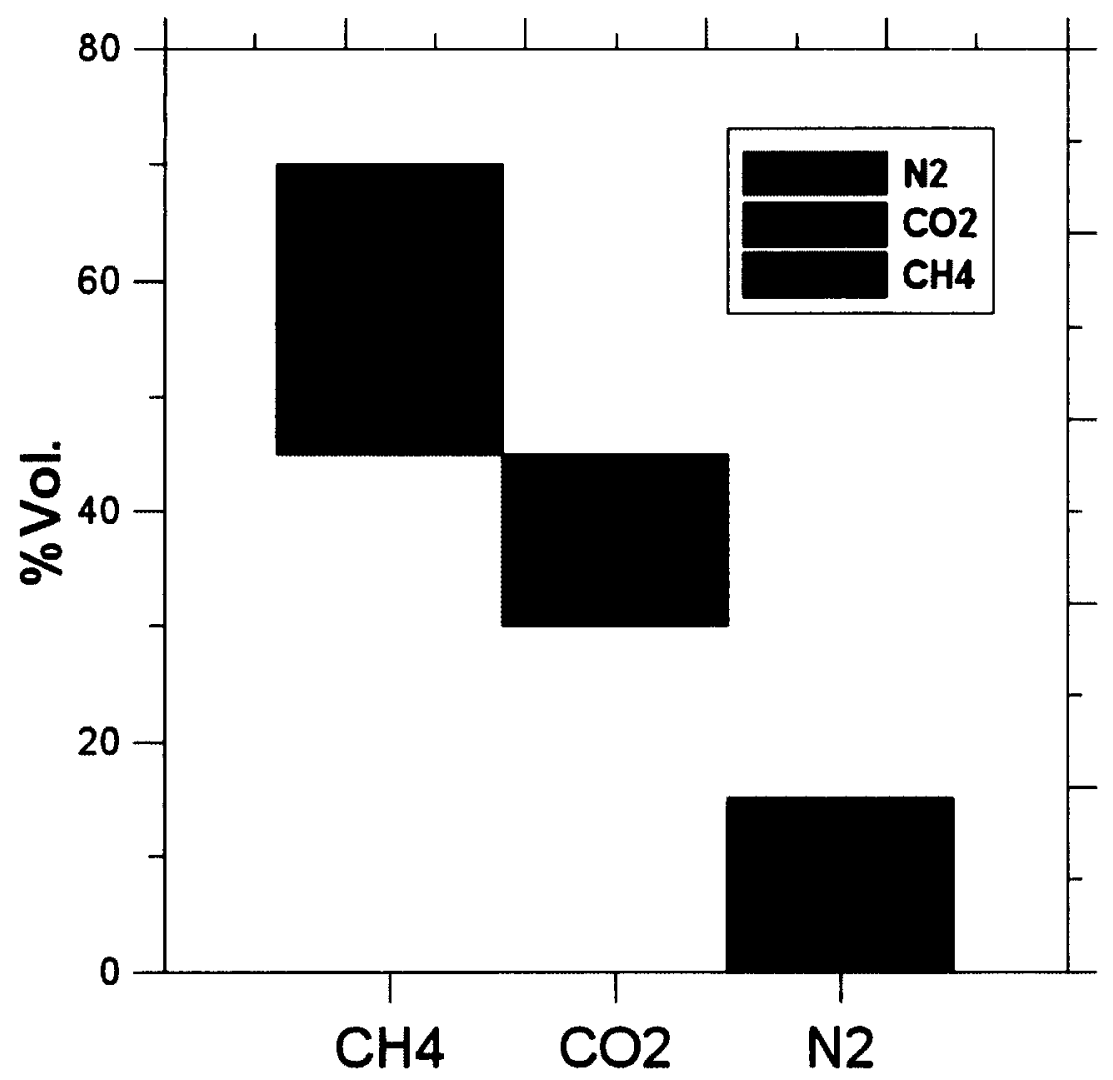

Figure A.7: Composition of all types of biogas considered 

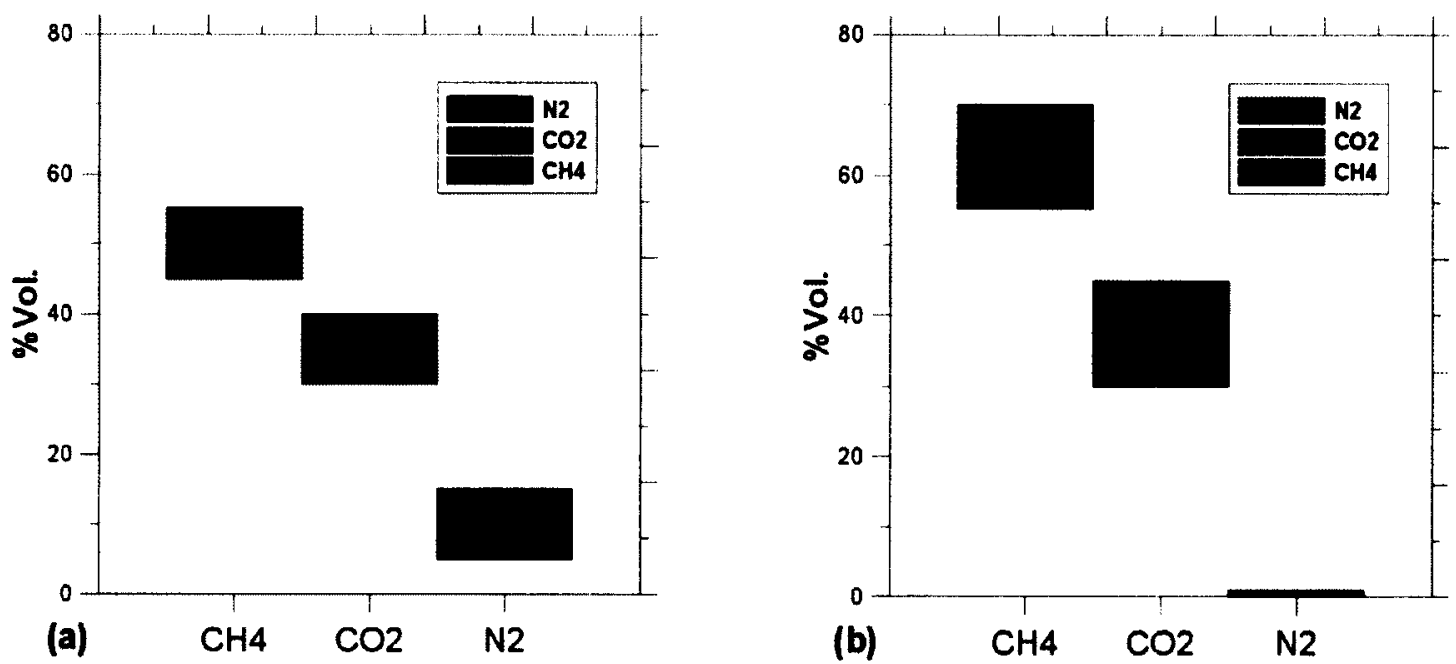

Figure A.8: Composition range of (a) landfill biogas and (b) digester biogas

Table A.2: Chosen Experimental Biogas Mixture

\begin{tabular}{|c|c|c|c|c|c|c|}
\hline Label & $\mathrm{H}_{2} / \mathrm{CO}$ ratio & $\mathrm{CO}(\% \mathrm{vol})$ & $\mathrm{H}_{2}(\%$ vol) & $\mathrm{CH}_{4}(\% \mathrm{vol})$ & $\mathrm{CO}_{2}$ (\%vol) & $\mathrm{N}_{2}$ (\%vol) \\
\hline B1 & - & 0 & 0 & 60 & 40 & 0 \\
\hline
\end{tabular}




\section{Appendix B Nozzle Contour Calculations}

For the work presented in this thesis, three nozzles had to be constructed as preexisting nozzles included the $50.8 \mathrm{~mm}$ inner and outer nozzles, and the $38.1 \mathrm{~mm}$ inner nozzle. Thus, the nozzles that needed design and construction were the $38.1 \mathrm{~mm}$ outer nozzle, and the $76.2 \mathrm{~mm}$ inner and outer nozzles. The outer nozzles only needed one contour, denoted as the outer nozzle inner contour. The inner nozzle constructed required two: the inner nozzle inner contour, and the inner nozzle outer contour. Due to this, between the three nozzles constructed, four contours had to be determined. A description of the contour design will be provided along with the nozzle contours selected.

The profile of a contracting nozzle can be developed using a cubic contour (Tavoularis, 2005). The starting and ending radii are specified along with their axial positions which provide a cubic equation at two locations. Along with these two equations, the starting and ending conditions are specified to be tangential which means the derivative of each of the first two equations equals zero. This gives four equations, and four unknowns (each coefficient of the cubic equation).

Using the left divide feature in MATLAB provides a solution to this system of linear equations as shown in Figure B.1:

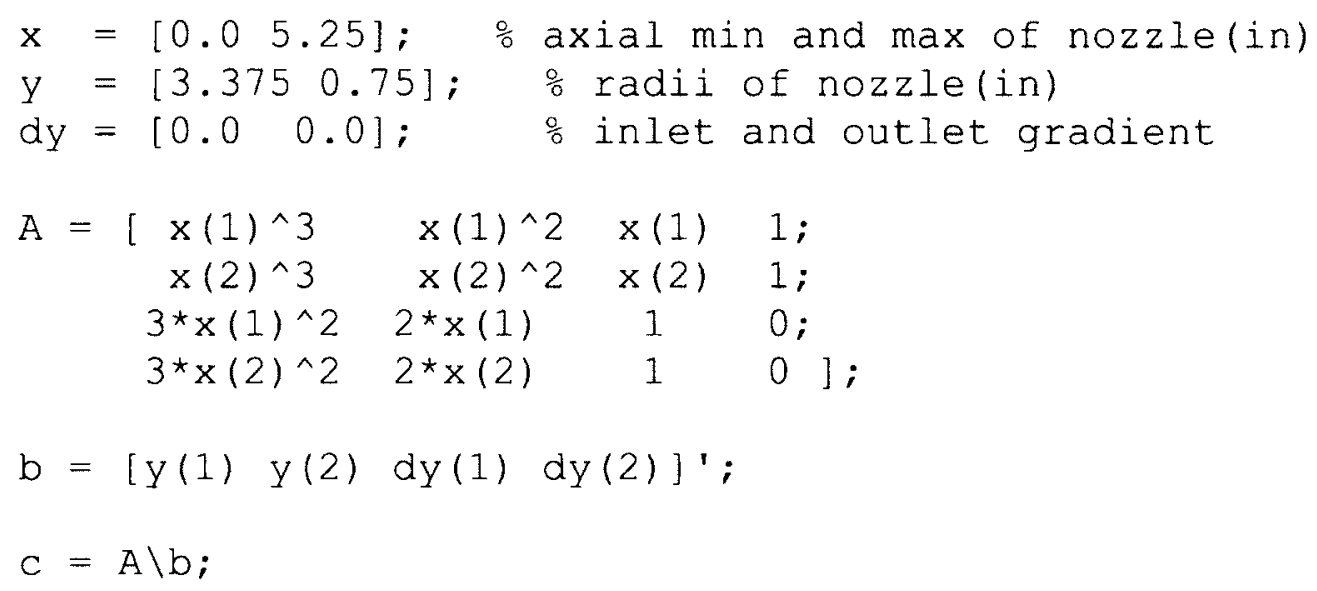

Figure B.1: Example MATLAB code for determining nozzle contours

After running this script, $\mathrm{c}$ is returned as a vector containing the cubic equation coefficients that satisfy the criteria specified. The coefficients are thus used to 
determine the spline locations that were used in Solidworks to create the contours that were machined on the nozzles. Figures Figure B.2, Figure B.3, B.4, and B.5 show the final contours chosen for the constructed nozzles.

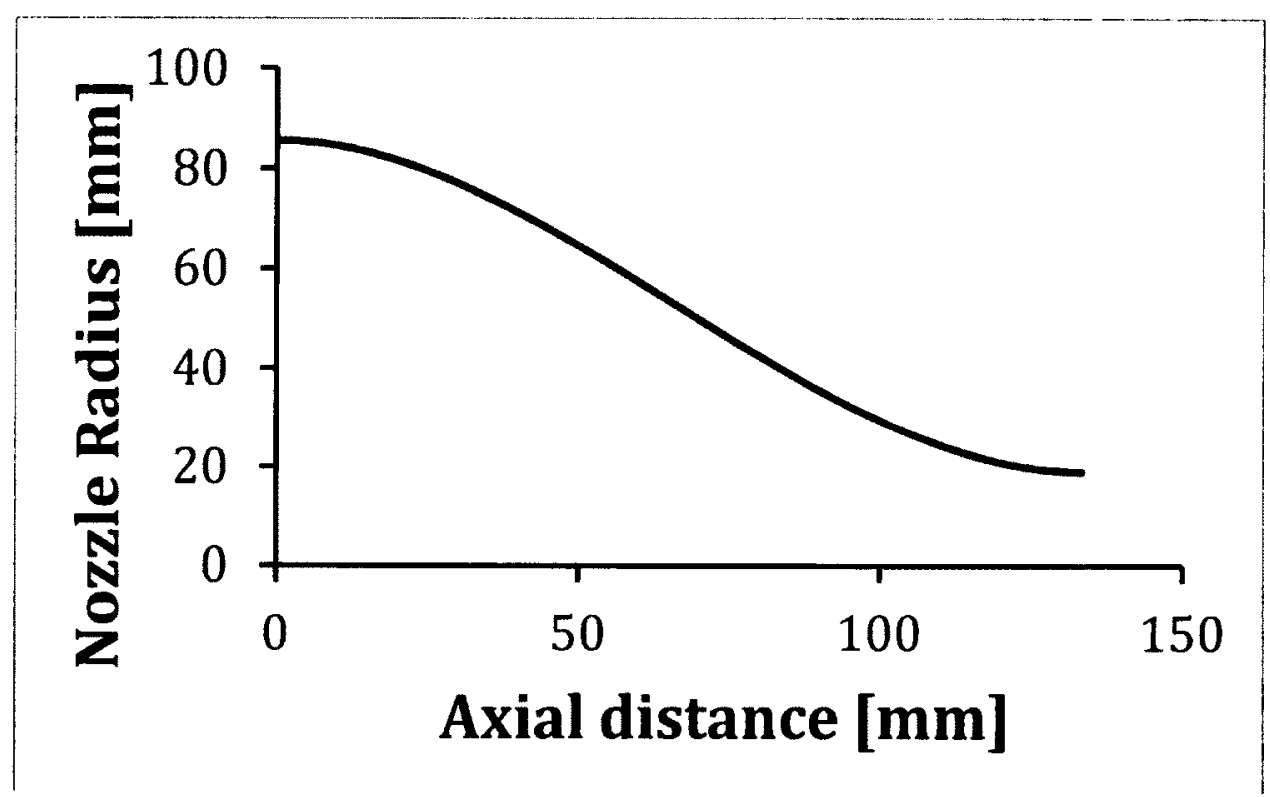

Figure B.2: Contour for $\mathbf{3 8 . 1} \mathbf{~ m m}$ outer nozzle inner contour

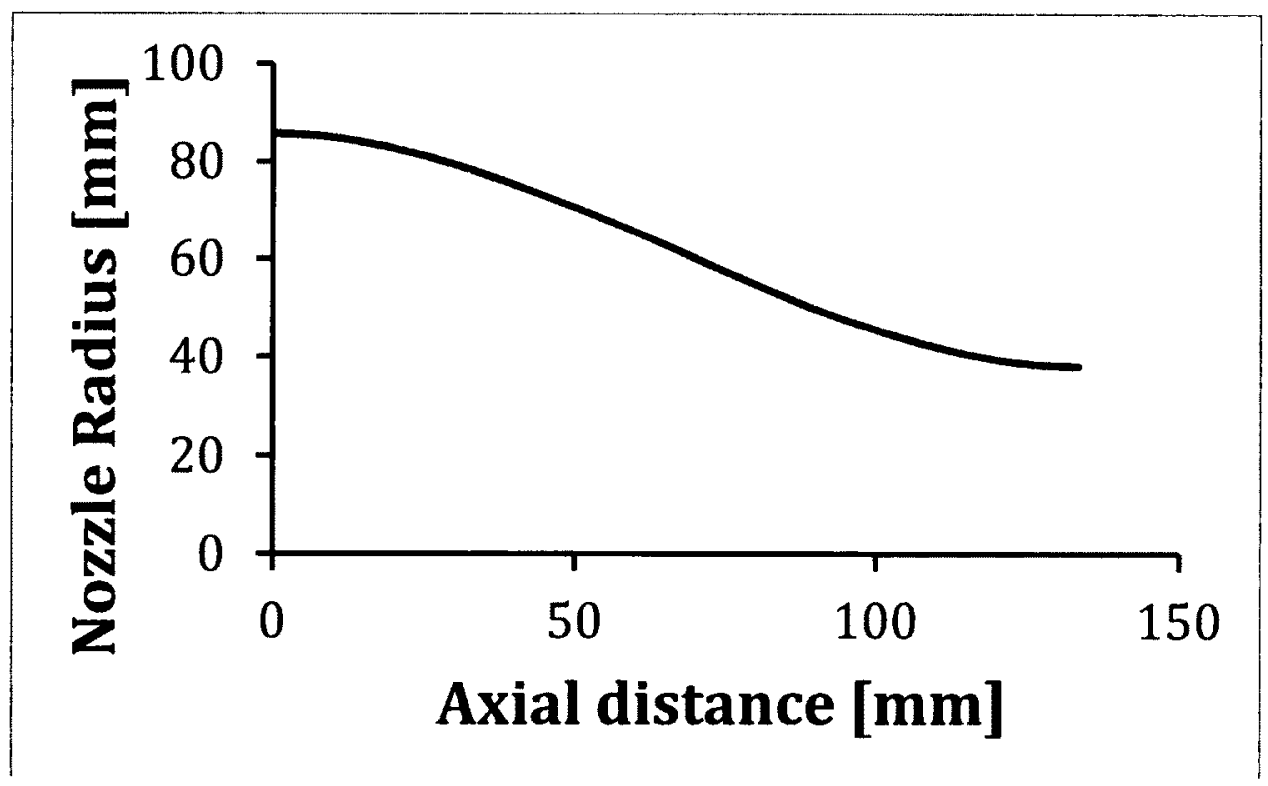

Figure B.3: Contour for $76.2 \mathrm{~mm}$ outer nozzle inner contour 


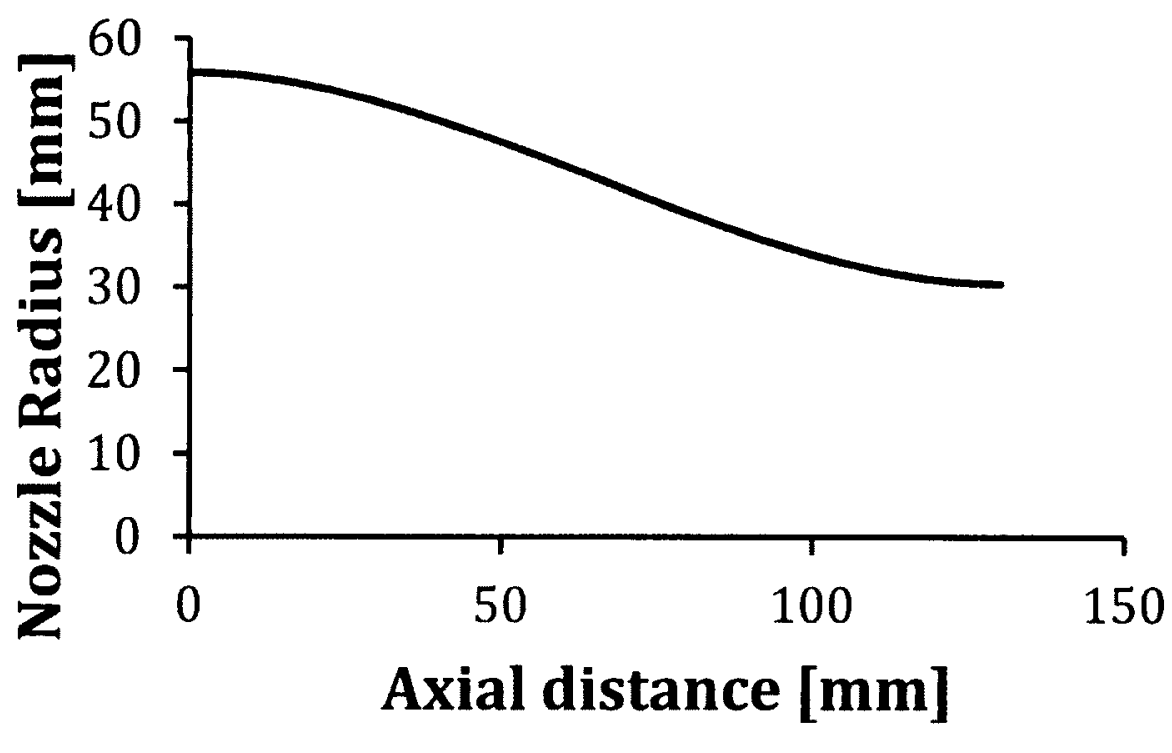

Figure B.4: Contour for $76.2 \mathrm{~mm}$ inner nozzle outer contour

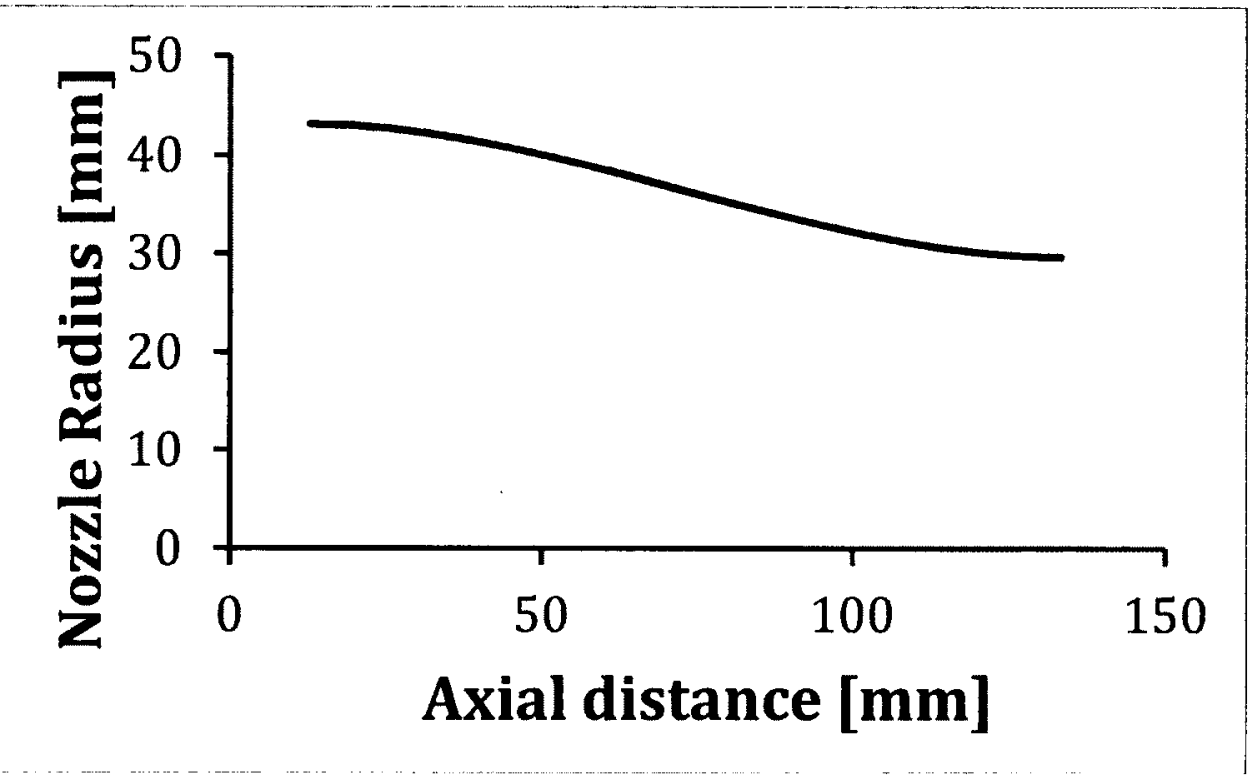

Figure B.5: Contour for $\mathbf{7 6 . 2} \mathbf{~ m m}$ inner nozzle inner contour 


\section{Appendix C MFC Operation and Calibration}

\section{Calibration}

Seventeen different Mass Flow Controllers (MFCs) were used in the experiments performed in this thesis. Depending upon the desired flowrates of each component in a gas mixture, different arrangements of the MFCs were required to ensure that each flow controller was operating within $10-100 \%$ of its rated flow rate. This was necessary because the rated measurement uncertainties of the MFCs are proportional to the full-scale range, so that uncertainties at flow rates below $10 \%$ of the full scale range are potentially quite large. Each of the available MFCs is listed in Table C.1 along with its rated full-scale range when flowing nitrogen and the gases for which in-house calibrations were performed. The factory calibration gas is contained in the MFC name.

Table C.1: Available mass flow controllers

\begin{tabular}{|c|c|c|}
\hline MFC Model and S/N & $\begin{array}{l}\text { Max Flow Rate }\left(\mathbf{N}_{2}\right) \\
\text { [SLPM] }\end{array}$ & Calibrated Gases \\
\hline Hastings- $2311 \mathrm{CH}_{4}-0753500001$ & 3041 & $\mathrm{Air}, \mathrm{CH}_{4}$ \\
\hline Hastings- $769 \mathrm{CH}_{4}-075430002$ & 1012 & Air, $\mathrm{CH}_{4}$ \\
\hline Hastings- $769 \mathrm{CH}_{4}-075430001$ & 1012 & $\mathrm{Air}, \mathrm{CH}_{4}$ \\
\hline Hastings-100 $\mathrm{CH}_{4}-075320001$ & 132 & $\mathrm{Air}, \mathrm{CH}_{4}, \mathrm{CO}, \mathrm{CO}_{2}$ \\
\hline Hastings-100 $\mathrm{CH}_{4}-075320002$ & 132 & $\mathrm{Air}, \mathrm{CH}_{4}, \mathrm{CO}, \mathrm{CO}_{2}$ \\
\hline Brooks-5853SBE-200Air-0108010357720003 & 200 & $\mathrm{Air}, \mathrm{CH}_{4}, \mathrm{CO}, \mathrm{CO}_{2}$ \\
\hline Brooks-5853SBE-200Air-0108010357720003 & 200 & $\mathrm{Air}, \mathrm{CH}_{4}, \mathrm{CO}, \mathrm{CO}_{2}$ \\
\hline Brooks-5853S-70N $2-0110010410664001$ & 70 & Air, $\mathrm{CH}_{4}, \mathrm{CO}, \mathrm{CO}_{2}$ \\
\hline Brooks-5853S-70N $2-0110010410664001$ & 70 & $\mathrm{Air}, \mathrm{CH}_{4}, \mathrm{CO}, \mathrm{CO}_{2}$ \\
\hline Brooks-5851S-40N $2-0110010410666001$ & 40 & $\mathrm{Air}, \mathrm{CH}_{4}, \mathrm{CO}, \mathrm{CO}_{2}$ \\
\hline Brooks-5851S-40N $2-0110010410666002$ & 40 & $\mathrm{Air}, \mathrm{CH}_{4}, \mathrm{CO}, \mathrm{CO}_{2}$ \\
\hline Brooks-5851S-40N $2-0110010410666003$ & 40 & Air, $\mathrm{CH}_{4}, \mathrm{CO}, \mathrm{CO}_{2}$ \\
\hline Brooks-5851S-40N $2-0110010410666004$ & 40 & $\mathrm{Air}, \mathrm{CH}_{4}, \mathrm{CO}, \mathrm{CO}_{2}$ \\
\hline Brooks-5851S-200H $2-0111030454952001$ & 200 & $\mathrm{H}_{2}$ \\
\hline Brooks-5851S-200H $\mathrm{H}_{2}-0111030454952002$ & 200 & $\mathrm{H}_{2}$ \\
\hline Brooks-5851S-40H $2-0110010410665001$ & 40 & $\mathrm{H}_{2}$ \\
\hline Brooks-5851S-40H $2-0110010410665002$ & 40 & $\mathrm{H}_{2}$ \\
\hline
\end{tabular}


The MFCs arrive with an existing factory calibration for one particular gas (the gas in the name of the MFC). Any MFC can be used for almost any gas, with the exception of hydrogen, which requires a special valve arrangement that can only be applied to hydrogen. To use the other MFC's (non-hydrogen) for other gases, there are two options. The manufacturers supply a table of gas conversion factors (GCF), which are based on the heat capacity at constant pressure of the relevant gases. The reading from the MFC is then converted to a flowrate based on the factory calibration, and then is multiplied by the GFC to obtain the flowrate in terms of the actual gas being measure. The GCF is determined as follows:

$$
G C F=\frac{C_{p, \text { factory gas }}}{C_{p, \text { gas used }}}
$$

While these gas conversion factors are convenient, their use incurs an accuracy penalty of up to $10 \%$. In the present experiments, to improve accuracy, independent calibrations were performed with each gas used in the experiments. A small ("Q-sized") pressurized bottle of the chosen calibration gas was positioned on a high-precision scale connected via RS-232 serial port to a computer. The flow through the MFC was then stepped through its full range in $10 \%$ intervals. For each flow rate, the mass depletion rate of the gas bottle was recorded. Calibration curves (MFC voltage vs. mass flowrate) were obtained in each case, and a linear calibration equation was determined. A sample such calibration curve (in this case, for the Brooks 70 SLPM $\left.\left(\mathrm{N}_{2}\right) \mathrm{MFC}\right)$ is shown in Figure C.1. 


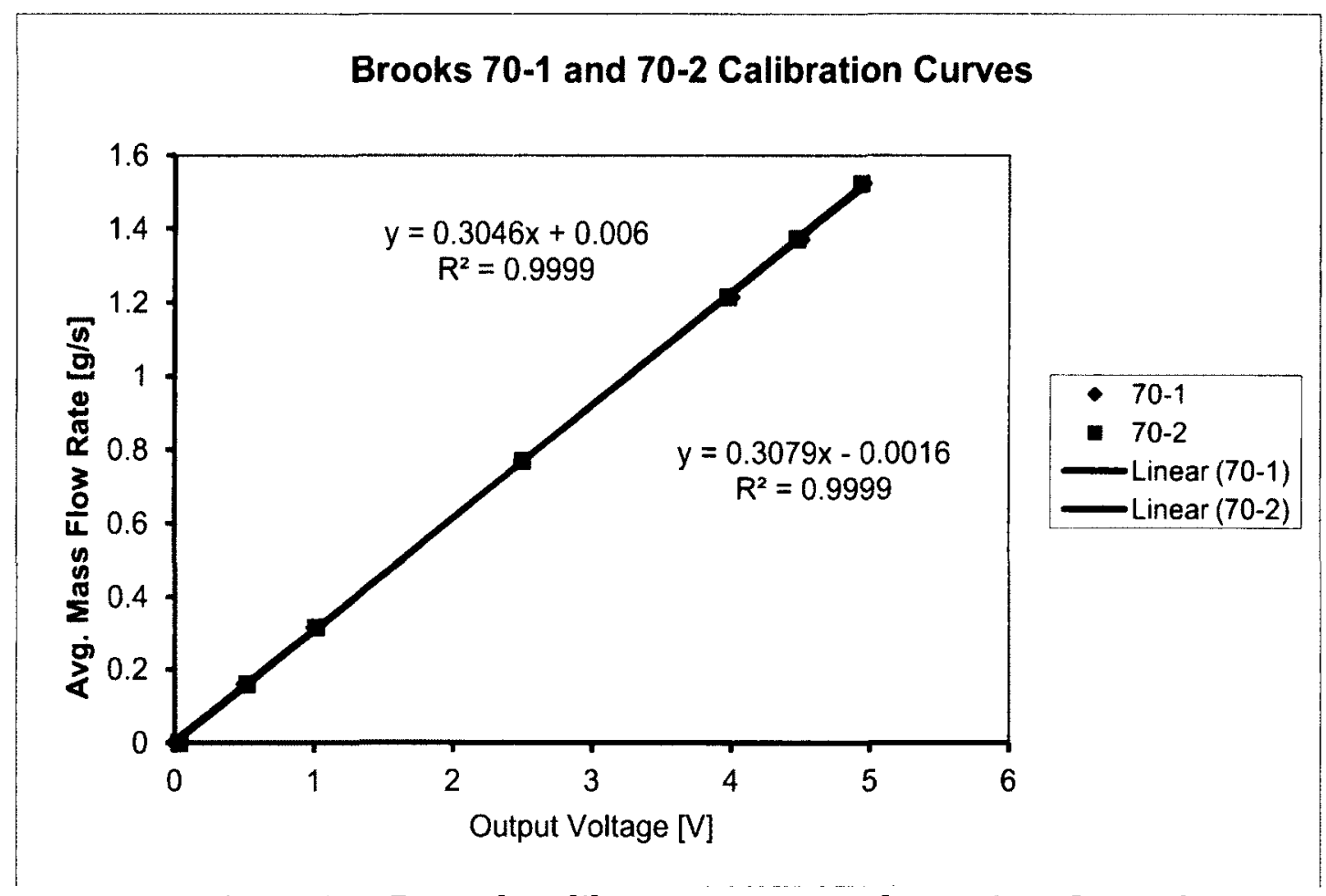

Figure C.1: Example calibration curves and equations for MFCs 


\section{Appendix D: Uncertainty in experimental measurements}

\section{D.1 Stability point uncertainty}

Stability maps were generally plotted with the heat release rate (HHV), the swirl number, and the equivalence ratio (or the directly-related adiabatic flame temperature.) To calculate swirl number, the inner core and outer annular velocities along with their mixture densities had to be measured first, which required the measurement of mass flow rates, and the conversion of mass flow rates to volume flow rates. These uncertainties will be the first to be estimated. The results from all the uncertainty calculations are summarized in Table D.1.

Table D.1: Relative uncertainties for measured and calculated values

\begin{tabular}{|c|c|c|}
\hline Parameter & $\mathbf{C H}_{\mathbf{4}}$ at $\boldsymbol{\Phi}=\mathbf{0 . 8}$ & $\mathbf{S 6}$ at $\boldsymbol{\Phi}=\mathbf{0 . 6}$ \\
\hline$M F_{\text {tot }}$ & $0.957 \%$ & $0.864 \%$ \\
\hline Heat release rate, all $\Phi$ & $1.00 \%$ & $0.643 \%$ \\
\hline$\Phi$ & $1.41 \%$ & $2.24 \%$ \\
\hline$Q_{\text {tot LPM }}$ & $1.47 \%$ & $1.36 \%$ \\
\hline$\rho$ & $1.71 \%$ & $1.61 \%$ \\
\hline$U_{\text {inner }}$ (50.8 mm nozzle) & $1.95 \%$ & $1.90 \%$ \\
\hline$U_{\text {outer }}$ (50.8 mm nozzle) & $3.33 \%$ & $3.33 \%$ \\
\hline$S_{g}$ at blowoff, 800 SLPM (bias and \\
precision)
\end{tabular}

\section{Mass flow rate uncertainty:}

To calculate all quantities considered for the stability points, first mass flow rates must be measured along with their experimental uncertainties. For each mass flow controller, the manufacturer lists the uncertainty to be $1 \%$ of the measured rate. Each flow channel (inner core flow and outer annular flow) have a fuel flow which can either be one fuel or a fuel mixture, and an air flow. The fuel flow can be either pure methane or a biofuel mixture consisting of up to four separate gas flows to create a given mixture as outlined in Table 1.1. For mass flow rate uncertainty consideration, and the propagation of this error into all other calculated values, both pure methane at $\Phi=0.8$ and S6 at $\Phi=0.6$ will be considered for the estimation of the bias error, but only the methane case will be considered for the precision and total error. All results are tabulated in Table D.2. The total mass flow rate in either the inner core flow or the outer annular flow is given as: 


$$
M F_{\text {tot }}=M F_{\text {air }}+M F_{\text {fuel }}
$$

Thus, the uncertainty in the total mass flow rate is:

$$
u_{M F_{\text {tot }}}=\sqrt{\left(\frac{\partial M F_{\text {tot }}}{\partial M F_{\text {air }}}\right)^{2}\left(u_{M F_{\text {air }}}\right)^{2}+\left(\frac{\partial M F_{\text {tot }}}{\partial M F_{\text {fuel }}}\right)^{2}\left(u_{M F_{f u e l}}\right)^{2}}
$$

where $\frac{\partial M F_{\text {tot }}}{\partial M F_{\text {air }}}$ and $\frac{\partial M F_{\text {tot }}}{\partial M F_{\text {fuel }}}$ are both equal to 1 . Both the uncertainties are $1 \%$ of the measured mass flow rates, so this reduces to:

$$
u_{M F_{\text {tot }}}=\sqrt{\left(0.01 * M F_{\text {air }}\right)^{2}+\left(0.01 * M F_{\text {fuel }}\right)^{2}}
$$

Dividing through by $\mathrm{MF}_{\text {tot }}$ to get the relative uncertainty:

$$
\frac{u_{M F_{\text {tot }}}}{M F_{\text {tot }}}=\sqrt{(0.01)^{2}\left(\frac{M F_{\text {air }}}{M F_{\text {tot }}}\right)^{2}+(0.01)^{2}\left(\frac{M F_{\text {fuel }}}{M F_{\text {tot }}}\right)^{2}}
$$

Thus, the uncertainty in the mixture mass flow rate is dependent on the relative amounts of fuel and air in the mixture as measured by their mass fractions. This can be changed by altering either the equivalence ratio, or the type of fuel used. As an example, $\mathrm{CH}_{4}$ at $\Phi=0.8$ will be compared to $\mathrm{S} 6$ at $\Phi=0.6$. For the $\mathrm{CH}_{4}$ mixture, there is only one fuel term, whereas for the $\$ 6$ mixture, there are four separate fuel with different weights depending on the molar ratio of the particular fuel within the fuel mixture $\left(\mathrm{H}_{2}=50 \%, \mathrm{CO}=25 \%, \mathrm{CH}_{4}=5 \%, \mathrm{CO}_{2}=20 \%\right)$. The relative contributions to the uncertainty in the mass flow rate are shown in Table D.2.

Table D.2: Mass fractions of fuel and air in $\mathrm{CH}_{4}$ at $\Phi=0.8$ and $\mathrm{S} 6$ at $\Phi=0.6$

\begin{tabular}{|c|c|c|}
\hline Mass fraction & $\mathrm{CH}_{4}$ at $\boldsymbol{\Phi}=\mathbf{0 . 8}$ & $\mathbf{S 6}$ at $\boldsymbol{\Phi}=\mathbf{0 . 6}$ \\
\hline$M F_{\text {air }} / M F_{\text {tot }}$ & 0.955 & 0.861 \\
\hline$M F_{C H 4} / M F_{\text {tot }}$ & 0.045 & 0.006 \\
\hline$M F_{H 2} / M F_{t o t}$ & $\mathbf{0}$ & 0.009 \\
\hline$M F_{c o} / M F_{t o t}$ & 0 & 0.055 \\
\hline$M F_{c o z} / M F_{t o t}$ & 0 & 0.069 \\
\hline
\end{tabular}

Using these values, the relative uncertainty in the total mass flow rate can be calculated. For $\mathrm{CH}_{4}$ at $\Phi=0.8$, this works out to $0.957 \%$, and for the S6 mixture at $\Phi=0.6$ it's $0.864 \%$. 


\section{Heat release rate uncertainty}

The heat release rate is determined from the following equation:

$$
H R R=(H H V)\left(M F_{\text {fuel }}\right)
$$

where HRR is the heat release rate and HHV is the higher heating value of the fuel (or fuel mixture). Considering only $\mathrm{CH}_{4}$ at $\Phi=0.8$, and assuming negligible error in the HHV, this means that only the uncertainty in the mass flow rate of the fuel will propagate to the HRR. Since the uncertainty in the mass flow rate is $1 \%$ of the rate, and this is a linear equation, the relative bias uncertainty in the heat release will always be $1 \%$ for a pure $\mathrm{CH}_{4}$ mixture. For a multi-fuel fuel mixture such as $\mathrm{S} 6$, this can be determined from the mass fractions of each individual fuel within the fuel mixture as compared to the total mass of the fuel. For the S6 mixture with $x$ denoting the constituent gases of the mixture $\left(\mathrm{H}_{2}, \mathrm{CO}, \mathrm{CH}_{4}, \mathrm{CO}_{2}\right), Y$ denoting the molar fraction within the fuel mixture, and $M W$ denoting the molecular weight:

$$
\frac{u_{H R R, S 6}}{H R R_{S 6}}=\sqrt{\sum_{x}(0.01)^{2}\left(\frac{\left(Y_{x} * M W_{x}\right)^{2}}{M W_{S 6}^{2}}\right)}
$$

where the term $\left(\frac{\left(Y_{x} * M W_{x}\right)^{2}}{M W_{S 6}^{2}}\right)$ is the mass fraction of the fuel constituent within the fuel mixture, and $\mathrm{MW}_{\mathrm{s} 6}$ is the average molecular weight of the fuel mixture at $17.62 \mathrm{~g} / \mathrm{mol}$. For $\mathrm{S6}$, this drops the relative uncertainty in the heat release rate to $0.64 \%$.

\section{Equivalence ratio uncertainty}

The equivalence ratio is calculated from the following equation for both the inner and outer flows:

$$
\Phi=\frac{(F / A)_{\text {actual }}}{(F / A)_{\text {stoich }}}
$$

where $F / A$ refers to the molar fuel/air ratio. The stoichiometric fuel/air ratio has negligible error, but the measured actual fuel/air ratio will have an uncertainty based on the measurement of the mass flow rates. The molar fuel/air ratio is calculated according to: 


$$
(F / A)_{a c t u a l}=\left(\frac{M F_{\text {fuel }}}{M F_{\text {air }}}\right)\left(\frac{M W_{\text {air }}}{M W_{\text {fuel }}}\right)
$$

where $M W$ refers to the molecular weight of the fuel, fuel mixture, or air. The molecular weight has negligible error, and as mentioned above the uncertainty in the mass flow rates is $1 \%$ of the rate. Since this is a ratio, the relative error of the measured fuel/air ratio can be determined as:

$$
\frac{u_{F / A_{\text {actual }}}}{(F / A)_{\text {actual }}}=\sqrt{\left(\frac{\left.u_{M F_{\text {air }}}\right)^{2}+\left(\frac{u_{M F_{\text {fuel }}}}{M F_{\text {air }}}\right)^{2}}{M F_{\text {fuel }}}\right)^{2}}
$$

For the $\mathrm{CH}_{4}$ mixture, there is only one $u_{M F_{f u e l}}$ term, but the $\mathrm{S} 6$ mixture, there are four terms leading to a higher uncertainty. For $\mathrm{CH}_{4}$ this works out to $1.41 \%$, and for the $\mathrm{S} 6$ fuel mixture it is $2.24 \%$. Since this is the only source of uncertainty for $\Phi$, the relative uncertainty for the measured fuel/air ratio is the same as the relative uncertainty for $\Phi$. Unlike the total mass flow rate, having more measurements in the fuel mixture ( $\mathrm{S} 6 \mathrm{vs}$. $\mathrm{CH}_{4}$ ) leads to a greater uncertainty in the equivalence ratio.

\section{Volume flow rate uncertainty}

To get the total volume flow rates $\left(Q_{t o t}\right)$ for the inner and outer flows in standard litres per minute (SLPM), the mass flow rate is converted to a volume flow rate at a standard temperature and pressure of $273 \mathrm{~K}$ and $101325 \mathrm{~Pa}$ according to the following equation:

$$
Q_{\text {tot }, S L P M}=\frac{M F_{\text {tot }} * R * T_{0}}{M W_{\text {mix }} P_{0}}
$$

where $R$ is the universal gas constant, $M W_{\text {mix }}$ is the molecular weight of the fuel/air mixture, $T_{0}$ is $273 \mathrm{~K}$, and $P_{0}$ is $101325 \mathrm{~Pa} . R, M W_{m i x}, T_{0}$, and $P_{0}$ are all assumed to be free of error, so the relative error in $Q_{t o t, S L P M}$ is the same as in $M F_{t o t}$. Converting to litres per minute (LPM) is necessary to determine the actual volume flow rates within the laboratory environment. It is calculated from the following equation:

$$
Q_{t o t, L P M}=\left(\frac{T_{1}}{T_{0}}\right)\left(\frac{P_{0}}{P_{1}}\right) * Q_{t o t, S L P M}
$$


where $T_{l}$ and $P_{l}$ are the assumed laboratory temperature and pressure. $T_{l}$ is assumed to be $293 \mathrm{~K}$, and $P_{l}$ is assumed to be $101325 \mathrm{~Pa}$ (same as standard pressure). The uncertainty in $T_{1}$ is assumed to be $\pm 2 \mathrm{~K}$, and the uncertainty in $P_{1}$ is assumed to be $\pm 4000 \mathrm{~Pa}$. This introduces additional uncertainty which must be quantified. Recalling that $T_{0}$ and $P_{0}$ contribute no error, the following equation is used to estimate the relative uncertainty in the volume flow rate:

$$
\frac{u_{Q_{t o t, L P M}}}{Q_{t o t, L P M}}=\sqrt{\left(\frac{u_{T_{1}}}{T_{1}}\right)^{2}+\left(\frac{u_{P_{1}}}{P_{1}}\right)^{2}+\left(\frac{u_{Q_{t o t, S L P M}}}{Q_{t o t, S L P M}}\right)^{2}}
$$

\section{Inner/outer density uncertainty}

The density of the fuel/air mixture is calculated according to the following equation:

$$
\rho=\frac{M F_{t o t}}{Q_{t o t, L P M}}
$$

Accordingly, the relative uncertainty is calculated as:

$$
\frac{u_{\rho}}{\rho}=\sqrt{\left(\frac{u_{M F_{t o t}}}{M F_{t o t}}\right)^{2}+\left(\frac{u_{Q_{t o t, L P M}}}{Q_{t o t, L P M}}\right)^{2}}
$$

\section{Inner/outer exit velocity uncertainty}

The equations used for the inner and outer flow exit velocities are as follows:

$$
\begin{gathered}
U_{\text {inner }}=\frac{Q_{\text {tot }, i, L P M}}{A_{i}}=\frac{Q_{\text {tot }, i, L P M}}{\pi * R_{H}{ }^{2}} \\
U_{\text {outer }}=\frac{Q_{\text {tot }, o, L P M}}{A_{o}}=\frac{Q_{\text {tot }, o, L P M}}{\pi *\left(R^{2}-R_{H}{ }^{2}\right)}
\end{gathered}
$$

where $R$ is the outer radius of the nozzle and $R_{H}$ is the radius of the hub (the separation between the inner core flow and the outer annular flow at the nozzle exit). The uncertainty in all radii considered is determined by the machining resolution at $0.127 \mathrm{~mm}\left(0.005^{\prime \prime}\right)$. The tabulated exit velocity uncertainty estimation will use the $50.8 \mathrm{~mm}$ nozzle as an example. The estimated relative uncertainty in the inner and outer exit velocities is given by: 


$$
\begin{gathered}
\frac{u_{U_{\text {inner }}}}{U_{\text {inner }}}=\sqrt{\left(\frac{u_{Q_{\text {tot }, L P M}}}{Q_{\text {tot }, L P M}}\right)^{2}+2\left(\frac{u_{R_{H}}}{R_{H}}\right)^{2}} \\
\frac{u_{U_{\text {outer }}}}{U_{\text {outer }}}=\sqrt{\left(\frac{u_{Q_{\text {tot }, L P M}}}{Q_{\text {tot }, L P M}}\right)^{2}+2\left(\frac{u_{R_{H}}}{R_{H}}\right)^{2}+2\left(\frac{u_{R}}{R}\right)^{2}}
\end{gathered}
$$

Due to the additional radius considered in the outer annular exit velocity, its uncertainty is correspondingly higher. The majority of the error in the outer velocity comes from the two radii considered, so the effect of the fuel mixture is negligible. For the inner velocity, however, the fuel mixture does have a noticeable effect on uncertainty (See Table D.1).

\section{Swirl number uncertainty}

The geometric swirl number is calculated from the equation Johnson et al. (2005) proposed for a vane-type LSB:

$$
S_{g}=\frac{(2 / 3) \tan (\alpha)\left(1-\frac{R_{H}^{3}}{R^{3}}\right)}{\left(1-\frac{R_{H}^{2}}{R^{2}}+\frac{\rho_{i} U_{i}^{2} R_{H}^{2}}{\rho_{o} U_{o}^{2} R^{2}}\right)}
$$

where $\alpha$ is the vane exit angle of $37.5^{\circ}$ with an estimated uncertainty of $0.5^{\circ}$. The relative uncertainties for density and inner and outer velocity determined above are propagated through in the same manner as in the previous uncertainty estimates to determine the bias error in the swirl number resulting from systematic uncertainty from the calculations.

For blowoff tests specifically, the precision error was estimated by conducting the same blowoff test five times at a range of flow rates from 400 to 1200 SLPM (spaced by 100 SLPM) total flow on the $50.8 \mathrm{~mm}$ nozzle with $\mathrm{CH}_{4}$ fuel at $\Phi=0.8$. The mean, standard deviation, and standard deviation of the means were calculated to determine the precision error at the $95 \%$ confidence level. The precision error was combined with the previously determined bias error to obtain the total uncertainty via the following equation: 


$$
u_{S_{g} @ b l o w o f f}=\sqrt{B^{2}+P^{2}}
$$

where $B$ is the bias error and $P$ is the precision error. The results for the bias, precision, and total uncertainty for blowoff tests on the $50.8 \mathrm{~mm}$ nozzle with $\mathrm{CH}_{4}$ fuel at $\Phi=0.8$ are shown in Table D.3.

Table D.3: Blowoff test uncertainty on $50.8 \mathrm{~mm}$ nozzle for $\mathrm{CH}_{4}$ fuel at $\Phi=0.8$

\begin{tabular}{|c|c|c|c|c|c|c|}
\hline$Q_{\text {tot }}$ [SLPM] & Mean $S_{g}$ & St.Dev. & $P(95 \%)$ & $B$ & Total error & $\begin{array}{c}\text { Total error } \\
(\%)\end{array}$ \\
\hline 401.1 & 0.395 & 0.00239 & 0.00296 & 0.0230 & 0.0231 & 5.86 \\
\hline 500.9 & 0.410 & 0.00089 & 0.00111 & 0.0227 & 0.0227 & 5.53 \\
\hline 601.0 & 0.416 & 0.00110 & 0.00136 & 0.0225 & 0.0226 & 5.43 \\
\hline 701.3 & 0.414 & 0.00114 & 0.00141 & 0.0226 & 0.0226 & 5.46 \\
\hline 801.4 & 0.426 & 0.00110 & 0.00136 & 0.0223 & 0.0223 & 5.24 \\
\hline 901.7 & 0.429 & 0.00071 & 0.00088 & 0.0222 & 0.0222 & 5.18 \\
\hline 1001 & 0.438 & 0.00173 & 0.00215 & 0.0220 & 0.0221 & 5.04 \\
\hline 1101 & 0.438 & 0.00114 & 0.00141 & 0.0220 & 0.0220 & 5.03 \\
\hline 1202 & 0.447 & 0.00152 & 0.00188 & 0.0217 & 0.0218 & 4.88 \\
\hline
\end{tabular}

\section{D.2 PIV uncertainty}

With upper case letters denoting the image plane, and lower case letter denoting the object plane (the laser sheet), the basic equation used in PIV calculations is (Crosland, 2008):

$$
v=\frac{\Delta X}{M \Delta t}
$$

where $\mathrm{v}$ is the velocity, $\Delta X$ is the displacement, $M$ is the magnification, and $\Delta t$ is the interframe time. The total uncertainty associated with the velocity calculation is thus:

$$
u_{v}=\sqrt{\left(\frac{\partial v}{\partial M}\right)^{2}\left(u_{M}\right)^{2}+\left(\frac{\partial v}{\partial(\Delta X)}\right)^{2}\left(u_{\Delta X}\right)^{2}+\left(\frac{\partial v}{\partial(\Delta t)}\right)^{2}\left(u_{\Delta t}\right)^{2}}
$$

Substituting in the partial derivatives, this becomes: 


$$
u_{v}=\sqrt{\left(\frac{-\Delta X}{M^{2} \Delta t}\right)^{2}\left(u_{M}\right)^{2}+\left(\frac{1}{M \Delta t}\right)^{2}\left(u_{\Delta X}\right)^{2}+\left(\frac{-\Delta X}{M \Delta t^{2}}\right)^{2}\left(u_{\Delta t}\right)^{2}}
$$

The uncertainty in the magnification, displacement, and interframe time can be estimated and used to estimate the uncertainty in the velocity vectors.

\section{D.2.1 Magnification uncertainty, $\mathbf{e}_{\mathbf{1}}$}

According to Ramasamy and Leishman (2007), the uncertainty in the magnification term is a result of improper alignment of the calibration plate with the laser sheet (Crosland, 2008). Assuming the laser sheet and calibration plate have been aligned as closely as possible in the centre of the sheet, there will be errors associated with rotation of the calibration plate about the r-axis (burner radial axis, $\alpha$ ), x-axis (burner flow axis, $\beta$ ), along with translation in the z-axis (across the burner exit plane, $z$ ). For this analysis, the r-dimension will be considered to be along the width, and the $y$-dimension will be considered to be along the height of the idealized location of the rectangular calibration plate (if it were perfectly aligned with the laser sheet). The total uncertainty in the calculation of the magnification is thus:

$$
u_{M}=\sqrt{\left(\frac{\partial M}{\partial \alpha}\right)^{2}\left(u_{\alpha}\right)^{2}+\left(\frac{\partial M}{\partial \beta}\right)^{2}\left(u_{\beta}\right)^{2}+\left(\frac{\partial M}{\partial z}\right)^{2}\left(u_{z}\right)^{2}}
$$

Once the calibration and self-calibration have been performed, the cameras will be imaging the true laser sheet (Crosland, 2008). The width and the height of the calibration plate projected onto the laser sheet plane (since we are assuming imperfect alignment) are expressed as:

$$
r_{C P}=\frac{r_{C P-P}}{\cos (\beta)} \quad x_{C P}=\frac{r_{C P-P}}{\cos (\alpha)}
$$

where $r_{C P}$ and $x_{C P}$ are the true width and height of the calibration plate, and $r_{C P-P}$ and $x_{C P-P}$ are the projected height and width onto the laser sheet. In the image plane, this becomes: 


$$
R_{C P}=\frac{R_{C P-P}}{\cos (\beta)} \quad X_{C P}=\frac{X_{C P-P}}{\cos (\alpha)}
$$

For PIV measurements, the magnification is defined as the ratio of the imaged size of the calibration plate to the true size of the calibration plate:

$$
M=\frac{R_{C P}}{r_{C P}}
$$

With a non-zero rotation of the plate, the magnification of the measurements taken in the laser sheet plane will be:

$$
M=\frac{R_{C P}}{r_{C P} \cos (\beta)}
$$

The sensitivity index for the magnification with respect to $\beta$ can now be expressed as:

$$
\frac{\partial M}{\partial \beta}=\frac{M \sin (\beta)}{\cos ^{2}(\beta)}=M \sec (\beta) \tan (\beta)
$$

Similarly, the sensitivity index for the magnification with respect to $\alpha$ is expressed as:

$$
\frac{\partial M}{\partial \beta}=M \sec (\alpha) \tan (\alpha)
$$

To calculate the sensitivity index for the magnification with respect to $z$, the magnification must first be expressed as a function of $z$. From Ramasamy and Leishman (2007), this is expressed as:

$$
M=\frac{R_{C P}}{2 z \tan (\gamma)-R_{C P}}
$$

where $\gamma$ is the half-angle-of-view. The sensitivity index with respect to $z$ is thus:

$$
\frac{\partial M}{\partial z}=\frac{-2 R_{C P} \tan (\gamma)}{\left(2 z \tan (\gamma)-R_{C P}\right)^{2}}
$$

Substituting all sensitivity indices into (D.37): 


$$
=\sqrt{(M \sec (\alpha) \tan (\alpha))^{2}\left(u_{\alpha}\right)^{2}+(M \sec (\beta) \tan (\beta))^{2}\left(u_{\beta}\right)^{2}+\left(\frac{-2 R_{C P} \tan (\gamma)}{\left(2 z \tan (\gamma)-R_{C P}\right)^{2}}\right)^{2}\left(u_{z}\right)^{2}}
$$

With no real way to measure $\alpha$ and $\beta$, they are assumed to have a maximum value of $1^{\circ}$. Because $\alpha$ and $\beta$ have nominal values of 0 , the uncertainty is calculated by setting $\alpha$ and $\beta$ to their maximum values of $1^{\circ}$ and by setting their uncertainties equal to 1(Ramasamy and Leishman, 2007). Using the LaVision software calibration output, the distance from the camera CCD surface to the laser sheet $(z)$ was determined to be $511 \mathrm{~mm}$, and the typical value of magnification used in these experiments was $M=0.10$. Substituting these values gives a maximum error in the magnification of:

$$
e_{1}=0.002607
$$

\section{D.2.2 Image Correction Uncertainty, $e_{2}$}

The uncertainty in the calculation of the displacement of a particle must account for the uncertainty due to the use of a 'pinhole-camera' model (LaVision, 2010) to map locations in the object plane to corresponding locations in the image plane (Crosland, 2008). This approximate mapping performed by the software reported the standard deviation of the error in fitting the 35 calibration dots (on the surface of the calibration plate). This can be used to calculate the precision error in determining the displacement of a particle. For these experiments, a maximum standard deviation of 0.3 was considered acceptable. The precision error is as follows:

$$
P_{X}=\left(\frac{t_{95} S_{X}}{\sqrt{N}}\right)
$$

where $S_{x}$ is the standard deviation (measured in pixels), $\mathrm{N}$ is the number of calibration dots used, and $t_{95}$ is the Student $t$-factor for $95 \%$ confidence and $\mathrm{N}-1$ degrees of freedom (Crosland, 2008). Since this uncertainty applies to both the initial and final position of the particle, it must be multiplied by two. For these experiments: 


$$
e_{2}=2 P_{X}=0.14 \mathrm{px}=1.04 \mu \mathrm{m}
$$

\section{D.2.3 Non-zero; laser pulse uncertainty, $e_{3}$}

Another displacement uncertainty results from the assumption that the laser pulse illuminates the particles instantaneously so as to freeze particle motion. In reality, the laser pulse lasts at most $5 \mathrm{~ns}$. Assuming a maximum value of particle motion at $30 \mathrm{~m} / \mathrm{s}$ (highest flow rates on smallest burner), the image of the particle will travel $0.155 \mu \mathrm{m}$. Again, this uncertainty applies to both the initial and final position of the particle, so must be multiplied by two (Crosland, 2008).

$$
e_{3}=0.31 \mu \mathrm{m}
$$

\section{D.2.4 Laser Timing Uncertainty, $\mathbf{e}_{\mathbf{4}}$}

The laser timing uncertainty is the only uncertainty directly affecting the time term in Equation D.28. The laser timing uncertainty arises from the error in the interframe time, $\Delta t$. The laser timing card has a temporal resolution of $50 \mathrm{~ns}$ (LaVision, 2010). Its precision error is thus assumed to be half of its resolution whilst triggering both the first and second laser pulses (Crosland, 2008). The maximum possible uncertainty is:

$$
e_{4}=50 \mathrm{~ns}
$$

\section{D.2.5 Noise and loss of particles uncertainty, $e_{5}$ and $e_{6}$}

Boillot and Prasad (1996) found that the random error associated with PIV measurements scales with the particle image diameter, $d_{\tau}$ :

$$
e_{5 / 6}=c d_{\tau}
$$

where the constant is typically between 0.05 and 0.07 . Since the scattered, rather than the reflected light is being imaged by the camera, the minimum particle image diameter $\left(d_{\tau}\right)$ will be a function of the true particle diameter $\left(d_{p}\right)$, the magnification, and the diffraction limited minimum image diameter $\left(d_{d i f f}\right)$ (Crosland, 2008):

$$
d_{\tau}=\sqrt{\left(M d_{p}\right)^{2}+d_{d i f f}^{2}}
$$


The diffraction limited minimum image diameter is given by Raffel (1998):

$$
d_{\text {diff }}=2.44 f(M+1) \lambda
$$

where $\lambda$ is the wavelength of the laser light ( $532 \mathrm{~nm}$ ), and $f$ is the f-number of the lens, which for camera 1 was 16 and will be used since it results in a greater uncertainty. According to the product information, Aerosil R 972 particles have an average primary particle size of $16 \mathrm{~nm}$, but previous analysis (See Section 3.1.5) shows that the actual particle sizes cannot be successfully determined from the PIV images. Thus, for these calculations, a generous estimate of $10 \mu \mathrm{m}$ will be used. This returns a random error of:

$$
e_{5 / 6}=1.61 \mu \mathrm{m}
$$

\section{D.2.6 Pixel-locking uncertainty, $e_{7}$}

Peak or pixel-locking uncertainty is a common concern in PIV measurements. It is characterized by a tendency of the correlation algorithm to calculate displacements that are integer pixel values due to improper seeding or timing. To check for pixel locking, a histogram of fractional pixel displacement is plotted with preliminary results before each measurement set. An example of a histogram of fractional displacement is shown in Figure D.1. 


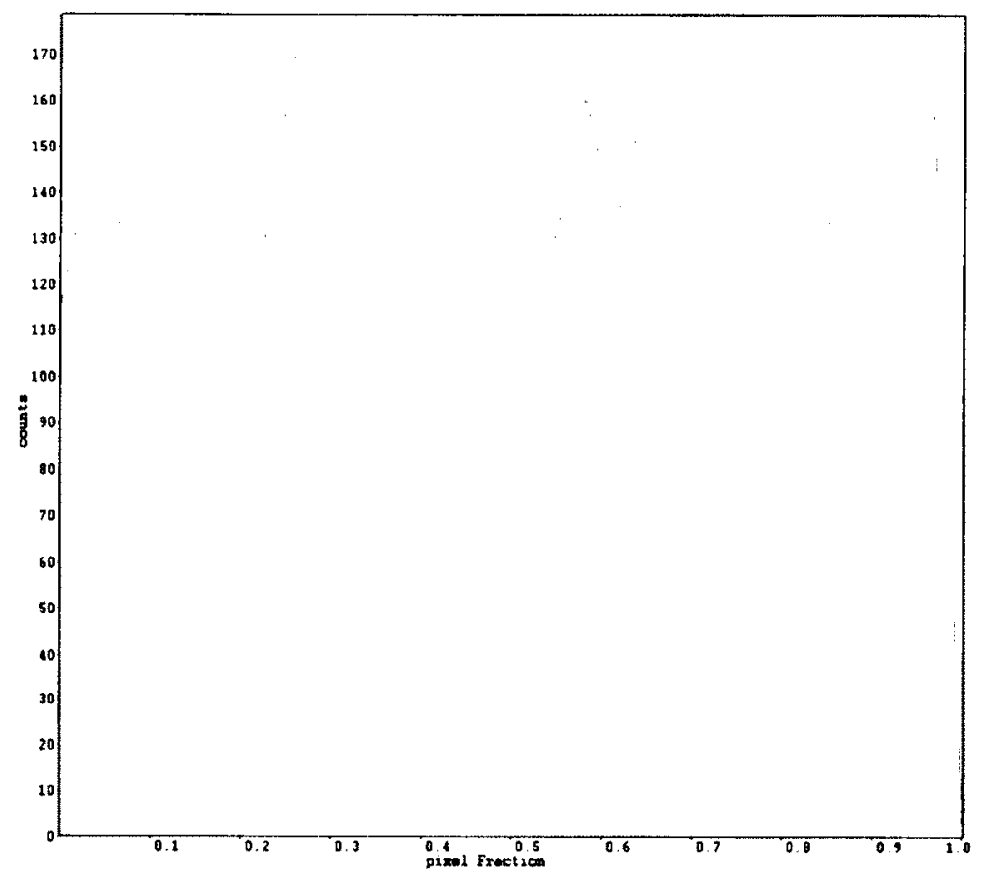

Figure D.1: A histogram of displacement, in pixels

If pixel locking were present, then the histogram would show relatively more counts at the left and right ends, at the integer value locations. All PIV measurements were checked for peak locking, and none was found, so this error can be neglected:

$$
e_{7} \sim 0
$$

\section{D.2.7 Velocity gradient bias uncertainty, $\mathbf{e}_{\mathbf{8}}$}

Another potential source of uncertainty in PIV results from the velocity gradient bias (Crosland, 2008). Strong velocity gradients within an interrogation window can cause the correlation peak to widen, introducing uncertainty. For evenly spaced interrogation windows, Ramasamy and Leishman (2007) suggest the interframe time and interrogation window size should be chosen such that (Crosland, 2008):

$$
\Delta V_{i, j+1} \Delta t=d_{\tau}
$$

where $\Delta V_{i, j+1}$ is the difference in velocity between neighbouring interrogation windows. Assuming a true particle size, $d_{p}$, of $10 \mu \mathrm{m}$, the imaged particle size $d_{\tau}$ can be calculated via (D.40) with $\mathrm{M}=0.10$ at $23.0 \mu \mathrm{m}$ and thus the maximum $\Delta V$ between interrogation windows can be determined based on the interframe time used. For 
these experiments, the interframe time was varied based on the exit velocities of the burner at the measured condition. For the $38.1 \mathrm{~mm}$ nozzle, $\Delta t$ was as low as $17 \mu \mathrm{s}$, and as high as $60 \mu \mathrm{s}$ for the $76.2 \mathrm{~mm}$ nozzle. An analysis of the vectors for three PIV measurements is shown in Table D.4. The first condition contains likely the greatest velocity gradients since it is a high flow rate (1000 SLPM), and at a high swirl number. It is also at a very low interframe time of $17 \mu \mathrm{s}$. The second condition is more typical of the conditions measured on the $50.8 \mathrm{~mm}$ nozzle with an interframe time of $50 \mu \mathrm{s}$. The third condition likely contains the smallest velocity gradients due to the use of the $76.2 \mathrm{~mm}$ nozzle, and also has the highest interframe time at $60 \mu \mathrm{s}$.

Table D.4: Analysis of velocity gradient bias uncertainty for three PIV measurements

\begin{tabular}{|c|c|c|c|c|c|c|c|c|}
\hline \multicolumn{3}{|c|}{ Data set } & \multirow[b]{2}{*}{$\Delta t[\mu s]$} & \multirow{2}{*}{$\begin{array}{c}\Delta V, \text {,limit } \\
{[\mathrm{m} / \mathrm{s}]}\end{array}$} & \multirow{2}{*}{$\begin{array}{l}\text { Total } \\
\text { vectors }\end{array}$} & \multirow{2}{*}{$\begin{array}{c}\text { \%above } \\
\text { limit }\end{array}$} & \multicolumn{2}{|c|}{ Vectors above: } \\
\hline Fuel & $\begin{array}{c}\text { Nozzle } \\
{[\mathrm{mm}]}\end{array}$ & $\begin{array}{c}U_{\text {ave }} \\
{[\mathrm{m} / \mathrm{s}]}\end{array}$ & & & & & $\begin{array}{l}\text { Mean } \\
{[\mathrm{m} / \mathrm{s}]}\end{array}$ & $\begin{array}{l}\text { St.Dev } \\
{[\mathrm{m} / \mathrm{s}]}\end{array}$ \\
\hline $\mathrm{CH}_{4}$ & 38.1 & 16.7 & 17 & 1.40 & 3898 & 21.3 & 2.75 & 1.66 \\
\hline S1 & 50.8 & 8.16 & 50 & 0.48 & 5546 & 13.1 & 0.71 & 0.19 \\
\hline $\mathrm{CH}_{4}$ & 76.2 & 6.68 & 60 & 0.40 & 5679 & 8.68 & 0.56 & 0.11 \\
\hline
\end{tabular}

Though it may seem as though there are vectors that will suffer from this uncertainty (especially with the $38.1 \mathrm{~mm}$ nozzle), it must be noted that this is exactly the type of error that the translation and deformation of interrogation windows discussed in Section 3.2.3 is designed to correct. Overall, due to the low amount of potentially affected vectors, and the translation and deformation of interrogation windows, it is believed that the velocity gradient bias error has a negligible effect on the measurement uncertainty:

$$
e_{8} \sim 0
$$

\section{D.2.8 Traceability of seed particles}

According to Melling (1997), the ability of particles to track a flow consisting of homogeneous, stationary turbulence with a maximum turbulence frequency of interest $\omega_{c}$ can be characterized by the relative amplitude, $\eta$, and the phase response, $\beta$, of the particle and fluid motions (Crosland, 2008). Thus, for a given amount of turbulence (and hence turbulence frequency), with a given particle 
diameter of interest, the relative amplitude and phase response of the particle motion relative to the fluid can be estimated. If the relative amplitude is close to unity, and the phase response is low, then the particles can be declared suitable for flow tracking.

A length scale is required to determine to maximum frequency of interest. From looking at turbulence statistics from PIV measurements, a typical axial integral length scale is $5 \mathrm{~mm}$, with an average axial velocity of $7.52 \mathrm{~m} / \mathrm{s}$. Using the Taylor hypothesis, a length scale can be used to approximate a time, and thus a frequency, associated with turbulence of this scale:

$$
f=\frac{u_{\text {avg }}}{L}=1504 \mathrm{~Hz}
$$

This indicates that in order for the particles to track the flow, they must be able to accurately follow velocity fluctuations at a frequency of $1504 \mathrm{~Hz}$. Melling (1997) shows that the relative amplitude and phase response of the particles in the fuel/air mixture can be determined as follows:

$$
\begin{gathered}
\eta=\sqrt{\left(1+f_{2}\right)^{2}+f_{2}^{2}} \\
\beta=\tan ^{-1}\left(\frac{f_{2}}{1+f_{1}}\right)
\end{gathered}
$$

where the functions $f_{1}$ and $f_{2}$ are given by:

$$
\begin{aligned}
& f_{1}=\frac{\left[1+\frac{9}{\sqrt{2}(s+1 / 2)} N_{S}\right]\left[\frac{1-s}{s+1 / 2}\right]}{\frac{81}{(s+1 / 2)^{2}}\left[2 N_{S}^{2}+\frac{N_{S}}{\sqrt{2}}\right]^{2}+\left[1+\frac{9}{\sqrt{2}(s+1 / 2)} N_{s}\right]^{2}} \\
& f_{2}=\frac{\left.\frac{9(1-s)}{(s+1 / 2)^{2}}\right]\left[2 N_{S}^{2}+\frac{N_{S}}{\sqrt{2}}\right]}{\frac{81}{(S+1 / 2)}\left[2 N_{S}^{2}+\frac{N_{S}}{\sqrt{2}}\right]^{2}+\left[1+\frac{9}{\sqrt{2}(s+1 / 2)} N_{S}\right]^{2}}
\end{aligned}
$$

where $s$ is the density ratio between the particles and the fluid: 


$$
s=\frac{\rho_{p}}{\rho_{f}}
$$

where the Stokes number is evaluated by:

$$
N_{S}=\left(\frac{v_{f}}{\omega d_{p}^{2}}\right)^{1 / 2}
$$

where $v_{f}$ is the kinematic viscosity of the fluid. Aerosil R 972 particles have a density of approximately $50 \mathrm{~kg} / \mathrm{m}^{3}$, and the density of a methane/air mixture at $\Phi=0.8$ is $1.17 \mathrm{~kg} / \mathrm{m}^{3}$ The same generous estimate of $10 \mu \mathrm{m}$ will be used for the particle diameter as above. With this information, it can be assumed that the relative amplitude and phase shift between the fluid velocity and the particle velocity will be:

$$
\begin{aligned}
& \eta=0.990 \\
& \beta=-0.6^{\circ}
\end{aligned}
$$

indicating that the particles are suitable for flow tracking.

\section{D.2.9 Total measurement uncertainty}

The total measurement uncertainty can now be calculated using Equation D.28 and the calculated values for each elemental error:

$$
u_{v}=\sqrt{\left(\frac{-\Delta X}{M^{2} \Delta t}\right)^{2}\left(e_{1}\right)^{2}+\left(\frac{1}{M \Delta t}\right)^{2}\left(e_{2}+e_{3}+e_{5 / 6}\right)^{2}+\left(\frac{-\Delta X}{M \Delta t^{2}}\right)^{2}\left(e_{4}\right)^{2}}
$$

The magnification used in these experiments was 0.10 , and the interframe time was as low as $17 \mu \mathrm{s}$, but generally on the order of $50 \mu \mathrm{s}$. The uncertainty in the measured velocities is shown in Table D.5 for both $\Delta t^{\prime}$ 's at pixel displacements of 110 pixels.

Table D.5: Relative uncertainties at two interframe times and various displacements:

\begin{tabular}{|c|c|c|c|c|c|}
\hline$\Delta \mathbf{t}[\mu \mathrm{s}]$ & PX.Disp. & $\Delta \mathbf{X}[\mu \mathrm{m}]$ & $\mathbf{V}[\mathrm{m} / \mathrm{s}]$ & $\mathbf{u}_{\mathrm{v}}[\mathrm{m} / \mathrm{s}]$ & $\mathbf{u}_{\mathrm{v}} / \mathrm{V}[\%]$ \\
\hline 17 & 1 & 71.2 & 3.56 & 0.952 & 26.7 \\
\hline
\end{tabular}




\begin{tabular}{|c|c|c|c|c|c|}
\hline & 2 & 143 & 7.12 & 0.976 & 13.7 \\
\hline & 3 & 214 & 10.7 & 1.01 & 9.50 \\
\hline & 4 & 285 & 14.2 & 1.07 & 7.48 \\
\hline & 5 & 356 & 17.8 & 1.13 & 6.34 \\
\hline & 6 & 428 & 21.4 & 1.20 & 5.62 \\
\hline & 7 & 499 & 24.93 & 1.28 & 5.14 \\
\hline & 8 & 570 & 28.50 & 1.37 & 4.80 \\
\hline & 9 & 641 & 32.1 & 1.46 & 4.56 \\
\hline & 10 & 712 & 35.6 & 1.56 & 4.37 \\
\hline \multirow{10}{*}{50} & 1 & 71.2 & 1.42 & 0.380 & 26.6 \\
\hline & 2 & 143 & 2.85 & 0.385 & 13.5 \\
\hline & 3 & 214 & 4.27 & 0.394 & 9.24 \\
\hline & 4 & 285 & 5.70 & 0.408 & 7.15 \\
\hline & 5 & 356 & 7.12 & 0.424 & 5.94 \\
\hline & 6 & 428 & 8.55 & 0.442 & 5.17 \\
\hline & 7 & 499 & 9.97 & 0.463 & 4.64 \\
\hline & 8 & 570 & 11.4 & 0.486 & 4.27 \\
\hline & 9 & 641 & 12.8 & 0.511 & 3.99 \\
\hline & 10 & 712 & 14.2 & 0.538 & 3.78 \\
\hline
\end{tabular}

The results show that the dominant factor in determining the uncertainty in the velocity measurement is the displacement. As a rule during these experiments, the interframe time was tweaked until the high velocity regions were showing displacements of at least four pixels. This way, the higher velocities can be assumed to have an uncertainty of $\sim 7.5 \%$. The lower velocities within the flowfield, however, will have a higher associated uncertainty. The absolute uncertainty on a velocity measurement of $0 \mathrm{~m} / \mathrm{s}$ would be $\pm 0.37 \mathrm{~m} / \mathrm{s}$. 


\section{Appendix E: Turbulence Statistics Calculations}

For each of the 2000 image sets taken per flow condition, an instantaneous PIV vector field is calculated. Each of these PIV vector fields was converted to an ASCIItext document to be read in by MATLAB by an in-house code featuring a graphical user interface. If a convergence study is to be conducted on this particular data set, then the data are read in first with the first 500 vector fields, then the first 600 , until 2000 is reached. All these data sets are treated independently and the statistics are compared to determine whether the velocity field statistics converge at 2000 image sets or not. For the vast majority of the data sets all 2000 velocity fields were sent, and statistics were calculated only once.

Once the data is read in, the mean velocity components are calculated at each interrogation window on the condition that at least $40 \%$ of the velocity fields had a vector present at that location. If this condition is not met, that location receives "NaN" as its value (not a number), and thus no further statistics are calculated at that location. For each of the $\mathrm{n}$ vector fields, the fluctuations about the mean at each location are calculated in the following manner:

$$
\begin{gathered}
u(x, r, n)=U(x, r, n)-U_{\text {mean }}(x, r) \\
v(x, r, n)=V(x, r, n)-V_{\text {mean }}(x, r) \\
w(x, r, n)=W(x, r, n)-W_{\text {mean }}(x, r)
\end{gathered}
$$

where $u, U$, and $U_{\text {mean }}$ refer to the fluctuations, instantaneous velocity, and mean velocity in the axial direction. The same set of variables for $v$ and $w$ represent the radial and tangential directions. The variable $\mathrm{x}$ refers to the axial direction, and $\mathrm{r}$ is the radial direction. For the rest of this appendix, only the axial direction will be used as an example, but the statistics for all directions are calculated as well. The RMS of the axial fluctuations is calculated as follows: 


$$
u_{R M S}(x, r)=\sqrt{\sum_{n=1}^{2000} u_{n}^{2}(x, r)}
$$

where the subscript $\mathrm{n}$ refers to an instantaneous velocity field. After this is conducted, the data is filtered to remove instantaneous velocities that are more than $3^{*} u_{R M S}$ in either direction from the mean and replace that location with NaN. With these inferred extraneous vectors removed, the means, instantaneous fluctuations, and RMS fluctuations are recalculated in the same manner as described above. The 3D turbulence intensity is then calculated from these filtered means. First the 3D velocity magnitudes, $V_{\text {total }}$, are calculated:

$$
V_{\text {total }}(x, r)=\sqrt{U_{\text {mean }}^{2}(x, r)+V_{\text {mean }}^{2}(x, r)+W_{\text {mean }}^{2}(x, r)}
$$

followed by the 3D turbulence fluctuations, $V^{\prime}$ :

$$
V^{\prime}(x, r)=\sqrt{u_{R M S}^{2}(x, r)+v_{R M S}^{2}(x, r)+w_{R M S}^{2}(x, r)}
$$

which leads to the 3D turbulence intensity, given as:

$$
T_{\text {int }}(x, r)(\%)=\left(\frac{V^{\prime}(x, r)}{V_{\text {total }}(x, r)}\right) * 100
$$

In order to calculate the integral length scale, first the velocity fluctuation correlations must be obtained. For the LSB, the measured velocity fields are considered inhomogeneous and non-isotropic meaning that the turbulence is expected to vary with location and vary in direction at one location. For this study, the correlations were only considered in one direction meaning $u u, v v$, and ww correlations, and only ever at the same height above the burner (axial location), correlating in the radial direction (perpendicular to the dominant flow direction). The correlations are thus defined as follows:

$$
R_{u u}\left(x, r_{i}, n\right)=u\left(x, r_{0}, n\right) * u\left(x, r_{i}, n\right)
$$

where the subscript 0 refers to the radial location where the correlation is being calculated with respect to, and the subscript i refers to all radial locations at that 
axial height. Again, $\mathrm{n}$ refers to the specific instantaneous velocity field. Normalizing these correlations, we obtain the correlation coefficient:

$$
\rho_{u u}\left(x, r_{i}, n\right)=\frac{R_{u u}\left(x, r_{i}, n\right)}{u_{R M S}\left(x, r_{0}\right) * u_{R M S}\left(x, r_{i}\right)}
$$

The normalized correlation coefficients are then averaged over the 2000 instantaneous velocity field to obtain an average correlation coefficient at each position, $\rho_{\text {ave,uu }}\left(x, r_{i}\right)$, with respect to all other radial locations at that height. The integral length scale, at height $\mathrm{x}$ and radial location $r_{0}$, can then be determined from the following equation (Tropea, 2007):

$$
l_{0}\left(x, r_{0}\right)=\int_{0}^{\infty} \rho_{a v e, u u}\left(x, r_{i}\right) d r=\frac{\int_{-\infty}^{\infty} \rho_{a v e, u u}\left(x, r_{i}\right) d r}{2}
$$

To evaluate this integral, all $\rho_{\text {ave,uu }}\left(\mathrm{x}, \mathrm{r}_{\mathrm{i}}\right)$ with respect to a location $\mathrm{r}_{0}$ at height $\mathrm{x}$ are fitted using the non-linear least squares method in MATLAB, to a Gaussian, $G$, of the form:

$$
G(r)=a e^{-((r-b) / c)^{2}}
$$

where a and $\mathrm{c}$ are constants that arise from the curve fitting. This makes the integral length scale equal to:

$$
l_{0}\left(x, r_{0}\right)=\frac{\int_{-\infty}^{\infty} G(r) d r}{2}=\frac{\int_{-\infty}^{\infty} a e^{-((r-b) / c)^{2}} d r}{2}
$$

To evaluate the integral in the numerator requires some proof. To begin, the substitution $\mathrm{y}=\mathrm{r}-\mathrm{b}$ is made in $\mathrm{G}(\mathrm{r})$ :

$$
l_{0}\left(x, r_{0}\right)=\frac{a \int_{-\infty}^{\infty} e^{-y^{2} / c^{2}} d y}{2}
$$

followed by the substitution $\mathrm{z}=\mathrm{y} /|\mathrm{c}|$ :

$$
l_{0}\left(x, r_{0}\right)=\frac{a|c| \int_{-\infty}^{\infty} e^{-z^{2}} d z}{2}
$$

Now the integral can be evaluated using the Gaussian integral identity, given as: 


$$
\int_{-\infty}^{\infty} e^{-z^{2}} d z=\sqrt{\pi}
$$

Thus, the integral length scale is evaluated as:

$$
l_{0}\left(x, r_{0}\right)=\frac{a|c| \sqrt{\pi}}{2}
$$

The $\mathrm{r}^{2}$ value from the curve fitting had to be at least 0.7 to be accepted. First, this is evaluated with only the two neighbouring radial locations used in the fitting, and if the calculated length scale is less than half of the radial distance used, then the length scale is accepted as the final answer. If it is not, however, then a radial location in both directions is added, and the curve is fitted again. If the $\mathrm{r}^{2}$ value from the fit is still above 0.7 , the length scale is calculated again. This continues until both conditions are met of the curve fitting $\mathrm{r}^{2}$ value is above 0.7 , and the calculated length scale is less than the radial distance used to calculate it. 


\section{Appendix F: Swirler Deviation Analysis}

According to Dixon (2005), the difference between the fluid and blade inlet angles the inlet of a swirler vane is under the arbitrary control of the designer. However, at the exit of a swirler vane, the difference between the fluid and blade angles, called the deviation $\delta$, is a function of blade camber, blade shape, space-chord ratio, and stagger angle. The deviation is always positive in that the deflection of the fluid is always less than the swirler vane exit angle. Dixon (2005) quotes an empirical rule from Howell (1945) to relate nominal deviation, $\delta^{*}$ to the camber and space-chord ratio. The nominal deviation is the deviation that occurs when deflection is $80 \%$ of the stalling deflection for a given swirler vane, which is a function of the incident angle. In the case of the swirlers used in this study, the incident angle was always $0^{\circ}$ since the swirler vanes were parallel with the flow at the inlets. This is illustrated in Figure: F.1.

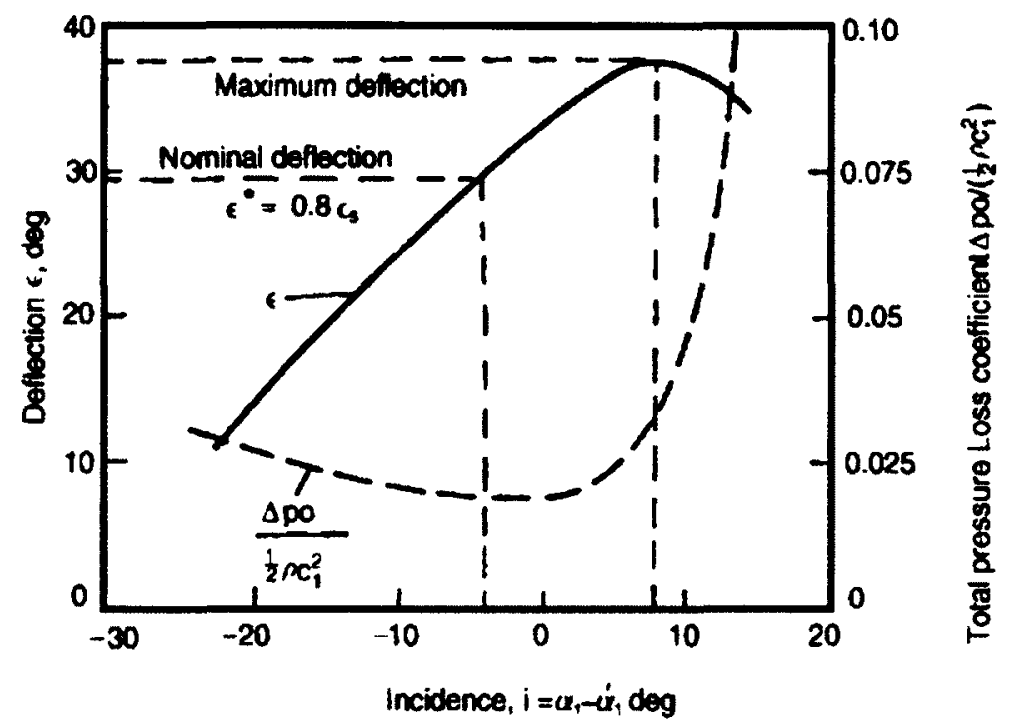

Figure: F.1: Deflection vs. incident angle for a compressor cascade. From Dixon (2005), page 69.

Observation of this graph shows that an incident angle of $0^{\circ}$ provides a condition close to the nominal condition, so the empirical rule from Howell (1945) can be used as an estimate of the nominal deviation. The empirical rule from Howell (1945) is as follows: 


$$
\delta^{*}=m \theta(s / l)^{n}
$$

where $\theta$ is the camber angle which in this case is the exit angle of the swirler vane, $s$ is the spacing between the swirler vanes at the inlet, $l$ is the axial length of the swirler vanes, and $m$ and $\mathrm{n}$ are constants which for inlet swirler vanes are 0.19 and 1 respectively. Results are presented in Table 3.2.

It is recognized here that since the swirler vanes accelerate the flow they are more like a turbine blade than a compressor blade row, which is what Howell's correlation is meant for. Howell's correlation, however, does provide a reasonable measure of the estimated fluid deviation from the vane-swirler exit angle as measured by the radial and axial velocities at the nozzle exits in sampled PIV flowfields. 


\section{Appendix G: 2D Versions of Stability Volumes}
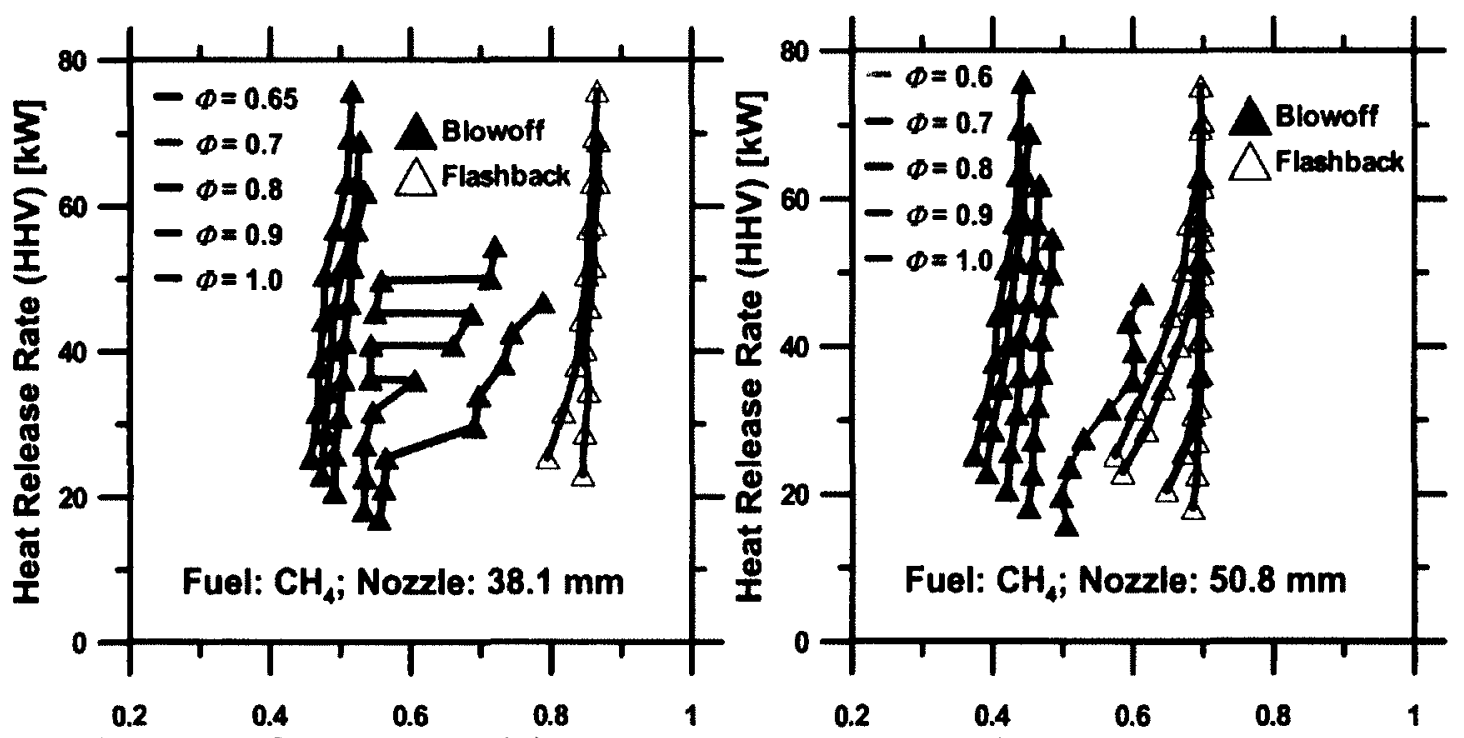

a)

Swirl Number (S)

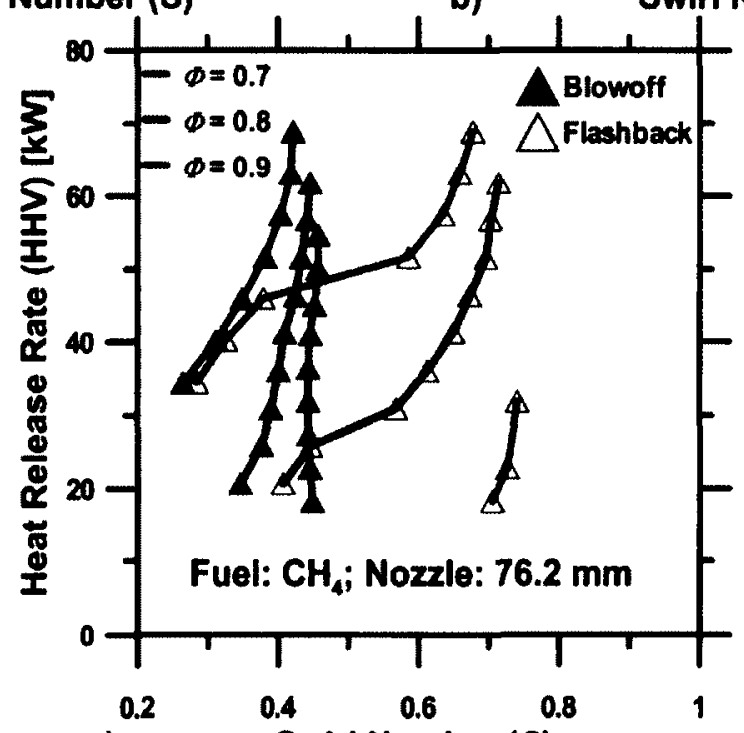

c) Swirl Number (S)

Figure G.1: Blowoff and flashback curves for methane fuel on a) $38.1 \mathrm{~mm} \mathrm{LSB} \mathrm{b)}$ $50.8 \mathrm{~mm} \mathrm{LSB} \mathrm{c)} 76.2 \mathrm{~mm} \mathrm{LSB}$ 

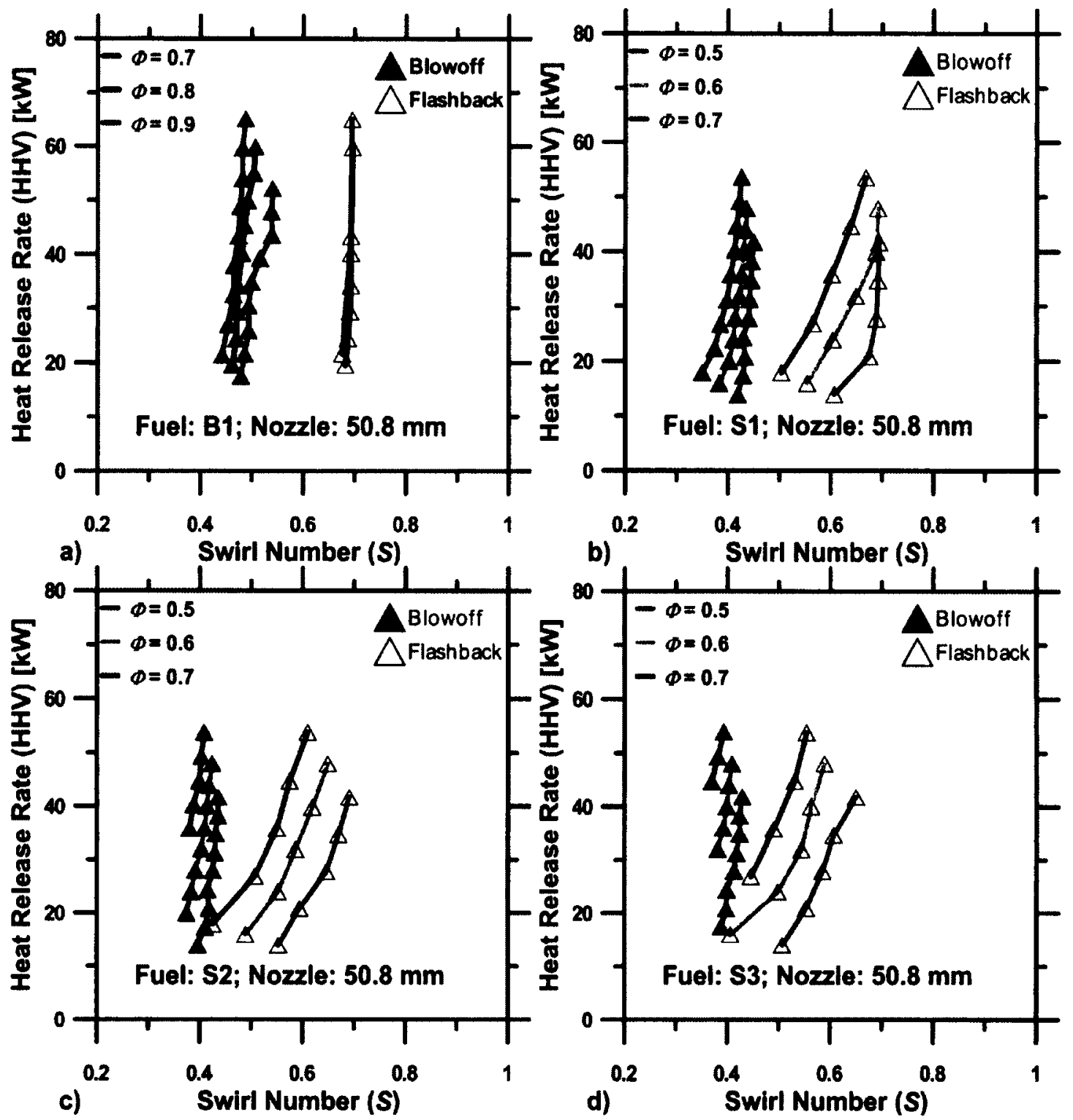

Figure G.2: Blowoff and flashback curves on $50.8 \mathrm{~mm} \mathrm{LSB}$ with a) B1 b) S1 c) S2 d) $\mathrm{S3}$ e) S4 f) S5 g) S6 h) S14 i) S5M50 j) S5M25 

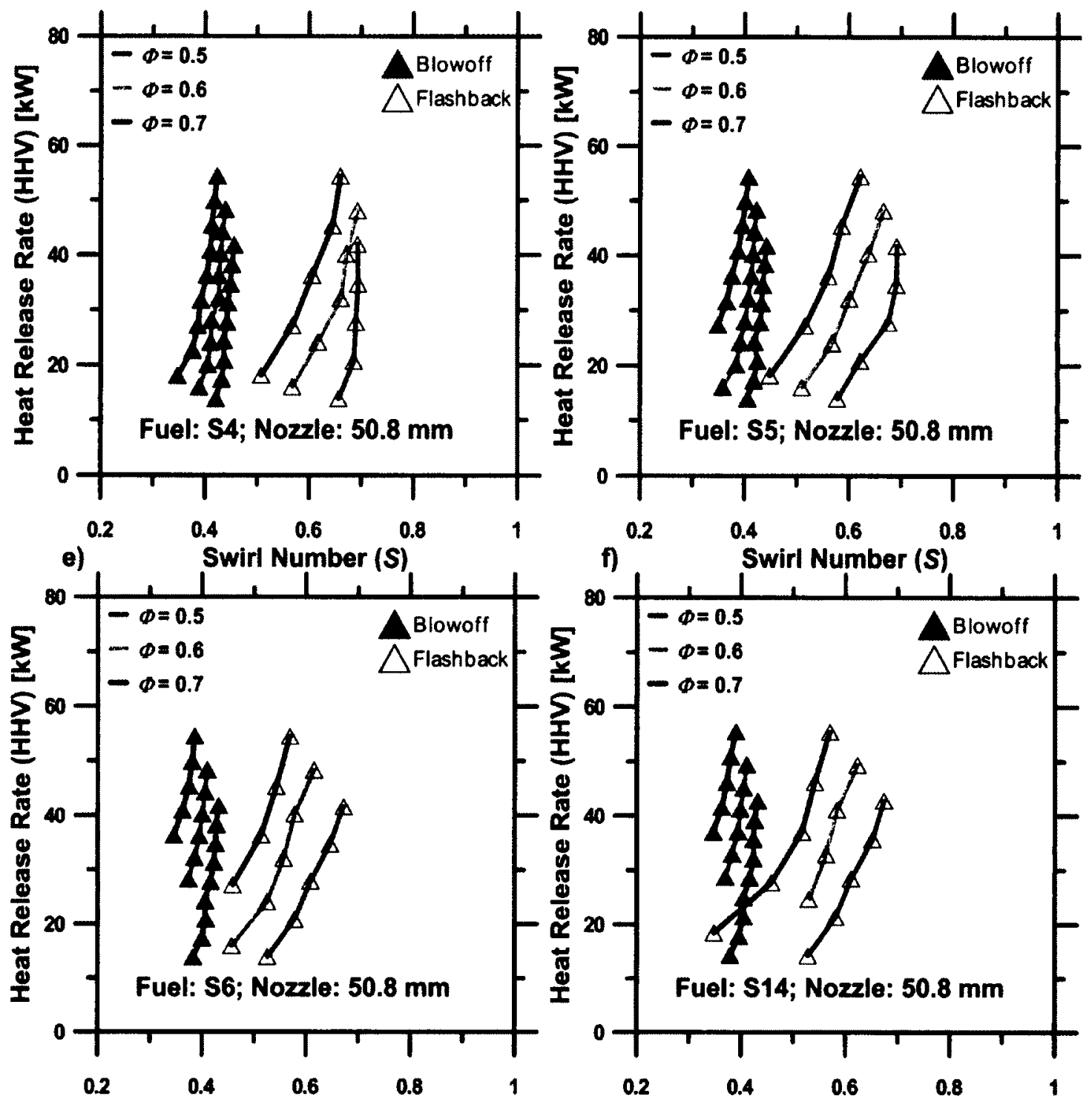

g) Swirl Number (S)

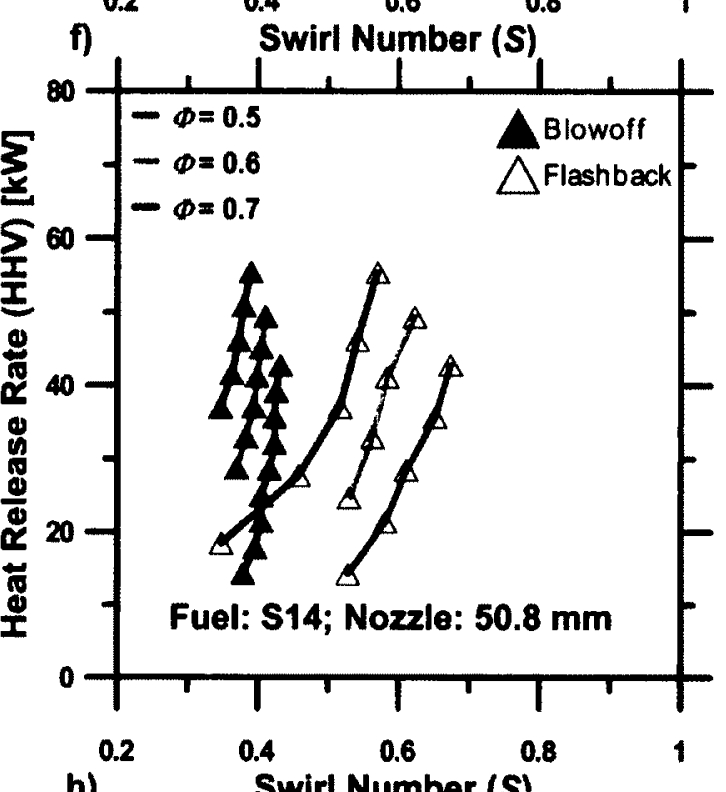

Figure G.2 (continued): Blowoff and flashback curves on $50.8 \mathrm{~mm}$ LSB with a) B1 b) S1 c) S2 d) S3 e) S4 f) S5 g) S6 h) S14 i) S5M50 j) S5M25 

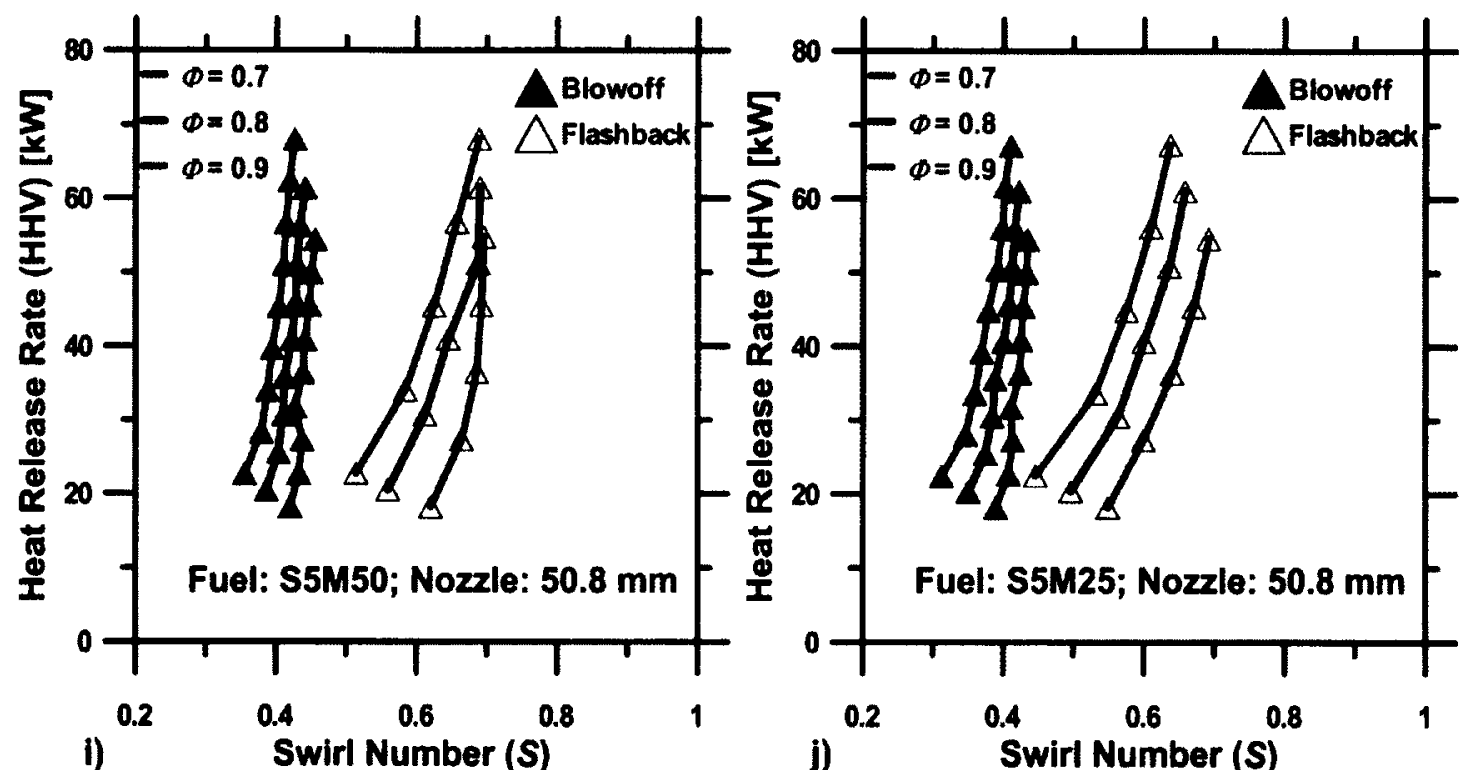

Figure G.2 (continued): Blowoff and flashback curves on $50.8 \mathrm{~mm}$ LSB with a) B1 b) S1 c) S2 d) S3 e) S4 f) S5 g) S6 h) S14 i) S5M50 j) S5M25 


\section{Appendix H: Derivation of the Swirl Number in terms of the Velocity Field}

The following derivation was performed by Prof. Matthew Johnson and it is reproduced here for convenient reference of the reader. From Beér and Chigier (1972), the swirl number is as follows:

$$
S=\frac{\text { axial flux of angular momentum }}{\text { axial thrust } \cdot R}=\frac{G_{\text {ang }}}{G_{x} R}
$$

where angular momentum is considered about the axis of the burner, $\mathrm{R}$ is the throat radius of the burner, and angular momentum flux and axial thrust are integrated over a plane perpendicular to the burner axis.

Although it is rarely specifically noted in the literature, almost always the fluctuating turbulence terms are ignored in comparison to mean flow contributions (e.g. Beér and Chigier, 1972; Feikema et al. 1990) and the flux of angular momentum in the flow is then calculated by integrating radially as follows:

$$
G_{\text {ang }}=\int_{0}^{R}(W r) \rho U 2 \pi r d r=2 \rho \pi \int_{0}^{R} U W r^{2} d r
$$

where $U$ and $W$ are axial and angular (tangential) velocity components. Similarly, the axial thrust, which contains both a momentum flux and a force (pressure) term, can be determined from the following equation:

$$
G_{x}=\int_{0}^{R} U \rho U 2 \pi r d r+\int_{0}^{R} p 2 \pi r d r
$$

where $p$ is the static pressure in any cross section of the jet. In the absence of viscous forces, both $G_{x}$ and $G_{a n g}$ are conserved quantities in the flow.

Unfortunately, there is considerable discrepancy in the literature on how the axial thrust term is defined. Generally there is no easy way of measuring the pressure term and it is therefore sometimes neglected entirely. With small amounts of swirl, this is generally a valid assumption, but as the angular momentum of the flow increases, the pressure term may be of the same magnitude or greater than the axial momentum flux term (Widmann et al. 2000).

In the free jet case, an alternative approach is to use the radial component of the momentum equation to express the pressure term of Eq.(H.3) in terms of 
angular velocity (c.f. Chigier and Chervinsky, 1966). In this case the axial thrust can be written as:

$$
G_{x}=\int_{0}^{\infty} U \rho U 2 \pi r d r+\int_{0}^{\infty} \frac{1}{2} W^{2} \rho 2 \pi r d r=2 \pi \int_{0}^{\infty} \rho\left(U^{2}-\frac{1}{2} W^{2}\right) r d r
$$

Using this approach the swirl number may be determined directly via the integration of the velocity field following Eq.(H.5) without requiring a direct measurement of the pressure field:

$$
S=\frac{\int_{0}^{\infty} \rho U W r^{2} d r}{R \int_{0}^{\infty} \rho\left(U^{2}-\frac{1}{2} W^{2}\right) r d r}
$$

